\author{
UNIVERSIDADE DE SÃO PAULO \\ ESCOLA DE ENGENHARIA DE SÃO CARLOS \\ DEPARTAMENTO DE HIDRÁULICA E SANEAMENTO
}

\title{
REMOÇ̃̃̃ DE SUBSTÂNCIAS HÚMICAS NO PROCESSO DE FILTRAÇÃO EM MÚLTIPLAS ETAPAS PRECEDIDO DE OXIDAÇÃO COM OZÔNIO
}

\section{HÉLIO DA SILVA ALMEIDA}

Dissertação apresentada à Escola de Engenharia de São Carlos, da Universidade de São Paulo, como parte dos requisitos para obtenção do título de Mestre em Engenharia Civil. Área de concentração Hidráulica e Saneamento.

Orientador: Prof.Dr. LUIZ DI BERNARDO

São Carlos 2001 


\section{SUMÁRIO}

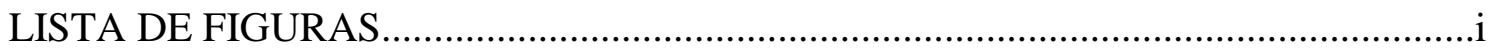

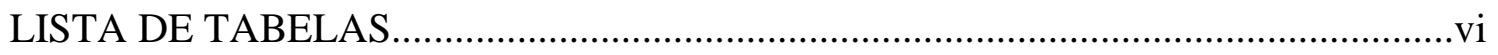

LISTA DE SÍMBOLOS, NOMECLATURAS E ABREVIAÇÕES...................................

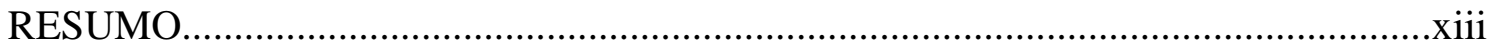

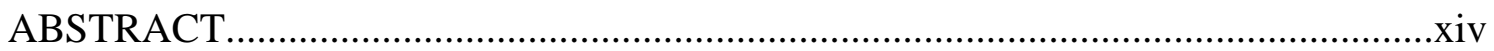

1. INTRODUÇÃO

2. OBJETIVOS

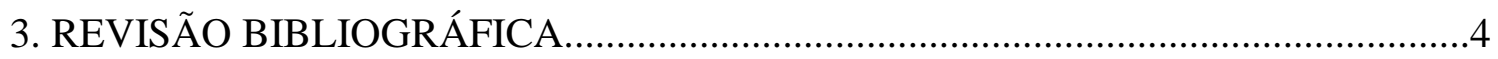

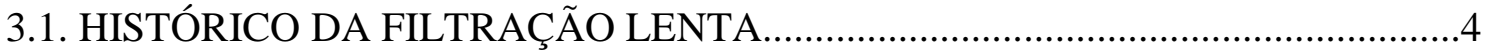

3.2. CONCEITUAÇÃO DA FILTRAÇÃO EM MÚLTIPLAS ETAPAS - FIME............5

3.3. O PRÉ-TRATAMENTO NA FILTRAÇÃO EM MÚLTIPLAS ETAPAS -FIME....7

3.3.1. Pré-filtro dinâmico de pedregulho - PFD............................................................9

3.3.2. Pré-filtro de pedregulho com escoamento vertical - PFV .......................................11

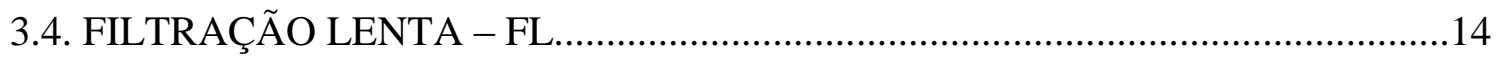

3.4.1. Comportamento dos filtros lentos......................................................................14

3.5. RESULTADOS DE ALGUNS TRABALHOS SOBRE FILTRAÇÃO LENTA.....17

3.6. UTILIZAÇÃO DA TECNOLOGIA DE FiME- FILTRAÇÃO EM MÚLTIPLAS

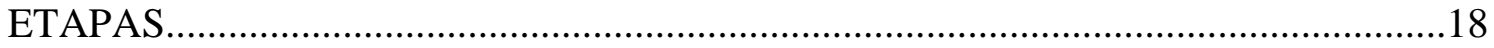

3.7. INFLUÊNCIA E CARACTERIZAÇÃO DAS SUBSTÂNCIAS HÚMICAS PARA

O TRATAMENTO DE ÁGUAS DE ABASTECIMENTO..........................................21 
3.8. A PRÉ-OZONIZAÇÃO DE SUBSTÂNCIAS HÚMICAS NO TRATAMENTO DE

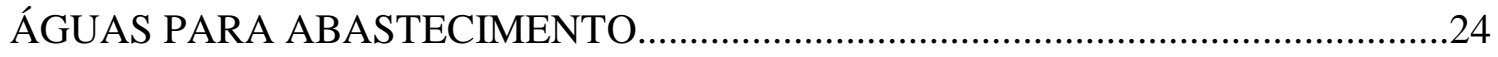

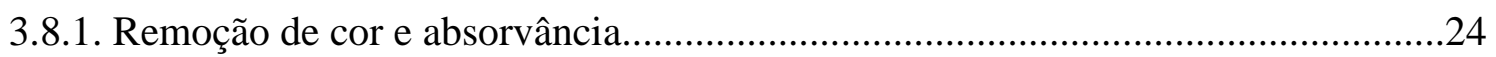

3.8.2. Redução de carbono orgânico total (COT) e de carbono orgânico dissolvido (COD)

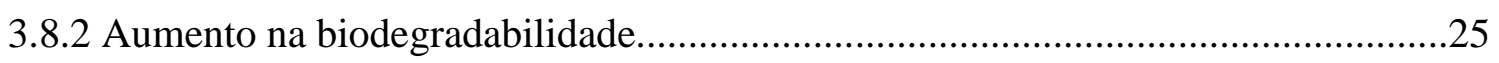

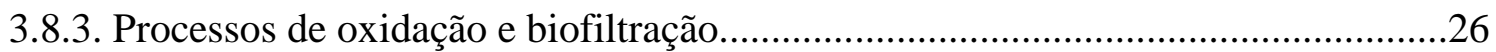

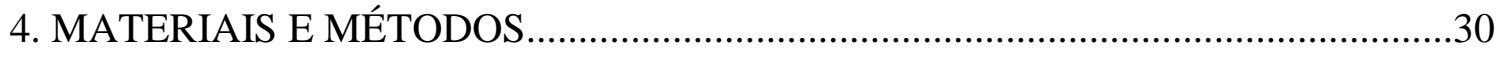

4.1. DESCRIÇÃO GERAL DA INSTALAÇÃO PILOTO...............................................30

4.2. CARACTERÍSTICAS DOS MEIOS GRANULARES............................................36

4.3. CARREIRAS DE FILTRAÇÃO DE LENTA......................................................

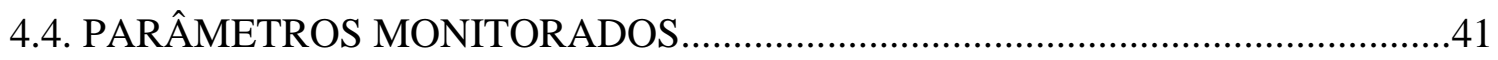

4.5. PREPARAÇÃO DA SOLUÇÃO MÃE DE SUBSTÂNCIAS HÚMICAS...............45

4.6. DEFINIÇÃO DA DILUIÇÃO DA SOLUÇÃO MÃE DE SUBSTÂNCIAS

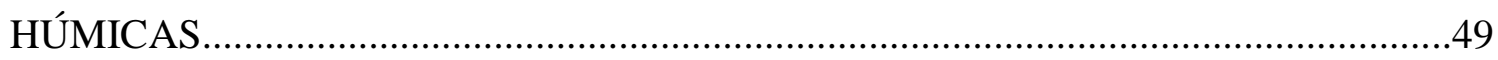

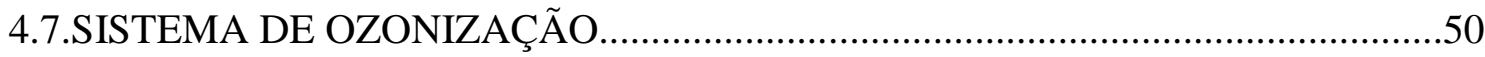

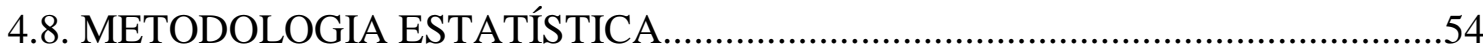

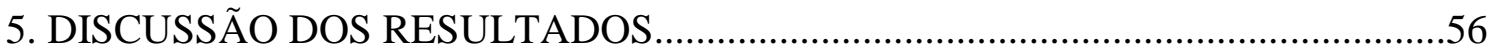

5.1. CARREIRA 1 DE FILTRAÇÃO LENTA............................................................56

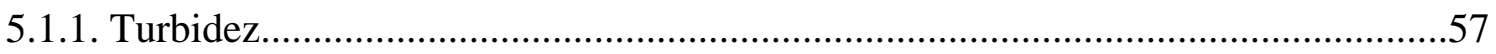

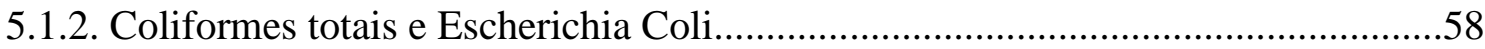

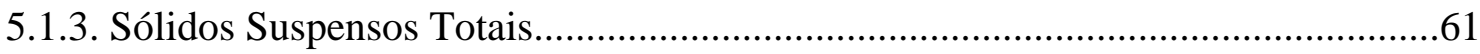

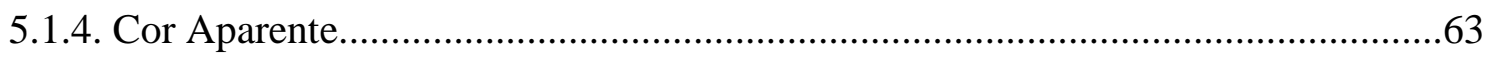

5.1.5. Cor verdadeira e Absorvância..............................................................................64

5.1.6. Carbono orgânico dissolvido...........................................................................67

5.1.7. Oxigênio Consumido - OC e Oxigênio dissolvido - OD...........................................69

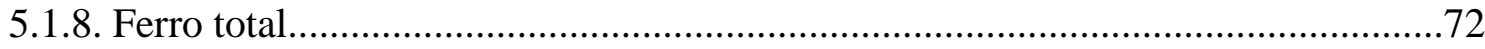

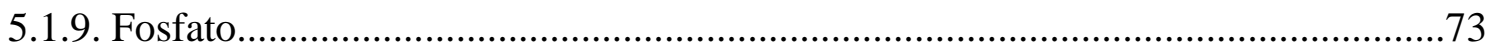




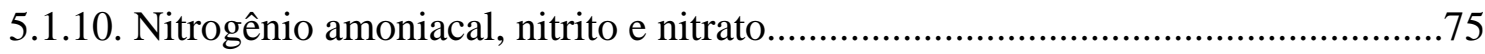

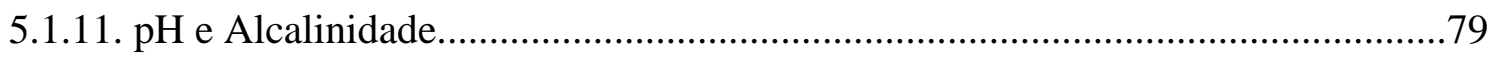

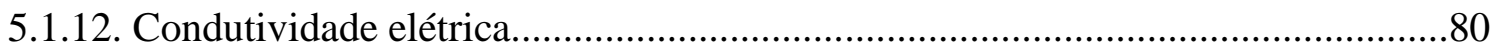

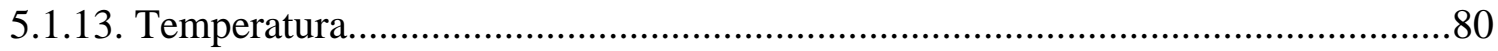

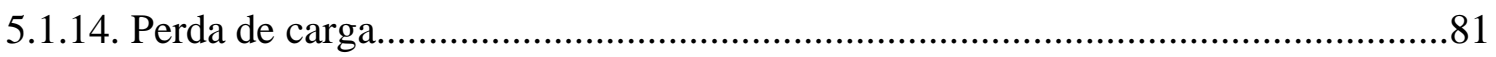

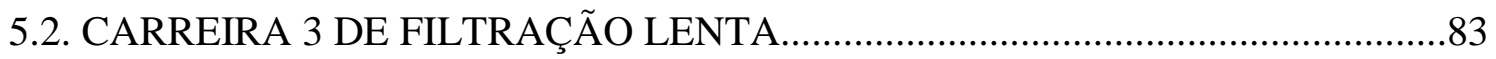

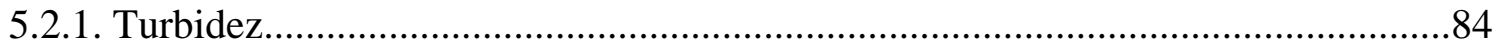

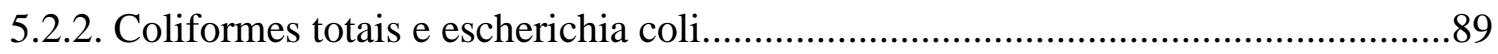

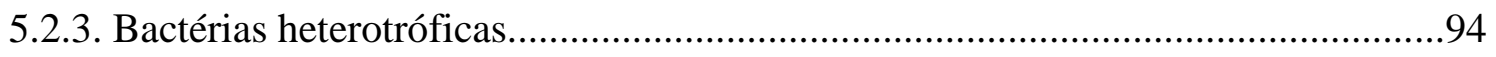

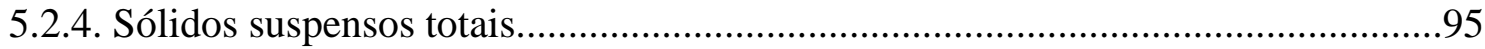

5.2.5. Cor aparente ...............................................................................................96

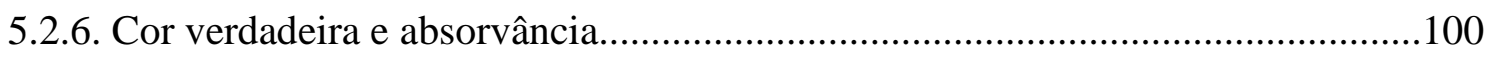

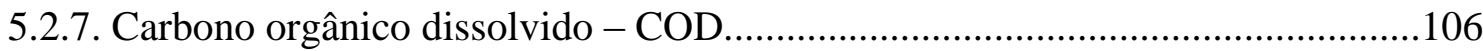

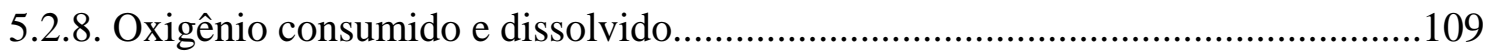

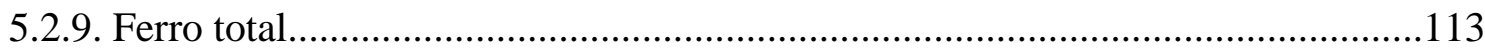

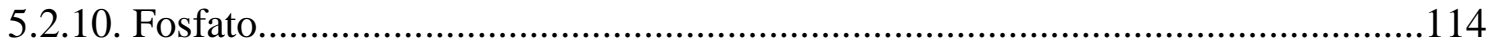

5.2.11. Nitrogênio amoniacal, nitrito e nitrato.............................................................116

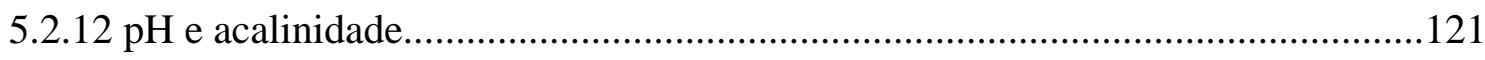

5.2.13. Condutividade elétrica.................................................................................123

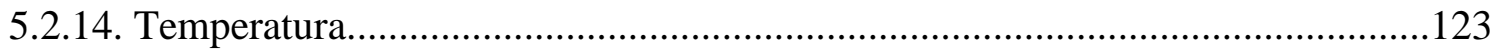

5.2.15 Perda de carga..........................................................................................124

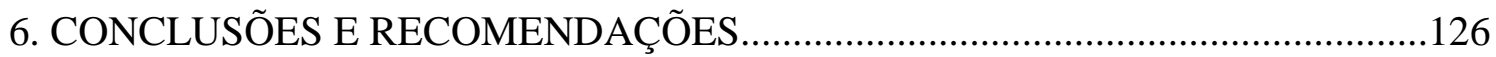

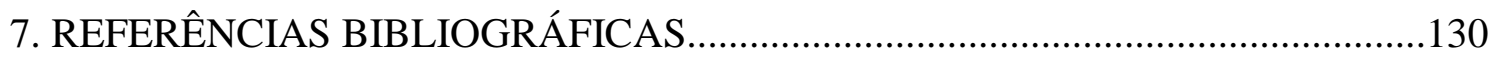

ANEXO A - RESULTADOS ESTATÍSTICOS CARREIRA 1...................................135

ANEXO B - GRÁFICOS DE CORRELAÇÃO CARREIRA 1...................................148 
ANEXO C - RESULTADOS ESTATÍSTICOS CARREIRA 3 .............................153

ANEXO D - GRÁFICOS DE CORRELAÇÃO CARREIRA 3 .............................170 ANEXO E - TABELAS COM RESULTADOS DE TURBIDEZ, SÓLIDOS SUSPENSOS TOTAIS, COR APARENTE, COR VERDADEIRA, ABSORVÂNCIA, E TEMPERATURA DA CARREIRA 1.................................181 ANEXO F - TABELAS COM RESULTADOS DE TURBIDEZ, SÓLIDOS SUSPENSOS TOTAIS, COR APARENTE, COR VERDADEIRA, ABSORVÂNCIA, COD, OC, PH, CONDUTIVIDADE ELÉTRICA E

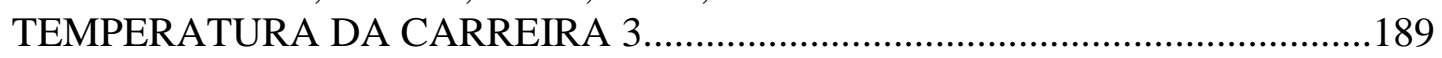




\section{LISTA DE FIGURAS}

FIGURA 1 - REPRESENTAÇÃO DA FILTRAÇÃO EM MÚLTIPLAS ETAPAS FiME. .6

FIGURA 2- PRÉ-FILTRO DINÂMICO. .10

FIGURA 3- PRÉ-FILTRO DE PEDREGULHO DE ESCOAMENTO VERTICAL

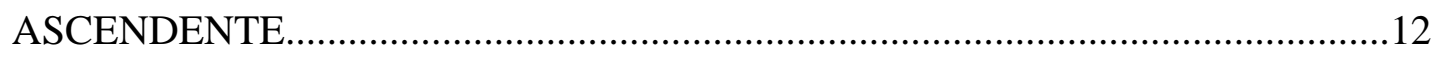

FIGURA 4 -DETALHES DE UM FILTRO LENTO................................................16

FIGURA 5 - FOTO DA INSTALAÇÃO PILOTO DE FiME........................................30

FIGURA 6 - PLANTA BAIXA DA INSTALAÇÃO PILOTO......................................31

FIGURA 7- FOTO DA DERIVAÇÃO NA ADUTORA DE ÁGUA BRUTA...........32

FIGURA 8 - FOTO DO PRÉ-FILTRO DINÂMICO....................................................33

FIGURA 9 - FOTO DA CAIXA DE DISTRIBUIÇÃO 1..........................................34

FIGURA 10 - FOTO DA CAIXA DE DISTRIBUIÇÃO 2........................................34

FIGURA 11 - FOTO DAS SEÇÕES DE APLICAÇÃO DE SUBSTÂNCIA

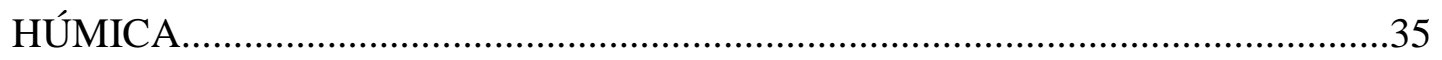

FIGURA 12 - FOTO DA CÂMARA DE MISTURA..............................................36

FIGURA 13 - ESQUEMA DO PFD...................................................................

FIGURA 14 - DETALHES DO PFVA...................................................................

FIGURA 15 - CORTE LONGITUDINAL MOSTRANDO DETALHES DOS FILTROS LENTOS

FIGURA 16 - FOTO ILUSTRANDO OS PONTOS DE COLETA NOS FILTROS LENTOS

FIGURA 17 - FOTO ILUSTRANDO OS SACOS DURANTE REALIZAÇÃO DA DIÁLISE COM ÁCIDO CLORÍDRICO. 48

FIGURA 18 - FOTO ILUSTRANDO O MATERIAL HÚMICO EM UMA PARCELA DA LAVAGEM 
FIGURA 19 - FOTO ILUSTRANDO TANQUE E BOMBA DE RECALQUE SOLUÇÃO DE SUBSTÂNCIAS HÚMICAS...................................................50 FIGURA 20 - FLUXOGRAMA ESQUEMÁTICO DO SISTEMA DE OZONIZAÇÃO. .51

FIGURA 21 - FOTO MOSTRANDO O OZONIZADOR MARCA EAGLESAT ..52 FIGURA 22 - FOTO ILUSTRANDO A CAIXA DE NÍVEL CONSTANTE...........53 FIGURA 23 - FOTO DA COLUNA DE OZONIZAÇÃO.......................................53 FIGURA 24 - FOTO DO DESTRUIDOR DE OZÔNIO.........................................54 FIGURA 25- VARIAÇÕES DE TURBIDEZ COM O TEMPO DE FUNCIONAMENTO NA CARREIRA 1, PARA ÁGUA BRUTA E UNIDADES DE FILTRAÇÃO. .58

FIGURA 26- VARIAÇÕES DE COLIFORMES TOTAIS COM O TEMPO DE FUNCIONAMENTO NA CARREIRA 1, PARA ÁGUA BRUTA E UNIDADES DE FILTRAÇÃO.

FIGURA 27 VARIAÇÕES DE ESCHERICHIA COLI COM O TEMPO DE FUNCIONAMENTO NA CARREIRA 1, PARA ÁGUA BRUTA E UNIDADES DE FILTRAÇÃO 61

FIGURA 28- VARIAÇÕES NA CONCENTRAÇÃO DE SÓLIDOS SUSPENSOS TOTAIS EM FUNÇÃO DO TEMPO DE FUNCIONAMENTO, PARA ÁGUA BRUTA E UNIDADES DE FILTRAÇÃO NA CARREIRA 1. .62

FIGURA 29 - VARIAÇÕES DE COR APARENTE EM FUNÇÃO DO TEMPO DE OPERAÇÃO PARA ÁGUA BRUTA E UNIDADES DE FILTRAÇÃO NA CARREIRA 1 .64

FIGURA 30 - VARIAÇÕES DE COR VERDADEIRA EM FUNÇÃO DO TEMPO DE OPERAÇÃO PARA ÁGUA BRUTA E UNIDADES DE FILTRAÇÃO NA CARREIRA 1 .65 FIGURA 31 - RESULTADOS DE ABSORVÂNCIA EM FUNÇÃO DO TEMPO DE OPERAÇÃO PARA ÁGUA BRUTA E UNIDADES DE FILTRAÇÃO NA CARREIRA 1 .66 
FIGURA 32 - VARIAÇÕES DE CARBONO ORGÂNICO DISSOLVIDO PARA ÁGUA BRUTA E UNIDADES DA FiME NA CARREIRA 1.............................68 FIGURA 33- VARIAÇÕES DE OXIGÊNIO CONSUMIDO PARA ÁGUA BRUTA E UNIDADES DA FiME DURANTE A CARREIRA 1 .70 FIGURA 34 - VARIAÇÕES DE OXIGÊNIO DISSOLVIDO PARA ÁGUA BRUTA E UNIDADES DA FiME DURANTE A CARREIRA 1 .71 FIGURA 35 - VARIAÇÕES NA CONCENTRAÇÃO DE FERRO TOTAL EM FUNÇÃO DO TEMPO DE OPERAÇÃO PARA A ÁGUA BRUTA E UNIDADES DA FiME NA CARREIRA 1 .73

FIGURA 36 - VARIAÇÕES NA CONCENTRAÇÃO DE FOSFATO PARA ÁGUA BRUTA E UNIDADES DA FiME EM FUNÇÃO DO TEMPO DE OPERAÇÃO NA CARREIRA 1 .75

FIGURA 37 - VARIAÇÕES NA CONCENTRAÇÃO DE NITROGÊNIO AMONIACAL EM FUNÇÃO DO TEMPO DE OPERAÇÃO PARA ÁGUA BRUTA E UNIDADES DA FiME NA CARREIRA 1 .76 FIGURA 38 - VARIAÇÕES NA CONCENTRAÇÃO DE NITRITO PARA ÁGUA BRUTA E UNIDADES DA FiME EM FUNÇÃO DO TEMPO DE OPERAÇÃO NA CARREIRA 1 .77

FIGURA 39- VARIAÇÕES NA CONCENTRAÇÃO DE NITRATO EM FUNÇÃO DO TEMPO DE OPERAÇÃO PARA ÁGUA BRUTA E UNIDADES DA FiME DURANTE A CARREIRA 1 .78 FIGURA 40 - DESENVOLVIMENTO DA PERDA DE CARGA NO FILTRO LENTO 1 CARREIA 1

FIGURA 41 - DESENVOLVIMENTO DA PERDA DE CARGA NO FILTRO LENTO 2 CARREIRA 1 .82

FIGURA 42 - HISTOGRAMA DE TURBIDEZ DO FILTRO LENTO 1 .86 FIGURA 43 - HISTOGRAMA DE TURBIDEZ DO FILTRO LENTO 2. .87 FIGURA 44 - VARIAÇÃO DE TURBIDEZ NO PFVA, FL1 MONT E FL2 MONT. 
FIGURA 46 - VARIAÇÕES DE COLIFORMES TOTAIS EM FUNÇÃO DO TEMPO DE OPERAÇÃO PARA ÁGUA BRUTA E EFLUENTES DAS UNIDADES DA FiME DURANTE A CARREIRA 3 .91

FIGURA 47 - VARIAÇÕES DE ESCHERICHIA COLI EM FUNÇÃO DO TEMPO DE OPERAÇÃO PARA ÁGUA BRUTA E UNIDADES DA FiME AO LONGO DA CARREIRA 3. . .93

FIGURA 48 - VARIAÇÕES NO NÚMERO DE BACTÉRIAS HETEROTRÓFICAS EM FUNÇÃO DO TEMPO DE OPERAÇÃO PARA ÁGUA BRUTA E UNIDADES DA FiME NA CARREIRA 3.

FIGURA 49 - VARIAÇÕES NA CONCENTRAÇÃO DE SÓLIDOS SUSPENSOS TOTAIS EM FUNÇÃO DO TEMPO DE OPERAÇÃO PARA ÁGUA BRUTA E UNIDADES DA FiME NA CARREIRA 3 .........................................................96

FIGURA 50 - AUMENTO DE COR APARENTE NO EFLUENTE DO PFVA......97 FIGURA 51 - VARIAÇÕES DE COR APARENTE NOS EFLUENTES DOS FILTROS LENTOS E SEÇÃO FL13 EM FUNÇÃO DO TEMPO DE OPERAÇÃO NA CARREIRA 3 . .98

FIGURA 52- VARIAÇÕES DE COR APARENTE EM FUNÇÃO DO TEMPO DE OPERAÇÃO PARA ÁGUA BRUTA E UNIDADES DA FiME NA CARREIRA 3

FIGURA 53 - VALORES DE COR VERDADEIRA NO EFLUENTE DO PFVA EM FUNÇÃO DO TEMPO DE OPERAÇÃO NA CARREIRA 3.

FIGURA 54 - VARIAÇÕES DE COR VERDADEIRA NOS EFLUENTES DOS FILTROS LENTOS E SEÇÃO FL13 EM FUNÇÃO DO TEMPO DE OPERAÇÃO NA CARREIRA 3. 102

FIGURA 55 - VARIAÇÕES DE COR VERDADEIRA EM FUNÇÃO DO TEMPO DE OPERAÇÃO PARA ÁGUA BRUTA E UNIDADES DA FiME NA CARREIRA 3 104 
FIGURA 56 - VARIAÇÕES DE ABSORVÂNCIA PARA ÁGUA BRUTA E UNIDADES DE FILTRAÇÃO NA CARREIRA 3 106

FIGURA 57 - VARIAÇÕES DE CARBONO ORGÂNICO DISSOLVIDO EM FUNÇÃO DO TEMPO DE OPERAÇÃO PARA ÁGUA BRUTA E UNIDADES DA FiME CARREIRA 3 107

FIGURA 58 - VARIAÇÕES NA CONCENTRAÇÃO DE OXIGÊNIO CONSUMIDO EM FUNÇÃO DO TEMPO DE OPERAÇÃO PARA ÁGUA BRUTA E UNIDADES DA FiME CARREIRA 3.

FIGURA 59 - VARIAÇÕES NA CONCENTRAÇÃO DE OXIGÊNIO DISSOLVIDO EM FUNÇÃO DO TEMPO DE OPERAÇÃO PARA A ÁGUA BRUTA E UNIDADES DA FiME NA CARREIRA 3 112 FIGURA 60 - VARIAÇÕES NA CONCENTRAÇÃO DE FERRO TOTAL EM FUNÇÃO DO TEMPO DE OPERAÇÃO PARA ÁGUA BRUTA E UNIDADES DA FiME NA CARREIRA 3 114

FIGURA 61 - VARIAÇÕES NA CONCENTRAÇÃO DE FOSFATO DA ÁGUA BRUTA E DAS UNIDADES DA FiME NA CARREIRA 3.

FIGURA 62 - VARIAÇÕES DA CONCENTRAÇÃO DE NITROGÊNIO AMONIACAL EM FUNÇÃO DO TEMPO DE OPERAÇÃO PARA ÁGUA BRUTA E UNIDADES DE FILTRAÇÃO NA CARREIRA 3. .118 FIGURA 63 - VARIAÇÕES NA CONCENTRAÇÃO DE NITRITO PARA ÁGUA BRUTA E UNIDADES DE FILTRAÇÃO NA CARREIRA 3. 119 FIGURA 64 - VARIAÇÕES NA CONCENTRAÇÃO DE NITRATO PARA ÁGUA BRUTA E UNIDADES DA FiME NA CARREIRA 3 121 FIGURA 65 - VARIAÇÕES DO VALORES DE pH NOS EFLUENTES DOS FILTROS LENTOS E SEÇÃO FL13 NA CARREIRA 3. 123

FIGURA 66 - DESENVOLVIMENTO DA PERDA DE CARGA DO FILTRO

LENTO 1 NA CARREIRA 3 125

FIGURA 67 - DESENVOLVIMENTO DA PERDA DE CARGA NO FILTRO LENTO 2 CARREIRA 3 


\section{LISTA DE TABELAS}

TABELA 1- CARACTERÍSTICAS GERAIS DA ÁGUA BRUTA EM FUNÇÃO DO ARRANJO DA ETA-FiME 7

TABELA 2- CARACTERÍSTICAS DOS MEIOS FILTRANTES DOS PRÉFILTROS DINÂMICOS.

TABELA 3 - CARACTERÍSTICAS DOS MEIOS FILTRANTES DOS PRÉFILTROS VERTICAIS ASCENDENTES

TABELA 4 - REMOÇÃO DE MICRORGANISMOS EM FILTROS LENTOS SEGUNDO VÁRIOS AUTORES .18

TABELA 5 - DESCRIÇÃO GERAL DAS ESTAÇÕES DE TRATAMENTO FiME EM ESCALA REAL

TABELA 6 - TAXAS EMPREGADAS NAS UNIDADES

TABELA 7 - REMOÇÕES DE COR USUALMENTE ALCANÇADAS POR PRÉOZONIZAÇÃO E FILTRAÇÃO LENTA.

TABELA 8 - CARACTERÍSTICAS DOS MEIOS FILTRANTES DA UNIDADES

DA FiME. .37

TABELA 9 -TAXAS EMPREGADAS NAS CARREIRAS DE FILTRAÇÃO.........41 TABELA 10 - PARÂMETROS MONITORIZADOS E FREQÜÊNCIA DE AMOSTRAGEM...

TABELA 11 - MÉTODOS E EQUIPAMENTOS UTILIZADOS NA DETERMINAÇÃO DOS PARÂMETROS.

TABELA 12- CARACTERIZAÇÃO DA ÁGUA BRUTA NA CARREIRA 1........57

TABELA 13- RESUMO DOS VALORES DE TURBIDEZ EM UT CARREIRA 1.

TABELA 14 - RESULTADOS DE COLIFORMES TOTAIS EM NMP/100 ML CARREIRA 1 
TABELA 15 - RESULTADOS DE ESCHERICHIA COLI EM NMP/mL CARREIRA 1 .60

TABELA 16 - RESULTADOS DE SÓLIDOS SUSPENSOS TOTAIS EM mg/L CARREIRA 1

TABELA 17 - RESUMO DE DADOS DE COR APARENTE EM UH CARREIRA 1 .64

TABELA 18 - COEFICIENTES DE CORRELAÇÃO ENTRE COR VERDADEIRA E ABSORVÂNCIA .66

TABELA 19 - COEFICIENTES DE CORRELAÇÃO ENTRE COD E ABSORVÂNCIA. .67

TABELA 20 - RESULTADOS DE COD EM mg/L CARREIRA 1 .68 TABELA 21 - RESULTADOS DE OXIGÊNIO CONSUMIDO EM mg/L CARREIRA 1 .69

TABELA 22 - RESULTADOS DE OXIGÊNIO DISSOLVIDO EM mg/L CARREIRA 1 .70

TABELA 23 - RESULTADOS DE FERRO TOTAL EM mg/L CARREIRA 1.......72

TABELA 24 - RESULTADOS DE FOSFATO EM mg/L CARREIRA 1................74 TABELA 25 - RESULTADOS DE NITROGÊNIO AMONIACAL EM mg/L CARREIRA 1 .75

TABELA 26 - RESULTADOS DE NITRITO EM mg/L CARREIRA 1.................77

TABELA 27 - RESULTADOS DE NITRATO EM mg/L CARREIRA 1.................78

TABELA 28 - RESULTADOS DE pH CARREIRA 1 .79

TABELA 29 - RESULTADOS DE ALCALINIDADE EM mgCaCO $3 / \mathrm{L}$ CARREIRA 1 .79

TABELA 30 - RESULTADOS DE CONDUTIVIDADE ELÉTRICA EM mS/cm CARREIRA 1

TABELA 31-. RESUMO DE VALORES DE TEMPERATURA $\left({ }^{\circ} \mathrm{C}\right)$ CARREIRA1

TABELA 32 - CARACTERIZAÇÃO DA ÁGUA BRUTA NA CARREIRA 3.......84 TABELA 33 - CÁLCULOS DAS DISTRIBUIÇÕES DE FREQÜÊNCIAS DE TURBIDEZ DO FILTRO LENTO 1 CARREIA 3 .85 
TABELA 34 - CÁlCULOS DAS DISTRIBUIÇÕES DE FREQÜÊNCIAS DE TURBIDEZ DO FILTRO LENTO 2 CARREIA 3

TABELA 35 - RESULTADOS DE COLIFORMES TOTAIS EM NMP/100 mL CARREIRA 3. .90

TABELA 36 - RESULTADOS DE ESCHERICHIA COLI EM NMP/100mL CARREIRA 3 .92

TABELA 37 - RESULTADOS DE BACTÉRIAS HETEROTRÓFICAS EM UFC/100 mL CARREIRA 3

TABELA 38 - RESUMO DOS VALORES DE SÓLIDOS SUSPENSOS TOTAIS EM mg/L CARREIRA 3.

TABELA 39 - RESULTADOS DE REMOÇÃO DE COR APARENTE POR OZONIZAÇÃO .99

TABELA 40 - RESUMO DOS VALORES DE COR APARENTE EM uH CARREIRA 3 .99

TABELA 41 - REMOÇÃO DE COR VERDADEIRA POR APLICAÇÃO DE OZÔNIO 102

TABELA 42 - DADOS DE REMOÇÃO MÍNIMA, MÉDIA E MÁXIMA DE COR VERDADEIRA NOS PONTOS FL11, FL13 E FL21, COM E SEM APLICAÇÃO DE OZÔNIO..... 103

TABELA 43 - RESUMO DOS VALORES DE COR VERDADEIRA EM UH DA CARREIRA 3 103

TABELA 44- REMOÇÃO DE ABSORVÂNCIA PELA APLICAÇÃO DE OZÔNIO .105

TABELA 45 - COEFICIENTES DE CORRELAÇÃO ENTRE COR VERDADEIRA E ABSORVÂNCIA CARREIRA 3. . .105

TABELA 46 - COEFICIENTES DE CORRELAÇÃO ENTRE CARBONO ORGÂNICO DISSOLVIDO E ABSORVÂNCIA 254 nm CARREIRA 3. 108 TABELA 47 - RESUMO DOS VALORES DE CARBONO ORGÂNICO TOTAL EM mg/L CARREIRA 3. 108 TABELA 48 - COEFICIENTES DE CORRELAÇÃO ENTRE OXIGÊNIO CONSUMIDO E ABSORVÂNCIA - $254 \quad \mathrm{~nm}$ CARREIRA 3. 110 
TABELA 49 - COEFICIENTES DE CORRELAÇÃO ENTRE OXIGÊNIO CONSUMIDO E CARBONO ORGÂNICO DISSOLVIDO CARREIRA 3............110 TABELA 50 - RESULTADOS DE OXIGÊNIO DISSOLVIDO EM mg/L CARREIRA 3 .112

TABELA 51 - RESULTADOS DE FERRO TOTAL EM mg/L CARREIRA 3.....113 TABELA 52 - RESULTADOS DE FOSFATO EM mg/L CARREIRA 3...............115 TABELA 53 - RESULTADOS DE NITROGÊNIO AMONIACAL EM mg/L

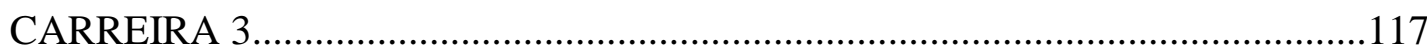

TABELA 54 - RESULTADOS DE NITRITO EM mg/L CARREIRA 3................119

TABELA 55 - RESULTADOS DE NITRATO EM mg/L CARREIRA 3 .120

TABELA 56 - RESULTADOS DE ALCALINIDADE EM mg/L CARREIRA $3 . .122$ TABELA 57 - RESUMO DOS VALORES DE TEMPERATURA EM ${ }^{\circ} \mathrm{C}$ CARREIRA 3 .124 


\section{LISTA DE SÍMBOLOS, NOMENCLATURAS E ABREVIAÇÕES}

ABS

ETA Estação de tratamento de água FiME. .Filtração em múltiplas etapas

FLA ..Filtração lenta em areia

FL11 Efluente do filtro lento 1 FL13. Efluente da interface areia-carvão ativado no filtro lento 1 FL21 ..Efluente do filtro lento 2

FL11 mont. Afluente ao filtro lento 1

FL21 mont. Afluente ao filtro lento 2 
FGAC

Filtros grossos ascendentes em camadas

FGAS

Filtros grossos ascendentes em série

FGD

Filtros grossos de fluxo descendente

$\mu \mathrm{m}$.

.Micrometro

$\mu \mathrm{S} / \mathrm{cm}$

Microsiemens por centímetro

$\mathrm{m}$

Metro

$\mathrm{m} / \mathrm{d}$

Metros por dia

$\mathrm{mg} / \mathrm{L}$

Miligramas por litro

$\mathrm{m}^{2}$

Metro quadrado

$\mathrm{m}^{3}$

Metro cúbico

$\mathrm{mm}$

Milímetro

MON

.Matéria orgânica natural

$\eta \mathrm{m}$

Nanometro

NMP/100 mL

.Número mais provável em 100 mililitros

$\phi$

Diâmetro

$\mathrm{O}_{2}$

Oxigênio

OC

.Oxigênio consumido

OD

Oxigênio dissolvido

$\mathrm{O}_{3}$

.Ozônio

$p$

Probabilidade

PFD.

Pré-filtro dinâmico

PFVA

Pré-filtro vertical ascendente

PFVAsh...................Efluente do pré-filtro vertical ascendente com substância húmica $\mathrm{pH}$

Potencial hidrogeniônico

PROSAB.

SAAE

SST.

Q

$\mathrm{Q}_{\mathrm{c}}$

TAM

TAMt

$\mathrm{uH}$.
Programa de pesquisa em saneamento básico

Serviço autônomo de água e esgoto

..Sólidos suspensos totais

.Vazão afluente à unidade

..Vazão coletada pelo sistema de drenagem trialometanos trialometanos totais Unidade de Hazen 


\section{RESUMO}

No presente trabalho foi investigada a remoção de substâncias húmicas na Filtração em Mútiplas Etapas - FiME, com aplicação de ozônio antecedendo o processo de filtração lenta.

A instalação piloto era constituída de um pré-filtro dinâmico operado com taxa de $18 \mathrm{~m} /$ dia, um pré-filtro de escoamento vertical ascendente operado com taxa de $12 \mathrm{~m} /$ dia e dois filtros lentos trabalhando com taxas de filtração iguais a $4 \mathrm{~m} / \mathrm{dia}$, com diferentes composições dos leitos filtrantes, sendo um somente de areia e o outro de areia e carvão ativado granular disposto como camada "sanduíche" entre duas camadas de areia, e sistema de ozonização.

Foi injetada solução de substância húmica na água efluente do pré-filtro vertical ascendente, preparada a partir da turfa retirada de uma área localizada no município de Luís Antônio, para proporcionar aumento de cor verdadeira na água.

A eficiência das unidades filtrantes, na remoção de matéria orgânica foi avaliada pela determinação de cor verdadeira, carbono orgânico dissolvido, absorvância a $254 \eta m$ e oxigênio consumido.

O resultados obtidos mostraram que o filtro lento 1, com carvão ativado, foi superior na remoção de matéria orgânica nas duas carreiras desenvolvidas e que não houve diferença entre os filtros lentos quanto a remoção de Escherichia Coli, bactérias heterotróficas, sólidos suspensos totais e ferro total. Fortes correlações entre cor verdadeira e absorvância foram identificadas na carreiras de filtração. $O$ mesmo ocorreu só na carreira 3 entre carbono orgânico dissolvido e absorvância e entre COD e oxigênio consumido. 


\section{ABSTRACT}

The current research was carried out investigate the removal of humic substances in the multistage filtration system - MSF, with ozone application upstream slow sand filters.

The pilot plant was compose by one dynamic roughing filter operated at a filtration rate of $18 \mathrm{~m} /$ day, one upflow roughing filter with filtration rate of $12 \mathrm{~m} /$ day and two slow sand filters, both operated with filtration rate of $4 \mathrm{~m} /$ day, with different "filtering beds"; one with sand only and another with sand and granular activated carbon, disposed as a "sandwich" layer between two sand layers, and the ozonation system.

Solution of humic substance was injected in the effluent water from the upflow roughing filter, which was prepared using turf extracted from Luís Antônio County, to provide a raise in the real color of the water.

The efficiency of the filtering units in the remotion of organic matter was evaluated by using the following parameters: true color, dissolved organic carbon, $\mathrm{Uv}-$ absorbance at $254 \eta \mathrm{m}$ and the consumed oxygen.

The results show that the slow sand filter 1, with activated carbon, was better for the removal of organic matter in the two runs carried out and that there were no differences between the slow sand filters in the removal of Escheyichia Coli, heteroph bacteria, total suspended solids. Strong correlation between true color and UV - absorbance was identified in run 1 . The same occurred in run 3, relating the dissolved organic carbon and UV - absorbance and between DOC and consumed oxygen. 


\section{INTRODUCẼO}

A matéria orgânica natural presente nos suprimentos de água de escoamento superficial pode prejudicar sua qualidade, quando reage com oxidantes químicos durante a desinfecção com cloro com produção de trialometanos, ácidos haloáceticos e outros subprodutos halogenados, em quantidade que pode causar cânceres em animais quando em pesquisa de laboratório.(SINGER, 1999)) Também, a matéria orgânica contribui para estabilização de partículas inibindo sua remoção durante o tratamento de água e serve como doador de elétrons para o "recrescimento" de bactérias heterotróficas nos sistemas de distribuição.

A seqüência de tratamento que envolve a utilização de pré-filtro dinâmico, pré-filtro de pedregulho com escoamento horizontal ou vertical (ascendente ou descendente) e a filtração lenta como barreira microbiológica, é denominada Filtração em múltiplas etapas (FiME). A filtração lenta em areia, embora seja um método de tratamento apropriado para produzir água potável, quando a água bruta apresenta qualidade adequada, não é efetiva para remoção de cor (YORDANOV et al, 1996) e apresenta limitada capacidade para remoção de matéria orgânica natural, expressa na forma de carbono orgânico dissolvido, absorvância e precursores de trialometanos.(COLLINS et al, 1992). Entretanto, bons resultados podem ser alcançados, quando se associa o emprego dessa tecnologia com o ozônio e o carvão ativado granular. O ozônio, além de ser um poderoso oxidante, é consumido rapidamente e em doses típicas não deixa residual que possa causar efeitos adversos no biofilme do filtro lento. Em geral, os resultados disponíveis indicam que a ozonização de substâncias húmicas tende a aumentar sua biodegradabilidade, todavia, quantificar a extensão deste aumento, é difícil devido a variedade de métodos utilizados nesta tarefa (GRAHAM, 1999). Segundo BAUER et al (1996) e COLLINS et al (1996), o uso do carvão ativado granular (CAG), como leito "sanduíche" associado às vantagens do processo de filtração lenta, alcançou 
desempenho muito superior na remoção de compostos orgânicos, quando comparado com a filtração lenta somente em filtro com areia.

Com a presente pesquisa avaliou-se a remoção de substâncias húmicas, em instalação de Filtração em Múltiplas Etapas (FiME), constituída por pré-filtro dinâmico, pré-filtro de escoamento vertical ascendente e filtros lentos, precedidos da ozonização. 


\section{OBJETIVOS}

Os objetivos do presente trabalho são:

a) Avaliar o desempenho da filtração em múltiplas etapas na remoção de substâncias húmicas, com uso de oxidante aplicado em uma das fases.

b) Comparar o desempenho da filtração lenta, com meios filtrantes diferentes, compostos de areia e de areia com carvão ativado granular na remoção de material orgânico

c) Avaliar o efeito da ozonização antecedendo a filtração lenta, na remoção de substâncias húmicas. 


\section{REFERÊNCIAS BIBLIOGRÁFICAS}

BAKER, M.N. (1948). The Quest for Pure Water. Journal AWWA, v.1

BAUER, M.J. et al. (1996). GAC Enhanced slow sand filtration (GAC Sandwich). In: ADVANCES IN SLOW SAND AND ALTERNATIVE BIOLOGICAL FILTRATION. John Wiley and Sons, England, april, 1996

BELLAMY, W.D.; HENDRICKS, D. W.; LOGSDON, G.S. (1985). Slow Sand Filtration: Influences of Some Selected Process Variables. Journal American Water Works Association, v.77,n.12, p. 62-66, december.

CAMEL, V.; BERMOND, A.(1998). The use of ozone and associated oxidation processes in drinking water treatment. Water Research, v.32, n.11, p.32083222.

CANEPA, L. (1982). Filtros de Arena en Acueductos Rurales. Informe Final. CEPIS/OMS/OPS. Lima, Peru.

CLESCERL, S. L et al. (1985). Standard Methods for the Examination of Water and Wastewater. 16 Th edition, APHA, AWWA and WEF, Whashington D.C.

COLLAZOS, A.E.A.P.(1990). Pré-filtração de pedregulho e areia grossa de fluxo descendente como pré-tratamento de filtro lento de areia. São Carlos. Dissertação (Mestrado)- Escola de Engenharia de São Carlos, Universidade de São Paulo. 
COLLINS, R.M. et al.(1992). Removing natural organic mattter by conventional slow sand filtration. Journal American Water Works Association. v.84, n.5, p.8090. May.

COLLINS, R.M. et al.(1996). Using granular media amendments to enhance NOM removal. Journal American Water Works Association. v.88, n.12, p. 48-61, december

DI BERNARDO, L. (1993). Métodos e técnicas de tratamento de água. Rio de Janeiro, ABES, v.2, p.281-401.

DI BERNARDO, L.; BRANDÃO, C.C.S.; HELLER, L. (1999). Tratamento de Águas de abastecimento por filtração em múltitplas etapas. Rio de Janeiro, ABES.

DI BERNARDO, L.; ROCHA, O. (1990). Remoção de algas em pré-filtro de fluxo ascendente com meio granular e pedregulho de areia grossa. In: IV SIMPÓSIO LUSO -BRASILEIRO DE ENGENHARIA SANITÁRIA E AMBIENTAL, Belo Horizonte, Brasil.

FOGEL, D. et al. (1993). Removing Giardia and Cryptosporidium by slow sand Filtration. Journal of Americam Water Works Association, v.85, n.11, p.77-85.

GALVIS, G.; FERNÁNDEZ, J.;VISSCHER, J.T.(1992). Comparative study of different pretreatment alternatives. In: ROUGHING FILTRATION IN WATER TREATMENT. June, Zurich, Switzerland.

GALVIS, G.;DI BERNARDO, L.; BRANDÃO, C.C.S.(1998). Filtração em múltiplas etapas no tratamento de águas de abastecimento. In: SIMPÓSIO LUSO -BRASILEIRO DE ENGENHARIA SANITÁRIA E AMBIENTAL, João Pessoa, Paraíba, Brasil. 
GALVIS, G.;LATORRE, J.; VISSCHER, J.T.(1999). Filtracíon en múltiples etapas: Tecnología innovativa para el tratamiento de agua. Santiago de Cali, Artes gráficas de Univalle.

GRAHAM, N.J.D.(1999). Removal of humic substances by oxidation/biofiltration processes - A review. Water Science \& Technology, v.40, n.9, p.141- 48.

HAARHOFF, J.; CLEASBY, J.L.(1991). Biological and physical mechanisms in slow sand filtration. In: LOGSDON, G.S.(ed.) SLOW SAND FILTRATION, ASCE, New York.

HAZEN, A. (1913). The Filtration of Water Public Supplies. 3.ed. New York, Jhon Wiley and Sons

HESPANHOL, I. (1969). Investigação sobre o comportamento e aplicabilidade de filtros lentos no Brasil. São Paulo, 163p. Tese (Doutorado) Faculdade de Higiene e Saúde Pública, Universidade de São Paulo.

HUISMAN,L.; WOOD, W.E.; (1974). Slow Sand Filtration. Geneva. World Health Organization.

LAPPONI, JUAN CARLOS (1997).Estatística usando Excel 5 e 7. São Paulo, Lapponi Treinamento e Editora.

LATORRE, J.;GALVIS. J.; VISSCHER, J.T. (1996). Performance evaluation of dynamic roughing filtration. In: ADVANCES IN SLOW SAND AND ALTERNATIVE BIOLOGICAL FILTRATION. John Wiley and Sons, England, april, 1996.

LLOYD, B. (1996). La vigilância y control de la calidad del agua: El desarollo de una herramienta de gestíon en el sector. In: CONFERENCIA 
INTERNACIONAL SOBRE MEJORAMIENTO DE LA CALIDAD DEL AGUA. Cali, de 30 de abril a 4 de maio, Colômbia.

MALLEY, J.P. et al.(1993). The performance and microbiology of ozone-enhanced biological filtration. Journal American Water Works Association. v.85, n.12,p. 47-57, december

MINISTÉRIO DA SAÚDE. Portaria № 1469 de 29 de dezembro de 2000.Diário Oficial $n^{0}$ 1, Brasília, 02/01/01.Seção 1, pág.19 e Diário Oficial $n^{\circ}$ 7, Brasília, 10/01/01.Seção 1, pág.26.

MOLL, D.M. (1999). Impact of temperature on drinking water biofilter performance and microbial community structure .Environmental Science \& Technology,v.33, n.14, p.2377-2382.

OWEN, D.M. et al.(1995). NOM characterization and treatability. Journal American Water Works Association. v.87, n.1, p. 46-63, january.

RICE, R.G. et al.(1981). Uses of ozone in drinking water treatment. Journal American Water Works Associaton. v.73, n.1, p.44-56.January.

SINGER, P.C.(1999). Humic substances as precursors for potentially harmful disinfection by-products. Water Science \& Technology, v.40, n.9, p.25-30.

TOLEDO, A. P. P. ( 1973). Contribuição ao estudo físico-químico de ácido húmico extraído de sedimento. São Paulo. 112p. Dissertação (Mestrado) - Instituto de Química da Universidade de São Paulo.

TOMINAGA, M.Y.; MIDIO, A .F. (1999). Exposição humana a trialometanos presentes em água tratada. Revista de Saúde Pública, v.33, n.4, p.413-21, agosto. 
VERAS, L.R.V.(1999). Tratamento de água superficial por meio de diferentes alternativas da tecnologia de filtração em múltiplas etapas. São Carlos. 246 p. Tese (Doutorado) - Escola de Engenharia de São Carlos, Universidade de São Paulo.

VISSCHER, J.T.; GALVIS, G.; LATORRE, J.(1996). Filtracíon en multiples etapas -FiME: bondades e limitaciones. In: CONFERENCIA INTERNACIONAL SOBRE MEJORAMIENTO DE LA CALIDAD DEL AGUA. Cali, de 30 de abril a 4 de maio, Colômbia.

WEBER, W.J.J.; JODELLAH, A.M.(1985). Removing humic substances by chemical treatment and adsorption. Journal American Water Works, v.77, n.4 p.132-37. April. 


\section{MATERIAIS E MÉTODOS}

\subsection{Descrição geral da instalação piloto}

O presente trabalho foi realizado na instalação piloto construída junto à Estação de Tratamento de Água de São Carlos (ETA-SC) do Serviço Autônomo da Água e Esgoto (SAAE). As Figuras 5 e 6 mostram uma visão geral do sistema.

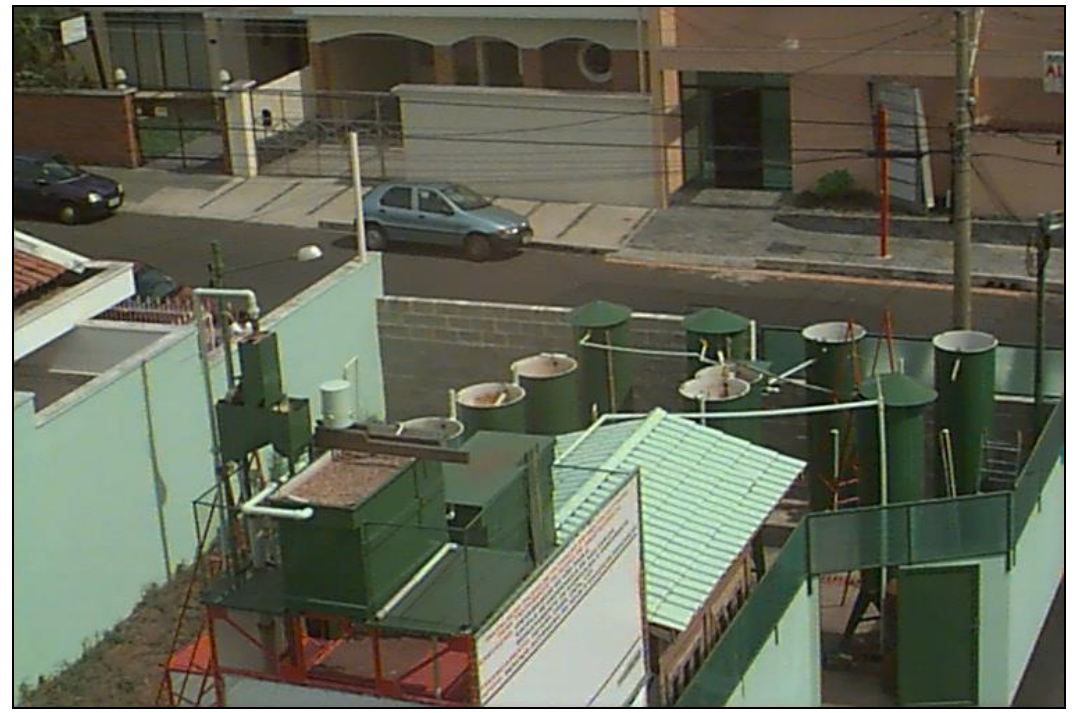

FIGURA 5 - Foto da instalação piloto de FiME 


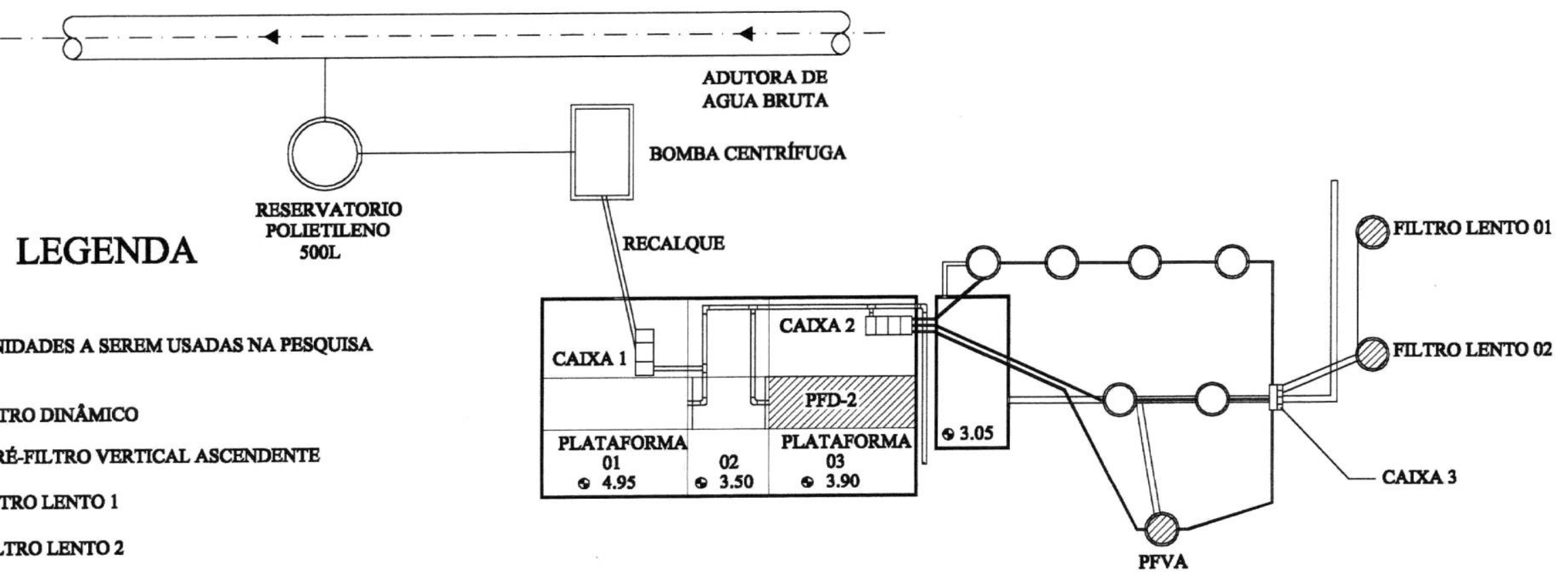

FIGURA 6 - Planta baixa da instalação piloto 
A água objeto de estudo, era proveniente de uma derivação feita na adutora de água bruta da ETA-SC, que transporta água do manancial superficial denominado Ribeirão Feijão (ver Figura 7). A derivação foi feita com tubos de PVC de $50 \mathrm{~mm}$ e alimentava um reservatório apoiado de $500 \mathrm{~L}$, com torneira de bóia, a partir do qual água era recalcada, por bomba centrífuga afogada, para a caixa de distribuição1 provida de vertedor triangular. Nesta caixa podia ser feito o controle da vazão afluente ao sistema de FiME, através de manobra de registro de gaveta colocado na tubulação de recalque e observando-se o nível de água na crista do vertedor. Outra possibilidade de controlar a vazão, era através de uma válvula borboleta colocada numa tubulação de $32 \mathrm{~mm}$ de diâmetro, que retornava água da tubulação de recalque para o reservatório.

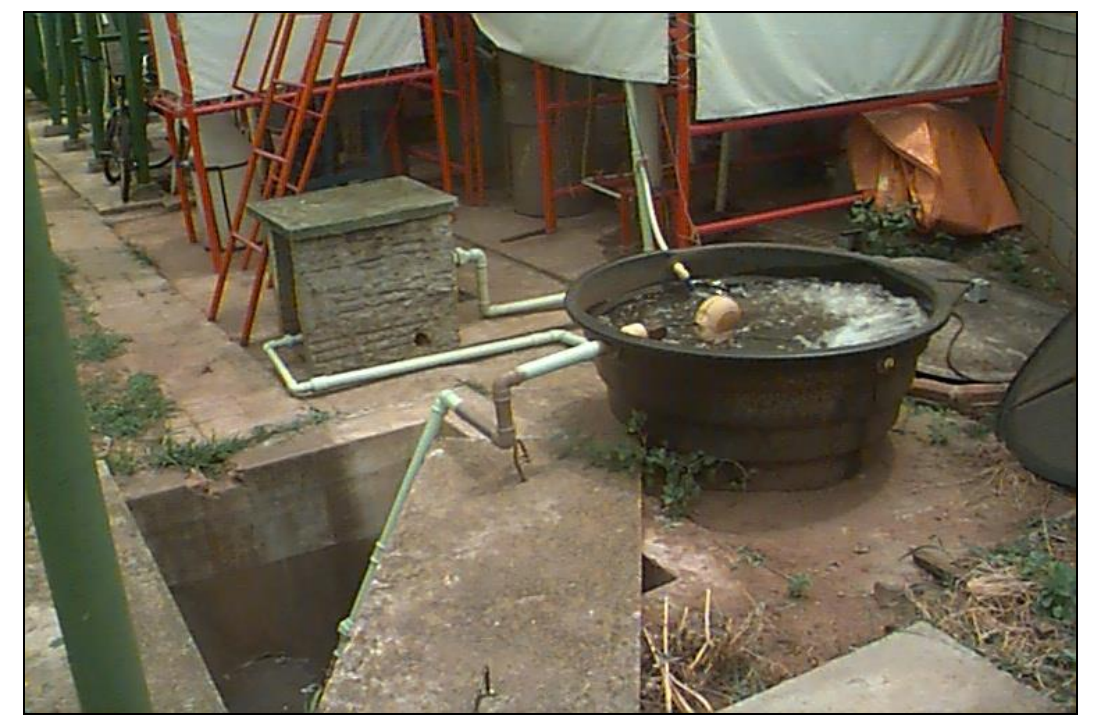

\section{FIGURA 7- Foto da derivação na adutora de água bruta}

Da caixa de distribuição 1, a água bruta era conduzida à primeira unidade da Filtração em Múltiplas Etapas - FiME, o pré-filtro dinâmico - PFD, no qual uma parte da água afluente escoava superficialmente, e era então lançada no sistema de drenagem da instalação piloto e a outra parte era filtrada e coletada numa segunda caixa de distribuição com vertedor triangular denominada caixa de distribuição 2. O PFD pode ser visto na Figura 8. 


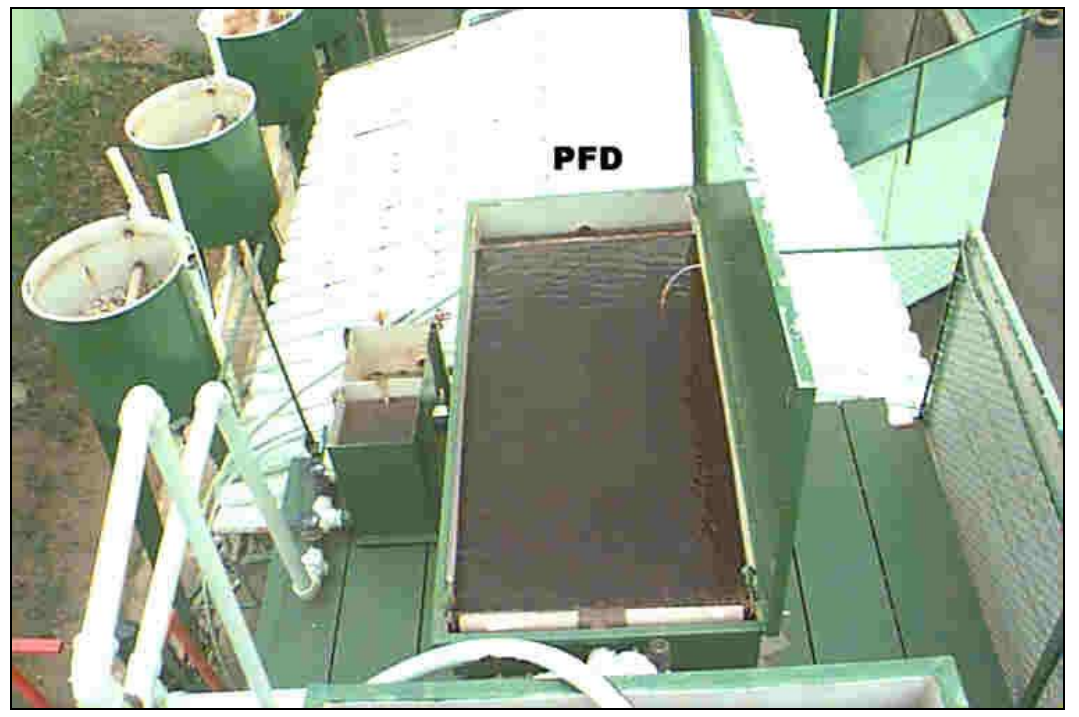

FIGURA 8 - Foto mostrando o pré-filtro dinâmico

A caixa de distribuição 2 continha quatro registros de gaveta por meio dos quais era feita o controle de vazões para que se obtivessem as taxas de filtração desejadas no PFD e na unidade subseqüente, o pré-filtro de pedregulho com escoamento vertical ascendente - PFVA, uma vez que da caixa 2 a água pré-filtrada era, em seguida, enviada para este último. A medição de vazões era feita com auxílio de becker e cronômetro e observando-se o nível de água sobre a crista do vertedor. Deste modo conforme aumentava a perda de carga no PFD, o registro de gaveta da saída do mesmo era manobrado, até que o nível de água sobre a crista do vertedor atingisse a uma marcação pré-determinada que correspondia a vazão desejada. As caixas de distribuição 1 e 2 podem ser visualizadas nas Figuras 9 e 10 respectivamente. 


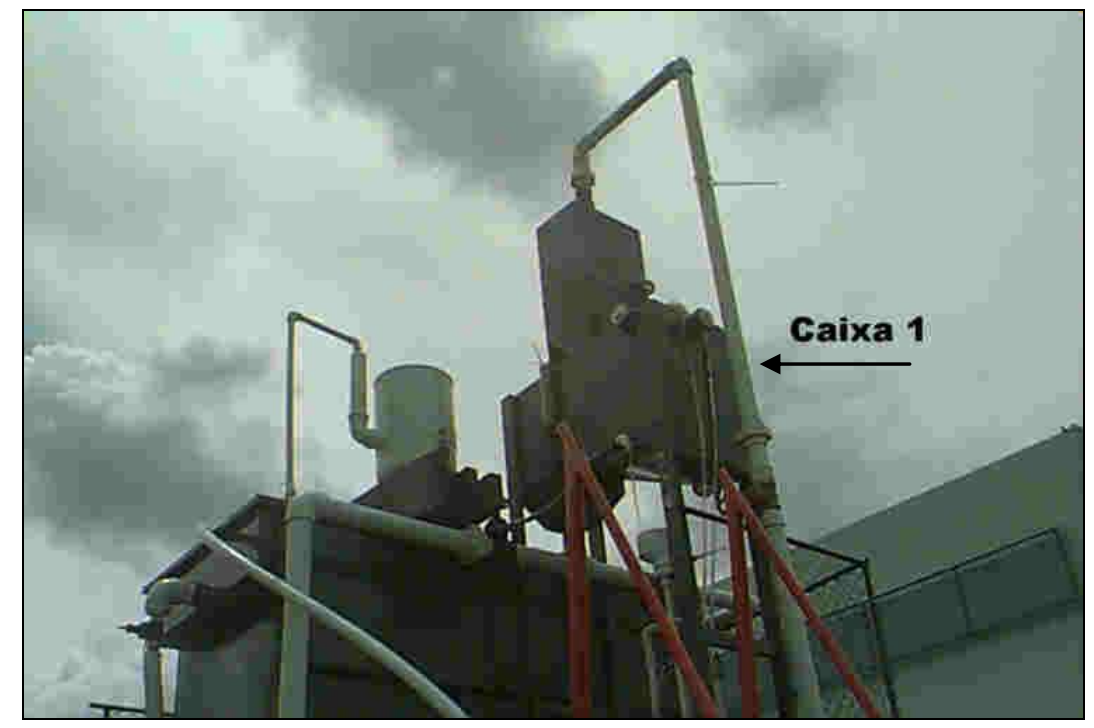

FIGURA 9 - Foto da caixa de distribuição 1

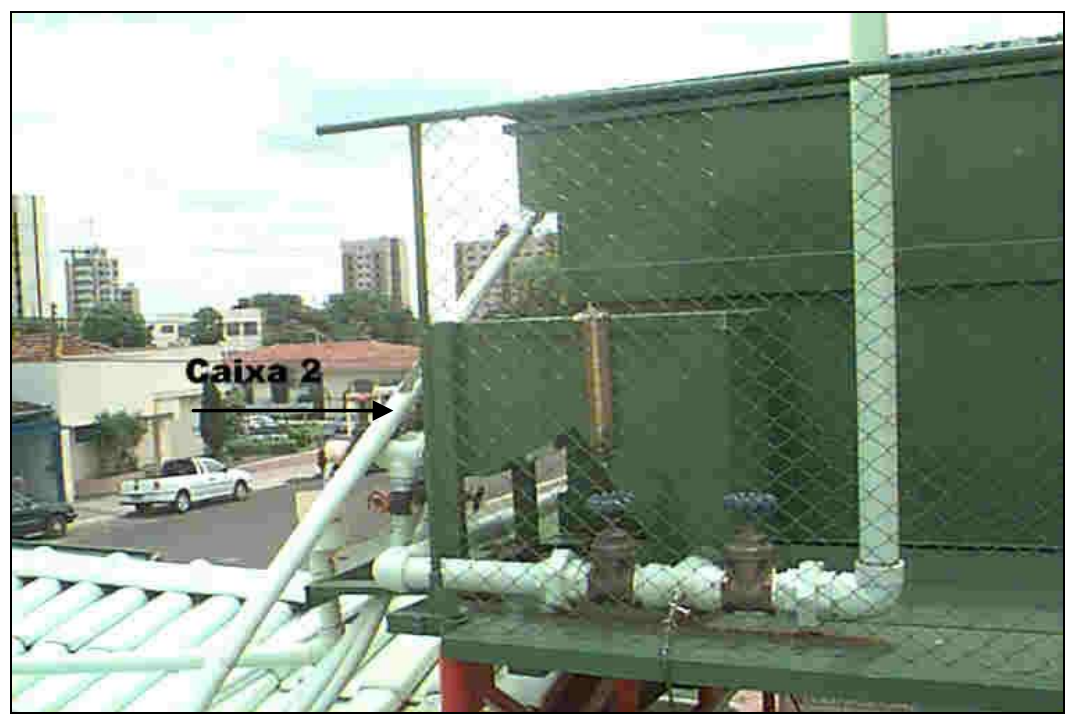

FIGURA 10 - Foto da caixa de distribuição 2

Do PFVA a água, numa primeira etapa, conduzida, com uma tubulação de 20 mm de diâmetro, para uma terceira caixa de distribuição, a caixa 3, que era dotada de quatro registros para a limpeza e de quatro vertedores individualizados, sendo dos quais foram utilizados apenas dois. Da caixa 3 partiam duas tubulações de $\phi=20$ $\mathrm{mm}$, responsáveis pela alimentação dos filtros lentos 1 e 2, $\mathrm{FL}_{1}$ e $\mathrm{FL}_{2}$, última etapa do sistema de tratamento. $\mathrm{O} \mathrm{FL}_{1}$ tinha meio filtrante heterogêneo, constituído de areia e carvão ativado e o $\mathrm{FL}_{2}$ tinha leito composto apenas de areia. 
Para avaliar a remoção de substâncias húmicas na filtração lenta, foi colocado, na tubulação que levava água do PFVA para a caixa 3 , um TE $90^{\circ}$ de 20mm, com um tubo do mesmo diâmetro, no qual através de bomba dosadora, era injetada a solução de substâncias húmicas. Esta seção foi chamada de seção 1 de aplicação de substância húmicas.

Posteriormente, com o objetivo de avaliar o efeito da pré-ozonização na remoção de substâncias húmicas antecedendo o processo de filtração lenta, a tubulação que levava água do PFVA para a caixa 3, foi desativada e deste modo procedeu-se a tomada de uma nova seção para aplicação de substâncias húmicas. Essa seção era feita de um segmento de tubo de $25 \mathrm{~mm}$ de diâmetro, uma luva de 25 mm, uma luva de redução de $25 \mathrm{~mm}$ para 1/2" com bucha de latão, 2 (dois) bicos metálicos para amostragem e uma mangueira plástica com de diâmetro de $0,5 \mathrm{~cm}$. $\mathrm{O}$ efluente do PFVA, já com a substância húmica, foi conduzido para um reservatório de fibra, denominado câmara de mistura, com volume de 300 L, de onde água era bombeada para o que se convencionou chamar de caixa de nível constante e desta para a coluna de ozonização. A caixa de nível constante será melhor explicada mas adiante. A Figura 11, permite uma visualização dos seções de aplicação da substância húmica. Já na Figura 12 constata-se a câmara de mistura de substâncias húmicas.

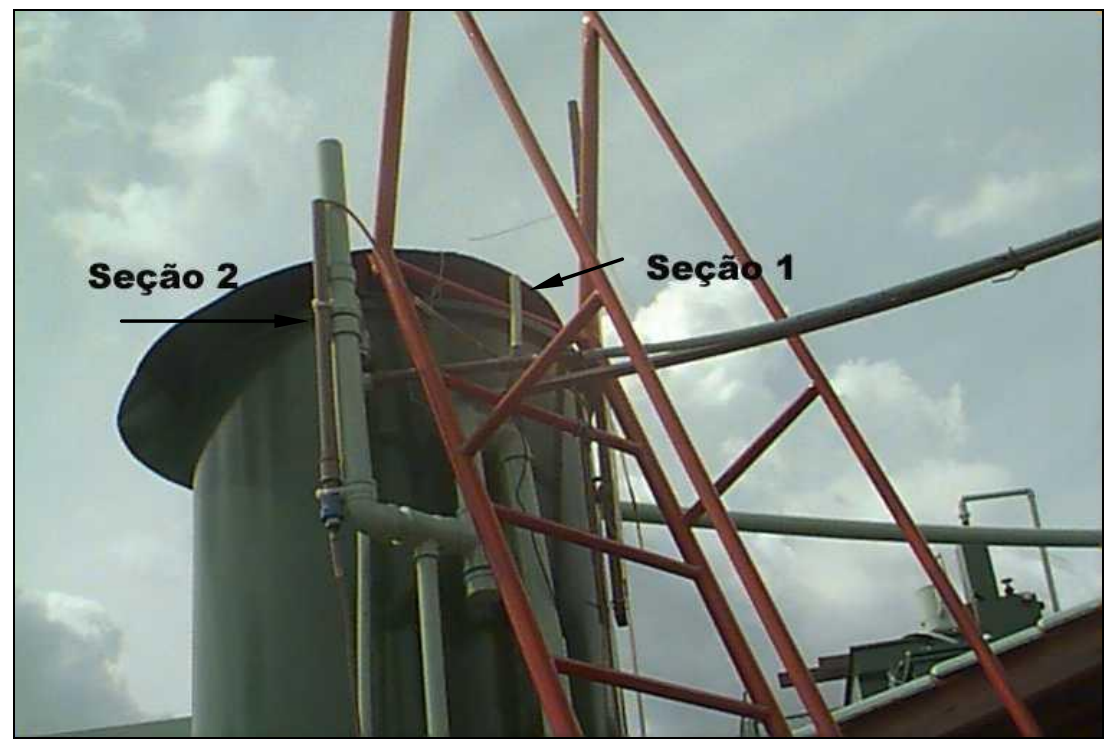

FIGURA 11 -Foto ilustrando as seções de aplicação de substância húmica 


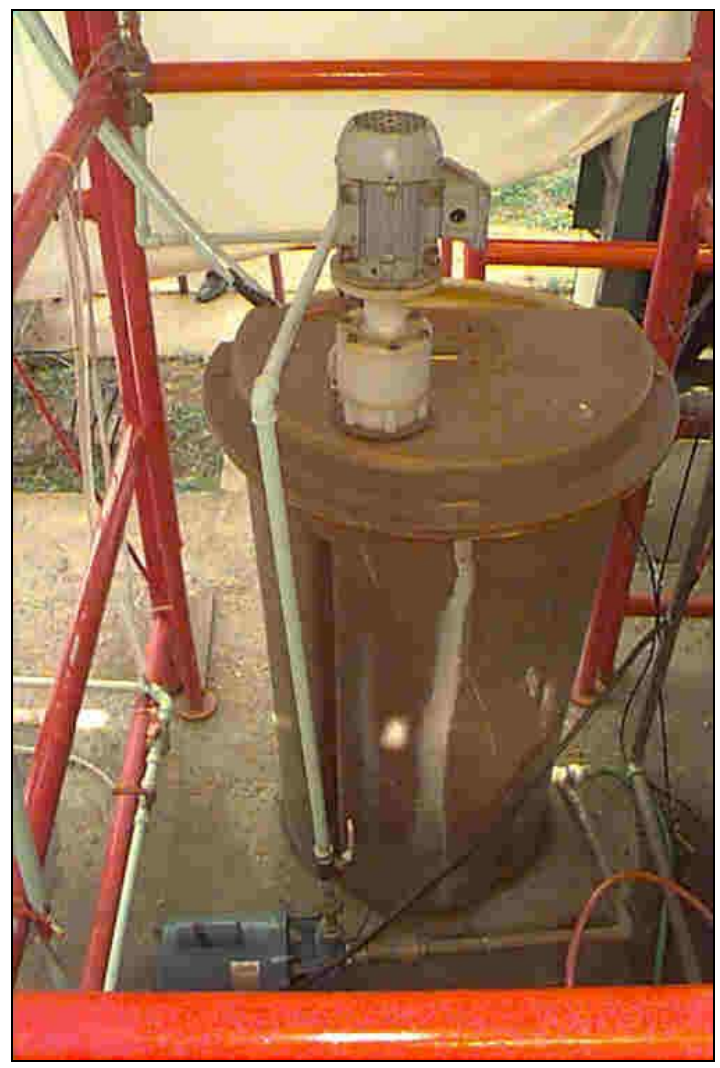

FIGURA 12 -Foto da câmara de mistura de substâncias húmicas

A água ozonizada era então destinada a caixa 3 e, em seqüência, aos filtros lentos. Com exceção da água bruta e da água afluente a coluna de ozonização, as demais vazões foram distribuídas por gravidade, com tubos de PVC de 50 e de 20 $\mathrm{mm}$ de diâmetro, para os pré-filtros e filtros lentos respectivamente.

\subsection{Características dos meios granulares}

Na Tabela 8, são mostradas as características do meio filtrante de cada unidade do sistema de FiME. 
TABELA 8 - Características dos meios filtrantes da unidades da FiME

\begin{tabular}{|c|c|c|}
\hline Unidade & $\begin{array}{c}\text { Tamanho } \\
\text { (mm) }\end{array}$ & $\begin{array}{c}\text { Espessura da camada } \\
\qquad(\mathrm{cm})\end{array}$ \\
\hline \multirow[t]{3}{*}{ PFD } & $4,80-9,60$ & 25 \\
\hline & $9,60-15,90$ & 25 \\
\hline & $19,00-25,40$ & 40 \\
\hline \multirow[t]{5}{*}{$\overline{P F V A}$} & $1,41-3,20$ & 40 \\
\hline & $3,20-6,40$ & 40 \\
\hline & $9,60-15,90$ & 40 \\
\hline & $19,00-25,40$ & 40 \\
\hline & $31,40-50$ & 50 \\
\hline \multirow{8}{*}{$\begin{array}{l}\text { FL } 1 \\
\text { (Com } 30 \mathrm{~cm} \text { de carvão } \\
\text { ativado entre duas camadas } \\
\text { de areia) }\end{array}$} & $0,08-1,00$ & 30 \\
\hline & $0,30-0,84(\mathrm{CAG})$ & 30 \\
\hline & $0,08-1,00$ & 10 \\
\hline & $1,41-3,20$ & 10 \\
\hline & $3,20-6,40$ & 10 \\
\hline & $7,90-12,70$ & 10 \\
\hline & $15,90-25,40$ & 15 \\
\hline & $31,40-50,00$ & 30 \\
\hline \multirow{6}{*}{$\begin{array}{l}\text { FL } 2 \\
\text { (somente areia) }\end{array}$} & $0,08-1,00$ & 70 \\
\hline & $1,41-3,20$ & 10 \\
\hline & $3,20-6,40$ & 10 \\
\hline & $7,90-12,70$ & 10 \\
\hline & $15,90-25,40$ & 15 \\
\hline & $31,40-50,00$ & 30 \\
\hline
\end{tabular}

A areia utilizada na filtração lenta tinha tamanho efetivo $\left(D_{10}\right)$ de 0,20 a 0,25 $\mathrm{mm}$, coeficiente de desuniformidade $(\mathrm{CD})$ de 2 a 3 e tamanho dos grãos entre 0,08 $1,00 \mathrm{~mm}$. 
O carvão ativado granular colocado no filtro lento 1 era da marca BAHIACARBON, tipo 350 e tinha tamanhos entre 0,30 a $0,85 \mathrm{~mm}$, coeficiente de desuniformidade $\leq 1,7$, índice de iodo de $4800 \mathrm{mgI} / \mathrm{g}$ carvão e tamanho efetivo entre 0,4 e 0,45 mm. Nas Figuras 12, 13 e 14, são apresentados detalhes das unidades do sistema de FiME.

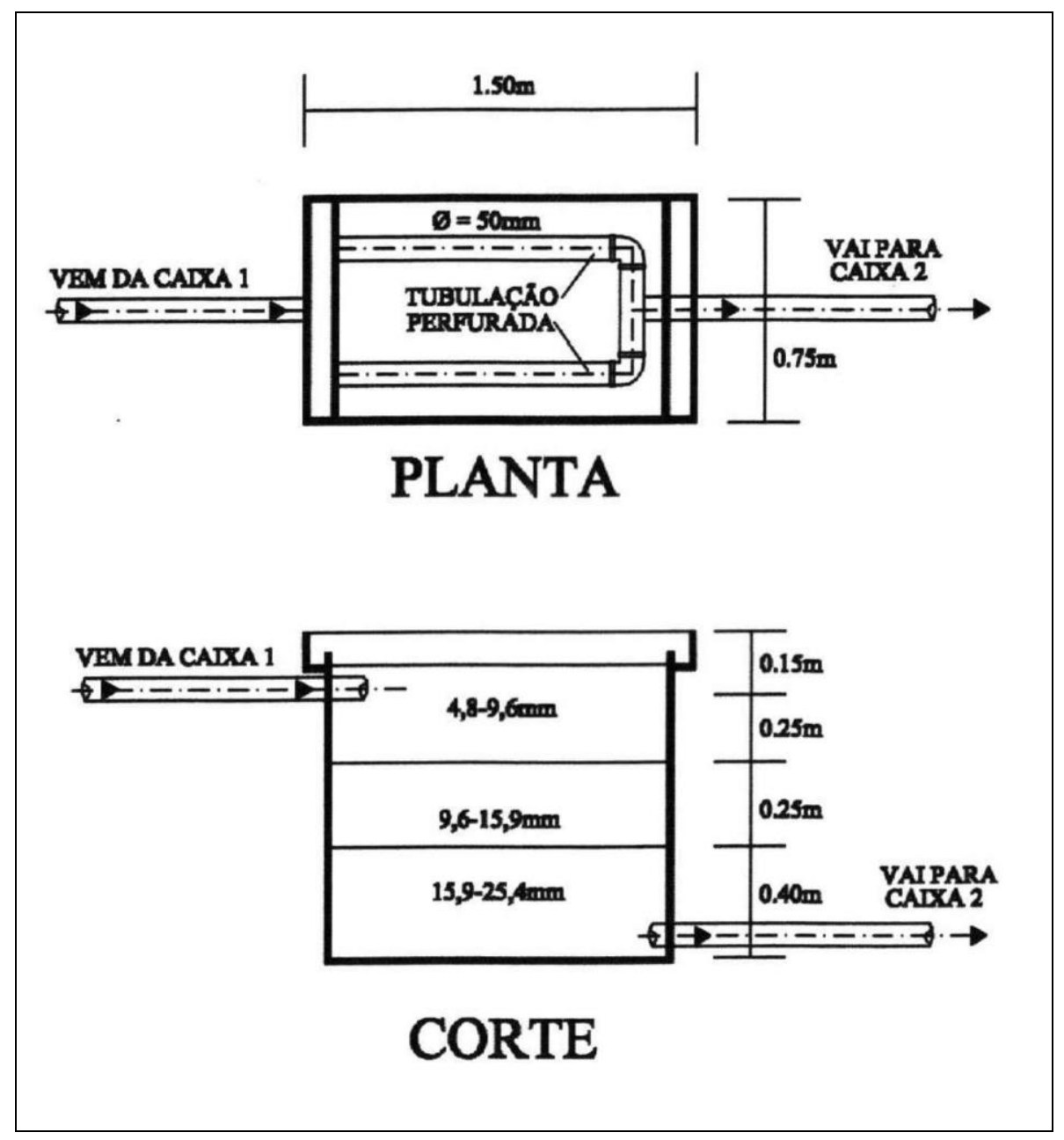

FIGURA 13 - Esquema do PFD 


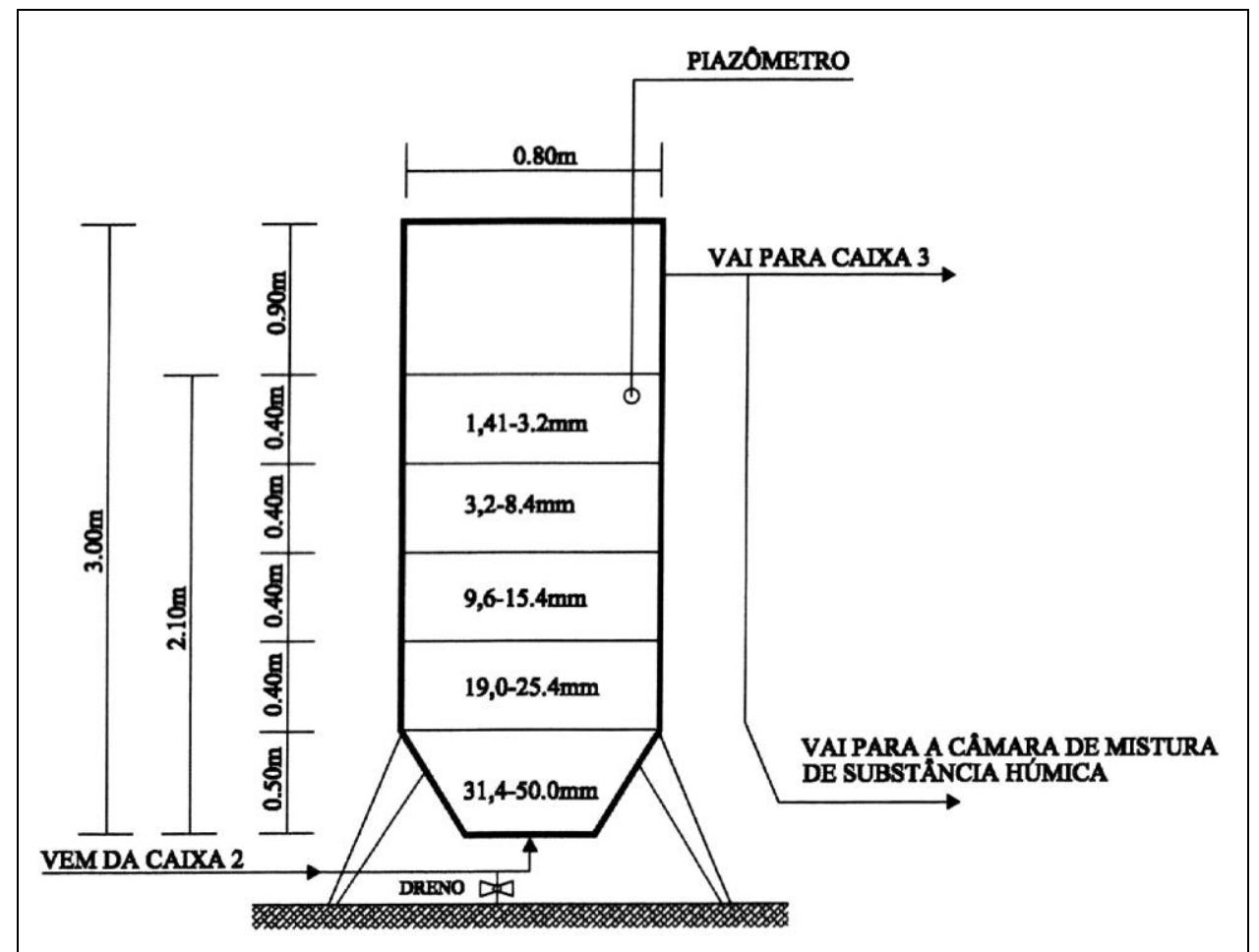

FIGURA 14 - Esquema do material granular do PFVA 

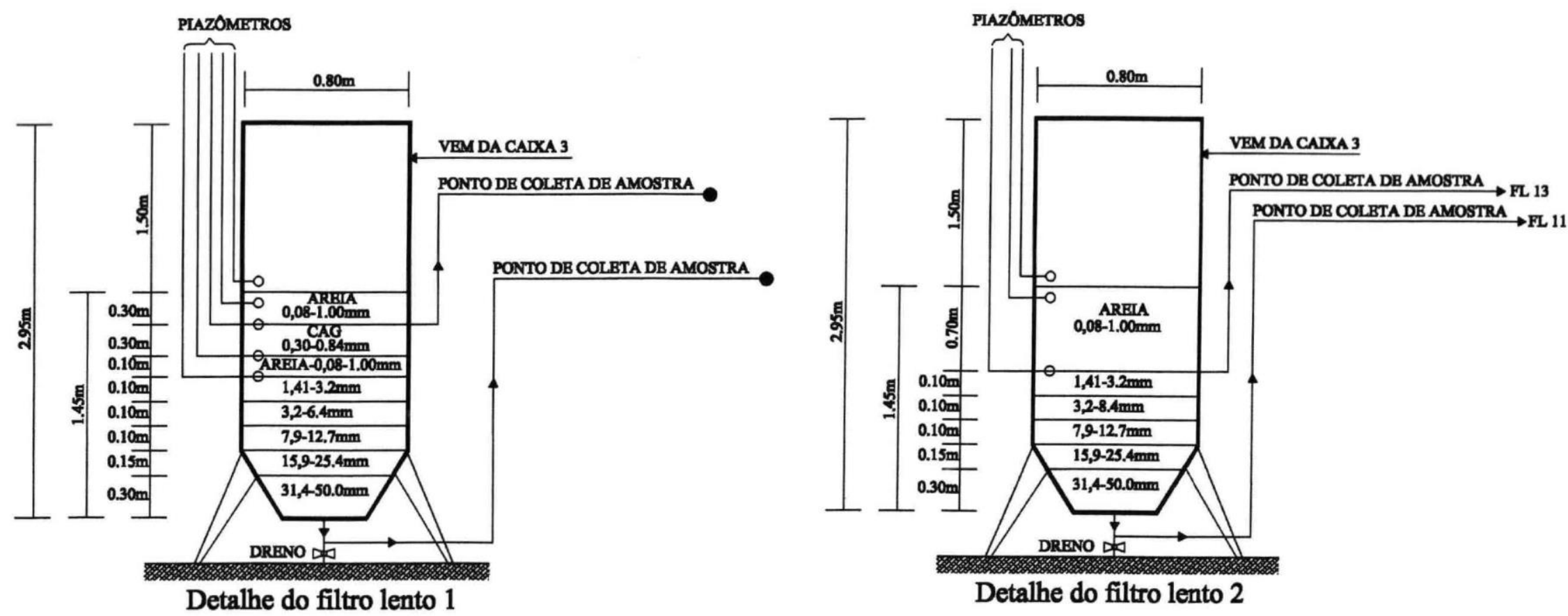

FIGURA 15 -Corte longitudinal mostrando detalhes dos filtros lentos 


\subsection{Carreiras de filtração}

Para efeito deste trabalho, foram consideradas duas carreiras de filtração, nos filtros lentos 1 e 2, precedidas de pré-filtração, que foram convencionalmente chamadas de carreias 1 e 3 . A carreira 2 desenvolvida no período compreendido, entre as carreiras citadas anteriormente, não foi utilizada nesta pesquisa, pois na mesma foi aplicado um pesticida denominado atrazina, sendo objeto de estudo de outro trabalho.

$\mathrm{Na}$ Tabela 9 são apresentadas as taxas de filtração empregadas nas unidades da FiME durante ambas as carreiras de filtração.

TABELA 9 -Taxas empregadas nas carreiras de filtração

\begin{tabular}{cc}
\hline Unidades & Taxa $\left(\mathbf{m}^{\mathbf{3}} / \mathbf{m}^{2} \cdot \mathbf{d}\right)$ \\
\hline PFD & 18 \\
\hline PFVA & 12 \\
\hline Filtros Lentos & 4 \\
\hline
\end{tabular}

\subsection{Parâmetros monitorados}

Para avaliar o desempenho da instalação na remoção de matéria orgânica e demais contaminantes da água, foram medidos parâmetros físicos, químicos e bacteriológicos. As leituras de $\mathrm{pH}$, turbidez, temperatura e perda de carga foram feitas "in situ", as demais determinações foram feitas no laboratório de saneamento da Escola de Engenharia de São Carlos- USP.

As amostras foram colhidas em garrafas plásticas de $2 \mathrm{~L}$, com exceção daquelas destinadas à determinação de oxigênio dissolvido - OD, coliformes e bactérias heterotróficas, que foram colhidas em recipientes especiais. Terminada a coleta todas as amostras foram imediatamente conduzidas ao laboratório de 
saneamento para análises e exames. A vazões nos pré-filtros foram controladas diariamente por manobra de registros e verificação do nível de água nos vertedores. As vazões para os filtros lentos foram medidas por meio de mangueiras conectadas na caixa 3, com auxílio de becker e cronômetro. Na Tabela 10 observa-se os parâmetros monitorados e a frequiência de amostragem. Em seguida a Tabela 11 lista os métodos e equipamentos utilizados.

TABELA 10 - Parâmetros monitorados e freqüência de amostragem

\begin{tabular}{|c|c|}
\hline Parâmetro & Freqüiência prevista \\
\hline Absorvância $\lambda=254 \eta \mathrm{m}$ & $2 \mathrm{x}$ por semana \\
\hline Alcalinidade total & $1 \mathrm{x}$ por semana \\
\hline Bactérias heterotróficas & $2 \times$ por mês \\
\hline Carbono orgânico total & $2 \mathrm{x}$ por semana \\
\hline Coliformes totais e Escherichia Coli & $1 \times$ por semana \\
\hline Condutividade elétrica & $2 \mathrm{x}$ por semana \\
\hline Cor aparente & $1 \times$ por dia \\
\hline Cor verdadeira & $\begin{array}{c}2 \times \text { por semana (carreira } 1) \\
1 \times \text { por dia (carreira } 3)\end{array}$ \\
\hline Fosfato & $1 \mathrm{x}$ por semana \\
\hline Ferro total & $1 \times$ por semana \\
\hline Nitrato & $1 \mathrm{x}$ por semana \\
\hline Nitrito & $1 \mathrm{x}$ por semana \\
\hline Nitrogênio amoniacal & $1 \times$ por semana \\
\hline Oxigênio consumido & $2 \mathrm{x}$ por semana \\
\hline Oxigênio dissolvido & $1 \mathrm{x}$ por semana \\
\hline $\mathrm{pH}$ & $1 \times$ ao dia \\
\hline Sólidos suspensos & $2 \times$ por semana \\
\hline Temperatura & $1 \times$ ao dia \\
\hline Turbidez & $1 \mathrm{x}$ ao dia \\
\hline
\end{tabular}


TABELA 11 - Métodos e equipamentos utilizados na medição dos parâmetros

\begin{tabular}{|c|c|}
\hline Parâmetro & Método/Equipamento \\
\hline Absorvância $\lambda=254 \eta \mathrm{m}$ & $\begin{array}{l}\text { Espectrofotometria com espectrofotômetro UV } \\
\text { 160-A-SHIMADZU }\end{array}$ \\
\hline Alcalinidade total & $\begin{array}{l}\text { Titulação potenciométrica com solução de ácido } \\
\text { sulfúrico }\end{array}$ \\
\hline Bactérias heterotróficas & $\begin{array}{l}\text { Contagem de bactérias em placas (IDEXX } \\
\text { SIMPLATE) }\end{array}$ \\
\hline Carbono orgânico total & $\begin{array}{l}\text { Combustão utilizando o aparelho TOC-5000-A- } \\
\text { SHIMADZU }\end{array}$ \\
\hline Coliformes totais e Escherichia Coli & $\begin{array}{l}\text { Método do substrato definido utilizando-se } \\
\text { enzima COLILERT (IDEXX) }\end{array}$ \\
\hline Condutividade elétrica & Condutivímetro modelo DS-15, marca HORIBA \\
\hline Cor aparente & Espectrofotometria com o DR 4000-HACH \\
\hline Cor verdadeira & $\begin{array}{l}\text { Centrífuga de bancada, FANEM, modelo } 215 \\
\text { (3500 RPM, durante } 30 \text { minutos) } \\
\text { Espectrofotometria com o DR 4000-HACH }\end{array}$ \\
\hline Fosfato & Método do ácido ascórbico \\
\hline Ferro total & $\begin{array}{l}\text { Espectofotometria de absorção atômica, modelo } \\
\text { INTRALAB, modelo AA- } 1275 \text {. }\end{array}$ \\
\hline Nitrato & $\begin{array}{l}\text { Espectrofotometria com espectrofotômetro UV } \\
\text { 160-A- SHIMADZU }\end{array}$ \\
\hline Nitrito & $\begin{array}{l}\text { Método colorimétrico com leitura no } \\
\text { espectrofotômetro UV 160-A-SHIMADZU }\end{array}$ \\
\hline Nitrogênio amoniacal & $\begin{array}{l}\text { Método de Nessler }(\mathrm{HACH}) \text { leitura } \\
\text { espectrofotômetro UV } 160-\mathrm{A}-\mathrm{SHIMADZU}\end{array}$ \\
\hline Oxigênio consumido & $\begin{array}{l}\text { Método CETESB, operação e manutenção de } \\
\text { ETA. }\end{array}$ \\
\hline Oxigênio dissolvido & $\begin{array}{l}\text { Método do eletrodo de membrana, oxímetro, } \\
\text { marca DIGIMED, modelo DM4 }\end{array}$ \\
\hline $\mathrm{pH}$ & Potenciômetro ORION, modelo 310 \\
\hline Sólidos suspensos & $\begin{array}{l}\text { Filtração em membrana }(\phi=0,45 \mu \mathrm{m}) \text { GF- S2- } \\
\text { C-SxS }\end{array}$ \\
\hline Temperatura & Termômetro de mercúrio marca INCOTERM \\
\hline Turbidez & $\begin{array}{l}\text { Nefelometria, aparelho } \\
\text { 2100P-HACH }\end{array}$ \\
\hline
\end{tabular}


$\mathrm{Na}$ primeira carreira de filtração foram colhidas amostras em seis pontos da instalação piloto sendo designados pela seguintes simbologias:

- $\mathrm{AB}$ - água bruta, coletada no reservatório de 500 L que armazenava água bruta

- PFD- efluente do pré-filtro dinâmico

- PFVA- efluente do pré-filtro dinâmico de escoamento vertical ascendente

- FL 11- efluente do filtro lento 1

- FL 13- água colhida na interface areia-carvão ativado, antes da camada de carvão ativado.

- FL 21- efluente do filtro lento 2

Já na carreira 3, além dos pontos supracitados, acrescentaram-se três novos pontos de amostragem, sendo os seguintes:

- FL11 mont - afluente ao filtro lento 1

- FL 21 mont - afluente ao filtro lento 2

- PFVAsh - efluente do PFVA com substâncias húmicas

O ponto FL13 foi introduzido com a finalidade de avaliar a influência do CAG na remoção de impurezas.

Os pontos FL11 mont e FL21 mont, foram locados nas tubulações independentes, que partiam da caixa 3, imediatamente antes da entrada da água em cada filtro. É importante mencionar que na carreira 3 o efluente do PFVA, já com a solução de susbtância húmica, foi colhido na câmara de mistura (Figura 12).

Na Figura 16 são indicados os pontos de coleta nos filtros lentos. 


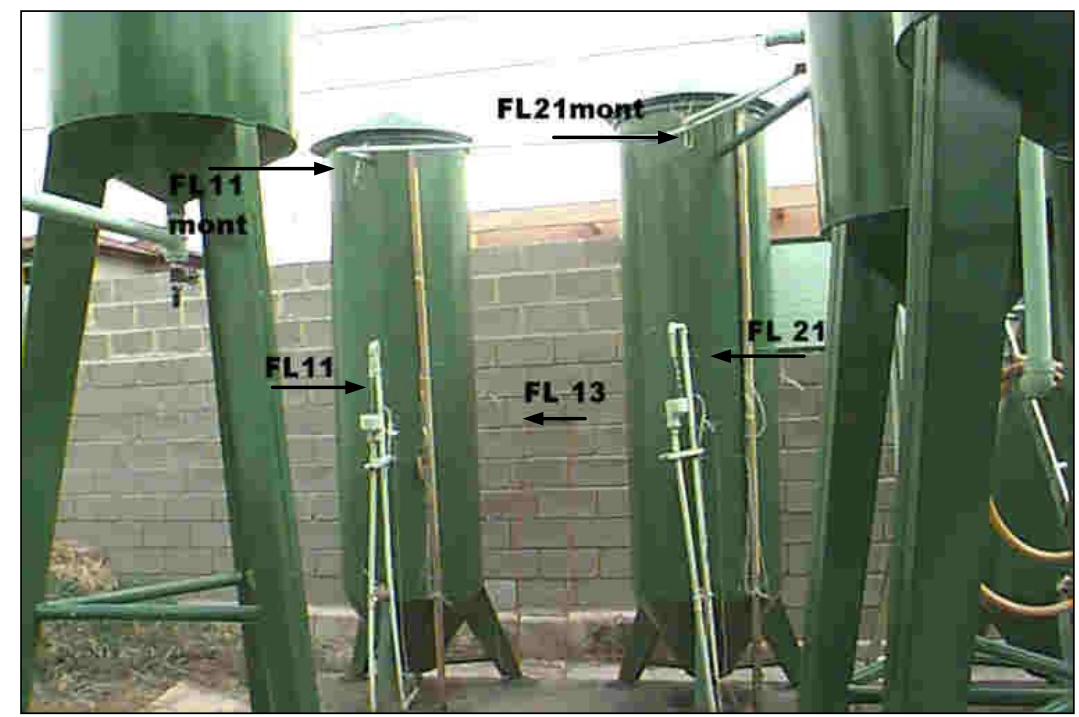

FIGURA 16 -Foto ilustrando os pontos de coleta nos filtros lentos

\subsection{Preparação da solução mãe de substâncias húmicas}

A matéria prima para preparação da solução mãe de substâncias húmicas, foi a turfa coletada, a trado, numa área situada no município de Luís Antônio Estado de São Paulo. Este material foi acondicionado em sacos plásticos e levado para o laboratório de saneamento da EESC-USP. Nesta fase da pesquisa os seguintes equipamentos foram utilizados:

- 01 Balança Mettler P1200

- 01 Agitador eletromecânico

Adicionalmente foram utilizados os seguintes materiais:

- 02 recipientes plásticos de 50 L (containeres de lixo)

- 02 caixas d'água de Polietileno sendo uma de 500 e outra de 1000 L

- 14 bandejas plásticas

- 01 tesoura 
- 70 folhas de papel celofane

- borrachas (elásticos)

- 02 beckers de $1 \mathrm{~L}$

- $\quad$ soda caustica $(3 \mathrm{~kg})$

- ácido clorídrico (1L)

- solução de nitrato de prata

- $\quad$ papel indicador de $\mathrm{pH}$ (uma cartela)

- água destilada (150 L)

- mangueiras plásticas com diâmetro de $0,5 \mathrm{~cm}$.

- 03 Pipetas de vidro

- 01 pêra

Para extração dos ácidos húmico e fúlvico da turfa procedeu-se da seguinte forma:

a) Foram preparados 50 litros de solução de $\mathrm{NaOH}-0,5 \mathrm{~N}$, adicionando-se $1 \mathrm{~kg}$ de $\mathrm{NaOH}$ em $50 \mathrm{~L}$ de água destilada. Nesta solução foram dissolvidos $500 \mathrm{~g}$ de turfa, sendo esta mistura mantida em agitação durante $18 \mathrm{~h}$ com o agitador mecânico.

b) Após a agitação, a solução foi deixada em repouso por cerca de 02 dias. Tampouse o recipiente para evitar a entrada de poeira e insetos.

c) O material sobrenadante foi retirado cuidadosamente por meio de beckers e colocado em sacos confeccionados com papel celofane, amarrados com o elásticos.

d) Os sacos foram colocados nas bandejas plásticas submersos em solução de ácido clorídrico, com pH em torno de 2, para que fosse efetuada a diálise. A solução de ácido clorídrico foi preparada adicionando-se $2 \mathrm{~mL}$ de ácido para cada 1 litro de água, sendo o pH medido com papel indicador. Vale ressaltar que na preparação da referida solução utilizou-se água do poço da USP, ao invés de água destilada, devido a grande demanda de água.

e) Durante dois dias a solução de ácido clorídrico das bandejas plásticas foi trocada três vezes ao dia. 
f) Depois da diálise, os sacos foram transferidos para a caixa d'água de $1000 \mathrm{~L}$, onde foi introduzida água proveniente do poço da USP, por meio de duas mangueiras plásticas de $\phi=0,5 \mathrm{~cm}$. Essas mangueiras estavam conectadas a caixa d'água de $500 \mathrm{~L}$, que foi locada em cota superior a caixa de $1000 \mathrm{~L}$, para que a água pudesse escoar continuamente por gravidade. Entre períodos de três horas a caixa elevada era reabastecida com água do poço. A água entrava na caixa e saia, também por meio de mangueiras plásticas, continuamente sem afogar os sacos de celofane que ficaram submersos. Esta etapa do procedimento durou um dia, pois decorrido esse período foi constatado reação negativa do cloreto para a água em torno dos sacos de celofane, pois a mesma foi colhida num becker em diferentes pontos da caixa e após adição de nitrato de prata não verificou-se, visualmente, turvação da água.

g) O material resultante dessas etapas foi colhido, perfurando-se os sacos de celofane, e transferidos para galões de plástico.

Todo o procedimento descrito anteriormente foi repetido por mais duas vezes, obtendo-se cerca de 130 litros de solução de substâncias húmicas (solução mãe), que foram transferidos para a instalação piloto, sendo na mesma diluídos e aplicados ao afluente dos filtros lentos. O procedimento em questão é uma parte das etapas descritas por TOLEDO (1973) para extração de substâncias húmicas de sedimento. Nas Figuras 17 e 18 verifica-se alguns passos do processo descrito acima. 


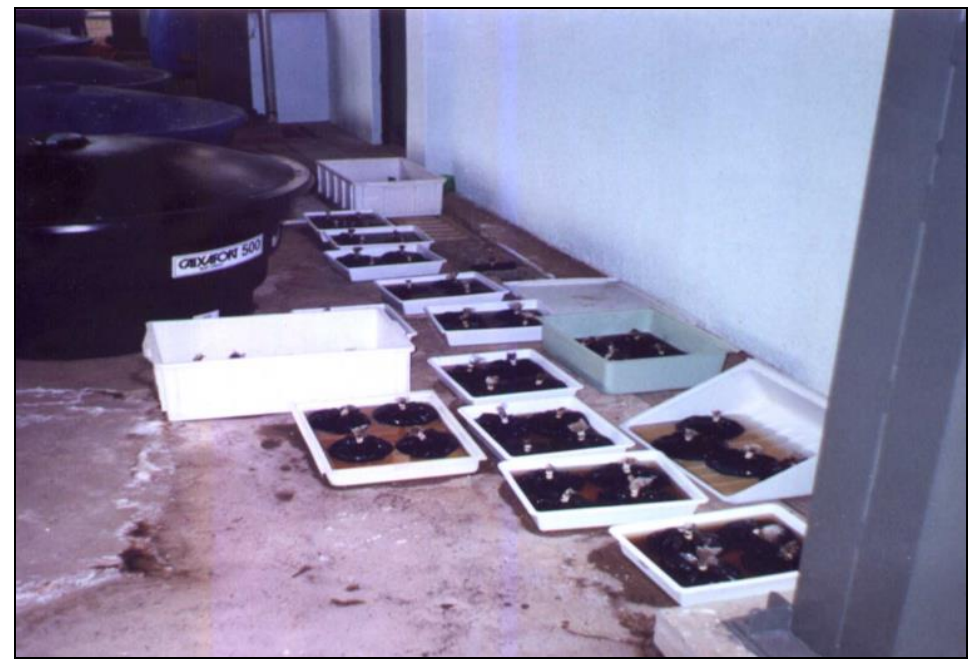

FIGURA 17 -Foto ilustrando os sacos durante a realização do processo de diálise com ácido clorídrico

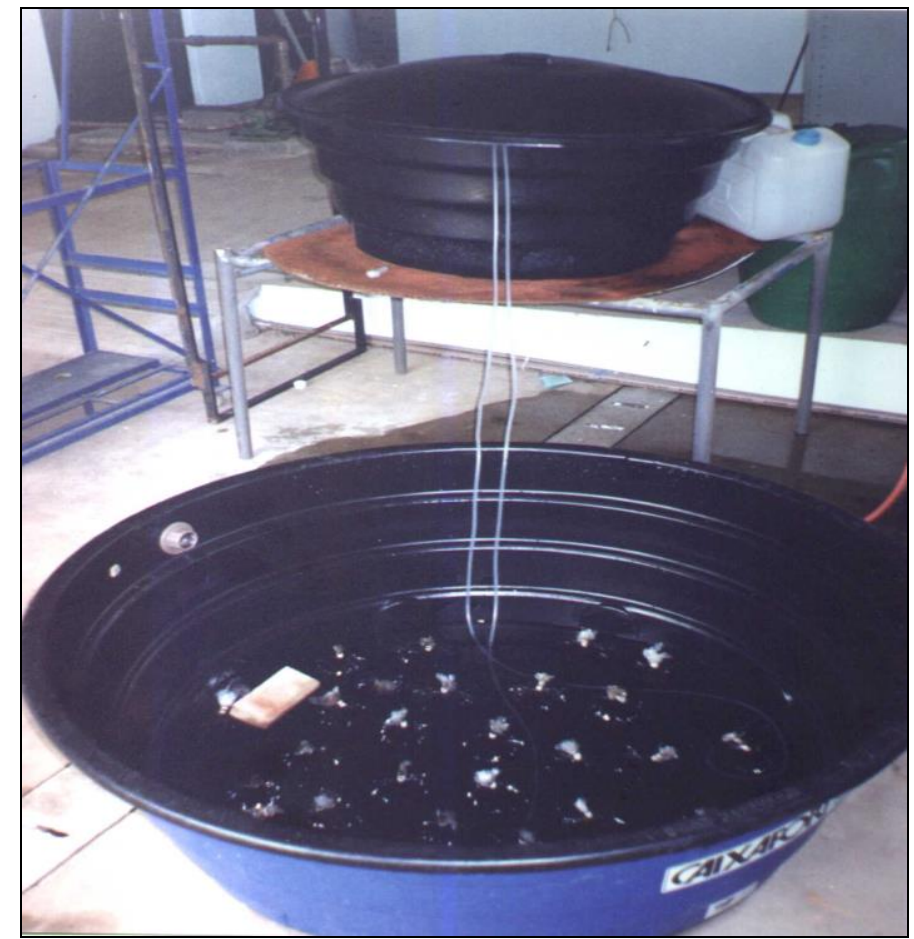

FIGURA 18 - Foto ilustrando o material húmico em uma parcela da lavagem 


\subsection{Definição da diluição da solução mãe de substâncias húmicas}

De posse da solução mãe de substâncias húmicas, foram feitos testes para definir a diluição da mesma, necessária para elevar a cor verdadeira da água efluente do PFVA para uma faixa de 45 a 55 uC. Para tanto procedeu-se da seguinte forma:

- Colheram-se amostras da água efluente do PFVA;

- Com essas amostras foram preparadas várias diluições em provetas, adicionandose $1 \mathrm{ml}$ da solução mãe para diferentes volumes de água, criando-se deste modo soluções com diferentes concentrações de substância húmica;

- Em erlenmeyers de $250 \mathrm{~mL}$, contendo cada um $100 \mathrm{~mL}$ da água do PFVA, adicionou-se $1 \mathrm{~mL}$ de cada solução resultante do passo anterior;

- Efetuou-se a leitura da cor verdadeira resultante em cada erlenmeyer, sendo selecionada aquela solução que gerou na água cor verdadeira na faixa supracitada.

A diluição escolhida foi de 1:10, pois promoveu o aumento de cor desejado, e a partir daí foi possível ajustar a vazão da bomba dosadora de substâncias húmicas, para que fosse elevada a cor verdadeira da água afluente aos filtros lentos. A bomba dosadora utilizada era da marca PROMINENT, tipo CONB1601PP1000A101, 230 $\mathrm{V}, 16 \mathrm{~W}, 1 \mathrm{~A}$, vazão máxima de $1 \mathrm{l} / \mathrm{h}$. Tal bomba estava anexa a um reservatório de 50 L(ver Figura 19) onde era colocada a solução diluída de substância húmica. A vazão de dosagem escolhida, em função dos testes anteriormente citados, foi de 10 $\mathrm{mL} / \mathrm{min}$, e deste modo o reservatório era reabastecido de três em três dias. A mangueira plástica utilizada na dosagem tinha diâmetro de $0,5 \mathrm{~cm}$.

A solução de substância húmica era preparada em um balde de 10 L, agitada manualmente e colocada no reservatório. 


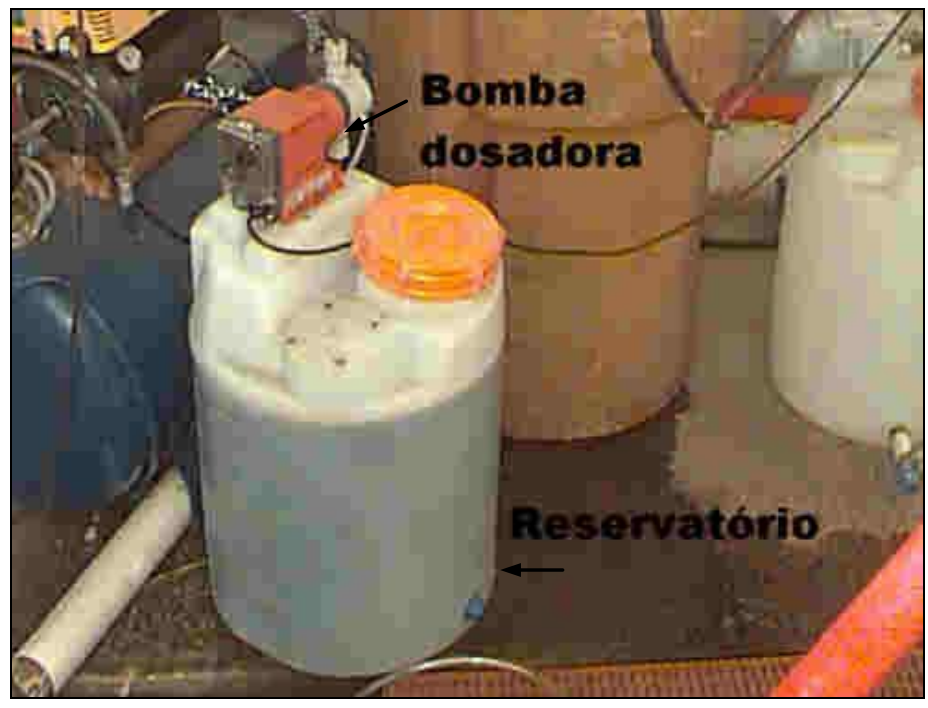

FIGURA 19. Foto mostrando tanque e bomba de recalque de solução de substâncias húmicas

\subsection{Sistema de ozonização}

Na Figura 20 é apresentado um esquema da FiME que inclui o sistema de ozonização. O ozonizador utilizado era da marca EAGLESAT, modelo OZ-7, do tipo "corona discharge", isto é, oxigênio seco escoa em uma célula onde se tem a descarga elétrica, produzida por uma fonte elétrica de alta voltagem. $\mathrm{O}$ aparelho em tela, tinha capacidade para produzir 7,0 $\pm 0,7$ gramas de $\mathrm{O}_{3}$ por hora, a partir de fluxo de oxigênio puro e era composto de uma reator de "corona discharge", um gerador de alta tensão e válvulas de controle de fluxo e pressão.(ver Figura 21) 


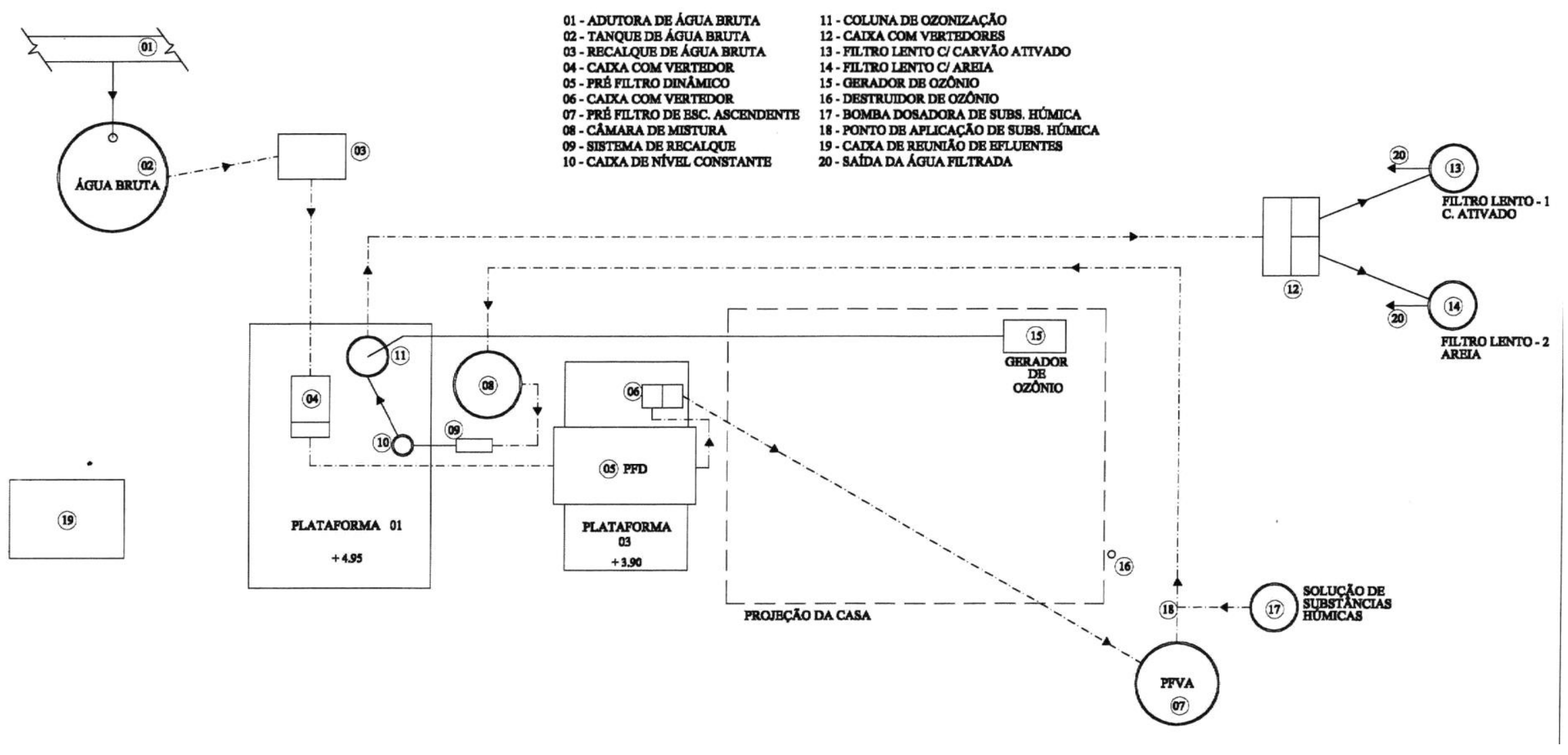

FIGURA 20 - Fluxograma esquemático do sistema de ozonização 


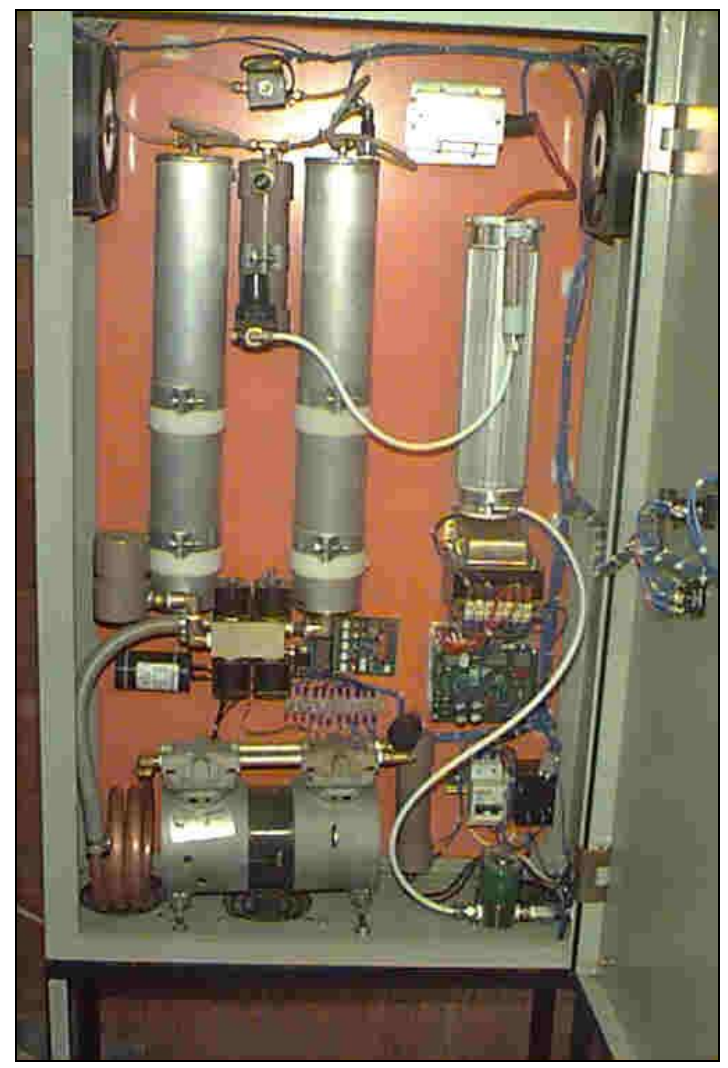

FIGURA 21 - Foto mostrando o ozonizador marca eaglesat, modelo oz-7

Adicionalmente o sistema de ozonização era composto de:

- Rotâmetro externo ao ozonizador para distribuição da dosagem de ozônio

- Caixa de nível constante

- Coluna de ozonização, de 4,5 m de altura, com 100 mm de diâmetro, dotada de uma vela para filtro d'água, feita de cerâmica microporosa, que funcionava como difusor

- Destruidor de ozônio, com carvão ativado granular.

A caixa de nível constante, que pode ser vista na Figura 22, era composta de uma caixa sifonada de PVC diâmetro $250 \mathrm{~mm}$, adaptada a uma mangueira de borracha de $1 / 2$ " conectada a um plug no qual havia um orifício e foi construída com a finalidade de manter constante a vazão afluente a coluna de ozonização. As vazões podiam ser alteradas trocando-se o plug, por outro com orifício de diâmetro diferente. Nas Figuras 23 e 24 constatam-se a coluna de ozonização e o destruidor de ozônio. 


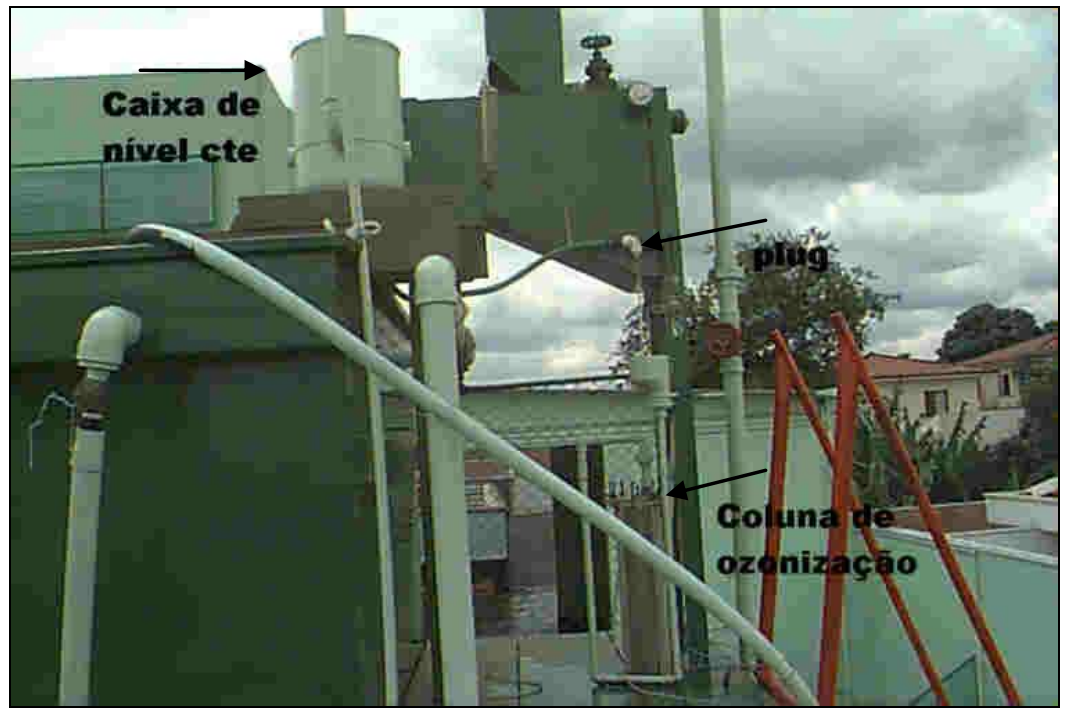

FIGURA 22 - Foto ilustrando a caixa de nível constante

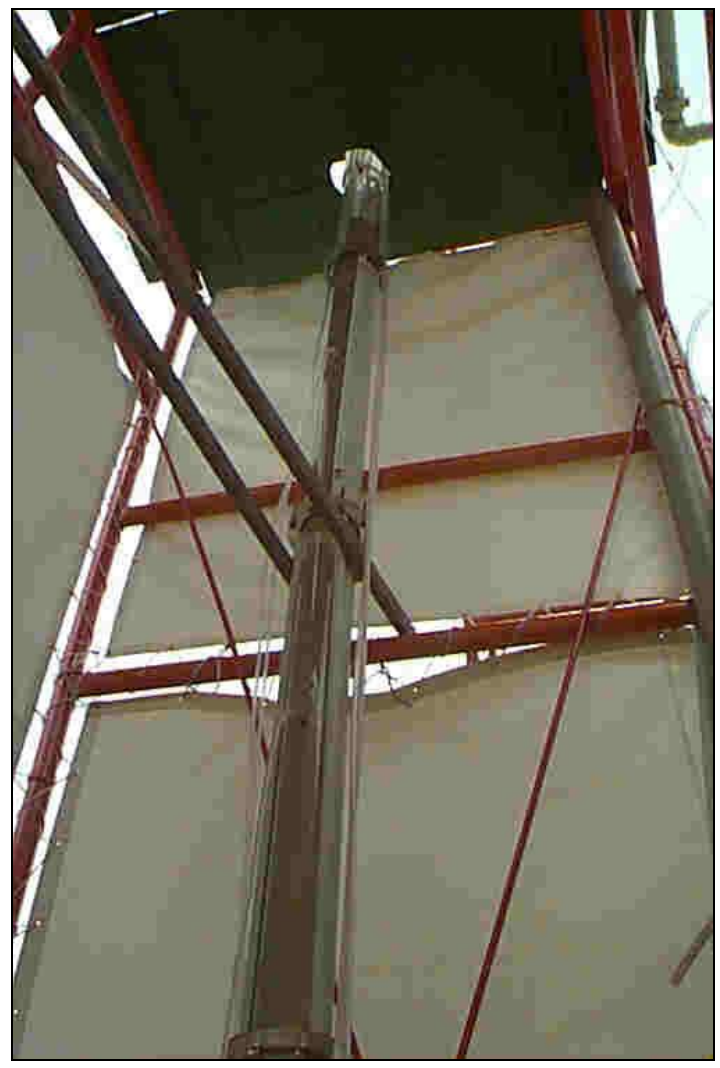

FIGURA 23 - Foto ilustrando a coluna de ozonização 


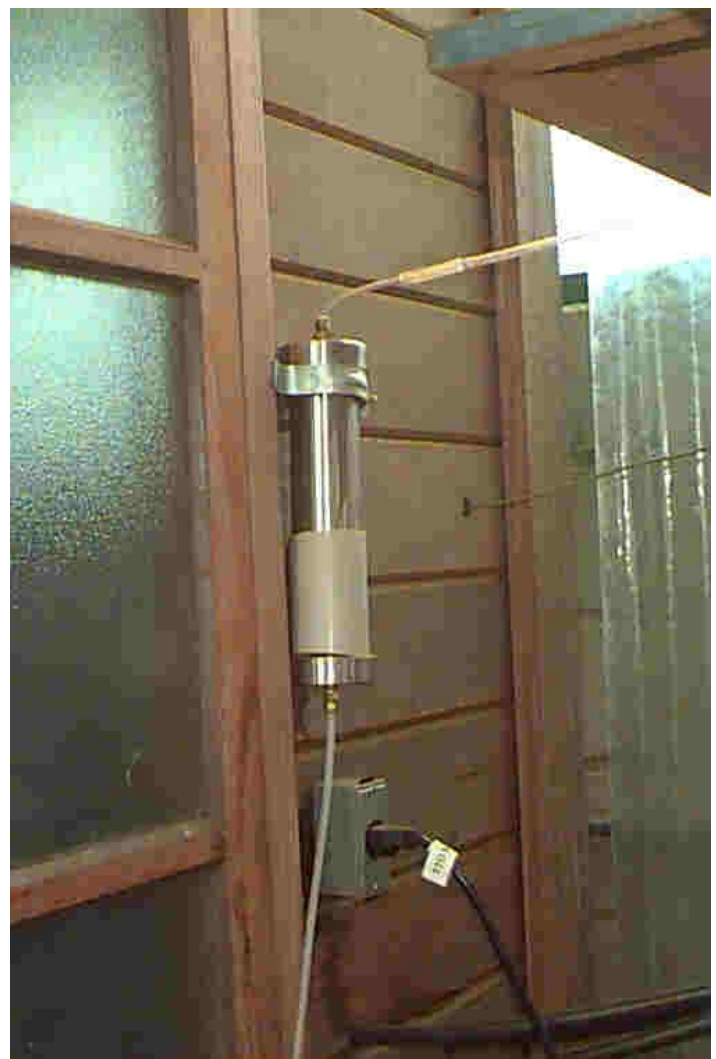

\section{FIGURA 24 - Foto ilustrando o destruidor de ozônio}

As determinações do residual de ozônio na fase líquida e na saída de excesso (off gas) foram feitas com o método da titulação iodimétrica descrito no Standard Methods 16 edition, 1985, sendo que obteve-se 0,06 para o residual e 0,0004 mgO $/ \mathrm{L}$ para o "off gas" e deste modo como a produção do aparelho utilizada foi de 4 $\mathrm{mgO}_{3} / \mathrm{L}$, a dosagem na água resultou igual a $3,4 \mathrm{mg} \mathrm{O}_{3} / \mathrm{L}$.

\subsection{Metodologia estatística}

As conclusões oriundas deste trabalho, foram obtidas com os cáculos estatísticos apresentados por LAPPONI(1997) e utilizando-se a versão 7 do EXCEL.

Para amostras grandes e independentes, ou seja populações com o tamanho de amostra $n$ maior que 30 , foi aplicada a distribuição $Z$, com a ferramenta de análise Teste Z: Duas Amostras para Média, que realiza análises estatísticas e teste de hipóteses de duas médias informadas como série de dados.

Em tratando de amostras pequenas e independentes, $n$ menor que 30, aplicouse primeiramente o Teste $F$ : duas amostras para variâncias, que verifica se a 
variância de uma população com distribuição normal é igual à variância de uma outra população com distribuição. De uma outra maneira, dadas duas séries de observações, que podem ter qualquer tamanho, o teste $F$ dá elementos para determinar se duas séries pertencem a mesma população.

Dependendo do resultado obtido com o Teste-F, utilizou-se oTeste-T: duas amostras presumindo-se variâncias equivalentes ou o Teste-T: duas amostras presumindo-se variâncias diferentes.

Quando se desejou comparar simultaneamente os resultados referentes aos efluentes do filtros lentos 1 e 2 e da seção FL13, foi aplicada a ferramenta Anova: fator único que realiza análise variância, procedimento estatístico de teste de hipóteses para comparação das médias de duas ou mais populações.

Utilizou-se a função estatística CORREL, do EXCEL, para os cálculos dos coeficientes de correlação. 


\section{DISCUSSÃO DOS RESULTADOS}

\subsection{CARREIRA 1 DE FILTRAÇÃO}

Na carreira 1, que teve início em 14 de fevereiro e se estendeu até 09 de maio de 2000 (85 dias), foi possível aprender a hidráulica do sistema, efetuar ajustes na instalação e se familiarizar com as técnicas de medição dos parâmetros físicos, químicos e bacteriológicos. No início da mesma, foi encaminhada para os filtros lentos água limpa, livre de cloro, com o objetivo de preencher os meios filtrantes. No $16^{0}$ e $17^{\circ}$ dia de operação, com o fim de reduzir o período de amadurecimento dos filtros lentos, a água bruta afluente ao PFD foi desviada, com um "by pass" e introduzida diretamente nos mesmos. Durante todo o desenvolvimento da referida carreira não houve necessidade de limpeza dos pré-filtros. Terminada a carreira nos filtros lentos procedeuse a limpeza de todas as unidades do sistema de FiME, de acordo com as recomendações sugeridas por DI BERNARDO et al.(1999). É importante recordar que nessa carreira foram feitas coletas de amostras em 6 (seis) pontos distintos: AB (água bruta), PFD (efluente do pré-filtro dinâmico), PFVA (efluente do pré-filtro vertical de escoamento ascendente), FL11 ( efluente do filtro lento 1), FL13 (água da interface carvão ativadoareia no filtro lento 1) e FL21 (efluente do filtro lento 2). 
TABELA 12- Caracterização da água bruta na carreira 1

\begin{tabular}{|c|c|c|c|c|}
\hline Parâmetro & Valor máximo & $\overline{\text { Valor mínimo }}$ & Média & Comparações \\
\hline$\overline{\text { Turbidez (uT) }}$ & 98,90 & $\overline{14,16}$ & 24,88 & $\begin{array}{l}100 \%<100 \\
100 \%<200\end{array}$ \\
\hline Cor verdadeira $(\mathrm{uH})$ & 65 & 34 & 44,78 & $\begin{array}{l}0 \%<10 \\
0 \%<25 \\
\end{array}$ \\
\hline Sólidos suspensos (mg/L) & 31,15 & 4,21 & 12,07 & $\begin{array}{l}100 \%<100 \\
100 \%<200\end{array}$ \\
\hline $\begin{array}{l}\text { Coliformes } \\
\text { (NMP/100mL) }\end{array}$ & 24192 & 3240 & 10125 & $\begin{array}{l}63,6 \%<10000 \\
91 \%<20000\end{array}$ \\
\hline $\begin{array}{l}\text { Escherichia } \\
\text { (NMP/100mL) }\end{array}$ & 2187 & 213 & 547 & $\begin{array}{l}100 \%<5000 \\
100 \%<10000\end{array}$ \\
\hline Ferro total $(\mathrm{mg} / \mathrm{L})$ & 2,1 & 1,1 & 1,7 & $\begin{array}{l}100 \%<3 \\
100 \%<5\end{array}$ \\
\hline
\end{tabular}

Pelos valores contidos na tabela 12 , verifica-se que a qualidade da água bruta não estava de acordo com o que especifica DI BERNARDO et al(1999) para aplicação da tecnologia de FiME, haja vista que os valores dos parâmetros cor verdadeira e coliformes totais excederam os limites estabelecidos pelos autores. Tais limites foram apresentados na revisão da literatura, na Tabela 1 .

\subsubsection{Turbidez:}

Para turbidez, o PFD apresentou remoção média de 28,4 \% e o PFVA de 38,6 \%. As seções FL11, FL13 e FL21 removeram, em média, 41,5, 26,5 e 39,4\% respectivamente (tabela A.1). Aplicando-se o teste estatístico Anova: fator único, da versão 7 do EXCEL, foi verificada diferença significativa de remoção de turbidez entre as seções FL11, FL13 e FL21, uma vez que o valor $p$ foi menor que 0,05.(tabela A.2). Pelos testes estatísticos, com método Teste-z: duas amostras para média, da versão 7 do EXCEL, determinou-se que não houve diferença entre os filtros lentos na remoção de turbidez e que ambos os filtros foram melhores que a seção FL13 no referido aspecto.(tabelas A.3, A.4 e A.5). A turbidez dos efluentes dos filtros lentos e da seção FL13 manteve-se consistentemente abaixo de 5 uT, em 48,7 e $46 \%$ dos dados, 
respectivamente, entretanto é importante ressaltar que nesta carreira os filtros estavam amadurecendo. A variação da turbidez da água bruta refletiu-se nas unidades do sistema, como pode ser verificado na figura 25 . Na tabela 13 , consta um resumo dos dados de turbidez da água bruta e unidades da FiME.

TABELA 13- Resumo dos valores médios de turbidez em uT carreira 1

\begin{tabular}{ccccccc}
\hline Valores & AB & PFD & PFVA & FL11 & FL13 & FL21 \\
\hline Máximo & 98,90 & 77,30 & 40,40 & 46,50 & 52,50 & 44,70 \\
\hline Médio & 24,88 & 17,86 & 11,16 & 7,45 & 8,97 & 7,51 \\
\hline Mínimo & 14,16 & 10,20 & 4,69 & 1,55 & 2,31 & 1,82 \\
\hline
\end{tabular}

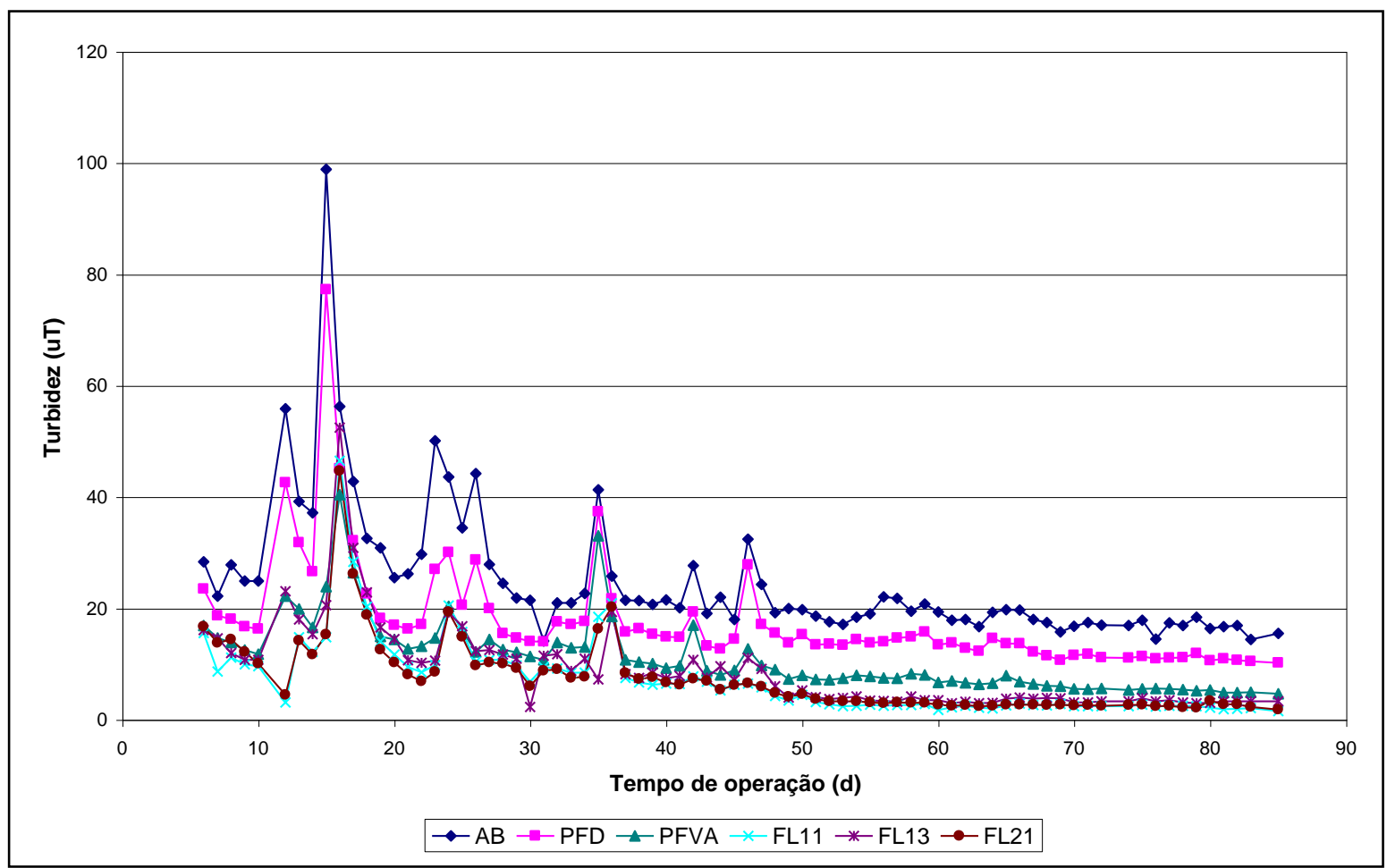

FIGURA 25- Variações de turbidez com o tempo de funcionamento na carreira 1, para água bruta e unidades de filtração

\section{Fonte: TABELA E.1}

\subsubsection{Coliformes totais e Escherichia Coli}

No que se refere a coliformes totais - CT e Escherichia Coli - E.Coli o PFD apresentou remoção média de 59 e 59\%, o PFVA removeu 77,1 e 79,3\%, o FL11 80,5 e 
85,2 \%, o FL13 73,9 e 67,3 \% e o FL21 82,7 e 79,8 \%, respectivamente. Não foram constatadas diferenças significativas de remoção de coliformes totais entre os efluentes dos filtros lentos e a da seção FL13, como pode ser observado na tabela A.7.(p>0,05). O mesmo foi verificado para Escherichia Coli, conforme tabela A.9.

Em 45,4\% dos dados os efluentes dos filtros lentos tiveram valores de E.Coli abaixo de $2 \mathrm{NMP} / 100 \mathrm{~mL}$. Esta mesma porcentagem foi obtida para coliformes totais no filtro lento 1, considerando-se NMP/100mL menor que 20, já para o filtro lento 2 somente $36,3 \%$ dos dados estiveram situados nesta faixa. Nas figuras 26 e 27 e nas tabelas 14 e 15 podem ser vistas as variações de coliformes totais e E.Coli, nesta ordem, durante o desenvolvimento da carreira 1. É importante notar que a partir do $38^{\circ}$ dia de operação os filtros lentos produziram água com valores de E.Coli abaixo de 5 e próximos ou iguais a $0 \mathrm{NMP} / 100 \mathrm{~mL}$ a partir do $65^{\circ}$ dia . Do $52^{\circ}$ dia em diante o filtro lento 1 produziu efluente com valores de CT abaixo de 20 e no filtro lento 2 os valores situaram-se abaixo de $23 \mathrm{NMP} / 100 \mathrm{~mL}$. Essas observações são coerentes com o que se verificou para turbidez, pois a partir do 48ำ dia de operação a turbidez dos filtros lentos manteve-se abaixo de 5 uT, ocorrendo o mesmo na seção FL13 a partir do 51ํ dia de operação. (tabela E.1).

TABELA 14 - Resultados de coliformes totais em NMP/100 mL para água bruta e unidades de filtração durante a carreira 1

\begin{tabular}{cccccccc}
\hline Data & TO* & AB & PFD & PFVA & FL11 & FL13 & FL21 \\
\hline 24.02 & 10 & 15531 & 3441 & 1299,7 & 204,6 & 410,6 & 488,4 \\
\hline 02.03 & 17 & 14136 & 3255 & 1732,9 & 816,4 & 248,1 & 387,3 \\
\hline 09.03 & 24 & 24192 & 14136 & 1732,9 & 770,1 & 980,4 & 248,1 \\
\hline 16.03 & 31 & 8664 & 2419,2 & 920,8 & 488,4 & 816,4 & 178,2 \\
\hline 23.03 & 38 & 6440 & 5475 & 2419,2 & 248,1 & 146,7 & 1413,6 \\
\hline 30.03 & 45 & 9804 & 5475 & 1119,9 & 161,6 & 313 & 125,9 \\
\hline 06.04 & 52 & 7800 & 2224 & 217,8 & 14,6 & 38,2 & 22,6 \\
\hline 13.04 & 59 & 10462 & 6488 & 866,4 & 8,6 & 50,4 & 16 \\
\hline 19.04 & 65 & 6500 & 1989 & 189,2 & 6,3 & 13,5 & 12 \\
\hline 26.04 & 72 & 3240 & 1013 & 50,4 & 6,4 & 12,4 & 2 \\
\hline 03.05 & 79 & 4611 & 1254 & 101,9 & 6,3 & 7,4 & 4,1 \\
\hline
\end{tabular}

*TO: Tempo de Operação (d) 


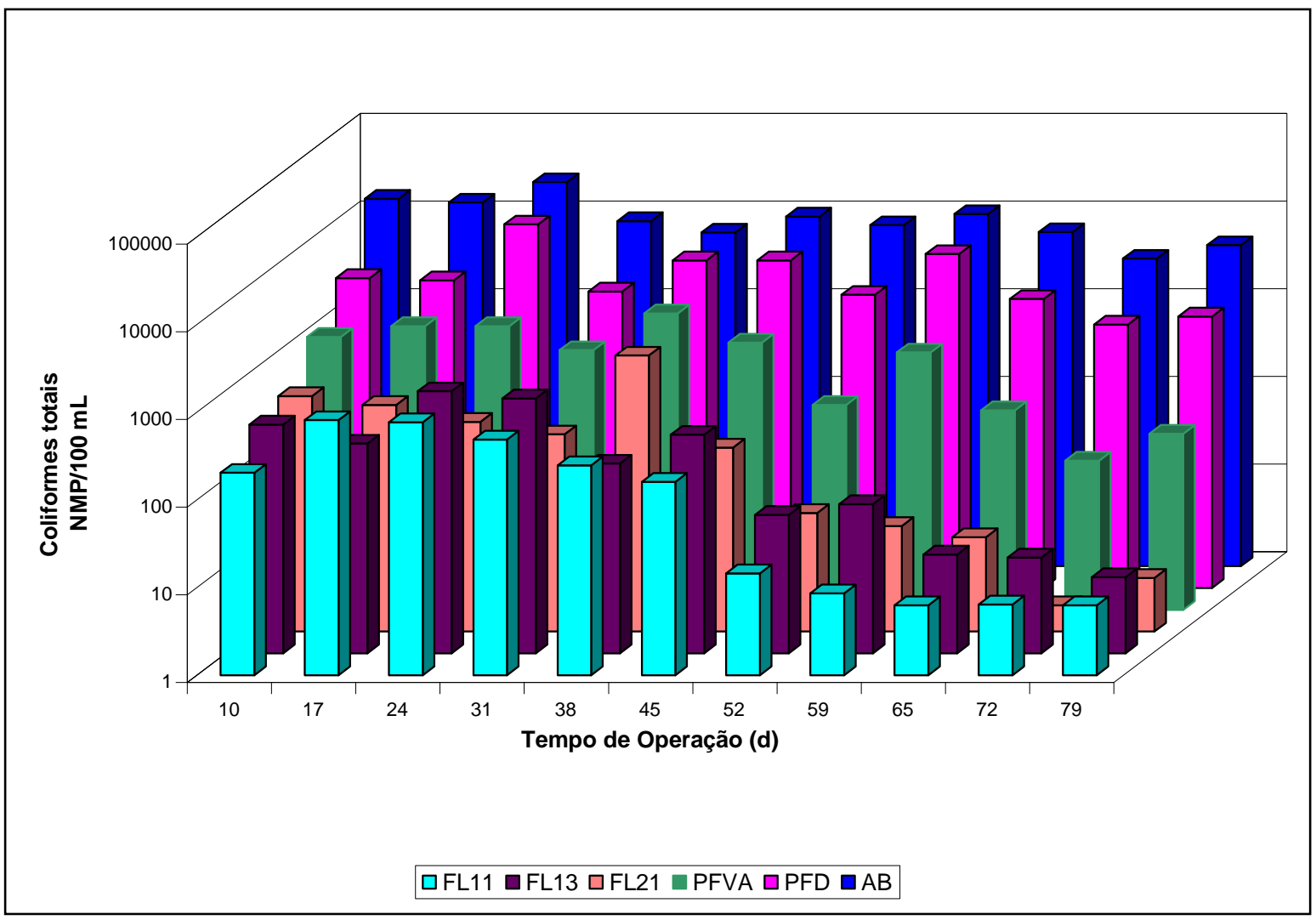

FIGURA 26- Variações de coliformes totais com o tempo de funcionamento na carreira 1, para água bruta e unidades de filtração

Fonte: TABELA 14

TABELA 15 - Resultados de Escherichia Coli em NMP/mL para água bruta e unidades de filtração durante a carreira 1

\begin{tabular}{cccccccc}
\hline Data & TO* & AB & PFD & PFVA & FL11 & FL13 & FL21 \\
\hline 24.02 & 10 & 213,0 & 98,0 & 30,5 & 5,2 & 10,0 & 2,0 \\
\hline 02.03 & 17 & 327,0 & 179,0 & 52,0 & 16,9 & 45,0 & 27,8 \\
\hline 09.03 & 24 & 2187,0 & 723,0 & 178,5 & 52,0 & 66,9 & 53,7 \\
\hline 16.03 & 31 & 305,0 & 133,4 & 53,0 & 17,3 & 36,8 & 22,6 \\
\hline 23.03 & 38 & 310,0 & 93,0 & 25,9 & 4,1 & 0,1 & 4,1 \\
\hline 30.03 & 45 & 600,0 & 259,0 & 41,6 & 3,0 & 14,3 & 5,0 \\
\hline 06.04 & 52 & 520,0 & 285,0 & 24,0 & 1,0 & 9,4 & 3,1 \\
\hline 13.04 & 59 & 588,0 & 272,3 & 48,8 & 2,0 & 7,4 & 2,0 \\
\hline 19.04 & 65 & 323,0 & 133,6 & 9,7 & 0,1 & 3,1 & 2,0 \\
\hline 26.04 & 71 & 238,0 & 87,0 & 13,7 & 1,0 & 0,1 & 0,1 \\
\hline 03.05 & 78 & 410,0 & 90,6 & 8,6 & 1,0 & 1,0 & 2,0 \\
\hline
\end{tabular}

* TO: Tempo de Operação (d) 


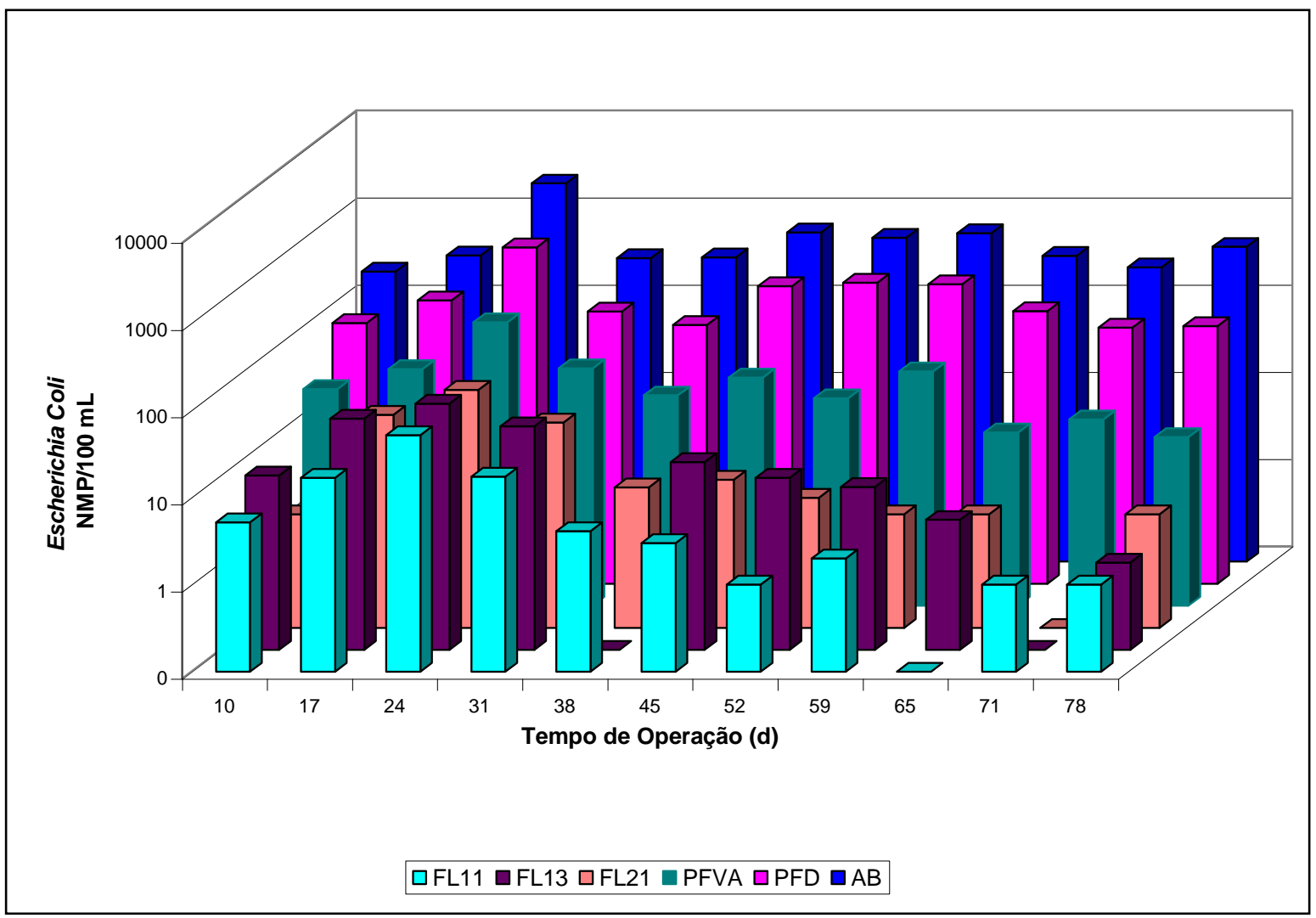

FIGURA 27-Variações de Escherichia Coli com o tempo de funcionamento na carreira 1, para água bruta e unidades de filtração

Fonte: TABELA 15

\subsubsection{Sólidos Suspensos Totais}

Para sólidos suspensos totais - SST, o PFD promoveu remoção média de 57,3 \%, o PFVA de 69 \%, o FL11 de 53,6 \%, o FL13 de 52,2 \% e o FL21 de 72,7\%. Não foi encontrada diferença estatisticamente significativa de remoção de SST entre os efluentes das duas unidades de filtração lenta e da seção FL 13 (método Anova), de acordo com a tabela A.11.

Do $43^{\circ}$ dia de operação, até o final da carreira 1 os efluentes dos filtros lentos e do seção FL13, tiveram valores de SST abaixo de 1 e próximos ou iguais a $0 \mathrm{mg} / \mathrm{L}$, conforme tabela 16 . 


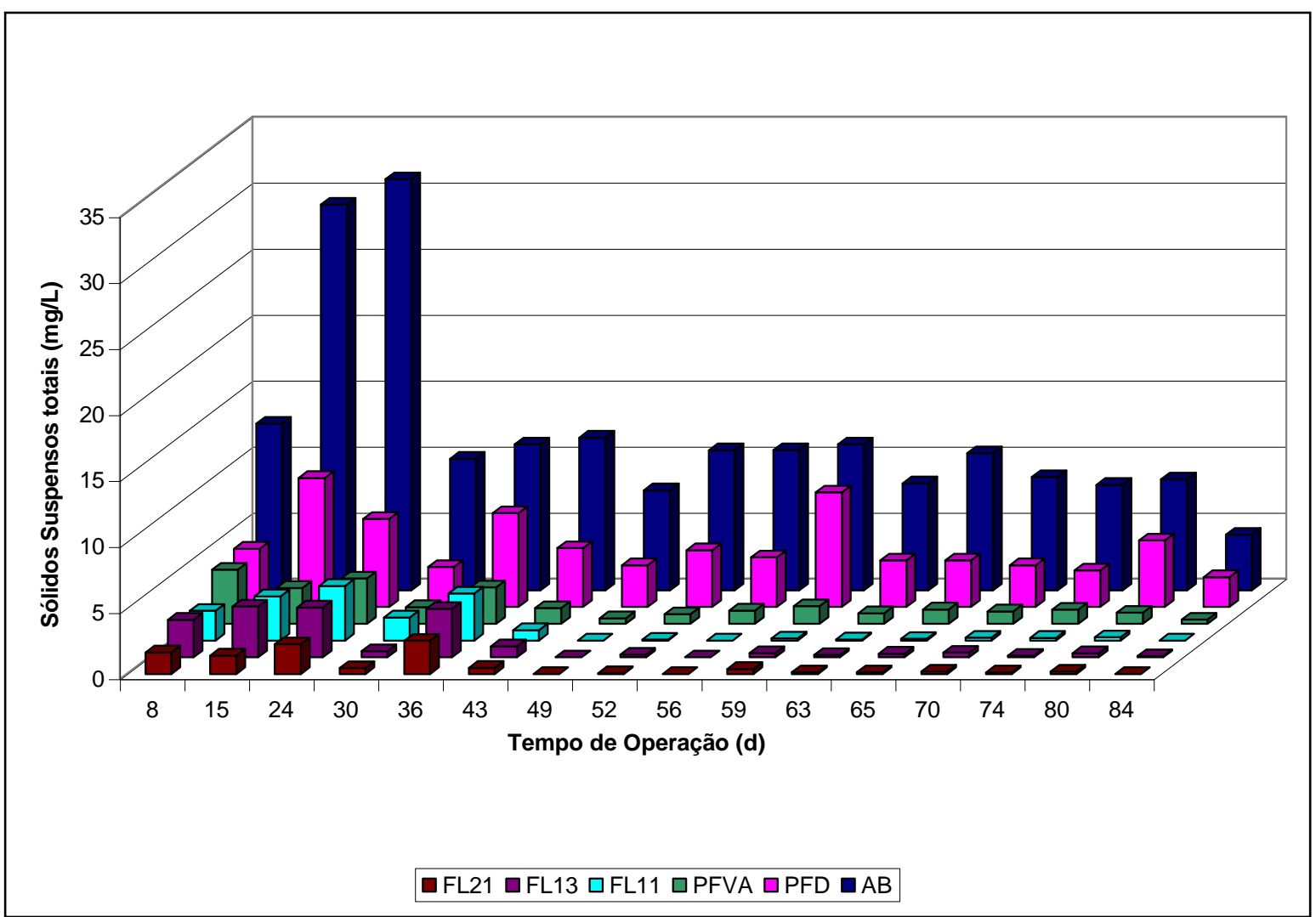

FIGURA 28 - Variações na concentração de sólidos suspensos totais em função do tempo de funcionamento, para água bruta e unidades de filtração na carreira 1 Fonte: TABELA 16 
TABELA 16 - Resultados de sólidos suspensos totais em mg/L para água bruta e unidades de filtração durante a carreira 1

\begin{tabular}{cccccccc}
\hline Data & $*$ TO & AB & PFD & PFVA & FL11 & FL13 & FL21 \\
\hline 22.02 .00 & 8 & 12,63 & 4,43 & 4,09 & 2,25 & 2,84 & 1,62 \\
\hline 29.02 .00 & 15 & 29,23 & 9,78 & 2,72 & 3,34 & 3,84 & 1,40 \\
\hline 09.03 .00 & 24 & 31,15 & 6,68 & 3,43 & 4,13 & 3,77 & 2,26 \\
\hline 15.03 .00 & 30 & 9,97 & 3,04 & 1,26 & 1,74 & 0,46 & 0,45 \\
\hline 21.03 .00 & 36 & 11,05 & 7,12 & 2,76 & 3,56 & 3,66 & 2,51 \\
\hline 28.03 .00 & 43 & 11,57 & 4,47 & 1,19 & 0,78 & 0,82 & 0,46 \\
\hline 03.04 .00 & 49 & 7,58 & 3,17 & 0,42 & 0,00 & 0,00 & 0,00 \\
\hline 06.04 .00 & 52 & 10,60 & 4,31 & 0,73 & 0,06 & 0,20 & 0,05 \\
\hline 10.04 .00 & 56 & 10,63 & 3,76 & 1,00 & 0,00 & 0,00 & 0,00 \\
\hline 13.04 .00 & 59 & 11,05 & 8,68 & 1,33 & 0,15 & 0,31 & 0,38 \\
\hline 17.04 .00 & 63 & 8,10 & 3,53 & 0,79 & 0,09 & 0,16 & 0,13 \\
\hline 19.04 .00 & 65 & 10,39 & 3,54 & 1,08 & 0,13 & 0,27 & 0,12 \\
\hline 24.04 .00 & 70 & 8,59 & 3,17 & 0,94 & 0,21 & 0,35 & 0,18 \\
\hline 27.04 .00 & 74 & 7,98 & 2,77 & 1,07 & 0,20 & 0,12 & 0,11 \\
\hline 04.05 .00 & 80 & 8,41 & 5,05 & 0,83 & 0,24 & 0,30 & 0,19 \\
\hline 08.05 .00 & 84 & 4,21 & 2,27 & 0,31 & 0,00 & 0,08 & 0,00 \\
\hline
\end{tabular}

\subsubsection{Cor aparente}

Não houve diferença significativa de remoção de cor aparente quando comparadas amostras dos diferentes filtros lentos. Pelos testes estatísticos(Teste-z) as amostras colhidas na seção FL11 foram melhores que as da seção FL13, e não se verificou diferenças comparando-se FL11 e FL21 e FL13 e FL21.(tabelas de A.14 a A.16). O PFD promoveu remoção média de 23,7\%, o PFVA de 35,4\%, o filtro lento 1 de $41,6 \%$, o filtro lento 2 de 33,9\% e o ponto FL13 de 27,5\%. Na tabela 17 aprecia-se um resumo dos valores obtidos de cor aparente da água bruta, das unidades da FiME e do ponto FL13. A figura 29 demonstra a variação do parâmetro em tela, ao longo dos dias de operação na carreira 1. Nota-se que os "picos" ocorridos na água bruta refletiram-se nas demais unidades do sistema(tabela E.2). 
TABELA 17 - Resumo de dados de cor aparente em uH carreira 1

\begin{tabular}{ccccccc}
\hline Dados & AB & PFD & PFVA & FL11 & FL13 & FL21 \\
\hline Máximo & 446 & 344 & 253 & 220 & 259 & 229 \\
\hline Médio & 216,1 & 165,7 & 111,0 & 70,4 & 87,2 & 78,7 \\
\hline Mínimo & 129 & 91 & 41 & 11 & 11 & 17 \\
\hline
\end{tabular}

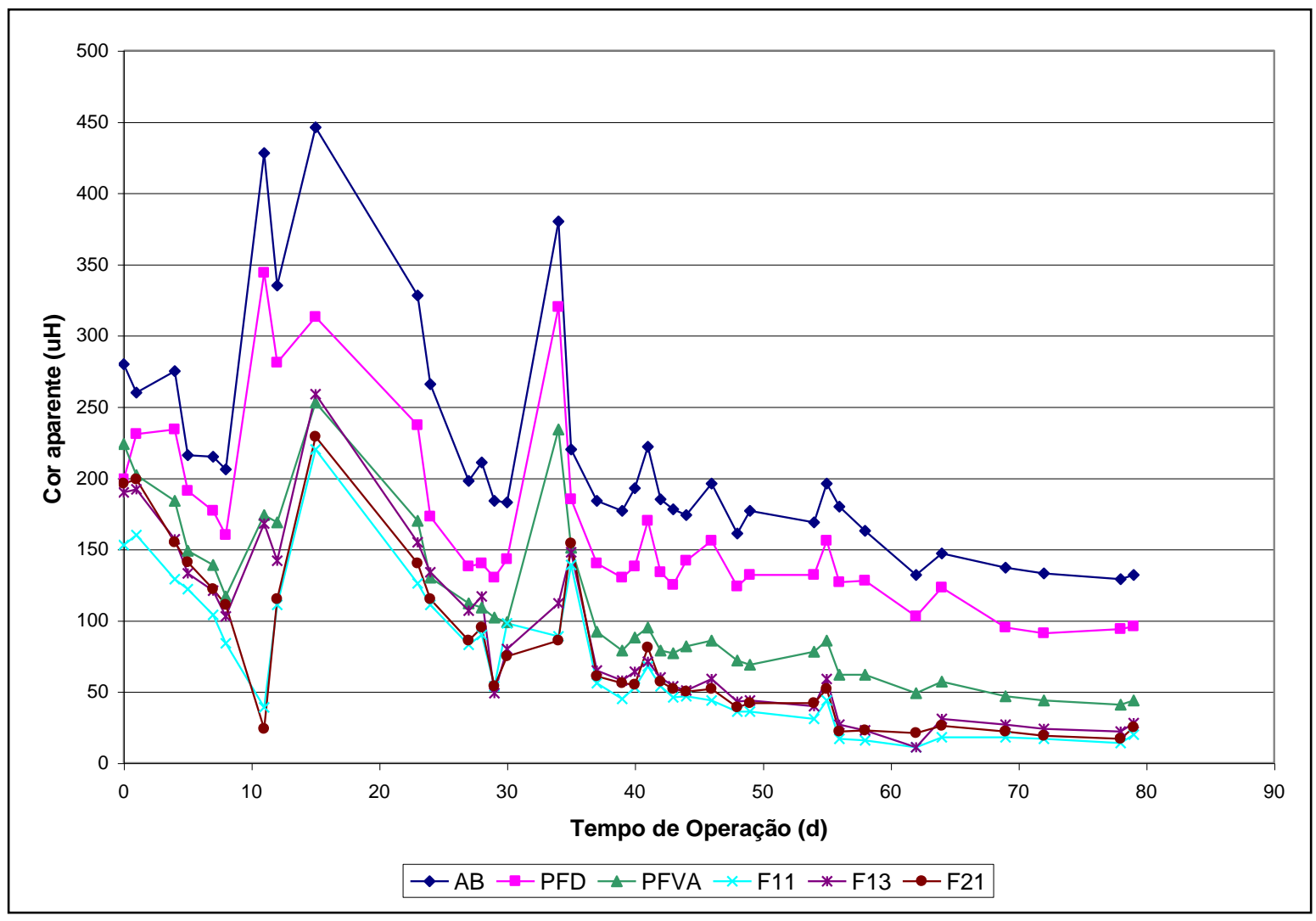

FIGURA 29 - Variações de cor aparente em função do tempo de operação para água bruta e unidades de filtração na carreira 1

Fonte: TABELA E.2

\subsubsection{Cor verdadeira e Absorvância}

Como já era esperado, o filtro lento 1 foi estatisticamente melhor na remoção de cor verdadeira e absorvância que o filtro lento 2. (COLLINS et al 1996). Avaliando-se os efluentes das seções FL11, FL13 e FL21, pelos métodos Anova e Teste - t, constatou- 
se que houve diferença significativa entre as médias de remoção para ambos os parâmetros citados, sendo superior o desempenho da seção FL11 em relação às outras duas seções e que não houve diferença significativa entre as seções FL13 e FL21.(tabelas de A.17 a A.22 e de A.23 a A.28). Para cor verdadeira o PFD apresentou remoção média de $17,42 \%$, o PFVA de $25,45 \%$, o filtro lento 1 de $59,05 \%$ e filtro lento 2 de 40,30\%. Na seção FL13 verificou-se remoção média de 39,52\%. No que diz respeito a absorvância (254 $\eta \mathrm{m})$ o filtro lento 1 removeu $58,31 \%$ e o filtro $215,25 \%$, e foi verificada remoção de 22,18\% para o efluente da seção FL13.

Na figura 30 pode-se observar a variação de cor verdadeira na carreira 1 .

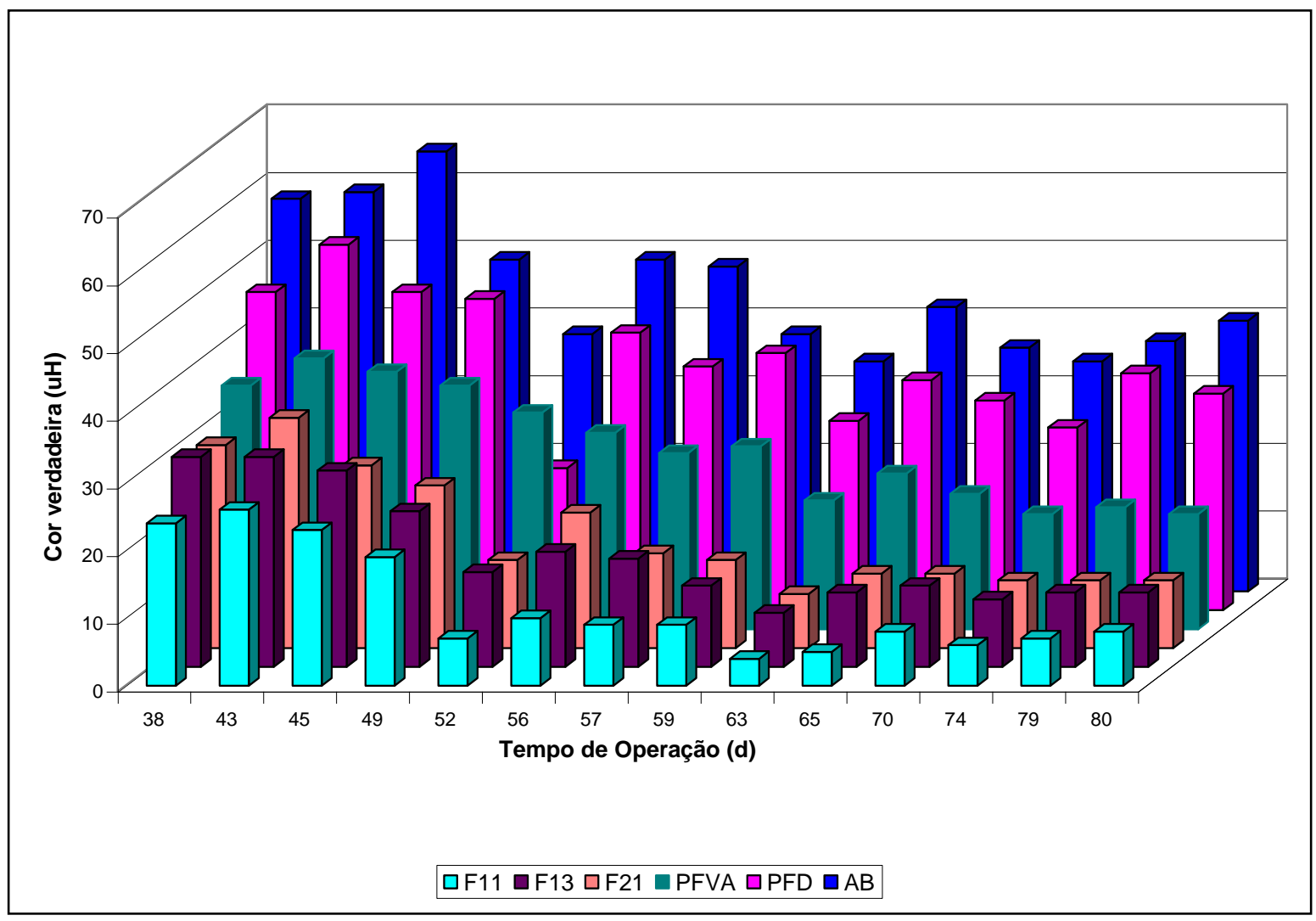

FIGURA 30 - Variações de cor verdadeira em função do tempo de operação para água bruta e unidades de filtração na carreira 1

Fonte: TABELA E.3 
Fato interessante foi verificado, quando se correlacionou os dados de cor verdadeira e absorvância, uma vez que maior correlação foi encontrada para as seções FL13 e FL21, apesar da seção FL11 ter apresentado maior remoção para tais parâmetros. Isto pode ser comprovado pela tabela 18 e pelas figuras de B.1 a B.6.

TABELA 18 - Coeficientes de correlação entre cor verdadeira e absorvância

\begin{tabular}{cccccc}
\hline AB & PFD & PFVA & FL11 & FL13 & FL21 \\
\hline 0,56 & 0,21 & 0,79 & 0,75 & 0,94 & 0,91 \\
\hline
\end{tabular}

A figura 31 permite apreciação dos dados de absorvância extraídos da carreira 1 .

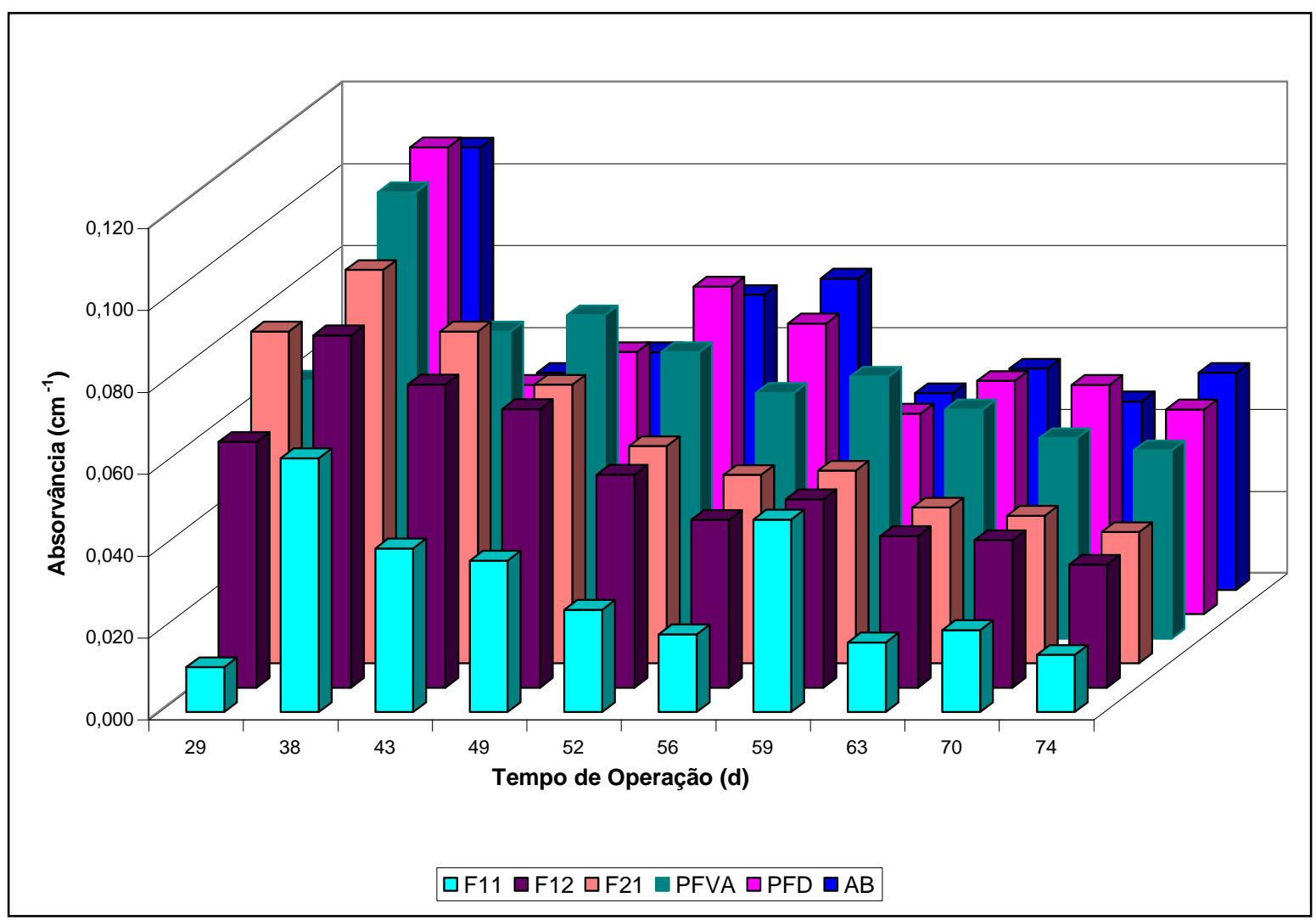

FIGURA 31 - Resultados de absorvância em função do tempo de operação para água bruta e unidades de filtração na carreira 1

Fonte: TABELA E.4

Os dados de cor verdadeira e absorvância são apresentados nas tabelas E.3 e E.4. 


\subsubsection{Carbono orgânico dissolvido}

No que se refere a Carbono Orgânico Dissolvido - COD, não se verificou diferenças estatisticamente significantes entre os efluentes dos filtros lentos (FL11 e FL21).(tabela A.30) O filtro lento 1 foi estatisticamente melhor na remoção de COD que a FL13, uma vez que pelo Teste-t, $p<0,05$ (tabela A.31), o que não foi encontrado para a seção FL21 (tabela A.32). A remoção média de COD encontrada para as seções FL11, FL13 e FL21, foram de 37,27, 6,9 e 19,46\% respectivamente.(tabela A.28) A maioria dos dados de remoção obtidos para os efluentes do PFD e PFVA foram negativos, sendo também encontrados com esse sinal alguns dados nas seções FL11, FL13 e FL21. Isto ocorreu, possivelmente, porque não foi levado em consideração o tempo de detenção hidráulica em cada unidade da FiME na coleta de amostras.

Foi feita também correlação entre os dados de COD e absorvância, e pela tabela 19 constata-se que o mais baixo valor encontrado foi para o FL11, sendo pior a correlação entre os parâmetros citados para tal seção.(figuras de B.7 a B.12 )

TABELA 19 - Coeficientes de correlação entre COD e absorvância

\begin{tabular}{cccccc}
\hline AB & PFD & PFVA & FL11 & FL13 & FL21 \\
\hline 0,58 & 0,61 & 0,41 & 0,13 & 0,65 & 0,66 \\
\hline
\end{tabular}

A tabela 20 mostra os resultados de COD e na figura 32 pode ser vista a variação dos mesmos ao longo do tempo de operação da carreira 1 
TABELA 20 - Resultados de COD em mg/L para água bruta e unidades da FiME carreira 1

\begin{tabular}{cccccccc}
\hline Data & $*$ TO & AB & PFD & PFVA & F11 & F13 & F21 \\
\hline $14 / 03 / 00$ & 29 & 2,806 & 3,263 & 3,517 & 1,658 & 2,662 & 3,147 \\
\hline $23 / 03 / 00$ & 38 & 3,232 & 3,334 & 3,488 & 2,006 & 2,952 & 3,009 \\
\hline $28 / 03 / 00$ & 43 & 1,697 & 1,552 & 1,635 & 1,380 & 2,041 & 1,613 \\
\hline $06 / 04 / 00$ & 52 & 1,445 & 1,777 & 1,521 & 1,497 & 1,304 & 1,225 \\
\hline $10 / 04 / 00$ & 56 & 1,621 & 1,479 & 1,665 & 0,595 & 1,889 & 0,876 \\
\hline $13 / 04 / 00$ & 59 & 1,037 & 0,712 & 0,595 & 0,595 & 0,595 & 0,595 \\
\hline $17 / 04 / 00$ & 63 & 1,030 & 1,331 & 1,398 & 1,206 & 1,596 & 0,880 \\
\hline $24 / 04 / 00$ & 70 & 0,721 & 0,890 & 0,609 & 0,044 & 0,873 & 0,823 \\
\hline $27 / 04 / 00$ & 74 & 0,933 & 2,268 & 2,006 & 0,914 & 1,724 & 1,978 \\
\hline $03 / 05 / 00$ & 79 & 2,090 & 2,226 & 2,716 & 2,760 & 1,725 & 2,220 \\
\hline $08 / 05 / 00$ & 84 & 1,899 & 1,447 & 1,468 & 0,383 & 0,482 & 0,000 \\
\hline
\end{tabular}

*TO : Tempo de Operação (d)

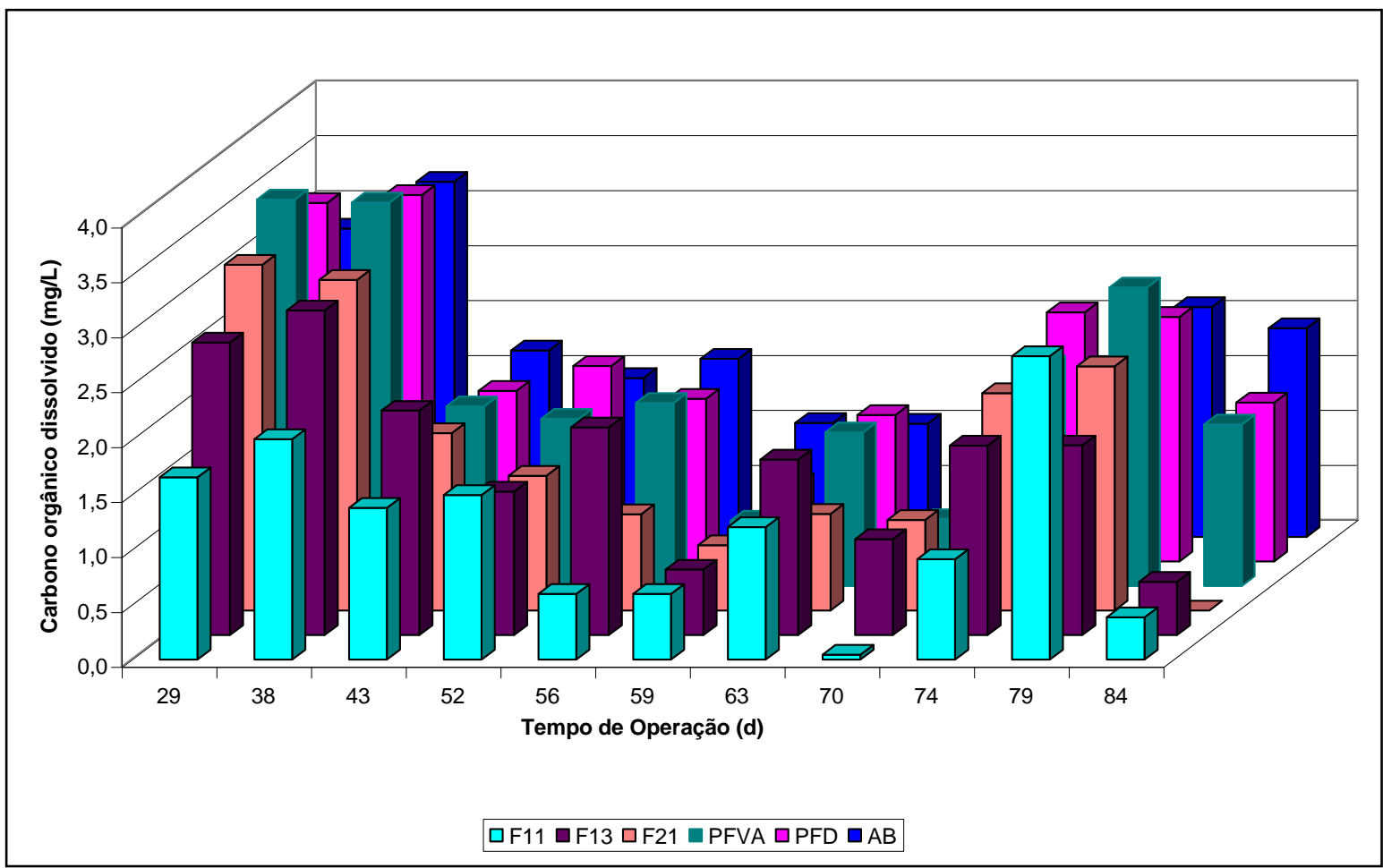

FIGURA 32 - Variações de carbono orgânico dissolvido para água bruta e unidades da FiME na carreira 1

Fonte: TABELA 20 


\subsubsection{Oxigênio Consumido - OC e Oxigênio dissolvido - OD}

Para oxigênio consumido o PFD apresentou remoção média de $33 \%$, o PFVA de $11,6 \%$, o FL11 de $77 \%$, o FL13 de $23 \%$ e o FL21 de 10\%. Estatisticamente a seção FL11 foi superior às seções FL13 e FL21 na remoção de OC (tabelas de A.34 a A.37).

O desempenho do filtro lento 1, em comparação com os demais pontos, pode ser visto na tabela 21 e na figura 33. Não foi encontrada diferença estatística de remoção entre as seções FL13 e FL21.( tabela A.38).

TABELA 21 - Resultados de oxigênio consumido para água bruta e unidades da FiME em mg/L na carreira 1

\begin{tabular}{cccccccc}
\hline Data & $*$ TO & AB & PFD & PFVA & F11 & F13 & F21 \\
\hline $23 / 03 / 00$ & 38 & 4,00 & 2,90 & 2,35 & 1,10 & 1,90 & 1,85 \\
\hline $28 / 03 / 00$ & 43 & 3,60 & 2,60 & 2,20 & 1,00 & 2,20 & 2,30 \\
\hline $06 / 04 / 00$ & 52 & 2,50 & 1,90 & 1,90 & 0,60 & 1,50 & 0,70 \\
\hline $12 / 04 / 00$ & 58 & 3,20 & 1,40 & 0,80 & 0,00 & 0,60 & 0,80 \\
\hline $19 / 04 / 00$ & 65 & 2,05 & 0,60 & 1,10 & 0,00 & 0,20 & 1,20 \\
\hline $26 / 04 / 00$ & 72 & 1,25 & 0,85 & 0,70 & 0,05 & 0,55 & 0,55 \\
\hline $03 / 05 / 00$ & 79 & 2,00 & 2,15 & 0,65 & 0,20 & 0,70 & 0,80 \\
\hline
\end{tabular}

*TO : Tempo de Operação (d) 


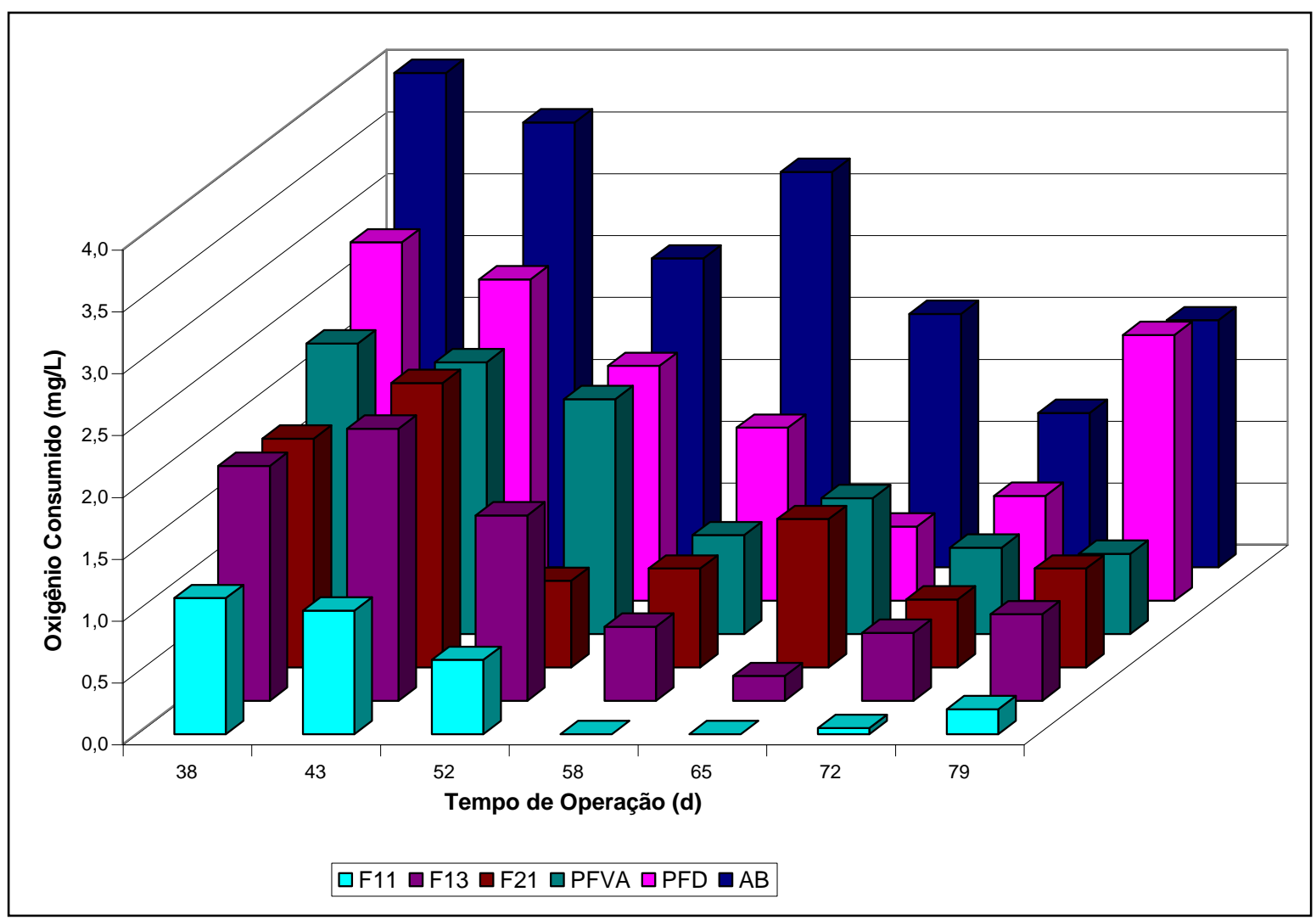

FIGURA 33 - Variações de oxigênio consumido para água bruta e unidades da

FiME durante a carreira 1

\section{Fonte: TABELA 21}

Relativo a oxigênio dissolvido o FL11 apresentou remoção média de 56,3\%, valor este muito superior ao que foi observado para os outros pontos conforme tabela A.39. Na figura 34 nota-se a variação de OD na carreira 1 e a diferença brusca entre o FL11 e os demais pontos de coleta do sistema. Já na tabela 22 estão os dados de OD.

TABELA 22 - Resultados de oxigênio dissolvido em mg/L carreira 1

\begin{tabular}{cccccccc}
\hline Data & $*$ TO & AB & PFD & PFVA & F11 & F13 & F21 \\
\hline $22 / 03 / 00$ & 37 & 6,2 & 6,0 & 6,1 & 3,2 & 6,0 & 6,0 \\
\hline $28 / 03 / 00$ & 43 & 7,4 & 7,4 & 7,4 & 3,6 & 7,4 & 7,2 \\
\hline $04 / 04 / 00$ & 50 & 7,5 & 7,2 & 7,1 & 4,8 & 7,3 & 7,3 \\
\hline $11 / 04 / 00$ & 57 & 7,9 & 7,1 & 7,0 & 2,7 & 6,9 & 6,7 \\
\hline $17 / 04 / 00$ & 63 & 7,5 & 7,2 & 7,4 & 3,3 & 7,4 & 7,4 \\
\hline $26 / 04 / 00$ & 72 & 7,9 & 7,7 & 7,6 & 3,3 & 7,5 & 7,4 \\
\hline $03 / 05 / 00$ & 79 & 7,8 & 7,5 & 7,4 & 2,0 & 7,1 & 7,0 \\
\hline
\end{tabular}

*TO : Tempo de Operação (d) 


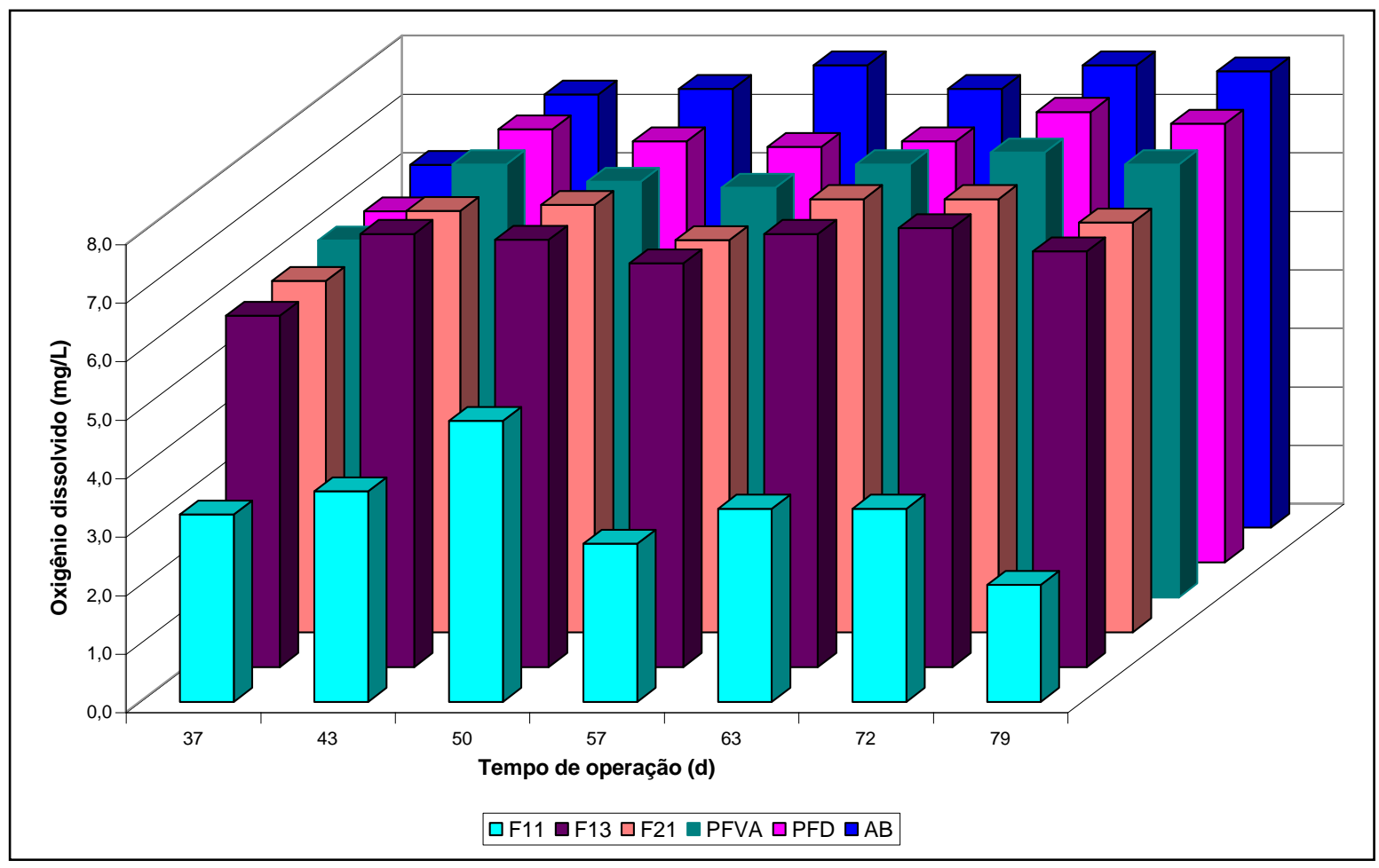

FIGURA 34 - Variações de oxigênio dissolvido para água bruta e unidades da

\section{FiME durante a carreira 1}

\section{Fonte: TABELA 22}

O PFD, PFVA, FL13 e FL21 praticamente não causaram variação de OD na água, pois as reduções médias de OD proporcionadas por estes pontos foram de 4,7, 0,3, 1,2 e $2,4 \%$, respectivamente. Pela tabela 22 nota-se que a remoção de OD causada pelo filtro lento 1 foi devida a presença da camada de carvão ativado granular, entre as camadas de areia, haja vista que no filtro lento 2 (leito filtrante somente de areia) e na seção FL13, locado no filtro lento 1 antes da camada de carvão ativado, não foram verificadas variações expressivas de OD. 


\subsubsection{Ferro total}

Não houve diferenças estatísticas de remoção de ferro total entre os filtros lentos e a seção FL13.(tabela A.41). O FL11 apresentou remoção média de 54,6 \%, o FL21 de $74 \%$ e o efluente da seção FL13 de 70,5\%. (tabela A.40) No dia 27 de abril de 2000, foi encontrado no efluente do filtro lento 2 concentração de ferro total igual a 3,63 mg/L, fato que deve ter ocorrido em virtude de contaminação externa da amostra de água ou erro de leitura, e deste modo tal ponto foi excluído dos cálculos estatísticos. O PFD removeu $30 \%$ de ferro, entretanto para o PFVA a maioria dos dados de remoção obtidos foram negativos, devido provavelmente a diferença nos tempos de detenção hidraúlica. O dados de ferro referentes a carreira 1 estão dispostos na tabela 23. Na figura 35 pode ser vista a variação de ferro nas unidades da FiME, na carreira 1.

TABELA 23 - Resultados de ferro total em mg/L para água bruta e unidades da FiME ao longo da carreira 1

\begin{tabular}{cccccccc}
\hline Data & TO & AB & PFD & PFVA & F11 & F13 & F21 \\
\hline $22 / 03 / 00$ & 37 & 2,06 & 1,14 & 1,36 & 0,56 & 0,64 & 0,76 \\
\hline $31 / 03 / 00$ & 45 & 1,61 & 1,09 & 1,31 & 0,49 & 0,38 & 0,32 \\
\hline $06 / 04 / 00$ & 52 & 2,1 & 2,04 & 2,53 & 0,34 & 0,25 & 0,05 \\
\hline $14 / 04 / 00$ & 60 & 1,71 & 1,02 & 0,39 & 0,35 & 0,07 & 0,14 \\
\hline $27 / 04 / 00$ & 73 & 1,08 & 1,15 & 0,34 & 0,4 & 0,15 & 3,63 \\
\hline
\end{tabular}

*TO : Tempo de Operação (d) 


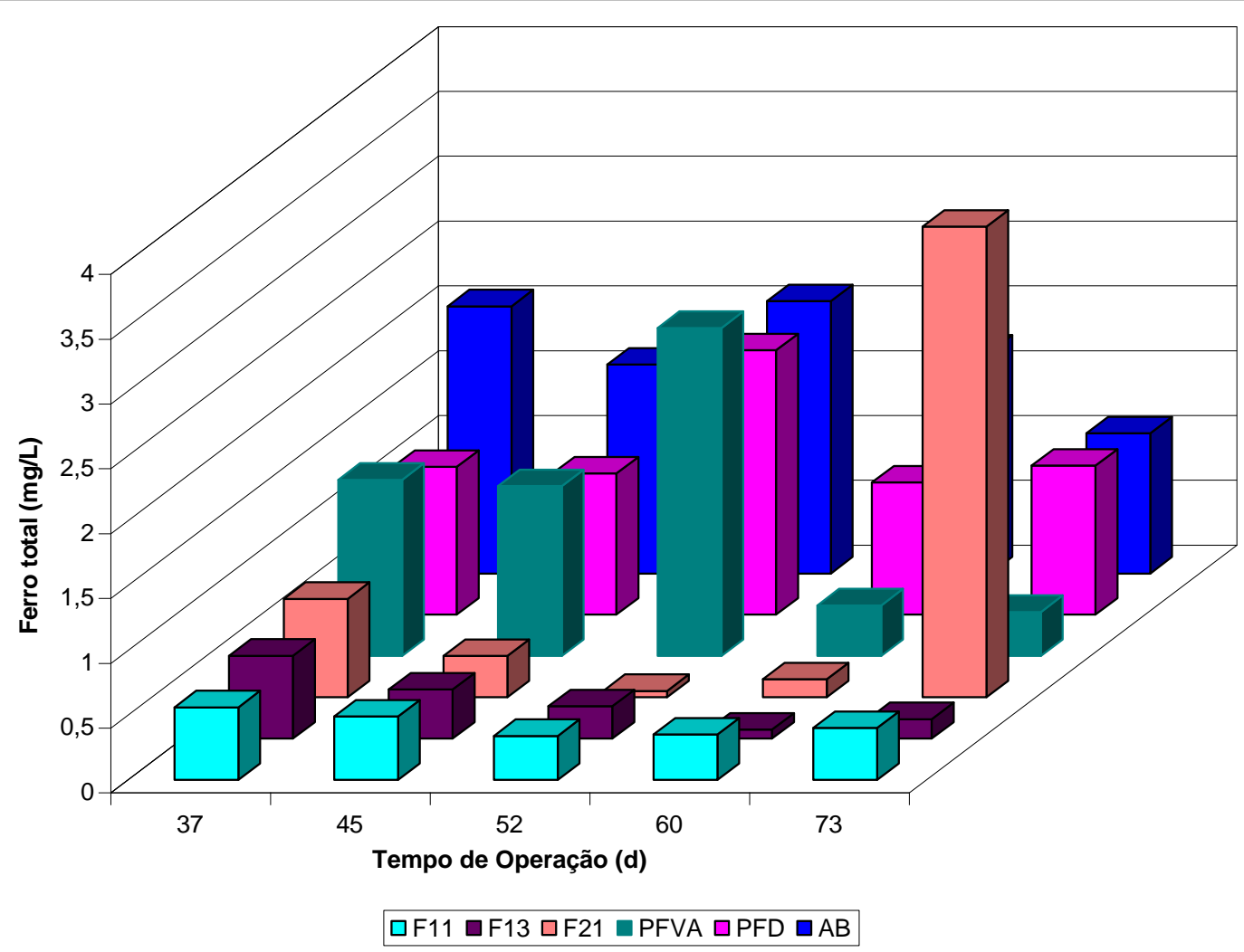

FIGURA 35 - Variações na concentração de ferro total em função do tempo de operação para a água bruta e unidades da FiME na carreira 1

Fonte: TABELA 23

\subsubsection{Fosfato}

Possivelmente devido a atividade microbiológica no meio filtrante, a maioria dos dados obtidos de fosfato, nos efluentes dos filtros lentos e da seção FL13, teve resultado superior aos valores encontrados no efluente do PFVA, o que sugere mineralização da matéria orgânica presente na água pré-filtrada, sendo tal matéria convertida a $\mathrm{CO}_{2}$, nitratos e fosfatos.(DI BERNARDO, 1993). No efluente do filtro lento 1 este fenômeno ocorreu para todos os dados obtidos, sendo que o aumento médio na concentração de fosfato foi de $63 \%$, e o aumento máximo de 87,68 \%. Para o efluente da seção FL13, em três coletas houve redução de fosfato em relação ao afluente e para o FL21 em quatro ocasiões o fosfato foi reduzido, ocorrendo aumento da concentração do parâmetro em questão nas demais coletas tanto para FL13 como para FL21. Pelo exposto, parece 
que a atividade biológica no carvão ativado, ocorrida no filtro lento 1 , foi mais intensa que no filtro lento 2 e ponto FL13. Na tabela 24 e na figura 36 podem ser apreciados os dados de fosfato conseqüentes da carreira 1.

TABELA 24 - Resultados de fosfato em mg/L para água bruta e unidades da FiME ao da carreira 1

\begin{tabular}{cccccccc}
\hline DATA & $*$ TO & AB & PFD & PFVA & F11 & F13 & F21 \\
\hline $14 / 03 / 00$ & 29 & 0,1421 & 0,0892 & 0,0780 & 0,1609 & 0,0886 & 0,1127 \\
\hline $28 / 03 / 00$ & 43 & 0,1021 & 0,0851 & 0,0745 & 0,3061 & 0,0915 & 0,0786 \\
\hline $04 / 04 / 00$ & 50 & 0,1215 & 0,0762 & 0,0333 & 0,2703 & 0,0450 & 0,0651 \\
\hline $11 / 04 / 00$ & 57 & 0,1150 & 0,0833 & 0,0604 & 0,2938 & 0,0668 & 0,0592 \\
\hline $19 / 04 / 00$ & 65 & 0,1080 & 0,0851 & 0,0604 & 0,1797 & 0,0445 & 0,0457 \\
\hline $24 / 04 / 00$ & 70 & 0,0892 & 0,0674 & 0,0498 & 0,1427 & 0,0439 & 0,0427 \\
\hline $03 / 05 / 00$ & 79 & 0,0563 & 0,0663 & 0,0733 & 0,1533 & 0,0792 & 0,1151 \\
\hline $08 / 05 / 00$ & 84 & 0,0986 & 0,1221 & 0,0692 & 0,0945 & 0,0510 & 0,0275 \\
\hline
\end{tabular}

*TO: tempo de operação (d) 


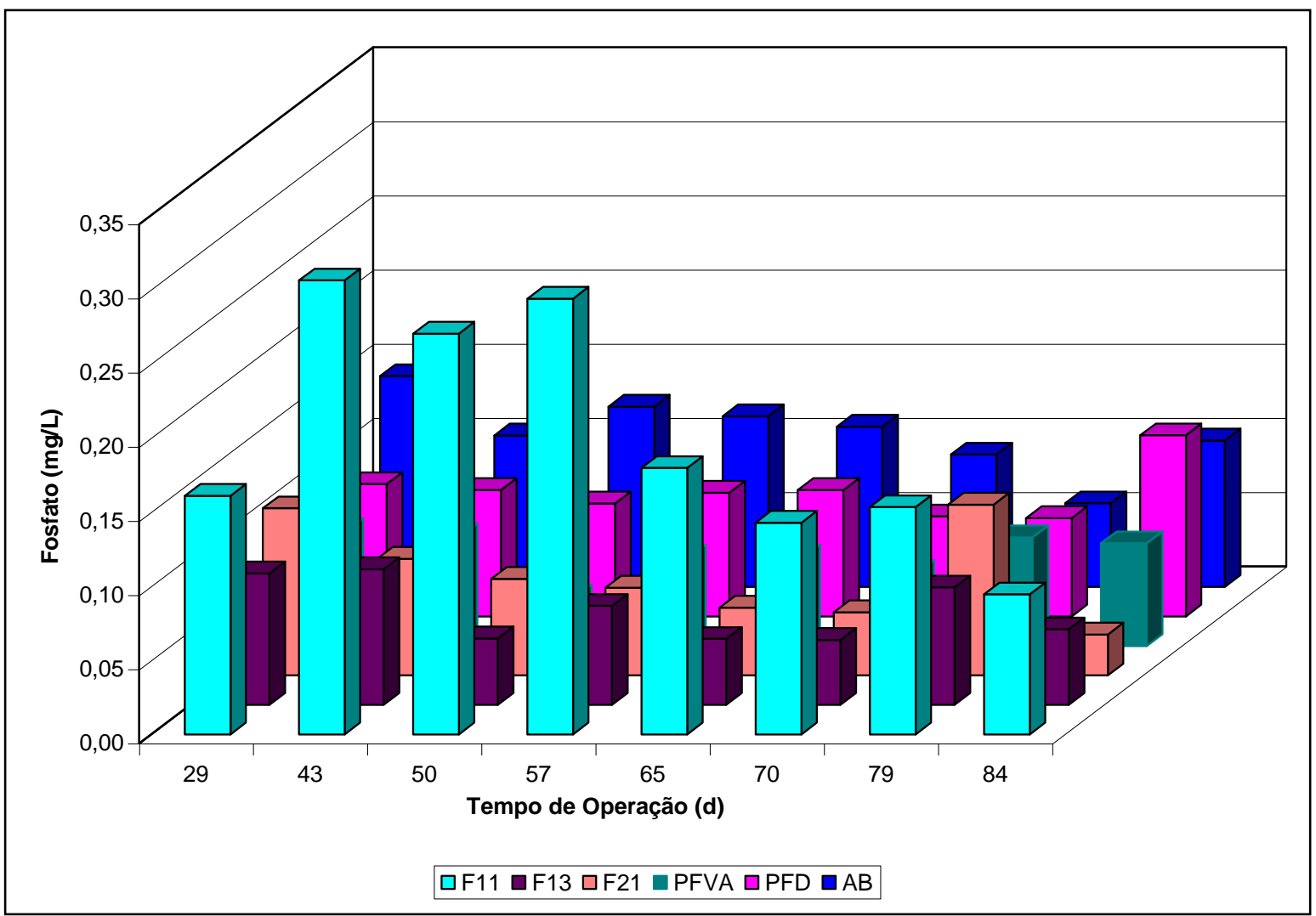

FIGURA 36 - Variações na concentração de fosfato para água bruta e unidades da FiME em função do tempo de operação na carreira 1

\section{Fonte: TABELA 24}

\subsubsection{Nitrogênio amoniacal, nitrito e nitrato}

Em relação a nitrogênio amoniacal, o PFD removeu, em média, 24,04 \%, o PFVA 38,18 \%, o FL11 51,42 \%, o FL13 31,73 \% e o FL21 35,55 \%. Efetuando-se testes estatísticos, não foram encontradas diferenças significativas de remoção entre os filtros lentos e A seção FL13.( tabela A.43). Na tabela 25 estão apresentados os dados de nitrogênio amoniacal e na figura 37 estão os dados em função do tempo de operação.

TABELA 25 - Resultados de Nitrogênio amoniacal em mg/L carreira 1

\begin{tabular}{cccccccc}
\hline Data & *TO & AB & PFD & PFVA & F11 & F13 & F21 \\
\hline $13 / 03 / 00$ & 28 & 0,3904 & 0,2562 & 0,1952 & 0,1708 & 0,2196 & 0,2074 \\
\hline $28 / 03 / 00$ & 43 & 0,305 & 0,244 & 0,1708 & 0,1464 & 0,1342 & 0,1464 \\
\hline $03 / 04 / 00$ & 49 & 0,2928 & 0,2318 & 0,1342 & 0,0488 & 0,0973 & 0,0854 \\
\hline $10 / 04 / 00$ & 56 & 0,25 & 0,2 & 0,09 & 0,01 & 0,03 & 0,03 \\
\hline $16 / 04 / 00$ & 62 & 0,2 & 0,15 & 0,09 & 0,02 & 0,04 & 0,03 \\
\hline
\end{tabular}




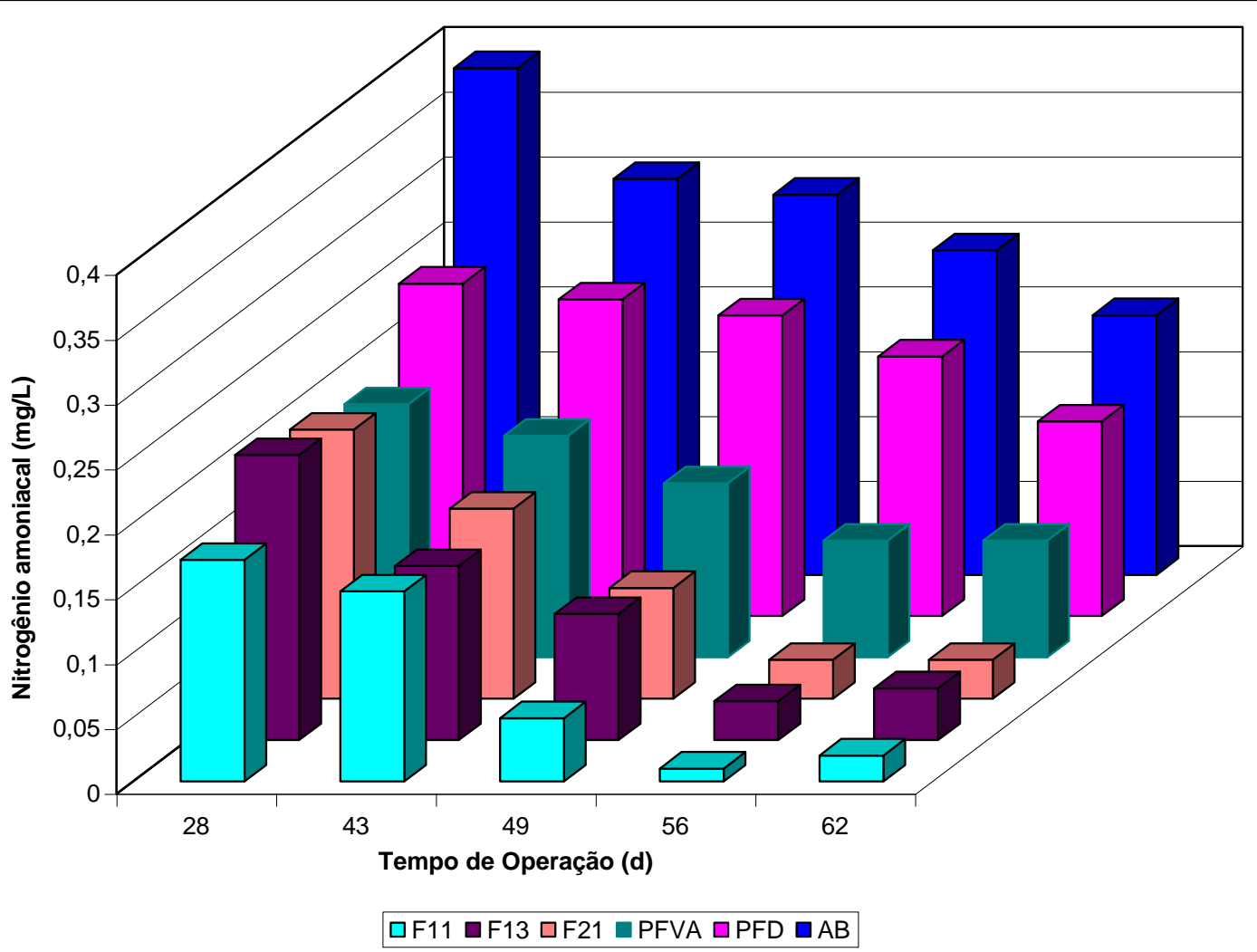

FIGURA 37 - Variações na concentração de nitrogênio amoniacal em função do tempo de operação para água bruta e unidades da FiME na carreira 1

Fonte: TABELA 25

Relativo a nitrito, as remoções médias no PFD e PFVA foram de 10,74 e 37,9 \% respectivamente. Também não foram identificadas diferenças significativas de remoção de nitrito entre os filtros lentos e a seção FL13.(tabela A.45). O filtro lento 1 proporcionou remoção média de $64,5 \%$, o filtro lento 2 de $23,9 \%$ e o efluente da seção FL13 apresentou remoção de 21,5\%. (tabela A.44) 
TABELA 26 - Resultados de nitrito para água bruta e unidades de filtração em $\mathrm{mg} / \mathrm{L}$ na carreira 1

\begin{tabular}{cccccccc}
\hline Data & $*$ TO & AB & PFD & PFVA & F11 & F13 & F21 \\
\hline $13 / 03 / 00$ & 28 & 0,4 & 0,6 & 0,8 & 0 & 0,7 & 0,7 \\
\hline $28 / 03 / 00$ & 43 & 8,4 & 5,6 & 2,9 & 1,2 & 1,5 & 1,4 \\
\hline $03 / 04 / 00$ & 49 & 8,2 & 6,3 & 2,12 & 1,8 & 3,3 & 2,2 \\
\hline $10 / 04 / 00$ & 56 & 8,5 & 6,7 & 3,4 & 0,5 & 1,2 & 3,8 \\
\hline $16 / 04 / 00$ & 62 & 7,3 & 5,4 & 2,2 & 0,8 & 1,1 & 0,9 \\
\hline
\end{tabular}

*TO: tempo de operação (d)

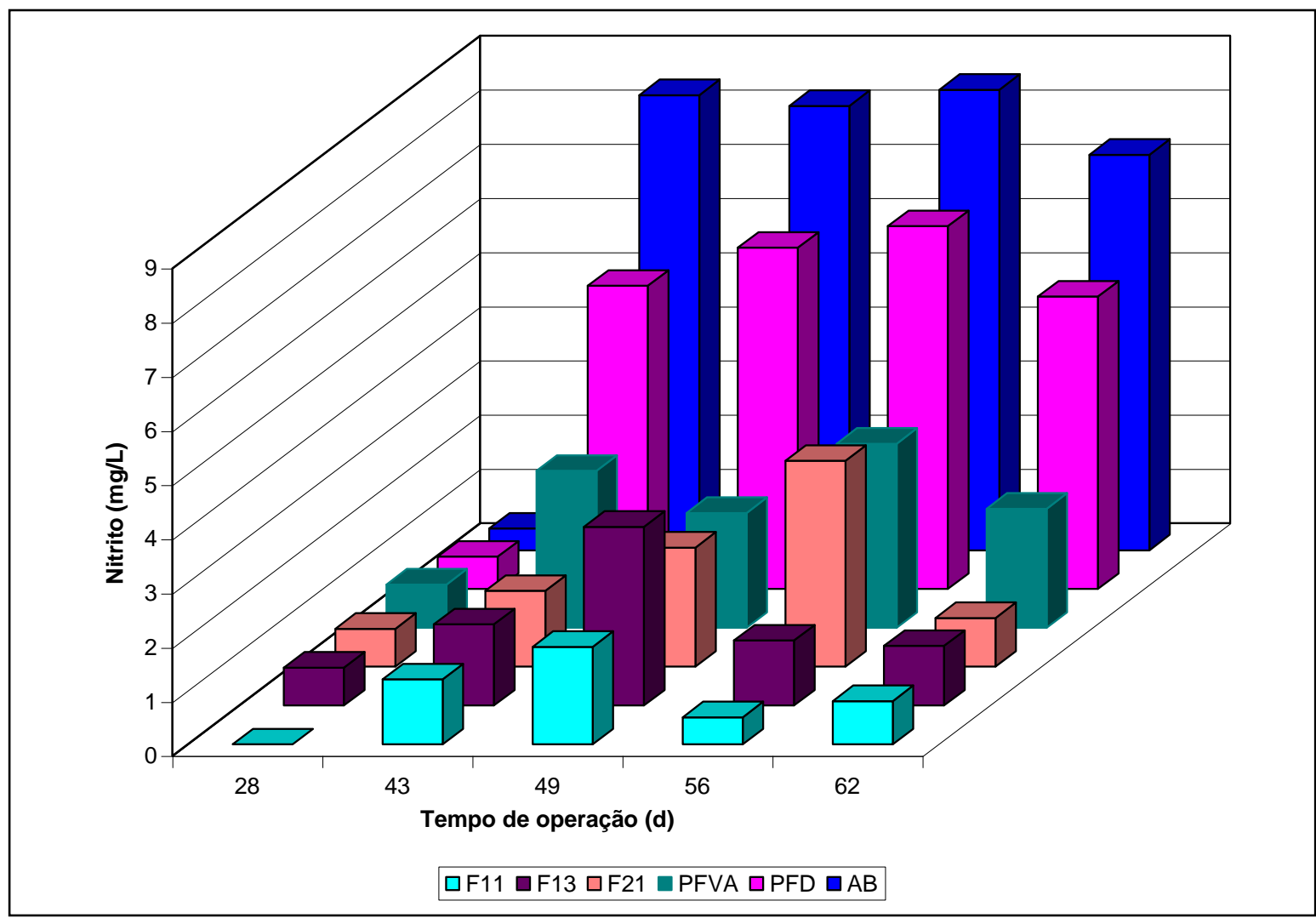

FIGURA 38 - Variações na concentração de nitrito para água bruta e unidades da

FiME em função do tempo de operação na carreira 1

Fonte: TABELA 26

O filtro lento 1 foi significativamente melhor na remoção de nitrato que o filtro lento 2 e a seção FL13 (tabelas de A.47 a A.51), apresentando remoção média de $80 \%$. O efluente da seção FL13 apresentou remoção média de 13,2 \%, o PFD, PFVA e FL21 
apresentaram valores negativos de remoção média, o que pode ter sido causado por erros nos procedimentos laboratoriais. Os resultados de nitrato podem ser vistos na tabela $27 \mathrm{e}$ na figura 39.

\section{TABELA 27 - Resultados de Nitrato em mg/L carreira 1}

\begin{tabular}{cccccccc}
\hline Data & $*$ TO & AB & PFD & PFVA & F11 & F13 & F21 \\
\hline $13 / 03 / 00$ & 28 & 0,4619 & 0,5952 & 0,5258 & 0,114 & 0,4759 & 0,6944 \\
\hline $28 / 03 / 00$ & 43 & 0,4061 & 0,4908 & 0,5402 & 0,183 & 0,5216 & 0,6045 \\
\hline $03 / 04 / 00$ & 49 & 0,4447 & 0,4983 & 0,5621 & 0,1406 & 0,5113 & 0,5495 \\
\hline $10 / 04 / 00$ & 56 & 0,5113 & 0,522 & 0,5439 & 0,0628 & 0,4294 & 0,4606 \\
\hline $16 / 04 / 00$ & 62 & 0,4387 & 0,5272 & 0,495 & 0,0409 & 0,38 & 0,3935 \\
\hline
\end{tabular}

*TO: tempo de operação $(\mathrm{d})$

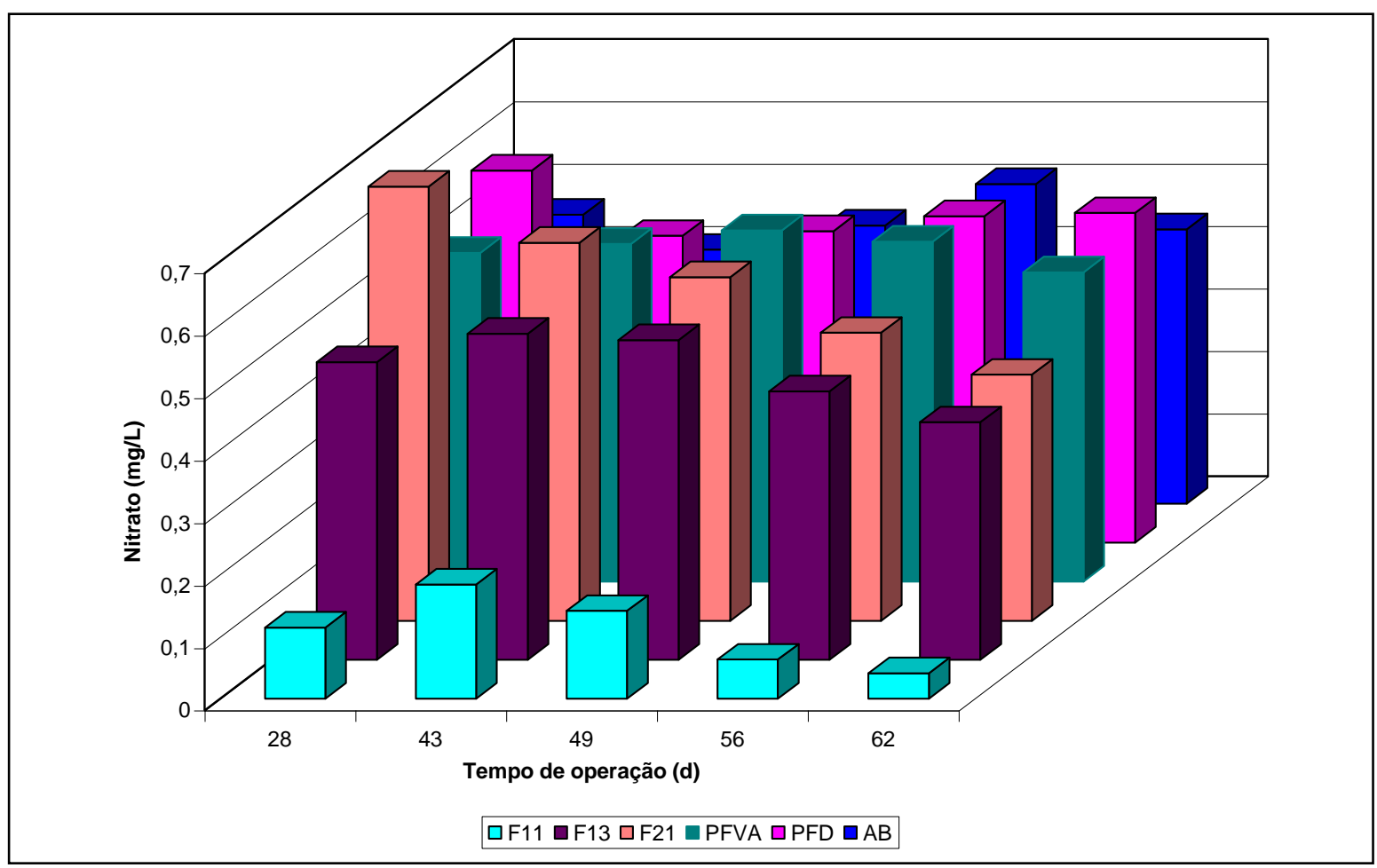

FIGURA 39 - Variações na concentração de nitrato em função do tempo de operação para água bruta e unidades da FiME durante a carreira 1

Fonte: TABELA 27 


\subsubsection{1. pH e alcalinidade}

$\mathrm{O} \mathrm{pH}$ da água bruta variou entre 6,10 e 7,9 e conforme os dados dispostos na tabela 28, as unidades da FiME não promoveram mudanças significativas de $\mathrm{pH}$ na água.

\section{TABELA 28 - Resultados de $\mathrm{pH}$ carreira 1}

\begin{tabular}{cccccccc}
\hline Data & *TO & AB & PFD & PFVA & F11 & F13 & F21 \\
\hline $11 / 03 / 00$ & 26 & 7,42 & 7,48 & 7,65 & 7,64 & 7,59 & 7,59 \\
\hline $14 / 03 / 00$ & 29 & 7,90 & 7,80 & 7,70 & 7,60 & 7,80 & 7,65 \\
\hline $21 / 03 / 00$ & 36 & 7,40 & 7,40 & 6,10 & 7,10 & 7,40 & 7,20 \\
\hline $30 / 03 / 00$ & 45 & 6,40 & 6,60 & 6,70 & 6,40 & 6,50 & 6,50 \\
\hline $01 / 04 / 00$ & 47 & 6,10 & 6,10 & 6,20 & 6,20 & 6,30 & 6,20 \\
\hline $04 / 04 / 00$ & 50 & 7,82 & 7,86 & 7,58 & 7,04 & 7,48 & 7,50 \\
\hline $05 / 04 / 00$ & 51 & 7,35 & 7,66 & 7,63 & 7,32 & 7,97 & 7,75 \\
\hline $06 / 04 / 00$ & 52 & 7,62 & 7,87 & 7,95 & 7,96 & 8,07 & 8,08 \\
\hline $07 / 04 / 00$ & 53 & 7,14 & 7,40 & 7,40 & 7,18 & 7,48 & 7,56 \\
\hline $08 / 04 / 00$ & 54 & 7,34 & 7,51 & 7,56 & 7,34 & 7,55 & 7,66 \\
\hline $09 / 04 / 00$ & 55 & 7,35 & 7,69 & 7,47 & 7,20 & 7,50 & 7,35 \\
\hline $10 / 04 / 00$ & 56 & 7,52 & 7,60 & 7,96 & 7,07 & 7,58 & 7,43 \\
\hline $13 / 04 / 00$ & 59 & 6,90 & 6,90 & 6,65 & 6,70 & 6,70 & 7,00 \\
\hline
\end{tabular}

*TO: tempo de operação (d)

A alcalinidade da água bruta variou entre 6 e $8 \mathrm{mg} / \mathrm{L}$ e também para este parâmetro as unidades de filtração não influenciaram significativamente na mudança dos valores na água.

TABELA 29 - Resultados de alcalinidade em $\mathrm{mgCaCO}_{3} / \mathrm{L}$ carreira 1

\begin{tabular}{cccccccc}
\hline Data & *TO & AB & PFD & PFVA & F11 & F13 & F21 \\
\hline $20 / 03 / 00$ & 35 & 8,00 & 8,00 & 7,20 & 8,40 & 7,60 & 7,60 \\
\hline $29 / 03 / 00$ & 44 & 6,40 & 6,40 & 6,40 & 6,40 & 6,00 & 6,00 \\
\hline $31 / 03 / 00$ & 46 & 7,20 & 6,40 & 7,20 & 7,20 & 4,40 & 6,40 \\
\hline $09 / / 04 / 00$ & 55 & 7,20 & 6,00 & 6,80 & 6,80 & 7,60 & 8,40 \\
\hline $12 / 04 / 00$ & 58 & 6,80 & 6,80 & 6,40 & 6,40 & 6,80 & 6,80 \\
\hline $16 / 04 / 00$ & 62 & 6,40 & 6,80 & 6,80 & 6,40 & 6,40 & 6,80 \\
\hline $23 / 04 / 00$ & 69 & 6,00 & 6,00 & 6,40 & 6,80 & 6,00 & 6,20 \\
\hline $03 / 05 / 00$ & 79 & 7,14 & 7,14 & 7,14 & 7,56 & 7,56 & 7,56 \\
\hline $07 / 05 / 00$ & 83 & 7,56 & 7,56 & 7,14 & 6,72 & 7,14 & 6,72 \\
\hline
\end{tabular}

*TO: tempo de operação (d) 


\subsubsection{Condutividade elétrica}

A condutividade elétrica permite avaliar a quantidade de sólidos totais dissolvidos - STD, que representa a medida dos íons na água . Na carreira 1 o parâmetro em questão foi medido em quatro oportunidades e os resultados obtidos, que podem ser contemplados na tabela 30, demonstram que não houve grande diferença entre os valores da água bruta e dos efluentes das unidades de filtração. Tais resultados são indícios de baixa concentração de íons na água.

TABELA 30 - Resultados de condutividade elétrica em $\mu \mathrm{S} / \mathrm{cm}$ para água bruta e unidades da FiME na carreira 1

\begin{tabular}{ccccccc}
\hline Data & AB & PFD & PFVA & F11 & F13 & F21 \\
\hline $21 / 03 / 00$ & 17,67 & 16,76 & 18,5 & 15,44 & 16,32 & 16,78 \\
\hline $06 / 04 / 00$ & 17,87 & 18,15 & 18,23 & 17,79 & 18,59 & 16,32 \\
\hline $10 / 04 / 00$ & 17,05 & 15,24 & 18,25 & 16,82 & 16,63 & 16,96 \\
\hline $13 / 04 / 00$ & 16,89 & 15,04 & 16,33 & 14,28 & 15,2 & 16,92 \\
\hline
\end{tabular}

\subsubsection{Temperatura}

As unidades filtrantes não causaram variação excessiva de temperatura, como pode ser observado na tabela E.5. Na tabela 31 pode ser visto um resumo dos dados de temperatura que são condizentes com a época do ano na cidade de São Carlos, uma vez que a carreira 1 foi realizada de fevereiro a maio de 2000 .

TABELA 31 - Resumo de valores de temperatura em ${ }^{\circ} \mathrm{C}$ para água bruta e unidades da FiME na carreira 1

\begin{tabular}{lcccccc}
\hline \multicolumn{1}{c}{ Valores } & AB & PFD & PFVA & FL11 & FL13 & FL21 \\
\hline Mínimo & 19,5 & 20,0 & 19,0 & 18,0 & 17,5 & 18,0 \\
\hline Médio & 22,7 & 22,8 & 22,3 & 22,2 & 21,9 & 22,1 \\
\hline Máximo & 26,0 & 28,0 & 28,0 & 28,5 & 30,0 & 27,0 \\
\hline
\end{tabular}




\subsubsection{Perda de carga}

Nas figuras 39 e 40, abaixo, verifica-se o desenvolvimento da perda de carga nos filtros lentos . O término da carreira ocorreu primeiramente no filtro lento 1 e deste modo foi dada como encerrada a carreira de filtração em ambos os filtros lentos.

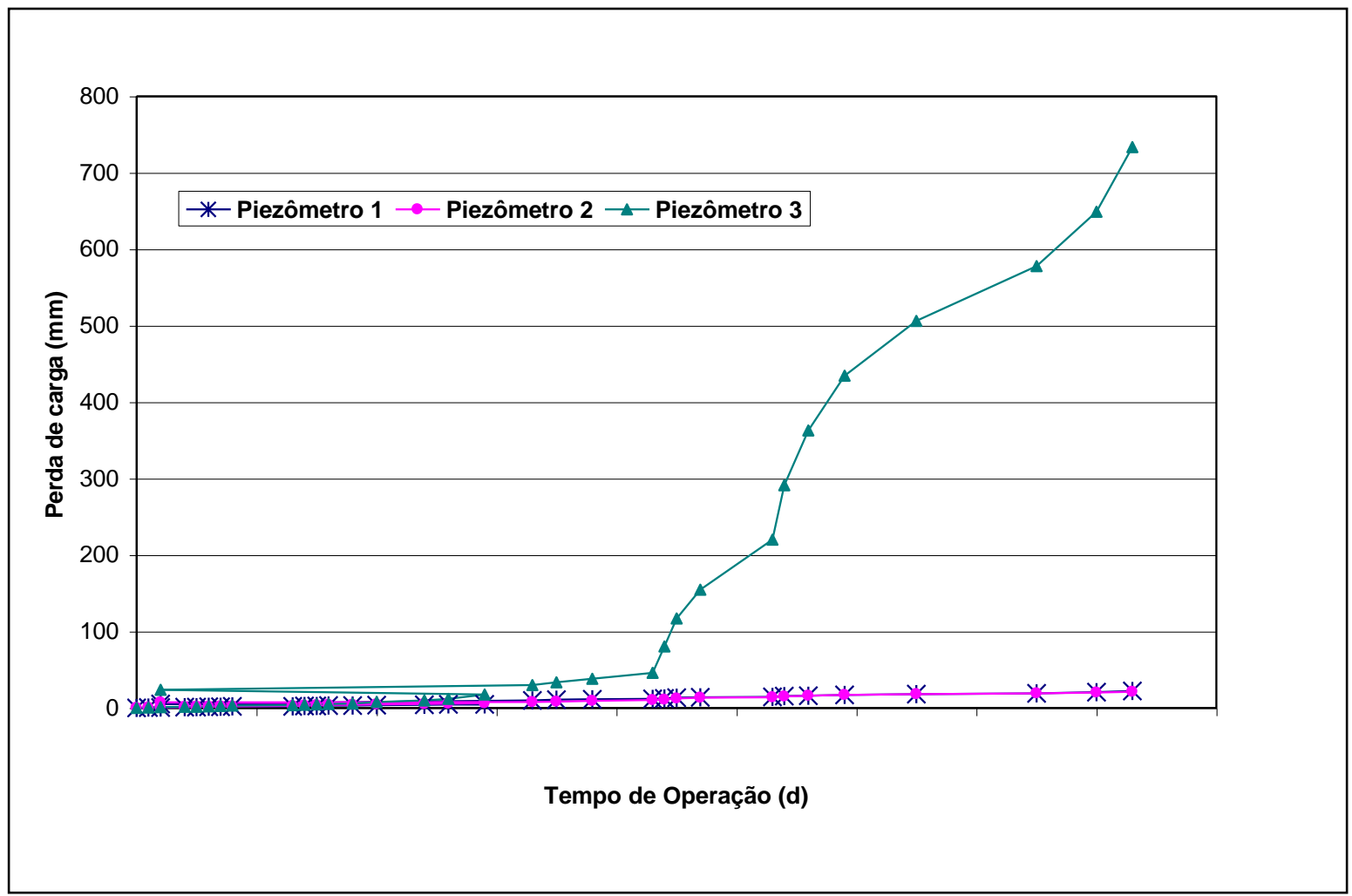

FIGURA 40 - Desenvolvimento da perda de carga no filtro lento 1 carreira 1 


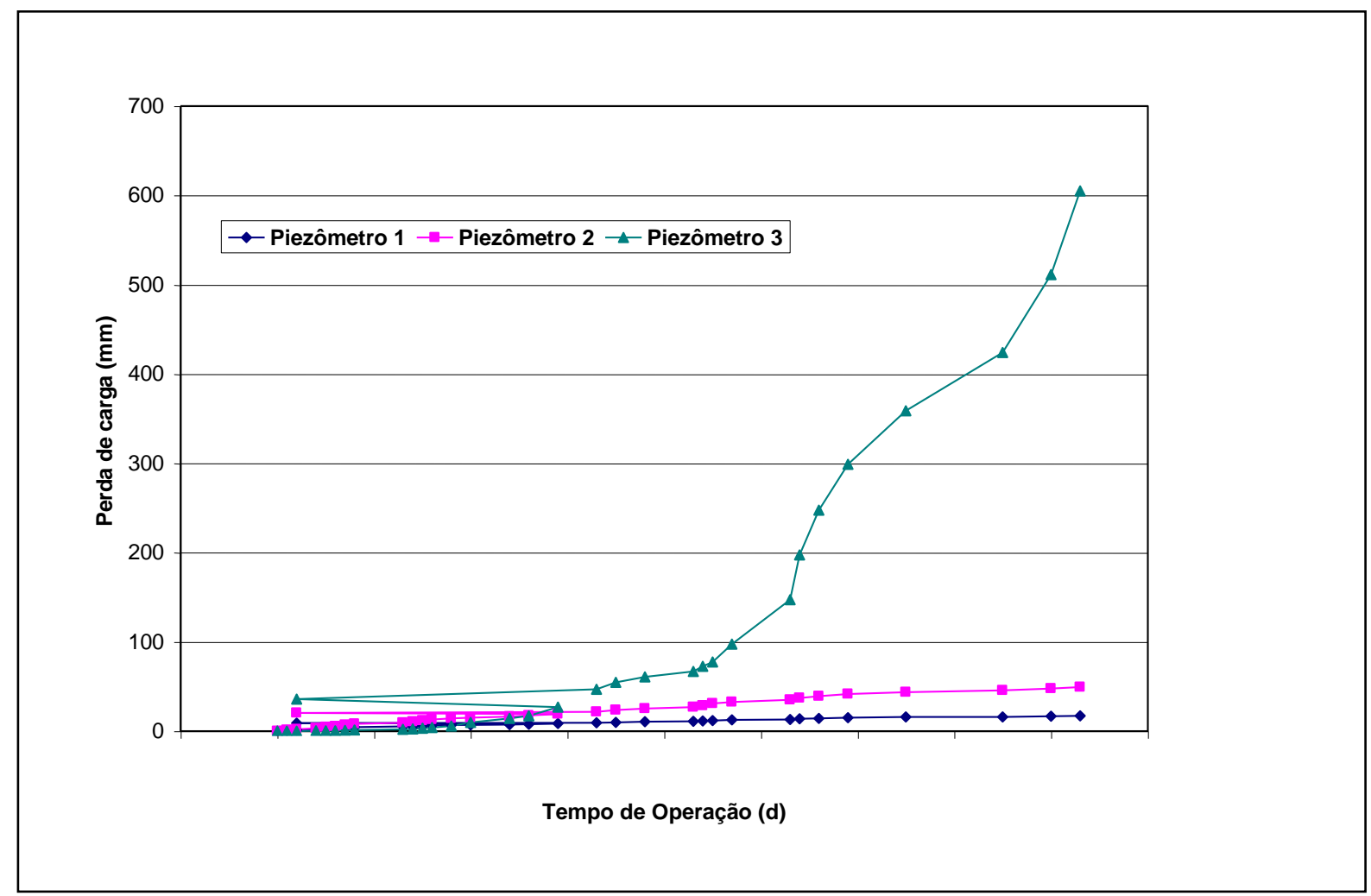

FIGURA 41 - Desenvolvimento da perda de carga no filtro lento 2 carreira 1 


\subsection{CARREIRA 3 DE FILTRAÇÃO}

Com o objetivo de avaliar a remoção de substâncias húmicas, com e sem préozonização antecedendo a filtração lenta, a carreira 3 foi iniciada no dia 21 de agosto de 2000 e terminada em 16 de novembro do mesmo ano. A aplicação do ozônio começou a ser feita praticamente no final da carreira de filtração 3 , tendo sido iniciada no $60^{\circ}$ dia da carreira em tela. No período compreendido entre o 65 e 78ํㅡㅁ dias de operação, não houve aplicação de ozônio pois o ozonizador apresentou pane, sendo retificado e recolocado

em operação no $79^{\circ}$ dia, permanecendo dosando sem demais problemas até o final da carreira de filtração. Deste modo o ozônio foi aplicado em apenas 11 dias de operação, intercalados por um período de 13 dias. Considerou-se nos cálculos estatísticos, os dados obtidos a partir do $4^{\circ}$ dia, pois foi neste dia que passou-se a utilizar a taxa de $4 \mathrm{~m} / \mathrm{d}$ nos filtros lentos.

Outro problema ocorrido prejudicou a determinação de cor verdadeira das amostras examinadas, haja vista que a centrífuga utilizada com parte de tal procedimento também entrou em pane, sendo que desta forma não foram feitas medidas do parâmetro em questão entre os dias 52 e $62^{\circ}$ da carreira 3 . Na carreira 3 por três vezes o sistema teve que ser paralizado para manutenção e troca das bombas centrífugas, e deste modo não houve medição de parâmetros nestes dias.

Foram feitas modificações no sistema de FiME e a introdução de três novos pontos de coleta de amostras, além dos já citados na carreira 1, sendo os seguintes: FL11 mont (afluente ao filtro lento1), FL21 mont (afluente ao filtro lento 2) e PFVAsh (efluente do PFVA com a solução de susbtâncias húmicas). As coletas no ponto PFVAsh, foram feitas a partir do $60^{\circ}$ dia de operação, com o intuito de avaliar o efeito da ozonização na qualidade da água, antes da entrada nos filtros lentos. Também a partir $60^{\circ}$ dia, deixou-se de coletar amostras no ponto FL21 mont, seguindo-se apenas com o ponto FL1mont, já que tratava-se da mesma água. Vale lembrar, que desde o início da presente carreira, foi injetada solução de substâncias húmicas no efluente do PFVA.

A qualidade água bruta mostrou-se em desacordo com o que estabelece DI BERNARDO et al (1999) para aplicação da tecnologia de FiME, uma vez que, 
semelhante o ocorrido na carreira 1, a água não atendeu aos limites estabelecidos para cor verdadeira e coliformes totais, como pode ser visto na tabela 32.

TABELA 32 - Caracterização da água bruta na carreira 3

\begin{tabular}{|c|c|c|c|c|}
\hline Parâmetro & Valor máximo & Valor mínimo & Média & Comparações \\
\hline Turbidez (uT) & 82,90 & 13,7 & 21,6 & $\begin{array}{l}100 \%<100 \\
100 \%<200\end{array}$ \\
\hline Cor verdadeira $(\mathrm{uH})$ & 118 & 34 & 58,7 & $\begin{array}{l}0 \%<10 \\
0 \%<25\end{array}$ \\
\hline $\begin{array}{l}\text { Sólidos suspensos } \\
\text { Totais }(\mathrm{mg} / \mathrm{L})\end{array}$ & 16,4 & 4,00 & 10,29 & $\begin{array}{l}100 \%<100 \\
100 \%<200\end{array}$ \\
\hline $\begin{array}{l}\text { Coliformes } \\
(\mathrm{NMP} / 100 \mathrm{~mL})\end{array}$ & 24192 & 4611 & 9646,8 & $\begin{array}{l}63,6 \%<10000 \\
91 \%<20000\end{array}$ \\
\hline $\begin{array}{l}\text { Escherichia } \\
(\mathrm{NMP} / 100 \mathrm{~mL})\end{array}$ & 1669 & 200 & 537 & $\begin{array}{l}100 \%<5000 \\
100 \%<10000\end{array}$ \\
\hline Ferro total $(\mathrm{mg} / \mathrm{L})$ & 1,9 & 0 & 1,31 & $\begin{array}{l}100 \%<3 \\
100 \%<5\end{array}$ \\
\hline
\end{tabular}

\subsubsection{Turbidez}

Na carreira 3 o PFD apresentou remoção média de turbidez de 29,25 \%, o PFVA de $44,54 \%$, o filtro lento 1 de 70,73 \%, o filtro lento 2 de 59,54 \% e o efluente da seção FL13 de 50,24\%.

Nos filtros lentos a percentagem de redução de turbidez variou entre 47 e 96,4 \% no filtro lento 1 e entre 25,4 e $90 \%$ no filtro lento 2 , o que condiz com o que reportado por COLLINS et al (1992). O método Anova identificou que houveram diferenças significativas de remoção entre FL11, FL13 e FL21.(tabela C.2). Pelo teste-z: duas amostras para médias, verificou-se que o filtro lento 1 foi significativamente melhor na remoção de turbidez que o filtro lento 2 e a seção FL13 e que o filtro lento 2 foi melhor que a seção FL13 (tabelas C.3 e C.4). 
TABELA 33 - Cálculos das distribuições de freqüências de turbidez do efluente do filtro lento 1 na carreira 3.

\begin{tabular}{ccccccc}
\hline Classe & $\begin{array}{c}\text { Limite } \\
\text { Inferior(uT) }\end{array}$ & $\begin{array}{c}\text { Limite } \\
\text { Superior(uT) }\end{array}$ & Excel & $\begin{array}{c}\text { Freqüência } \\
\text { absoluta }\end{array}$ & $\begin{array}{c}\text { Freqüência } \\
\text { relativa(\%) }\end{array}$ & $\begin{array}{c}\text { Freqüiência } \\
\text { acumulada(\%) }\end{array}$ \\
\hline 1 & 0 & 2 & 1,9 & 38 & 48,72 & 48,72 \\
\hline 2 & 2 & 4 & 3,9 & 34 & 43,59 & 92,31 \\
\hline 3 & 4 & 6 & 5,9 & 4 & 5,13 & 97,44 \\
\hline 4 & 6 & 8 & 8 & 2 & 2,56 & 100 \\
\hline & & & 78 & 100 & \\
\hline
\end{tabular}

Pela tabela 33 constata-se que na carreira $348,72 \%$ dos dados de turbidez efluente do filtro lento 1, foram menor que 2 uT e que 43,59\% estiveram compreendidos entre 2 e 4 uT. Com a função estatística freqüência do EXCEL 97, verificou-se que em 97,44 \% dos dias de operação a água apresentou turbidez menor que 5 uT. A figura 42 mostra a frequiência acumulada dos dados em função das faixas de turbidez. 


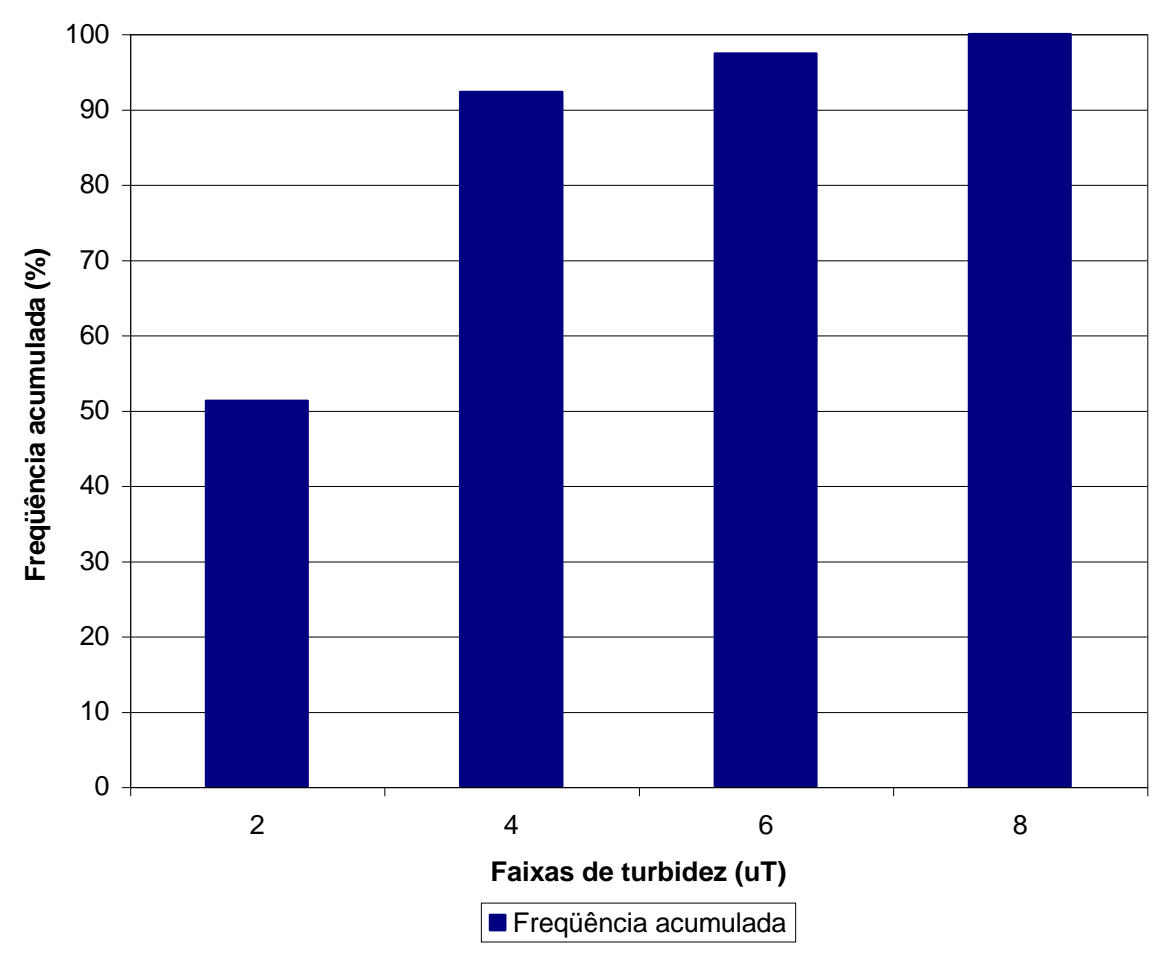

FIGURA 42 - Histograma de turbidez do efluente do filtro lento 1 durante desenvolvimento da carreira 3

Fonte: TABELA 33

Já para o efluente do filtro lento 2 em apenas 7,69 \% dos dados a água apresentou turbidez menor que $2 \mathrm{uT}$, porém a maioria dos valores obtidos, 80,77\%, situou-se na faixa de 2 a 4 uT. Em 92,31\% dos casos a água apresentou turbidez menor que 5. Deste modo o filtro lento 2 forneceu água de pior qualidade que o filtro lento 1, no que tange a turbidez (Ver figura 43). Na tabela 34 podem ser visualizados os cálculos das distribuições de freqüência referentes ao filtro lento 2. 
TABELA 34 - Cálculos das distribuições de freqüências de turbidez do efluente do filtro lento 2 carreia 3 .

\begin{tabular}{ccccccc}
\hline Classe & $\begin{array}{c}\text { Limite } \\
\text { Inferior(uT) }\end{array}$ & $\begin{array}{c}\text { Limite } \\
\text { Superior(uT) }\end{array}$ & Excel & $\begin{array}{c}\text { Freqüência } \\
\text { absoluta }\end{array}$ & $\begin{array}{c}\text { Freqüência } \\
\text { Relativa(\%) }\end{array}$ & $\begin{array}{c}\text { Freqüiência } \\
\text { Acumulada(\%) }\end{array}$ \\
\hline 1 & 0 & 2 & 1,9 & 6 & 7,69 & 7,69 \\
\hline 2 & 2 & 4 & 3,9 & 63 & 80,77 & 88,46 \\
\hline 3 & 4 & 6 & 5,9 & 3 & 3,85 & 92,31 \\
\hline 4 & 6 & 8 & 7,9 & 4 & 5,13 & 97,44 \\
\hline 5 & 8 & 10 & 9,9 & 0 & 0,00 & 97,44 \\
\hline 6 & 10 & 12 & 12 & 2 & 2,56 & 100,00 \\
\hline & & & & 78 & 100,00 & \\
\hline
\end{tabular}

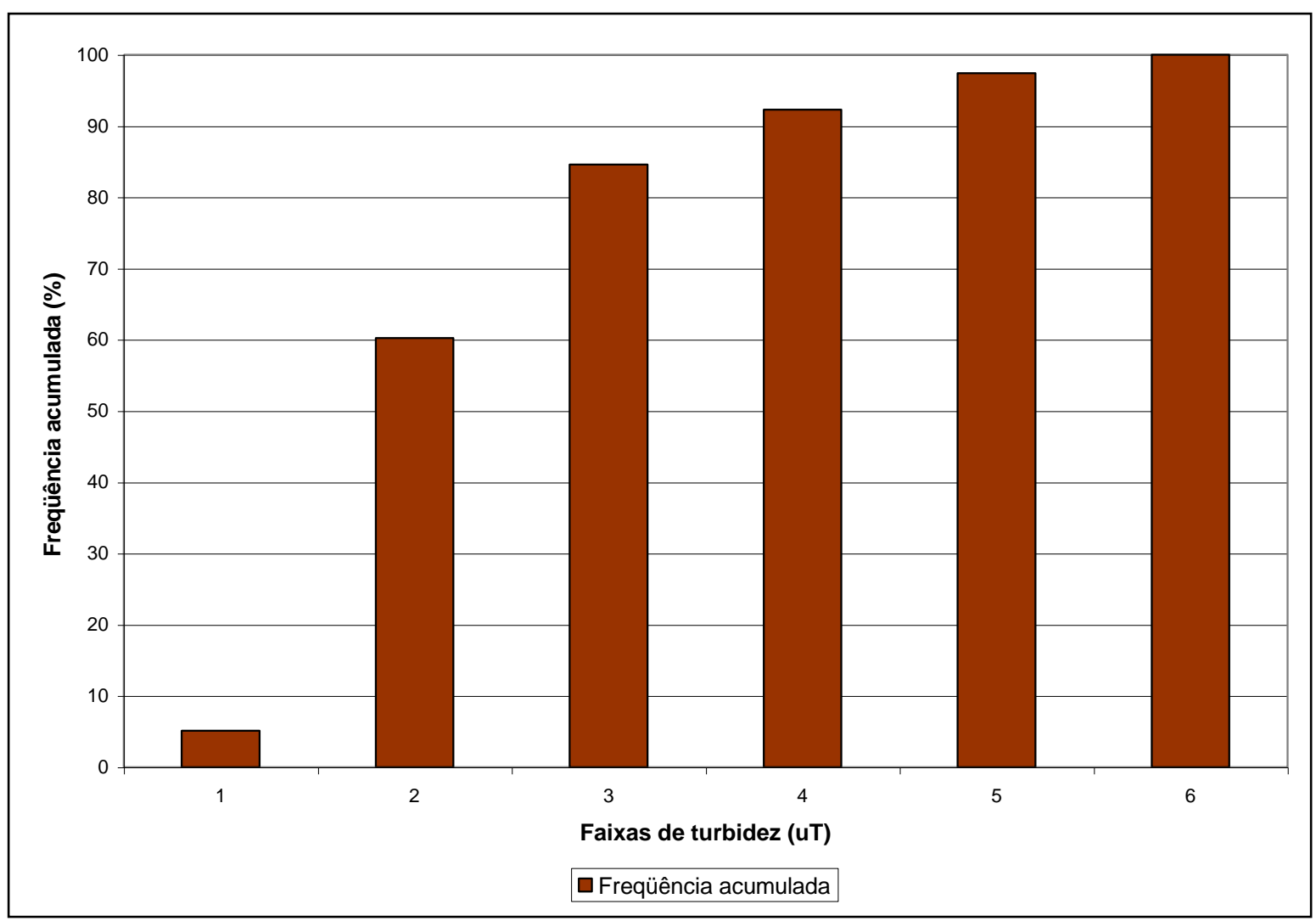

FIGURA 43 - Histograma de turbidez do efluente do filtro lento 2 durante desenvolvimento da carreira 3

\section{Fonte: TABELA 34}

A injeção da solução de substância húmica não causou variação significativa da turbidez no efluente do PFVA, como pode ser observado pela figura 44. Nota-se na referida figura a variação da turbidez no PFVA e nos pontos imediatamente a jusante do 
mesmo, o FL1mont e o FL21mont. Conforme dito anteriormente, após o $60^{\circ}$ dia de operação deixou-se de coletar água no ponto FL21 mont.

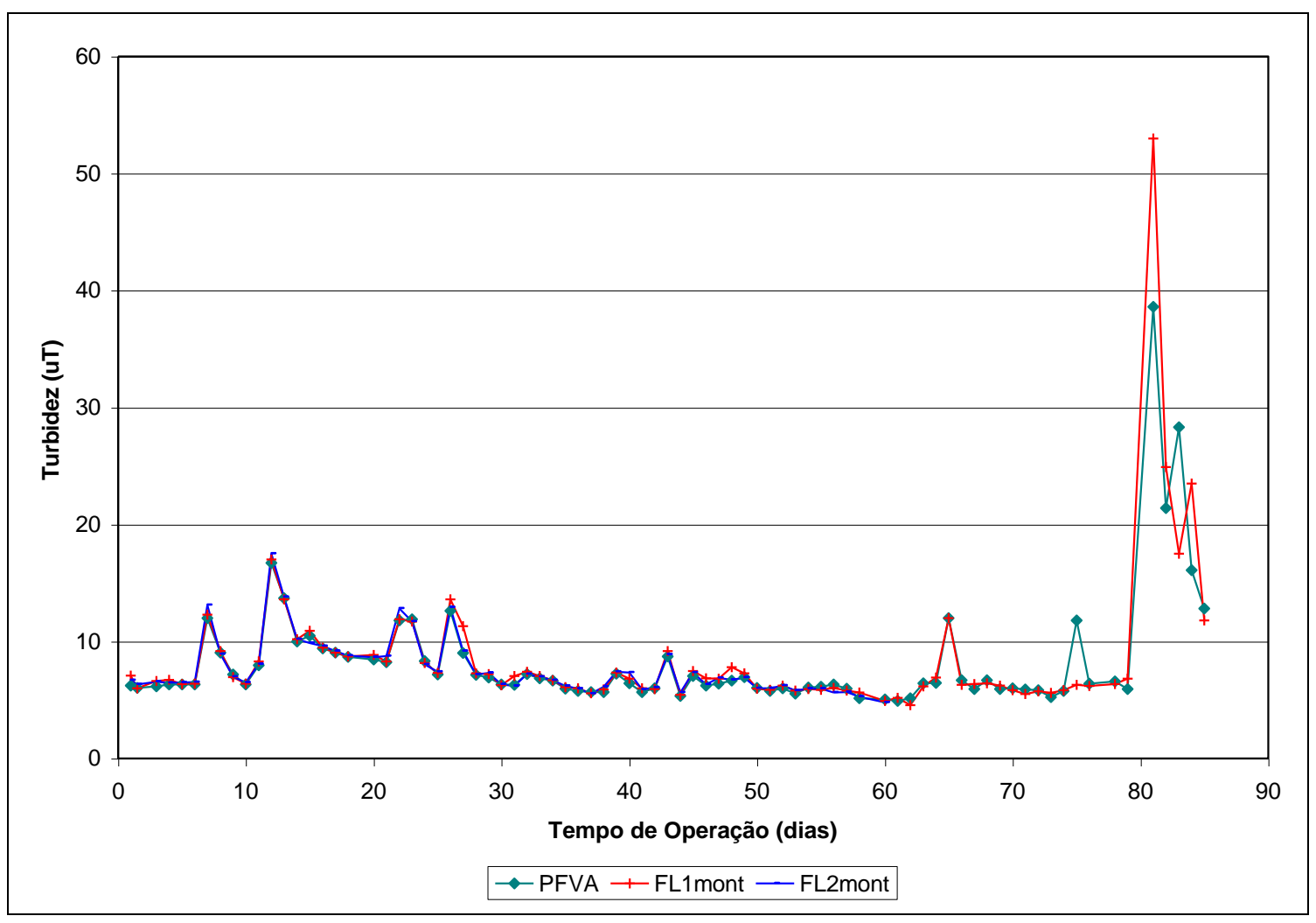

FIGURA 44 - Variações de turbidez nos efluentes do PFVA, FL1 mont e FL2 mont ao longo da carreira 3

Fonte: TABELA F.1

Os dados de turbidez da carreira 3 podem ser apreciados na tabela F.1 e na figura 45. 


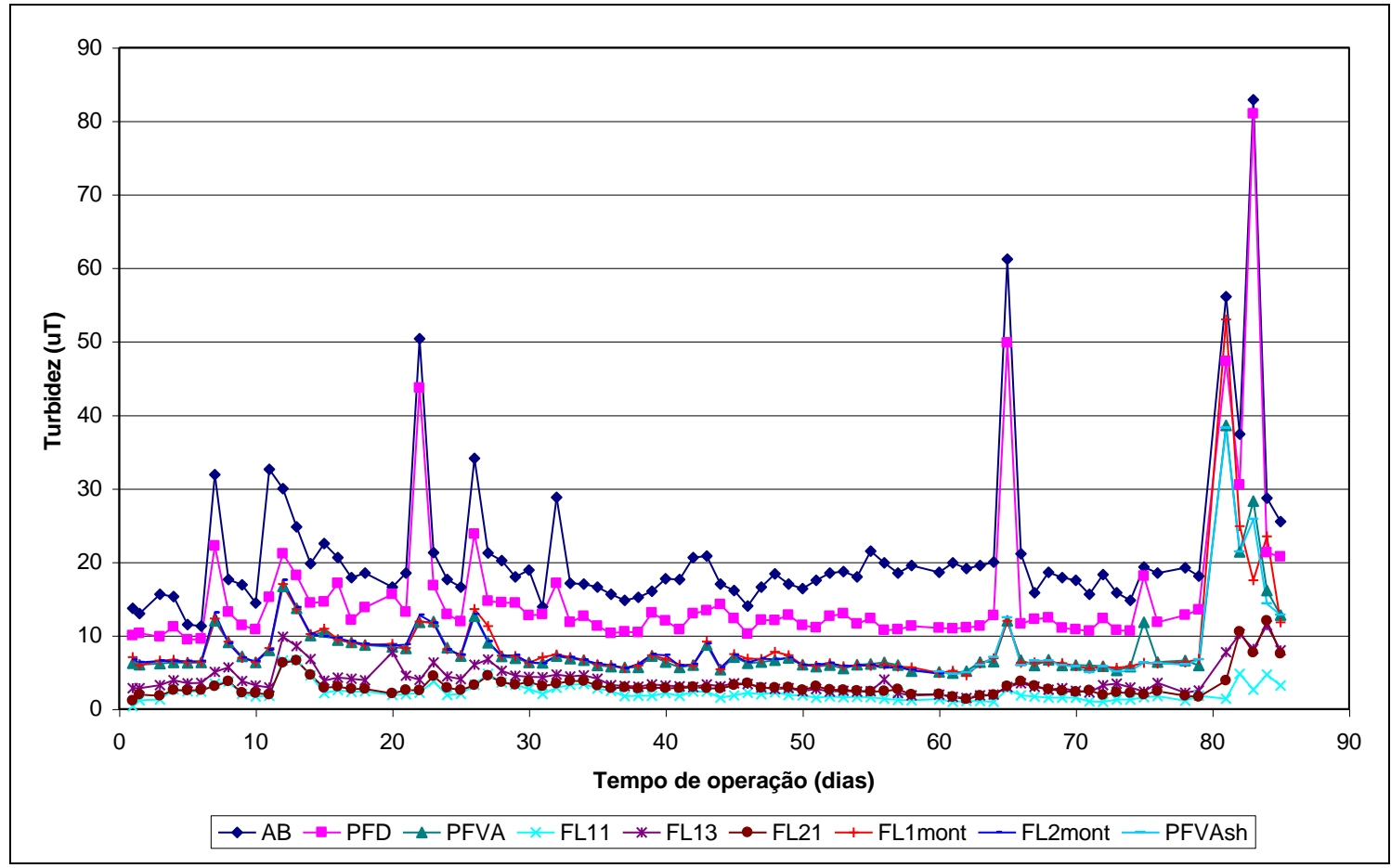

FIGURA 45 - Variações da turbidez em função do tempo de operação para água bruta e efluentes das unidades da FiME durante a carreira 3

Fonte: TABELA F.1

\subsubsection{Coliformes totais e Escherichia Coli}

Em se tratando de coliformes totais o PFD promoveu remoção média de 55,43 \% e o PFVA de 84,47 \%. As maiores médias de remoções em pré-filtros dinâmicos encontradas por VERAS (1999) foram de 67,6 e 41\%. VISSCHER et al (1996), afirmam que um PFVA em camadas, operando com taxas de filtração de 7 a $18 \mathrm{~m} / \mathrm{d}$, pode alcançar remoção de coliformes totais na faixa de 70 a $98 \%$.

Os filtros lentos 1 e 2, apresentaram médias de remoção iguais a 98,7 e $93 \%$, sendo verificada remoção de 96,8 \% no efluente da seção FL13. A elevada remoção de CT no ponto FL13 evidencia a importância do "schmutzdecke" na redução de microrganismos, visto que tal ponto estava situado entre o começo da camada de carvão e o final da camada de areia, que tinha espessura de $30 \mathrm{~cm}$ no início da carreira 1 . No final da carreira 1 e da carreira 2, a camada de areia acima do ponto FL13 foi raspada 
para limpeza do filtro, sendo removidos cerca de três centímetros de areia em cada limpeza. Destarte, sobraram na carreira 3, em torno de $24 \mathrm{~cm}$ de camada de areia, que foram responsáveis, pela alta remoção média apresentada, comprovando que a atividade biológica é mais pronunciada no topo do meio filtrante.

O filtro lento 1 foi estatisticamente melhor que o filtro lento 2 na remoção de CT e não foram encontradas diferenças significativas entre FL11 e FL13 e FL13 e FL21. (tabelas de C.7 a C.11).

Pela tabela 35, pode-se notar a eficiência das unidades da FiME e da seção FL13 na redução de coliformes.

TABELA 35 - Resultados de coliformes totais em NMP/100 mL carreira 3

\begin{tabular}{cccccccc}
\hline Data & $*$ TO & AB & PFD & PFVA & FL11 & FL13 & FL21 \\
\hline 31.08 .00 & 9 & 4884 & 3130 & 547,5 & 10,9 & 44,8 & 16,1 \\
\hline 14.09 .00 & 23 & 6131 & 1067 & 488,4 & 4,1 & 31,1 & 13,5 \\
\hline 21.09 .00 & 29 & 5794 & 3255 & 461,1 & 31,3 & 25,9 & 5,2 \\
\hline 28.09 .00 & 36 & 4611 & 2419,2 & 183,5 & 4,1 & 5,2 & 3,1 \\
\hline 05.10 .00 & 43 & 10462,4 & 4884 & 461,1 & 5,2 & 20,1 & 14,8 \\
\hline 11.10 .00 & 49 & 6810 & 1968 & 328,2 & 2,0 & 11,0 & 12,1 \\
\hline 19.10 .00 & 57 & 6867 & 3441 & 272,3 & 1,0 & 3,1 & 19,9 \\
\hline 27.10 .00 & 65 & 12033,1 & 2987 & 344,1 & 1,0 & 2,0 & 23,8 \\
\hline 01.11 .00 & 70 & 8800 & 2613 & 461,1 & 0 & 4,1 & 43,5 \\
\hline 09.11 .00 & 78 & 15530,7 & 8664 & 613,1 & 0 & 8,6 & 135,4 \\
\hline 13.11 .00 & 82 & 24192 & 15530,7 & 2419,2 & 0 & 18,9 & 387,3 \\
\hline
\end{tabular}

*TO: tempo de operação (d)

Os dados da tabela 35 estão plotados na figura 46. Para melhor visualização, os dados de coliformes foram colocados em escala logarítmica. 


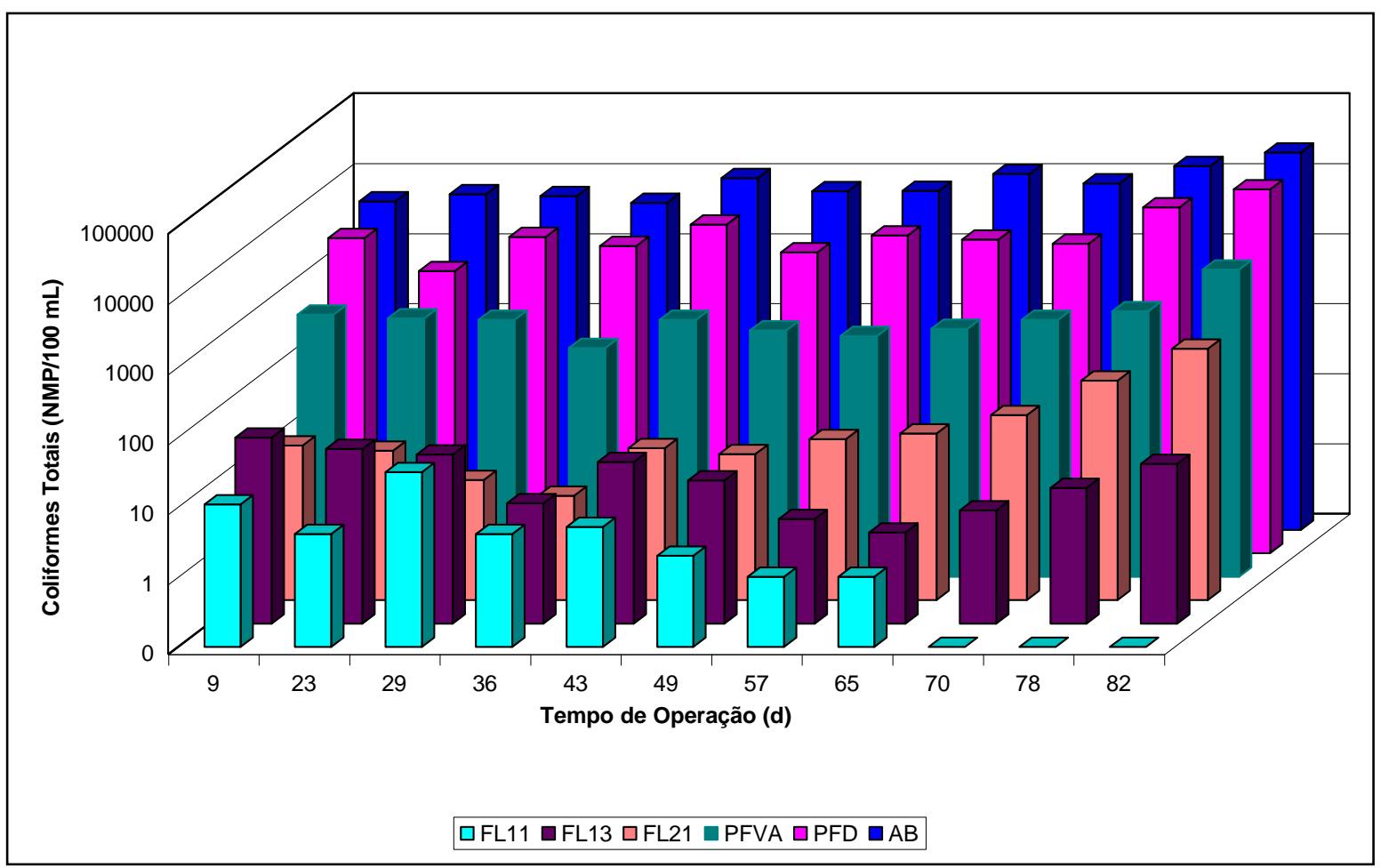

FIGURA 46 - Variações de coliformes totais em função do tempo de operação para água bruta e efluentes das unidades da FiME durante a carreira 3

Fonte: TABELA 35

Os resultados de E.Coli, foram coerentes com o que é geralmente citado pela literatura, haja vista que se verificou alta redução do parâmetro em tela nas unidades de filtração lenta. VERAS (1999) encontrou na filtração lenta percentuais médios de remoção acima de $99 \%$. Não se identificou diferenças estatísticas significativas de remoção de E.Coli entre FL11, FL13 e FL21 (tabelas C.12 e C.13). No PFD a remoção média alcançada foi de 61,3 \% e no PFVA de 78, $2 \%$. No filtro lento 1, na seção FL13 e no filtro lento 2, as remoções variaram nas faixas de 94,3 - 100, 89,7 - 100 e 78,8 - 100 $\%$, respectivamente. Na tabela 36 , pode ser detectada a importância da maturidade biológica do filtro lento na remoção de microrganismos, uma vez que após nove dias de operação o filtro lento 1 produziu água sem E.Coli, com exceção do 57ํㅜ dia. O valor máximo de E.Coli encontrado no efluente do ponto FL13 foi 2 NMP/100mL e no filtro lento 2 de 3,1 NMP/100mL. 
TABELA 36 - Resultados de Escherichia Coli para a água bruta e efluentes das unidades da FiME em NMP/100mL na carreira 3

\begin{tabular}{cccccccc}
\hline Data & TO & AB & PFD & PFVA & FL11 & FL13 & FL21 \\
\hline 31.08 .00 & 9 & 262,0 & 73,8 & 29,4 & 0,0 & 2,0 & 1,0 \\
\hline 14.09 .00 & 23 & 200,0 & 97,0 & 14,6 & 0,0 & 0,0 & 3,1 \\
\hline 21.09 .00 & 29 & 203,0 & 122,3 & 20,9 & 0,0 & 1,0 & 0,0 \\
\hline 28.09 .00 & 36 & 209,0 & 86,0 & 18,7 & 0,0 & 0,0 & 0,0 \\
\hline 05.10 .00 & 43 & 860,0 & 228,0 & 86,0 & 0,0 & 1,0 & 0,0 \\
\hline 11.10 .00 & 49 & 410,0 & 156,0 & 30,5 & 0,0 & 1,0 & 1,0 \\
\hline 19.10 .00 & 57 & 368,0 & 135,0 & 17,5 & 1,0 & 0,0 & 0,0 \\
\hline 27.10 .00 & 65 & 402,0 & 161,6 & 33,1 & 0,0 & 0,0 & 0,0 \\
\hline 01.11 .00 & 70 & 310,0 & 111,2 & 19,5 & 0,0 & 2,0 & 0,0 \\
\hline 09.11 .00 & 78 & 1014,0 & 325,5 & 27,2 & 0,0 & 0,0 & 0,0 \\
\hline 13.11 .00 & 82 & 1669,0 & 2359,0 & 686,7 & 0,0 & 0,0 & 0,0 \\
\hline
\end{tabular}

Na figura 47 estão os dados de E.Coli em função do tempo de operação 


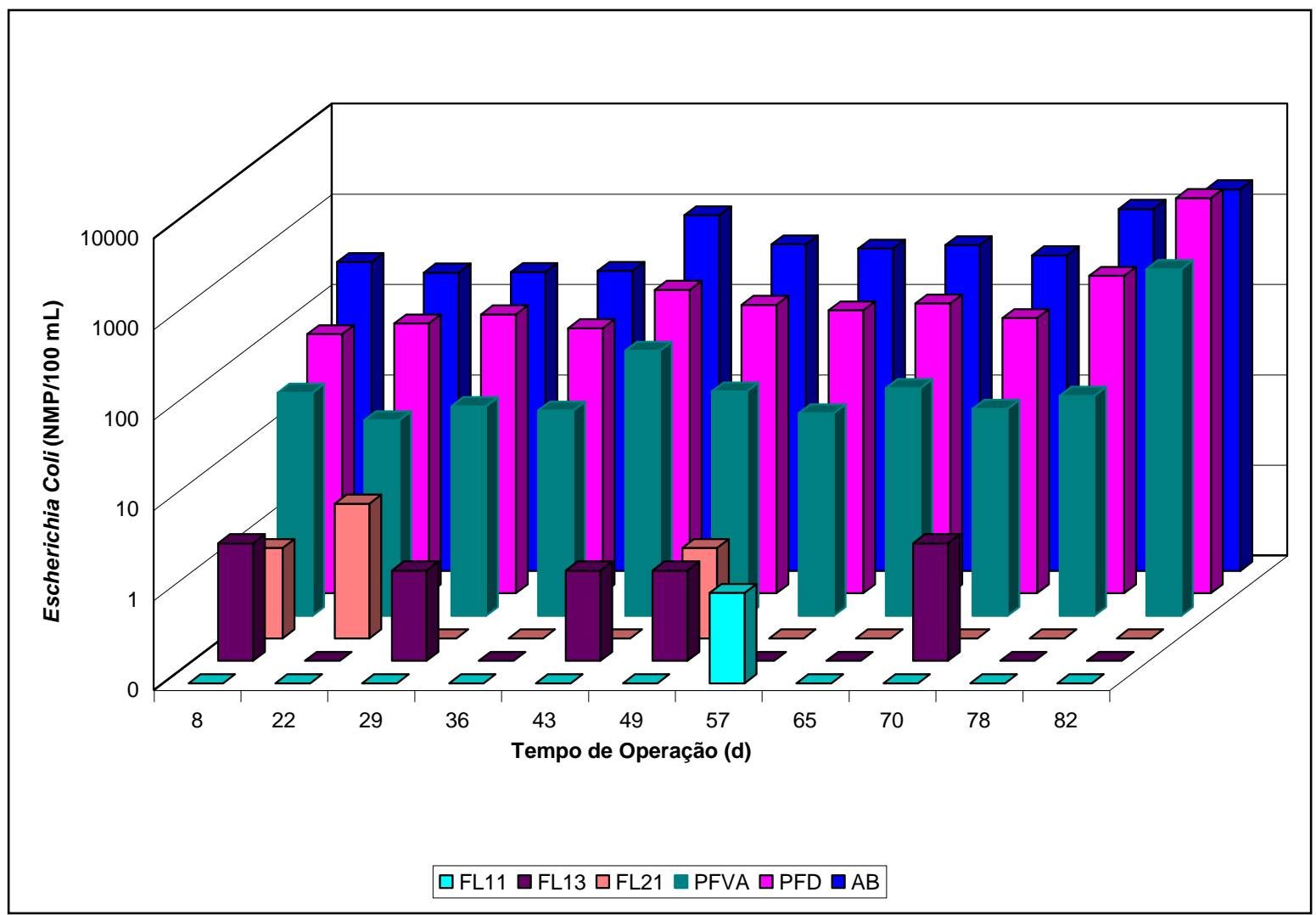

FIGURA 47 - Variações de Escherichia Coli em função do tempo de operação para água bruta e unidades da FiME ao longo da carreira 3

\section{Fonte: TABELA 36}

É importante ressaltar que a Portaria № 1469, de 29 de dezembro de 2000, do Ministério da Sáude, que estabelece os procedimentos e responsabilidades relativos ao controle e vigilância da qualidade da água para consumo humano e seu padrão de potabilidade, e dá outras o providências, em seu capítulo IV, do padrão de potabilidade, Art. 11, estabelece que :

$\Rightarrow$ A água potável, na saída do sistema de tratamento, deve ter ausência de coliformes totais em $100 \mathrm{~mL}$.

A mesma portaria, no mesmo capítulo citado, Art. 12, estabelece que:

$\Rightarrow$ Para garantia da qualidade microbiológica da água, em complementação às exigências relativas aos indicadores microbiológicos, o valor máximo permitido de 
turbidez, em $95 \%$ das amostras, para tratamento de água por filtração lenta deverá ser de 2 uT.

DI BERNARDO et al (1999) recomendam que o efluente do filtro lento apresente turbidez menor que $5 \mathrm{uT}$, e valores do NMP/100 mL para coliformes totais e E.Coli inferiores, respectivamente, a 100 e 25, para que o mesmo seja encaminhado para etapa de desinfecção, pois a qualidade bacteriológica da água é mais importante que o parâmetro turbidez. Os dados obtidos na carreira 3 reforçam as afirmações dos autores e questionam o que é estabelecido, para turbidez, pela Portaria № 1469, uma vez que mesmo não tendo atendido o estabelecido para o referido parâmetro, os filtros promoveram alta remoção de coliformes totais e E.Coli, e não houve etapa subsequente de desinfecção.

\subsubsection{Bactérias heterotróficas}

Efetuando-se cálculos estatísticos, não foram constatadas diferenças siginificativas de remoção de bactérias heterotróficas - BH entre os filtros lentos e o efluente da seção FL13.(tabela C.15).

O PFD apresentou remoção média de $44 \%$ e o PFVA de $62 \%$. O filtro lento 1, filtro lento 2 e a seção FL13, promoveram remoção média de 35,5, 50 e $10 \%$. Na tabela 37, os dados de $\mathrm{BH}$ podem ser observados.

TABELA 37 - Resultados de bactérias heterotróficas em UFC/100 ml carreira 3

\begin{tabular}{cccccccc}
\hline Data & TO & AB & PFD & PFVA & FL11 & FL13 & FL21 \\
\hline 31.08 & 9 & 7380 & 355 & 28,70 & 12,00 & 37,20 & 17,70 \\
\hline 21.09 & 29 & 372 & 239 & 35,50 & 15,60 & 27,60 & 4,50 \\
\hline 05.10 & 43 & 738 & 738 & 50,70 & 18,30 & 50,70 & 28,70 \\
\hline 19.10 & 57 & 372 & 29,9 & 50,7 & 28,7 & 33,9 & 19,5 \\
\hline 27.10 & 65 & 507 & 555 & 35,5 & 44 & 23,1 & 16,6 \\
\hline 01.11 & 70 & 738 & 355 & 73,8 & 62,3 & 73,8 & 62,3 \\
\hline
\end{tabular}

A figura 48 mostra os dados de BH em função do tempo de operação do sistema. 


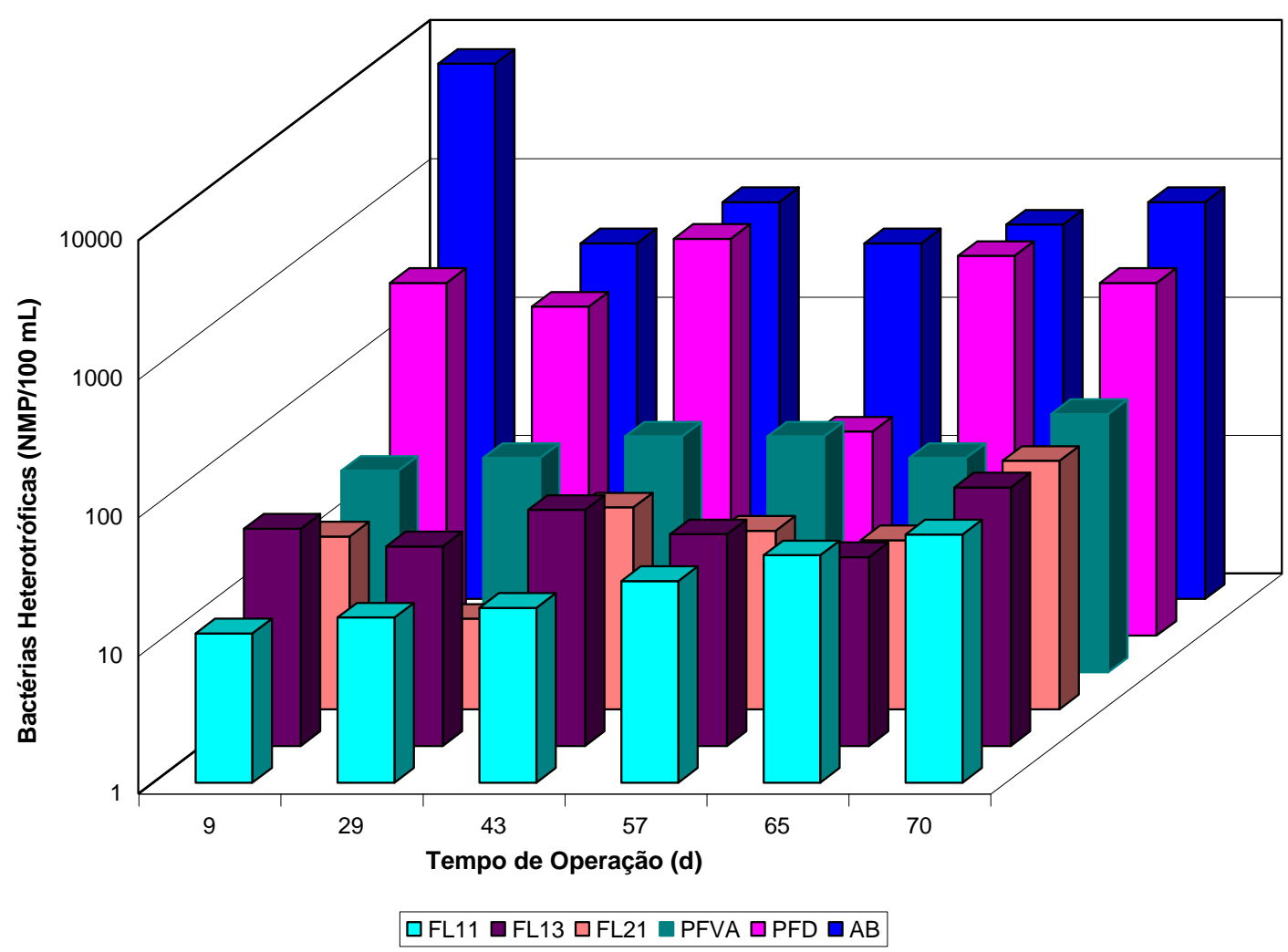

FIGURA 48 - Variações no número de bactérias heterotróficas em função do tempo de operação para água bruta e unidades da FiME na carreira 3

Fonte: TABELA 37

\subsubsection{Sólidos suspensos totais}

Não se verificou diferenças estatísticas significativas entre os filtros lentos e a seção FL13, na remoção de sólidos suspensos totais.(tabela C.17).

O PFD e o PFVA removeram em média 56 e $48 \%$. Na filtração lenta, médias de remoção iguais a 76,8, 79,74 e 71,45 \%, foram encontradas para o filtro lento 1, filtro lento 2 e seção FL13, nesta ordem.(tabela C. 16).

Na tabela 38 é apresentado um resumo dos valores de SST. Todos os dados de SST procedentes da carreira 3 podem ser apreciados na tabela F.2 e na figura 49 
TABELA 38 - Resumo dos valores de sólidos suspensos totais (mg/l) para água bruta e unidades da FiME na carreira 3

\begin{tabular}{ccccccc}
\hline Valores & AB & PFD & PFVA & FL11 & FL13 & FL21 \\
\hline Máximo & 4,00 & 0,72 & 0,29 & 0,03 & 0,00 & 0,00 \\
\hline Médio & 10,29 & 4,35 & 1,97 & 0,39 & 0,54 & 0,36 \\
\hline Mínimo & 16,40 & 8,67 & 5,80 & 0,74 & 1,77 & 1,48 \\
\hline
\end{tabular}

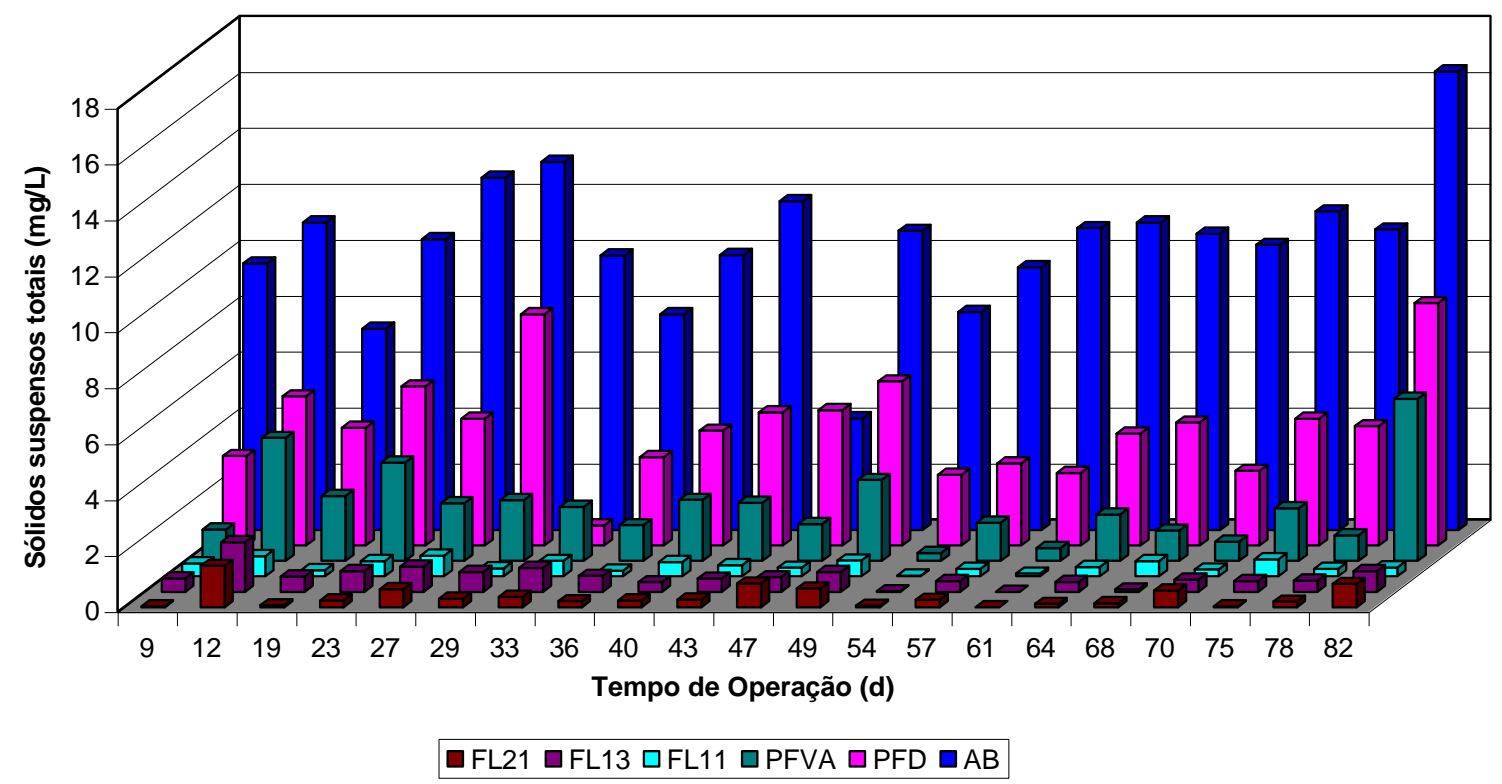

FIGURA 49 - Variações na concentração de sólidos suspensos totais em função do tempo de operação para água bruta e unidades da FiME na carreira 3

Fonte: TABELA F.2

\subsubsection{Cor aparente}

A introdução da solução de substância húmica causou um aumento médio de 29,7 \% na cor aparente do efluente do PFVA. Essa constatação foi possível comparandose os dados do efluente do PFVA, com os dados do FL1 mont até o 60º , e a partir daí 
passou-se a comparar os dados do PFVA, com os dados do PFVAsh, por causa da injeção de ozônio, visto que a coluna de ozonização estava situada a montante dos pontos FL11 mont e FL21 mont e a jusante do ponto PFVAsh. O aumento da cor aparente no efluente do PFVA pode ser visto na figura 49.

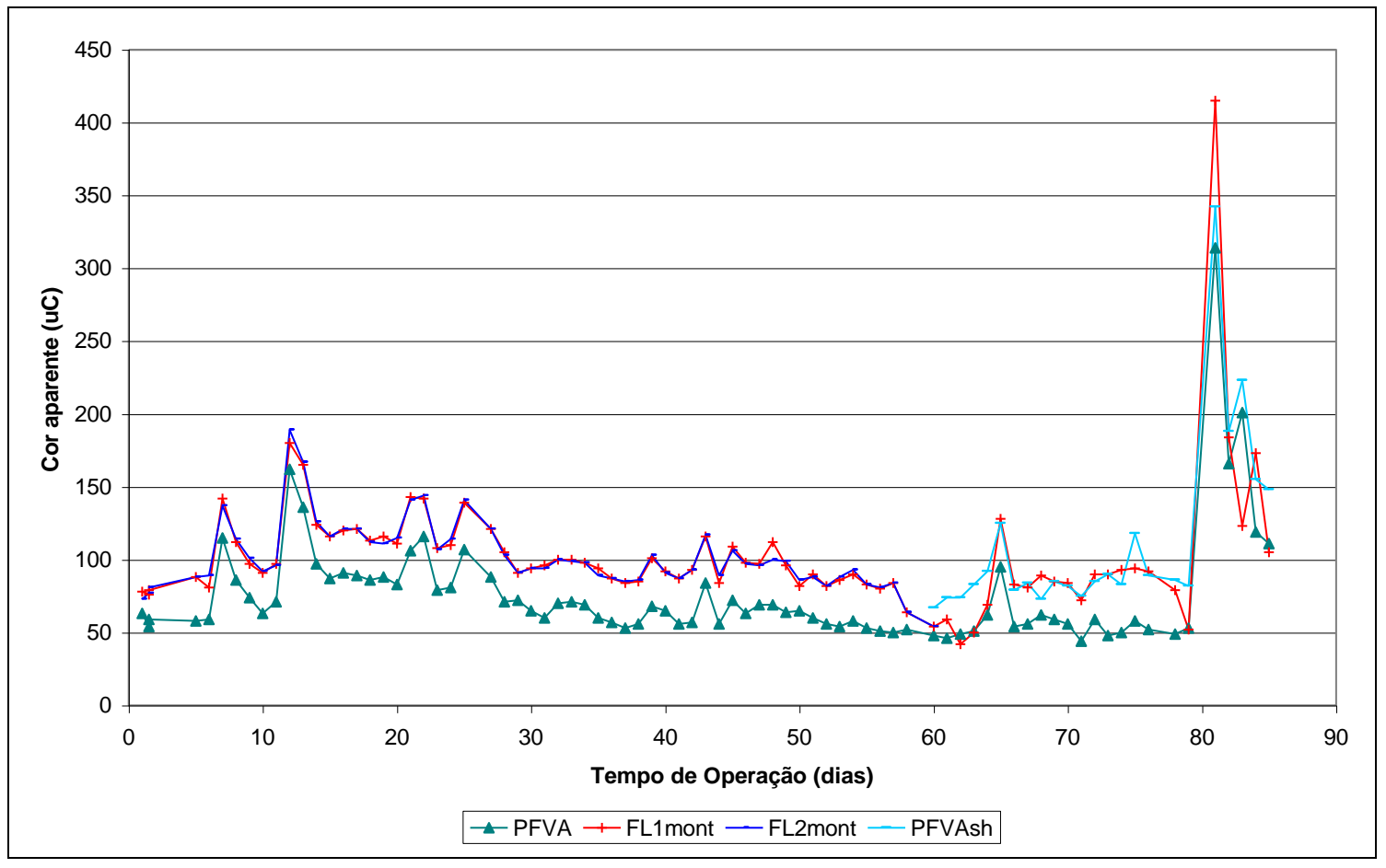

FIGURA 50 - Aumento de cor aparente no efluente do PFVA em função do tempo de operação na carreira 3

\section{Fonte: TABELA F.3}

Os testes estatísticos revelaram que o filtro lento 1 foi significativamente melhor na remoção de cor aparente que o filtro lento 2 e a seção FL13 e que o filtro lento 2 foi melhor que a seção FL13. (tabelas de C.19 a C.22). De um modo geral, incluindo-se os dias em que houve dosagem de ozônio, o filtro lento locasionou remoção média de 73,9 \%, o efluente da seção FL13 apresentou remoção de 49,6 \% e o filtro lento 2 removeu $57,65 \%$. BAUER et al (1996) estudando filtros lentos com carvão ativado encontraram redução da ordem de 60 - 70 \%. O PFD produziu remoção média de 22,53 e o PFVA de 43,4 \%. A redução na cor aparente da água afluente aos filtros lentos e a seção FL13, 
pode ser apreciada na figura 51, onde estão plotados os dados de FL11, FL13, FL21, FL11 mont e FL21 mont.

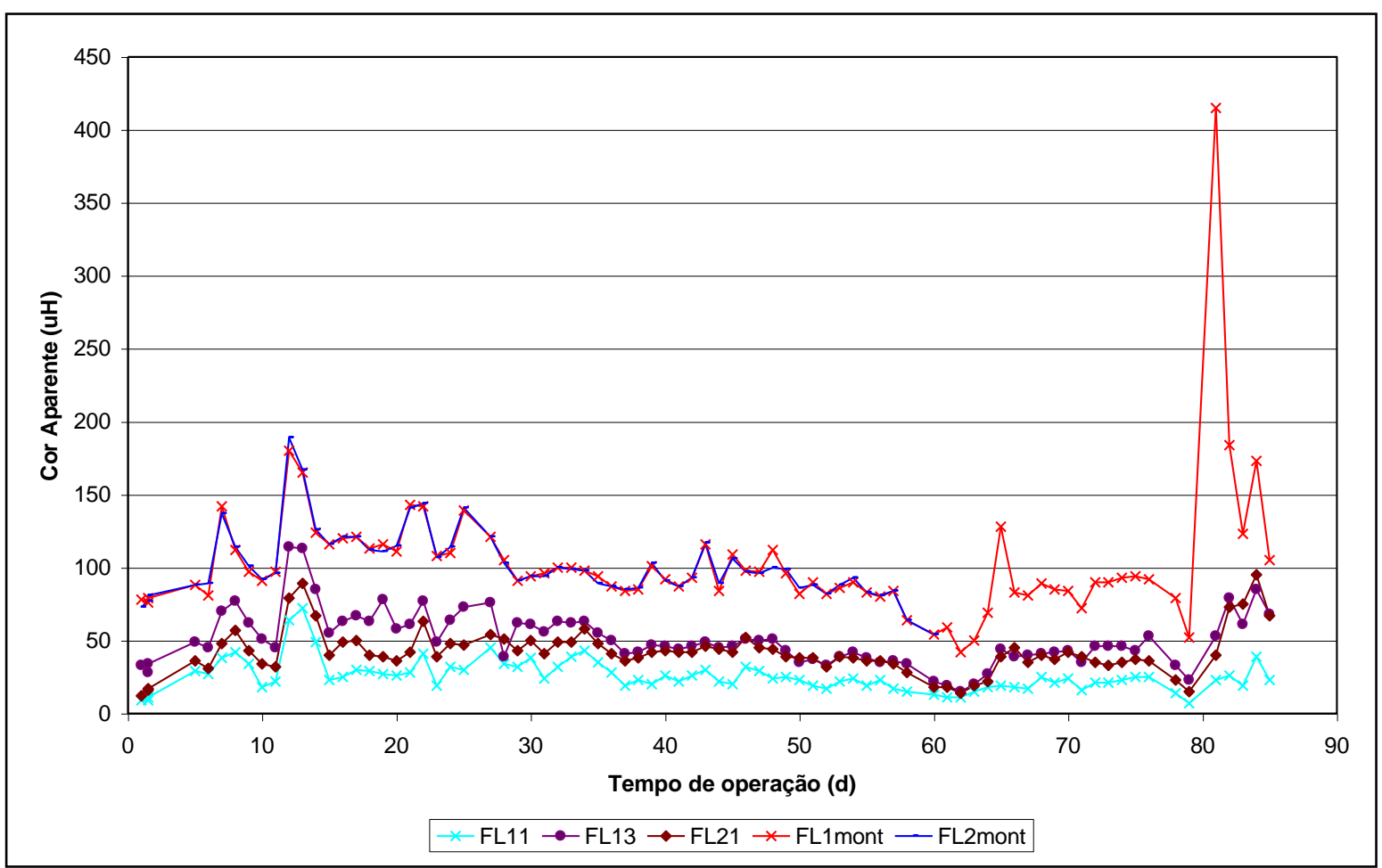

FIGURA 51 - Variações de cor aparente nos efluentes dos filtros lentos e seção FL13 em função do tempo de operação na carreira 3

Fonte: TABELA F.3

A dosagem de ozônio, por si só, acarretou remoção média de $29 \%$ e em apenas dois dias verificou-se remoção negativa, o que pode ter ocorrido por falhas experimentais.(tabela 39). Na tabela 39, podem ser vistos os dados de remoção com ozônio. Os dados negativos foram excluídos do cálculo da média de remoção. 
TABELA 39 - Resultados de remoção de cor aparente por ozonização na carreira 3

\begin{tabular}{cccc}
\hline TO & PFVAsh (uH) & FL11 mont (uH) & Remoção \% \\
\hline 60 & 67 & 54 & 19,4 \\
\hline 61 & 74 & 59 & 20,3 \\
\hline 62 & 74 & 42 & 43,2 \\
\hline 63 & 83 & 50 & 39,76 \\
\hline 64 & 92 & 69 & 25 \\
\hline 79 & 82 & 52 & 36,6 \\
\hline 81 & 342 & 415 & $-17,6$ \\
\hline 82 & 188 & 184 & 2,1 \\
\hline 83 & 223 & 123 & 44,8 \\
\hline 84 & 155 & 173 & $-10,4$ \\
\hline 85 & 148 & 105 & 29 \\
\hline
\end{tabular}

Na tabela 40 pode ser verificado um resumo dos dados de cor aparente obtidos da carreira 3.

TABELA 40 - Resumo dos valores de cor aparente em uH carreira 3

\begin{tabular}{lccccccccc}
\hline Valores & AB & PFD & PFVA & FL11 & FL13 & FL21 & $\begin{array}{c}\text { FL1 } \\
\text { mont }\end{array}$ & $\begin{array}{c}\text { FL21 } \\
\text { Mont }\end{array}$ & $\begin{array}{c}\text { PFVA } \\
\text { sh }\end{array}$ \\
\hline Mínimo & 100 & 87 & 50 & 7 & 15 & 12 & 42 & 54 & 67 \\
\hline Médio & 173 & 135 & 85 & 26 & 51 & 42 & 103 & 101,8 & 112 \\
\hline Máximo & 521 & 521 & 342 & 72 & 114 & 95 & 415 & 189 & 342 \\
\hline
\end{tabular}

Na tabela F.3, estão inclusos todos os dados de cor aparente provenientes da carreira 3. A figura 52., mostra a variação do parâmetro em tela ao longo dos dias de operação do sistema de FiME . 


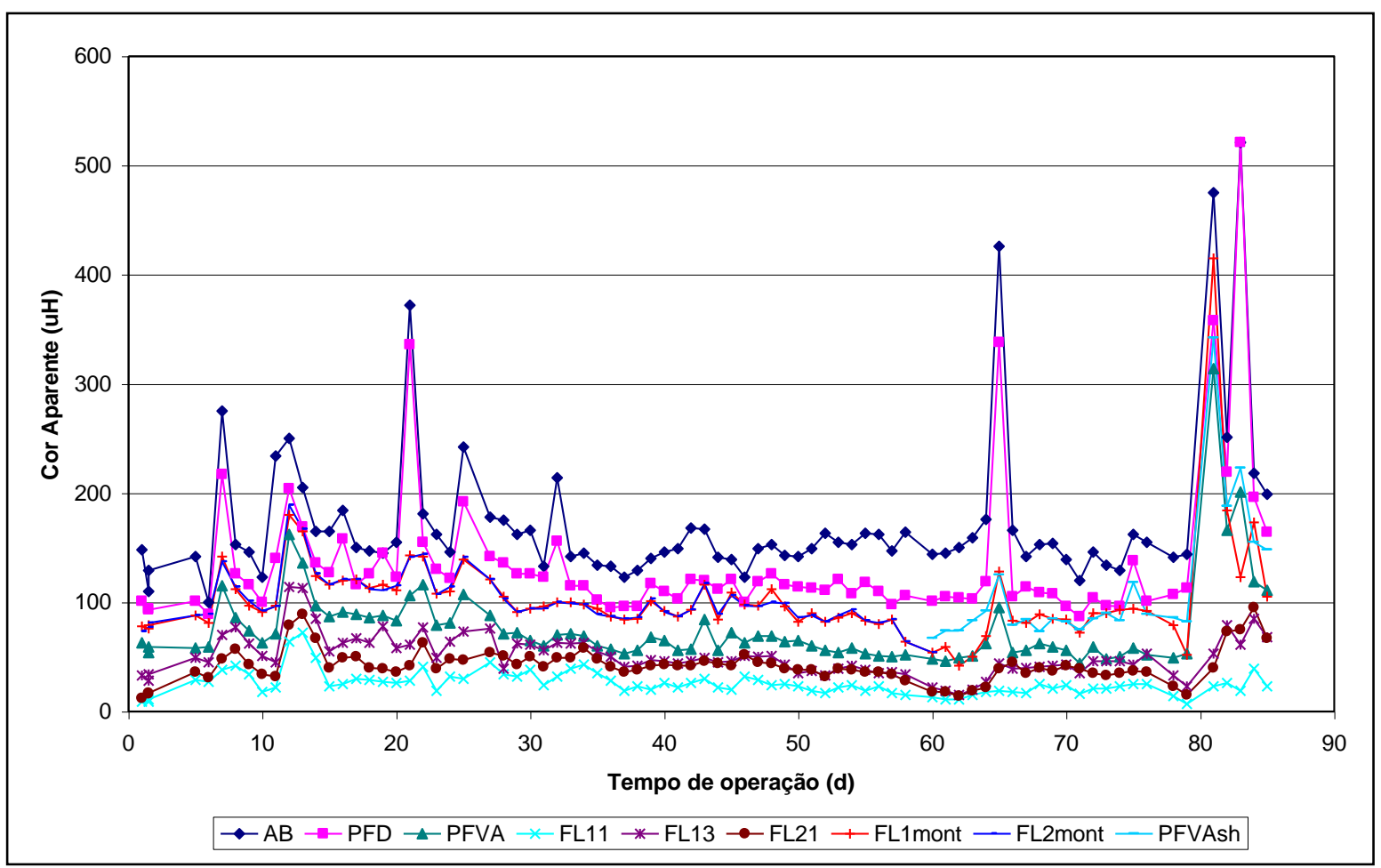

FIGURA 52- Variações de cor aparente em função do tempo de operação para água bruta e unidades da FiME na carreira 3

Fonte: TABELA F.3

\subsubsection{Cor verdadeira e absorvância}

No que diz respeito a cor verdadeira, a introdução da solução de substância húmica, causou um aumento médio de 44,53 \% no efluente do PFVA, o que resultou numa água com cor verdadeira média de 65 uH. ODEGAARD (1996) estudando um processo de ozonização/biofiltração para remoção de substâncias húmicas, utilizou em seus experimentos um concentrado húmico natural, regenerado de uma instalação de troca iônica, que resultou na água de estudo cor verdadeira típica de $50 \mathrm{uH}$. O aumento da cor verdadeira na água efluente do PFVA, decorrente da introdução de substâncias húmicas, pode ser visto na figura 53. 


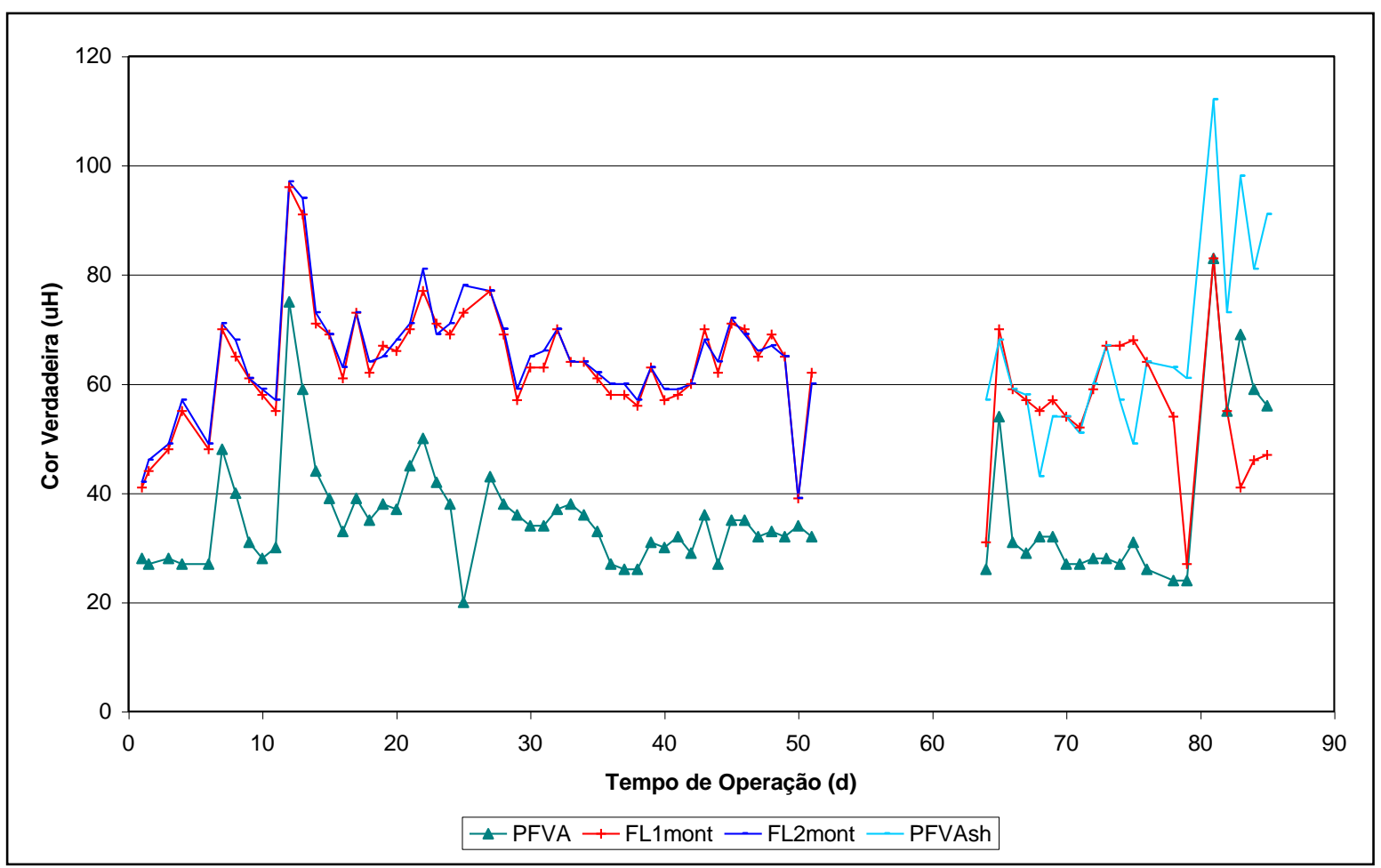

FIGURA 53 - Valores de cor verdadeira no efluente do PFVA em função do tempo de operação na carreira 3

\section{Fonte: TABELA F.4}

Estatisticamente o filtro lento 1( incluindo-se nos cálculos os dados dos dias onde houve dosagem de ozônio) foi melhor na remoção de cor que o filtro lento 2 e a seção FL13, evidenciando a superioridade do carvão ativado granular inserido como leito "sanduíche" no processo de filtração lenta, em relação ao leito homogêneo de areia. (tabelas de C.23 a C.27 ). Tal resultado condiz com o que é apresentado pela literatura.( COLLINS et al 1996). Considerando-se todos os dados obtidos, com e sem aplicação de $\mathrm{O}_{3}$, o PFD e o PFVA apresentaram remoções médias de 14,14 \% e 28,20 \%, já o filtro lento 1, filtro lento 2 e a seção FL13 foram responsáveis por reduções médias na cor verdadeira de 70,48, 51,02 e 42,90\%. Na figura 54 pode ser visualizado a diferença entre o desempenho do filtro lento 1 , o os outros dois pontos de coleta. 


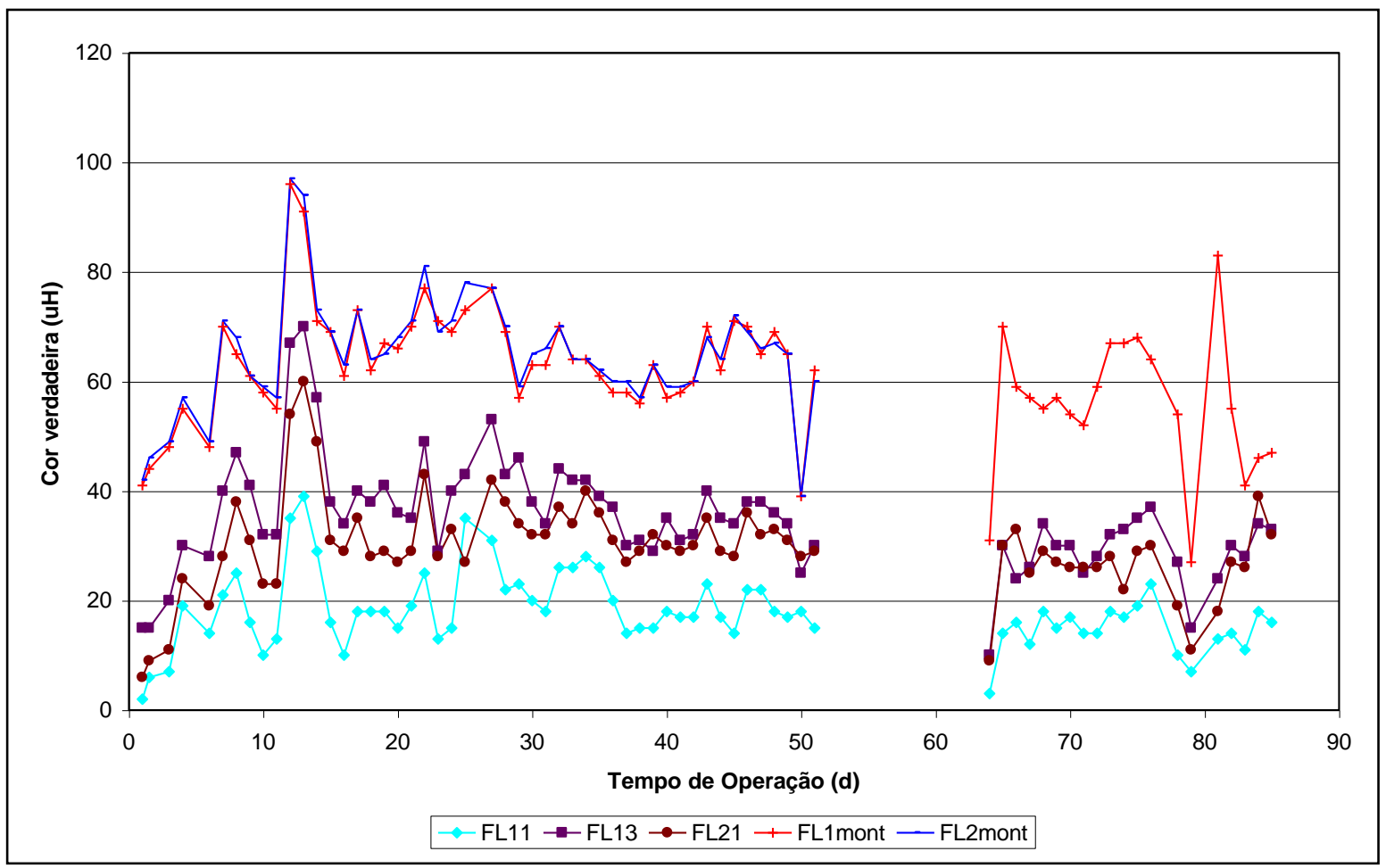

FIGURA 54 - Variações de cor verdadeira nos efluentes dos filtros lentos e seção FL13 em função do tempo de operação na carreira 3

Fonte: TABELA F.4

A aplicação de ozônio causou remoção que variou na faixa de 24,65 a 58,16 \% (média de 43,09\%), conforme tabela 41.

TABELA 41 - Remoção de cor verdadeira por aplicação de ozônio na carreira 3

\begin{tabular}{cccc}
\hline TO (d) & PFVA sh (uC) & FL11 mont(uC) & Remoção O3 (\%) \\
\hline 64 & 57 & 31 & 45,61 \\
\hline 79 & 61 & 27 & 55,73 \\
\hline 81 & 112 & 83 & 25,89 \\
\hline 82 & 73 & 55 & 24,65 \\
\hline 83 & 98 & 41 & 58,16 \\
\hline 84 & 81 & 46 & 43,21 \\
\hline 85 & 91 & 47 & 48,35 \\
\hline
\end{tabular}


Pode-se observar (tabela 42) pequenas diferenças de remoção para os filtros lentos e seção FL13, quando se compara os valores máximos, médios e mínimos, dos dados de remoção obtidos com e sem aplicação de ozônio. Parece que a dosagem de ozônio incrementou sensivelmente a remoção.

TABELA 42 - Dados de remoção mínima, média e máxima de cor verdadeira nos pontos FL11, FL13 e FL21, com e sem aplicação de ozônio.

\begin{tabular}{ccccccc}
\hline Pontos & $\begin{array}{c}\text { Remoção mínima } \\
(\mathbf{\%})\end{array}$ & $\begin{array}{c}\text { Remoção média } \\
(\mathbf{\%})\end{array}$ & $\begin{array}{c}\text { Remoção máxima } \\
(\mathbf{\%})\end{array}$ \\
\hline & & $\mathbf{O}_{3}$ & \multicolumn{3}{c}{$\mathbf{O}_{\mathbf{3}}$} \\
\hline FL11 & 52,05 & 60,9 & 70,22 & 74,75 & 83,61 & $\mathbf{O}_{\mathbf{3}}$ \\
\hline FL13 & 19,30 & 26,08 & 42,79 & 45,18 & 59,32 & 71,08 \\
\hline FL21 & 28,21 & 15,21 & 51,10 & 49,02 & 67,16 & 78,31 \\
\hline
\end{tabular}

É importante salientar que do $52^{\circ}$ ao $64^{\circ}$ dia de operação, não foi possível a determinação do parâmetro em questão, por falhas na centrífuga de bancada, por este motivo deixou-se de obter dados de cor em três dos onze dias onde houve uso do ozônio.

Na tabela 43 é apresentado um resumo dos dados de cor verdadeira da carreira 3, sendo que todos podem ser observados na tabela F.4 e na figura 55.

TABELA 43 - Resumo dos valores de cor verdadeira em uH da carreira 3

\begin{tabular}{cccccccccc}
\hline Valores & AB & PFD & PFVA & FL11 & FL13 & FL21 & $\begin{array}{c}\text { FL11 } \\
\text { Mont }\end{array}$ & $\begin{array}{c}\text { FL21 } \\
\text { Mont }\end{array}$ & $\begin{array}{c}\text { PFVA } \\
\text { sh }\end{array}$ \\
\hline Mínimo & 34 & 32 & 20 & 3 & 10 & 9 & 27 & 39 & 43 \\
\hline Médio & 59 & 51 & 37 & 18 & 36 & 31 & 62 & 66 & 66 \\
\hline Máximo & 118 & 96 & 83 & 39 & 70 & 60 & 96 & 97 & 112 \\
\hline
\end{tabular}




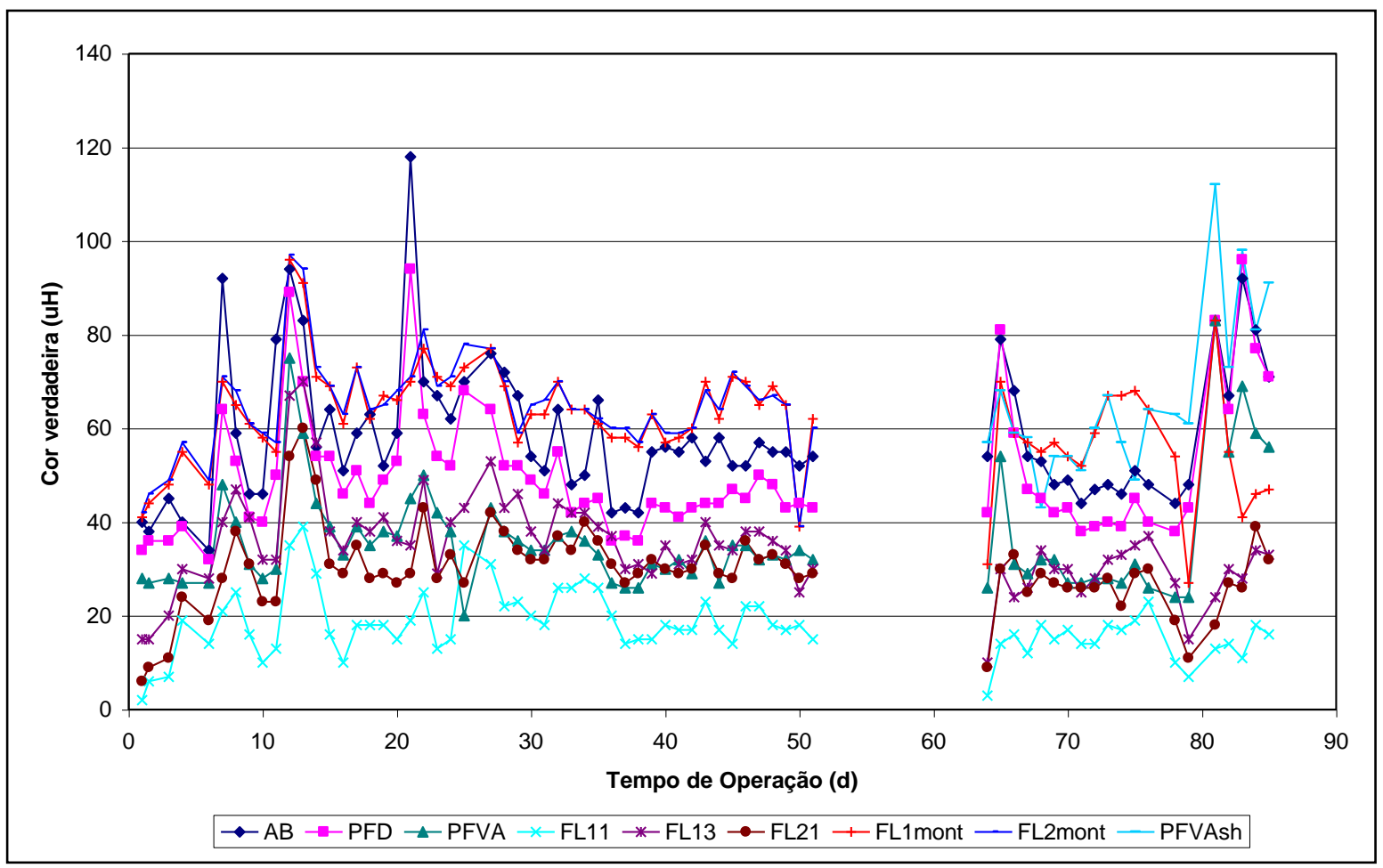

FIGURA 55 - Variações de cor verdadeira em função do tempo de operação para água bruta e unidades da FiME na carreira 3

Fonte: TABELA F.4

Os resultados estatísticos mostraram que não houve diferença significativa entre os filtros lentos e que ambos foram melhores que a seção FL13 na redução de absorvância - 254 ๆm.(tabelas C.28 a C.33) Alguns resultados de redução, encontrados para PFD, PFVA e FL13 tiveram sinal negativo, o que sugere erros experimentais. Tais dados foram excluídos dos cálculos das médias.

Levando-se em conta, também, os dias onde houve injeção de ozônio, de um modo geral o PFD proporcionou remoção média de 3,53 \%, o PFVA de 13,11 \%, o filtro lento 1 de 74,39 \%, o ponto FL13 de 32,87 \% e o filtro lento 2 de 73,9 \%. BAUER et al (1996) citam redução de $50 \%$ na absorvância $-254 \mathrm{~nm}$, em filtro lento com carvão ativado sem aplicação de $\mathrm{O}_{3}$

Em apenas três oportunidades determinou-se a absorvância de amostras ozonizadas, e os resultados encontrados demostram redução média de 27,2 \%.(tabela 44). 


\section{TABELA 44- Redução de absorvância pela aplicação de ozônio na} carreira 3

\begin{tabular}{cccc}
\hline TO & PFVAsh (uC) & FL11 mont (uC) & Remoção \% \\
\hline 61 & 0,104 & 0,078 & 25 \\
\hline 64 & 0,112 & 0,084 & 25 \\
\hline 82 & 0,174 & 0,119 & 31,6092 \\
\hline
\end{tabular}

Na tabela F.5, onde estão apresentados os dados de absorvância conseqüentes da carreira 3, nota-se, no $36^{\circ}$ dia de operação, a presença de dois dados suspeitos iguais a 0,79 e $0,73 \mathrm{~cm}^{-1}$, respectivamente na água bruta e no efluente do PFD. Esses dados foram excluídos dos cálculos estatísticos e da confecção gráfica apresentada na figura 56 , pois os mesmos devem ser resultados de erros de leitura no equipamento.

Foram obtidos altos coeficientes de correlação linear positiva entre os dados de cor verdadeira e absorvância, reforçando o que diz a literatura sobre a importância de tais parâmetros como indicativos do conteúdo de material orgânico. Pelas figuras de D.1 a D.8, verifica-se que o aumento de cor verdadeira representou aumentou da absorvância. Os coeficientes de correlação constam na tabela 45.

TABELA 45 - Coeficientes de correlação entre cor verdadeira e absorvância carreira 3

\begin{tabular}{cccccccc}
\hline AB & PFD & PFVA & FL11 & FL13 & FL21 & FL11mont & PFVA sh \\
\hline 0,81 & 0,87 & 0,91 & 0,83 & 0,80 & 0,81 & 0,81 & 0,77 \\
\hline
\end{tabular}




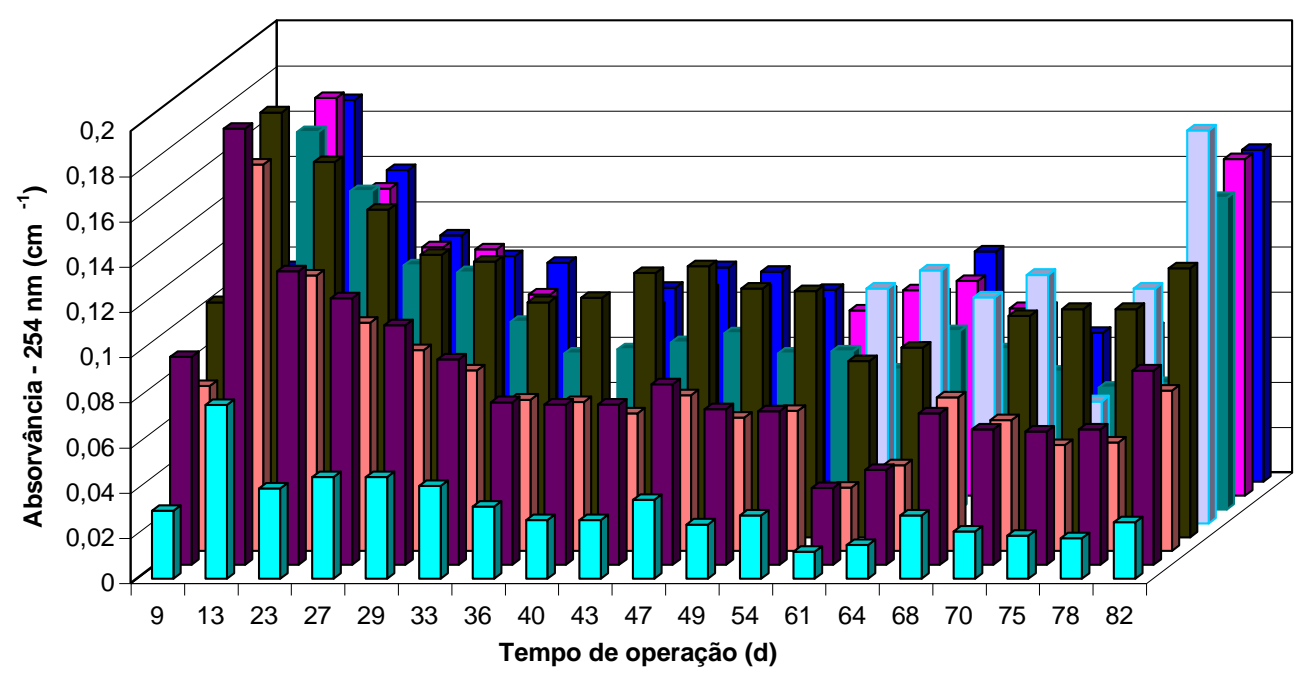

口FL11 घFL13 $\square \mathrm{FL} 21 \square \mathrm{FL} 11$ mont $\square \mathrm{PFVA}$ sh $\square \mathrm{PFVA} \square \mathrm{PFD} \square \mathrm{AB}$

FIGURA 56 - Variações de absorvância para água bruta e unidades de filtração na carreira 3

Fonte: TABELA F.5

\subsubsection{Carbono orgânico dissolvido - COD}

Resultados de remoção com sinal negativo foram encontrados para PFD, PFVA, FL13 e FL21, o que provavelmente ocorreu por erros nos procedimentos experimentais ou contaminação externa. Excluindo -se tais dados do cálculos, verifica-se que o PFD apresentou remoção média de $15,84 \%$ e o PFVA de 28,82 \%. Pelo método Anova, foram identificadas diferenças significativas de remoção de carbono orgânico dissolvido $(p<0,05)$ entre os pontos FL11, FL13 e FL21. (tabela C.35). Tal é resultado é confirmado pela aplicação do teste-t : duas amostras para médias presumindo variâncias equivalentes, onde se verificou que o filtro lento 1, foi melhor que o filtro lento 2 (tabela C.37) e seção FL13 (tabela C.38) e que não houve diferença estatística entre os desempenhos de FL13 e FL21. (tabela C.39) 
BAUER et al (1996) encontraram remoção de carbono orgânico total, em filtro lento com carvão ativado virgem como leito sanduíche, inicialmente na faixa de $90 \%$, declinando gradualmente ao longo do tempo e estabilizando na faixa de $30-40 \%$. Enquanto isso o filtro lento de controle, sem carvão ativado, operado pelos autores em paralelo nas mesmas condições removeu de 15 a $20 \%$ de COT. Remoções de carbono orgânico dissolvido e absorvância da ordem de $70 \pm 15 \%$, são reportadas por COLLINS et al (1996), em filtro lento piloto com carvão ativado sem pré-ozonização.

O filtro lento 1 acarretou remoção média de 62,15 \% de COT, enquanto o filtro lento 2, sem carvão ativado, removeu 25,07 \% e o ponto FL13, no filtro lento 1 antes da camada de carvão ativado, removeu 23,08 \%, sendo mais uma vez aqui confirmada a eficiência do sistema carvão ativado sanduíche na remoção de conteúdo orgânico e a relativa ineficiência da filtração lenta em areia para remoção de COD.

GRAHAM (1999) afirma que em contraste com o que ocorre para cor, o COD não é substancialmente removido por ozônio diretamente, entretanto com a combinação de $\mathrm{O}_{3}$ e filtração lenta em areia, valores de redução total acima de 50 \% são reportados. Em apenas três ocasiões $\left(61^{\circ}, 64^{\circ}\right.$ e $82^{\circ}$ dias de operação) foi determinado COD de amostras ozonizadas. Particularmente no dia $82^{\circ}$ dia de operação, verificou-se que a aplicação de ozônio promoveu remoção de 3,37 \% de COD, haja vista que o valor determinado para a amostra do PFVA sh (antes da coluna de ozonização) foi de 4, 44 mgCOD/L e para amostra do FL11 mont (após a coluna de ozonização) foi de de 4,29 mgCOD/L. Todavia quando se avalia os resultados obtidos nos efluentes do FL11, FL13 e FL21, verifica-se remoções totais de $88,7 \%, 39 \%$ e 46,1 \% respectivamente, pois as análises revelaram valores de COD nesses pontos iguais a 0,5, 2,7 e 2,4 mg/L, fato que condiz com o que é reportado pelo último autor supracitado.

Com exceção filtro lento 1 e do ponto FL11 mont, os demais pontos de coleta mostraram fortes correlações positivas entre COD e absorvância (figuras de D.9 a D.15), conforme tabela 46. 
TABELA 46 - Coeficientes de correlação entre carbono orgânico dissolvido e absorvância 254 ๆm carreira 3

\begin{tabular}{ccccccc}
\hline AB & PFD & PFVA & FL11 & FL13 & FL21 & FL11 mont \\
\hline 0,82 & 0,82 & 0,70 & 0,43 & 0,77 & 0,79 & 0,36 \\
\hline
\end{tabular}

Um resumo dos dados de COD é mostrado na tabela 47. Todos os resultados das determinações do parâmetro em tela da carreira 3 podem ser vistos na tabela F.6, e figura 57.

TABELA 47 - Resumo dos valores médios de carbono orgânico total em mg/L carreira 3

\begin{tabular}{lcccccccc}
\hline Valores & AB & PFD & PFVA & FL11 & FL13 & FL21 & FL11 mont & PFVA sh \\
\hline Máximo & 5,03 & 5,03 & 4,63 & 1,67 & 3,60 & 4,65 & 4,30 & 4,44 \\
\hline Médio & 2,37 & 2,28 & 2,17 & 0,93 & 2,09 & 2,12 & 2,25 & 3,26 \\
\hline Mínimo & 1,05 & 0,00 & 0,00 & 0,00 & 0,81 & 0,00 & 0,00 & 2,08 \\
\hline
\end{tabular}




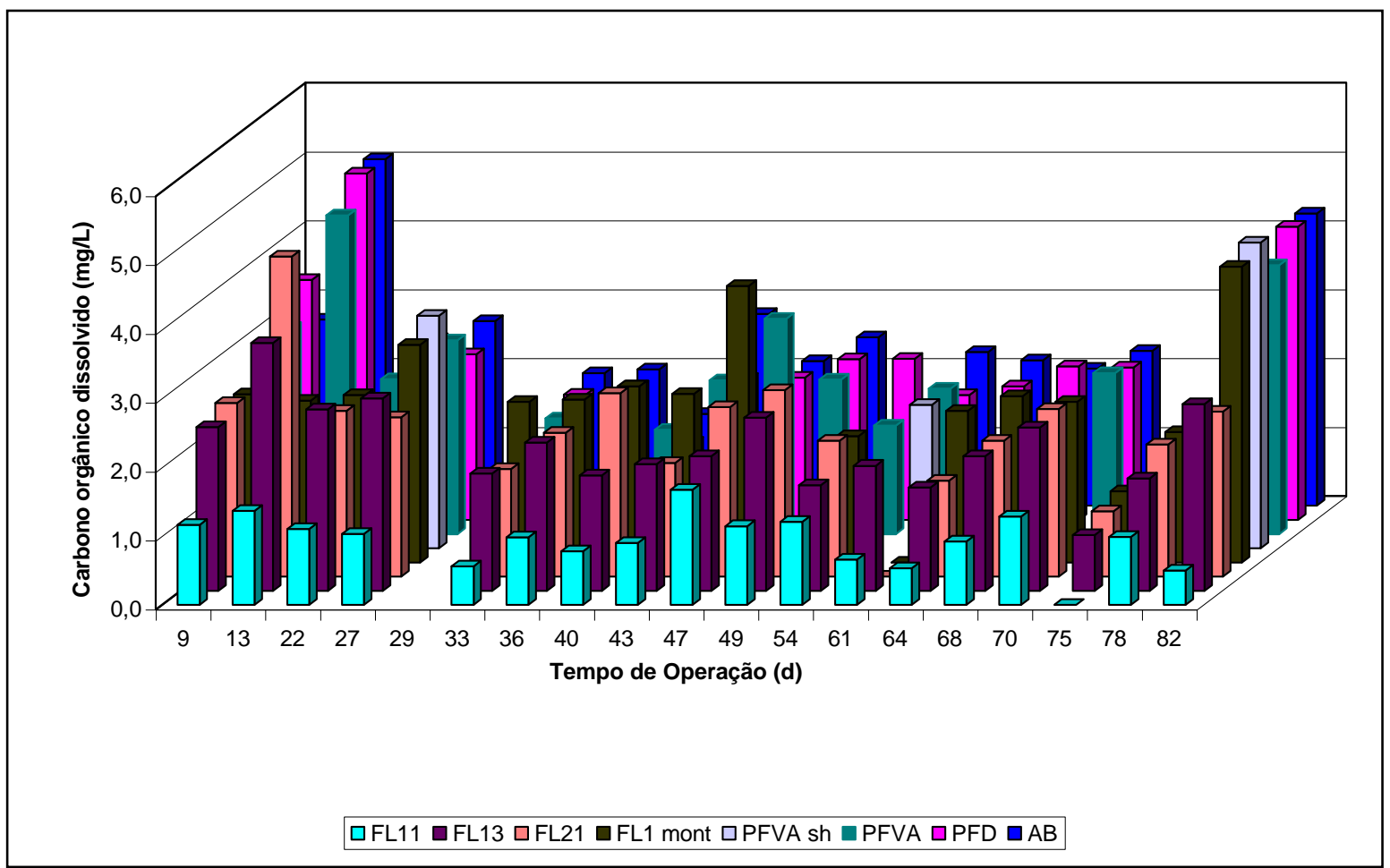

FIGURA 57 - Variações de carbono orgânico dissolvido em função do tempo de operação para água bruta e unidades da FiME carreira 3

\section{Fonte: TABELA F.6}

\subsubsection{Oxigênio consumido - OC e Oxigênio dissolvido - OD}

No caso de remoção de oxigênio consumido - OC, o filtro lento 1 foi significativamente melhor que o filtro lento 2 e a seção FL13, conforme é mostrado pelas tabelas de C.41 a C.44. O PFD e o PFVA acarretaram remoções médias de 25,5 e 23,51\%, respectivamente. O FL11, FL13 e FL21 removeram em média 80,27, 41,05 e 44,9\%.(tabela C.40)

Resultados muito interessantes foram encontrados quando se correlacionaram os dados de oxigênio consumido e absorvância, haja vista que conforme tabela 48 e figuras de D.16 a D.23, com exceção do ponto FL11 mont, os demais dados dos pontos apresentaram forte correlação linear positiva. É importante ressaltar que os coeficientes de correlação determinados para água bruta e efluentes do PFD e PFVA, foram valores 
muito próximos de 1 , sendo portanto mais forte ainda a correlação entre os referidos parâmetros (figuras D.16, D.17 e D.18).

TABELA 48 - Coeficientes de correlação entre oxigênio consumido e absorvância 254 ๆm carreira 3.

\begin{tabular}{cccccccc}
\hline AB & PFD & PFVA & FL11 & FL13 & FL21 & FL11 mont & PFVA sh \\
\hline 0,93 & 0,95 & 0,95 & 0,84 & 0,76 & 0,79 & 0,58 & 0,94 \\
\hline
\end{tabular}

Também encontrou-se fortes correlações entre OC e COD, como aprecia-se na tabela 49 e nas figuras de D.24 a D.30, menos para o FL11. Os dados de OC podem ser apreciados na tabela F.7 e na figura 58.

TABELA 49 - Coeficientes de correlação entre oxigênio consumido e carbono orgânico dissolvido carreira 3 .

\begin{tabular}{ccccccc}
\hline AB & PFD & PFVA & FL11 & FL13 & FL21 & FL11 mont \\
\hline 0,86 & 0,83 & 0,72 & 0,43 & 0,67 & 0,62 & 0,71 \\
\hline
\end{tabular}




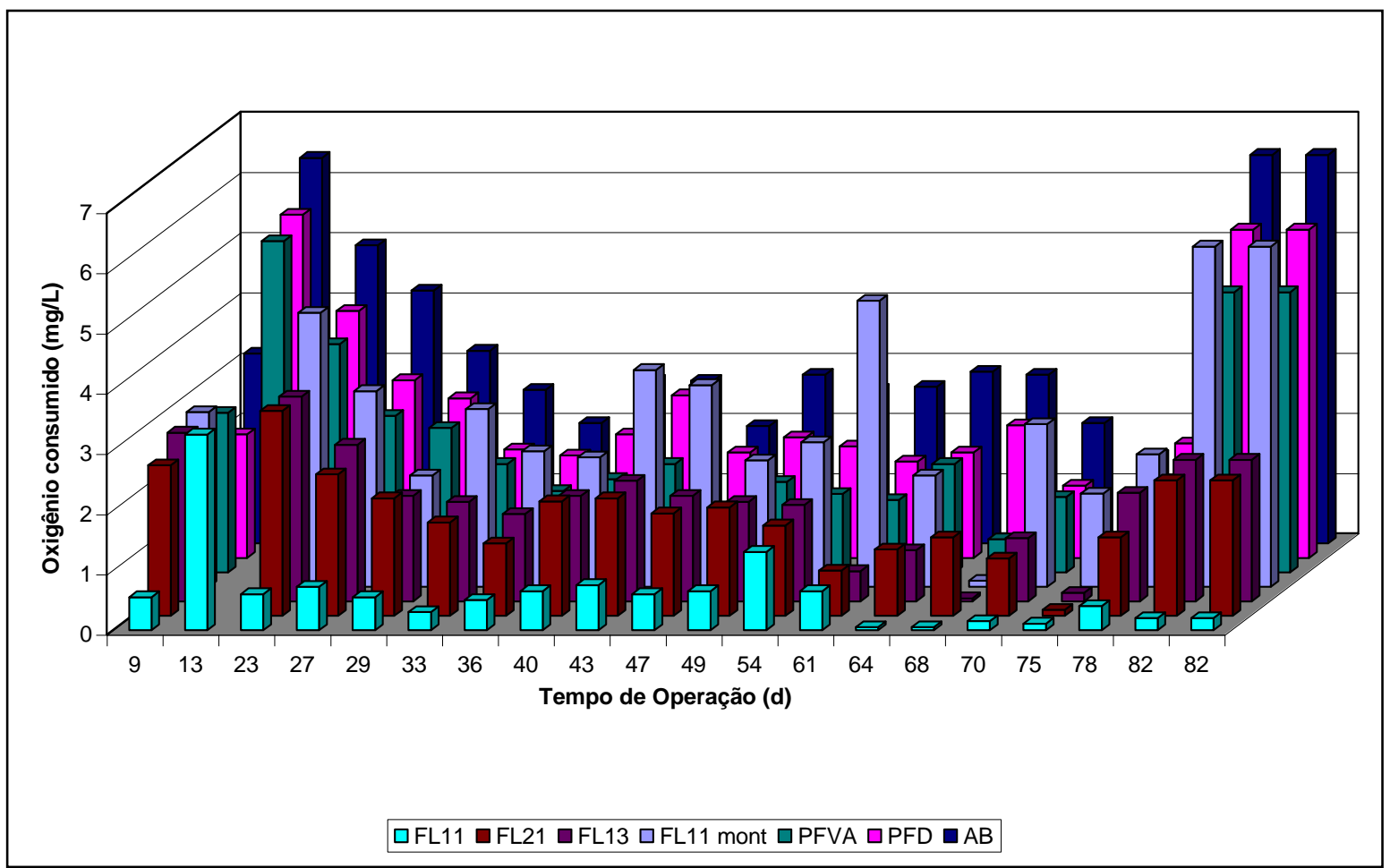

FIGURA 58 - Variações na concentração de oxigênio consumido em função do tempo de operação para água bruta e unidades da FiME carreira 3

\section{Fonte: TABELA F.7}

Semelhante o que ocorreu na carreira 1, o filtro lento 1 causou redução expressiva na concentração de oxigênio dissolvido presente na água, o que pode ser atribuído a alguma reação química com o carvão ativado granular. Tal fenômeno não foi identificado no estudo realizado por VERAS (1999), entretanto é importante frisar que a autora usou carvão ativado com características diferentes. A redução de OD ocorreu até o final da carreira de filtração, o que permite concluir que até o referido momento não havia terminado a capacidade do CAG de adsorver impurezas. $\mathrm{O}$ filtro lento 1 ocasionou remoção média de OD igual 64,22 \%. Os efluentes da seção FL13 e do filtro lento 2, apresentaram remoção média de 11,89 e 6,28 \% respectivamente, provavelmente em decorrência da atividade biológica do meio aeróbio nos filtros.(tabela C.46) Na tabela 50 e na figura 59, pode-se verificar que o PFD e o PFVA não causaram alteração significativa da quantidade de OD na água. 
TABELA 50 - Resultados de oxigênio dissolvido em mg/L para água bruta e unidades da FiME na carreira 3

\begin{tabular}{ccccccc}
\hline TO* & AB & PFD & PFVA & FL11 & FL13 & FL21 \\
\hline 9 & 8,2 & 8 & 8 & 8 & 7,5 & 7,7 \\
\hline 23 & 7,6 & 7,3 & 7,6 & 2,7 & 6,2 & 6,9 \\
\hline 27 & 7,7 & 7,4 & 7,4 & 2,7 & 6,6 & 6,9 \\
\hline 33 & 7,7 & 7,6 & 7,6 & 3,1 & 7 & 7,3 \\
\hline 40 & 7,9 & 7,2 & 7,5 & 2,3 & 6,9 & 7,3 \\
\hline 49 & 6,3 & 6,1 & 6,3 & 2,5 & 5,7 & 5,9 \\
\hline 54 & 7,1 & 7,6 & 7,5 & 2,1 & 6,5 & 7 \\
\hline 61 & 7,3 & 7 & 6,9 & 0,2 & 7,3 & 7,2 \\
\hline 68 & 7,6 & 7,3 & 7,4 & 1 & 6,8 & 7,2 \\
\hline 75 & 7,2 & 6,9 & 6,9 & 1,2 & 5,2 & 5,9 \\
\hline 82 & 7,4 & 7,6 & 7,2 & 3,5 & 7,8 & 7,7 \\
\hline
\end{tabular}

*TO : Tempo de operação (d)

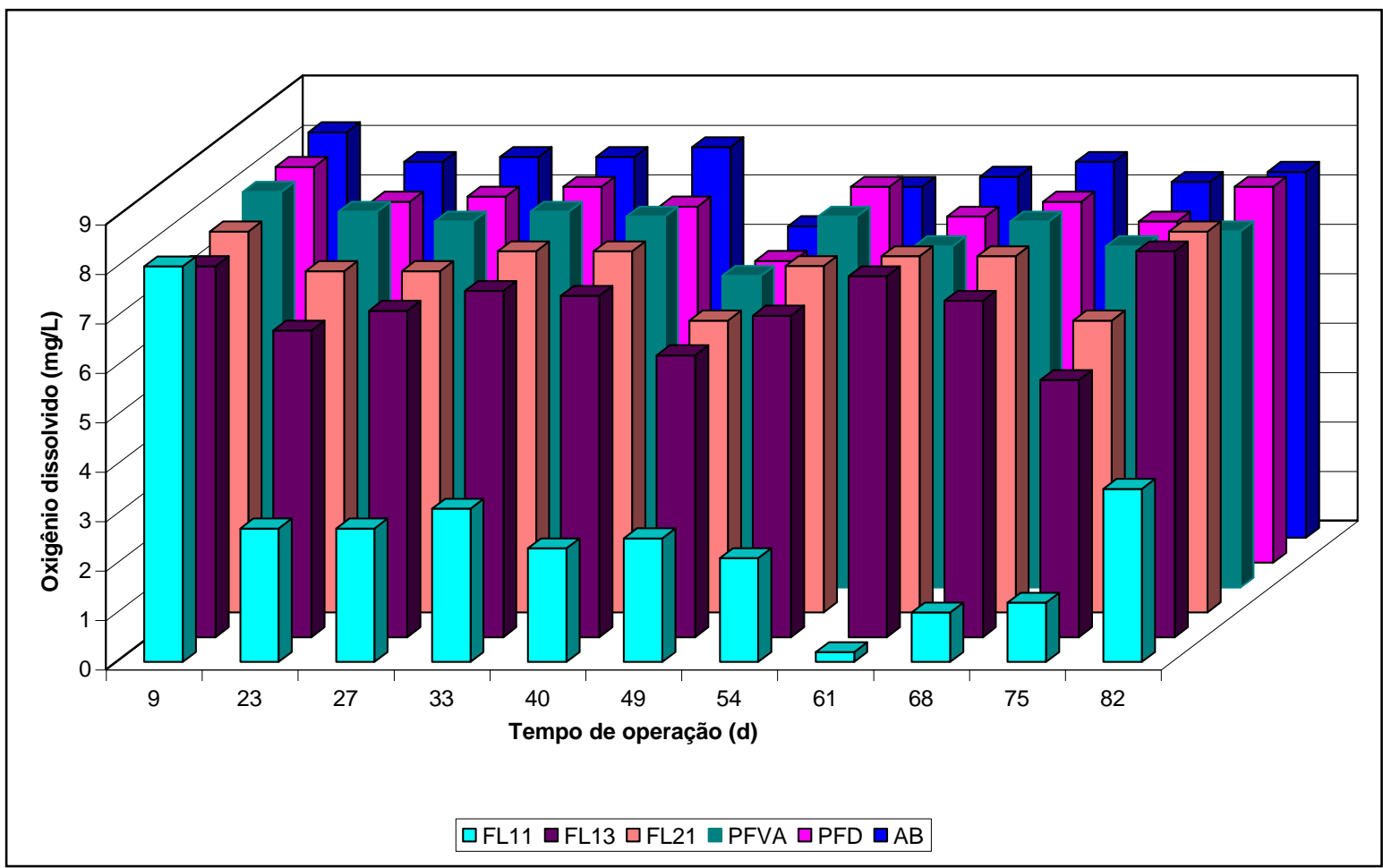

FIGURA 59 - Variações na concentração de oxigênio dissolvido em função do tempo de operação para a água bruta e unidades da FiME na carreira 3

Fonte: TABELA 50 


\subsubsection{Ferro total}

Relativo a ferro total, não foram constatadas diferenças significativas de remoção entre o filtro lento 1, filtro lento 2 e efluente da seçãoFL13.(tabela C.48). O filtro lento 1 removeu em média 74,50 \%, o filtro lento $262,9 \%$ e o efluente da seção FL13 apresentou remoção média de $57 \%$. Remoções médias iguais a 28,56 e 50,45\% foram encontradas para PFD e PFVA. O resultados de ferro são apresentados na tabela 51 e na figura 60 .

TABELA 51 - Resultados de Ferro total em mg/L para água bruta e efluentes das unidades de filtração na carreira 3

\begin{tabular}{cccccccccc}
\hline Data & TO* & AB & PFD & PFVA & FL11 & FL13 & FL21 & $\begin{array}{c}\text { FL11 } \\
\text { mont }\end{array}$ & $\begin{array}{c}\text { PFVA } \\
\text { sh }\end{array}$ \\
\hline 31.08 & 9 & 1,23 & 1,01 & 0,56 & 0,12 & 0,21 & 0,15 & 0,4 & 0 \\
\hline 08.09 & 17 & 0 & 0 & 0 & 0 & 0 & 0 & 0 & 0 \\
\hline 14.09 & 23 & 1,53 & 1,21 & 0,84 & 2,85 & 0,64 & 0,51 & 0,64 & 0 \\
\hline 21.09 & 29 & 1,9 & 1,75 & 0,69 & 0,35 & 0,27 & 0,12 & 1,47 & 0 \\
\hline 28.09 & 36 & 1,18 & 0,74 & 0,57 & 0,19 & 0,21 & 0,21 & 1,1 & 0 \\
\hline 05.10 & 43 & 1,58 & 1,08 & 5,69 & 0,25 & 0,36 & 0,3 & 0,73 & 0 \\
\hline 19.10 & 57 & 1,04 & 0,46 & 0,36 & 0 & 0 & 2,08 & 0,11 & 0,63 \\
\hline 26.10 & 64 & 1,65 & 3,16 & 0,86 & 0,2 & 0,26 & 0,46 & 0,42 & 0,63 \\
\hline 10.11 & 80 & 1,72 & 2,18 & 0 & 0 & 0 & 0,33 & 0 & 0 \\
\hline
\end{tabular}




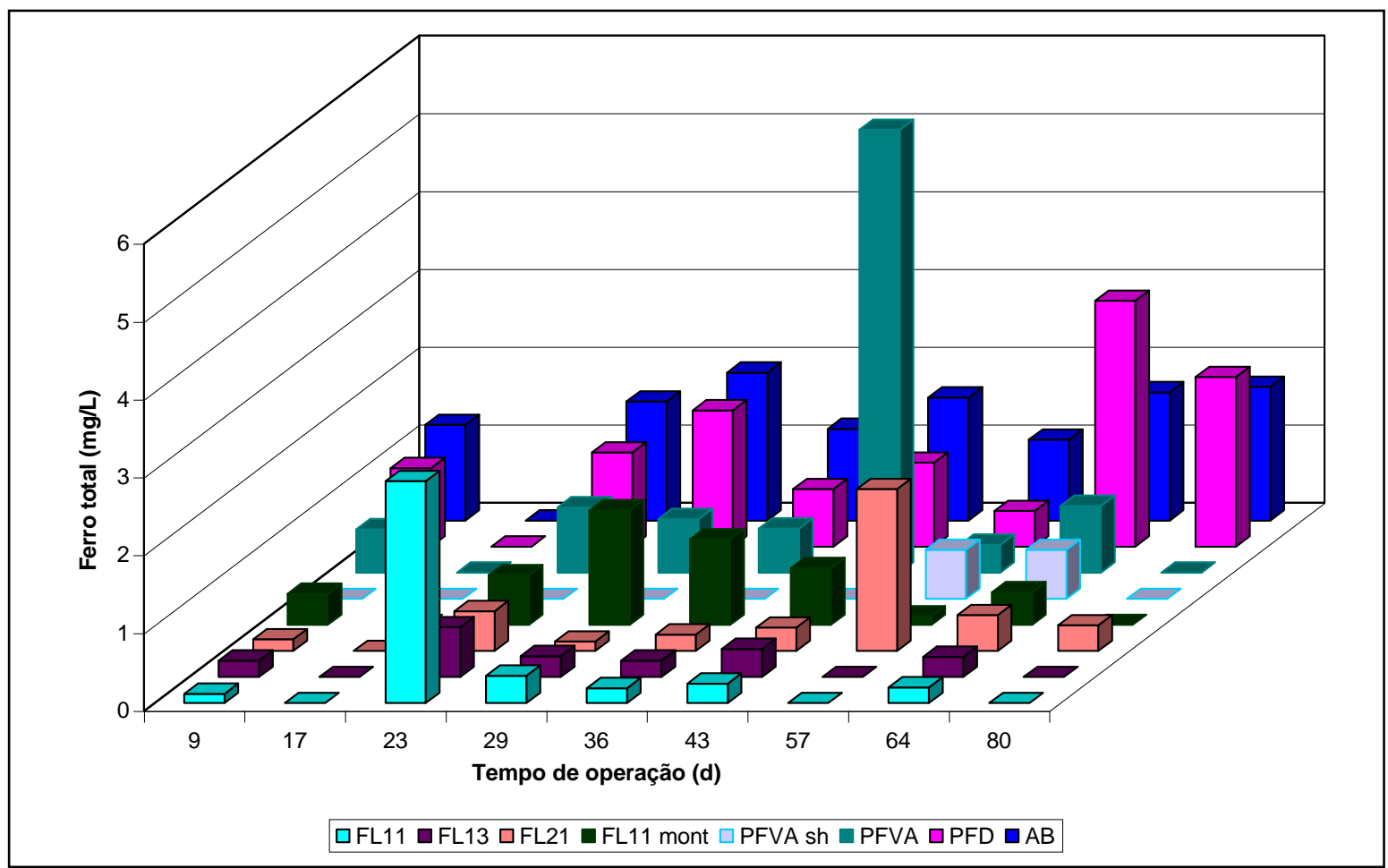

FIGURA 60 -Variações na concentração de ferro total em função do tempo de operação para água bruta e unidades da FiME na carreira 3

\section{Fonte: TABELA 51}

\subsubsection{Fosfato}

Alguns resultados de fosfato obtidos da careira 3 mostraram-se suspeitos, o que pode ter ocorrido por falhas nas determinações experimentais, talvez por isso os testes estatísticos tenham revelado que o efluente da seção FL13 foi significativamente melhor em relação a remoção de fosfato que o filtro lento 1, e que não houve diferenças nos desempenhos de remoção entre FL11 e FL21 e entre FL13 e FL21.(tabelas de C.52 a C.54). Ao contrário do que ocorreu na carreira 1, não foi observado aumento da concentração de fosfato no efluente do filtro lento 1.

Verificou-se remoção média de $35 \%$ no PFD e de 41,16 \%, no PFVA. O filtro lento 1 removeu em média $31,70 \%$, o filtro lento $259,12 \%$ e o efluente da seção FL13 apresentou remoção média de 67,22 \%. O dados de fosfato são demonstrados na tabela 52 e na figura 61. Nesta última pode-se notar que os dados parecem confusos. 
TABELA 52 - Resultados de fosfato em $\mathrm{mg} / \mathrm{L}$ para água bruta e unidades de

filtração na carreira 3

\begin{tabular}{cccccccc}
\hline *TO & AB & PFD & PFVA & FL11 & FL13 & FL21 & $\begin{array}{c}\text { FL11 } \\
\text { mont }\end{array}$ \\
\hline 9 & 0,0974 & 0,0686 & 0,0463 & 0,0574 & 0,0398 & 0,0345 & \\
\hline 13 & 0,0857 & 0,0645 & 0,0269 & 0,0504 & 0,0222 & 0,0569 & 0,0563 \\
\hline 23 & 0,1156 & 0,0857 & 0,0974 & 0,0486 & 0,0404 & 0,0551 & \\
\hline 27 & 0,0904 & 0,0686 & 0,0392 & 0,0621 & 0,0457 & 0,0345 & 0,0674 \\
\hline 33 & 0,0915 & 0,068 & 0,0398 & 0,051 & 0,0416 & 0,0363 & 0,0786 \\
\hline 40 & 0,0333 & 0,0357 & 0,0404 & 0,0475 & 0,0739 & 0,1057 & 0,0704 \\
\hline 47 & 0,0592 & 0,0345 & 0,0927 & 0,0175 & 0 & 0 & 0,0251 \\
\hline 54 & 0,1027 & 0,0516 & 0,0457 & 0,021 & 0,0028 & 0,0116 & 0,0222 \\
\hline 61 & 0,1098 & 0,0504 & 0,0316 & 0,0386 & 0,011 & 0,0216 & 0,0392 \\
\hline 68 & 0,171 & 0,0589 & 0,027 & 0,0041 & 0,0047 & 0,0476 & 0,094 \\
\hline 75 & 0,0821 & 0,0651 & 0,0286 & 0,0522 & 0,0298 & 0,028 & \\
\hline 82 & 0,1786 & 0,1374 & 0,0874 & 0,0569 & 0,0957 & 0,0522 & 0,1697 \\
\hline
\end{tabular}




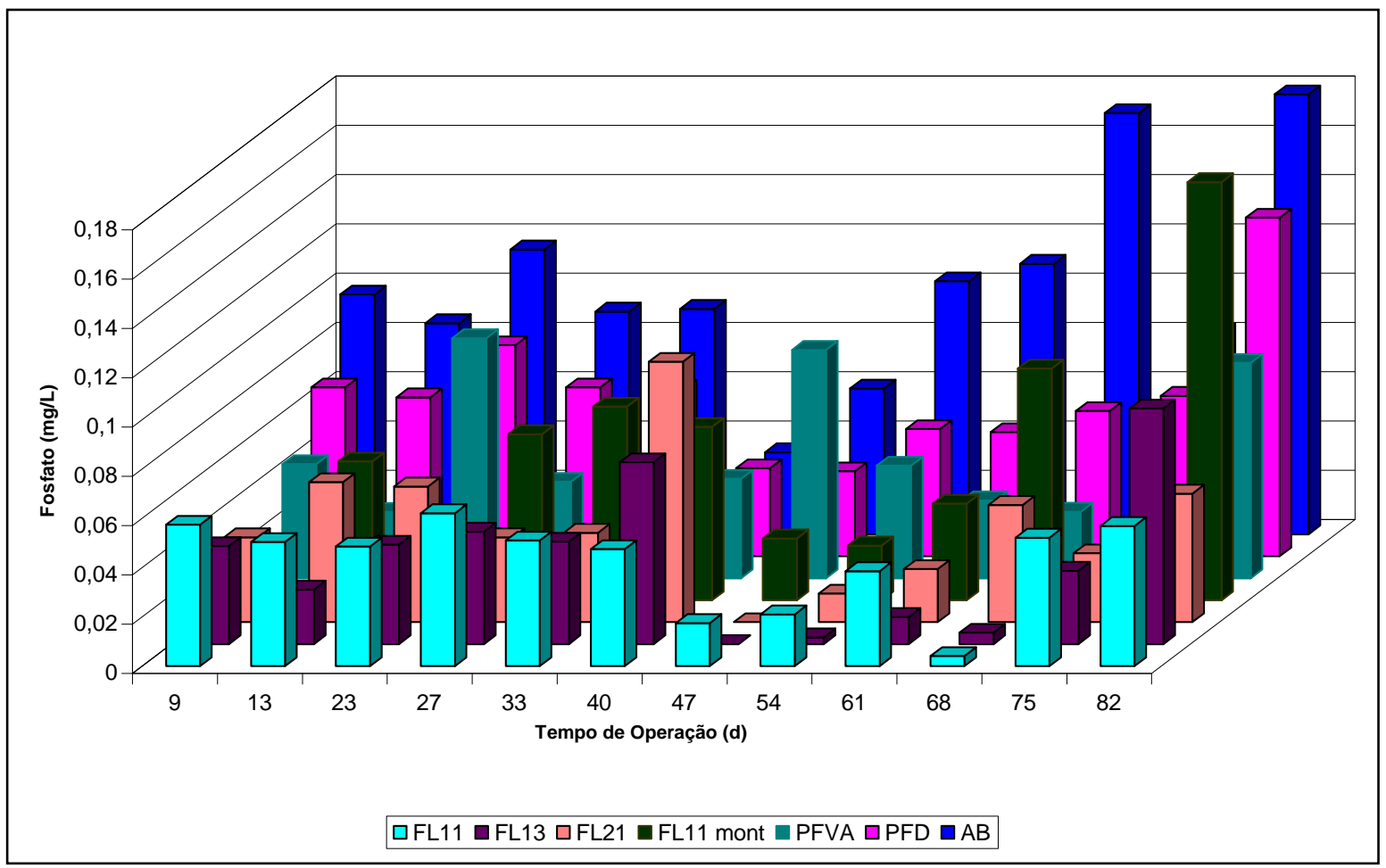

FIGURA 61 - Variações na concentração de fosfato da água bruta e das unidades da FiME na carreira 3

\section{Fonte:TABELA 52}

\subsubsection{Nitrogênio amoniacal, nitrito e nitrato}

O filtro lento 1 foi significativamente melhor na remoção de nitrogênio amoniacal que o filtro lento 2 e a seção FL13. (tabelas C.58 e C.59). Não houve diferença entre os efluentes do filtro lento 2 e da seção FL13 (tabela C.60), na remoção do parâmetro em questão. O PFD promoveu remoção média de 19,87 \% e PFVA de $32,05 \%$.

Remoções médias, iguais a 71,52, 47,89 e 44,56 \%, foram encontradas nos efluentes do filtro lento 1, seção FL13 e filtro lento 2, nesta ordem. A injeção de substâncias húmicas causou um aumento médio de $28,5 \%$ na concentração de nitrogênio amoniacal no efluente do PFVA. A tabela 53 permite a visualização dos dados oriundos da carreira 3. 
TABELA 53 - Resultados de nitrogênio amoniacal em mg/L para água bruta e unidades de filtração na carreira 3

\begin{tabular}{ccccccccc}
\hline TO & AB & PFD & PFVA & FL11 & FL13 & FL21 & $\begin{array}{c}\text { FL11 } \\
\text { mont }\end{array}$ & $\begin{array}{c}\text { PFVA } \\
\text { Sh }\end{array}$ \\
\hline 9 & 0,23 & 0,18 & 0,11 & 0,05 & 0,1 & 0,09 & - & - \\
\hline 13 & 0,33 & 0,33 & 0,22 & 0,14 & 0,22 & 0,24 & 0,34 & - \\
\hline 23 & 0,29 & 0,27 & 0,2 & 0,07 & 0,14 & 0,15 & - & - \\
\hline 27 & 0,28 & 0,23 & 0,17 & 0,08 & 0,14 & 0,13 & 0,23 & - \\
\hline 33 & 0,2 & 0,18 & 0,1 & 0,07 & 0,1 & 0,12 & 0,17 & - \\
\hline 40 & 0,24 & 0,15 & 0,11 & 0,02 & 0,08 & 0,07 & 0,16 & - \\
\hline 47 & 0,22 & 0,19 & 0,12 & 0,05 & 0,09 & 0,11 & 0,18 & - \\
\hline 54 & 0,26 & 0,19 & 0,12 & 0,06 & 0,08 & 0,1 & 0,17 & - \\
\hline 61 & 0,26 & 0,16 & 0,09 & 0,01 & 0,05 & 0,04 & 0,15 & - \\
\hline 68 & 0,26 & 0,17 & 0,12 & 0,02 & 0,09 & 0,08 & - & 0,14 \\
\hline 75 & 0,26 & 0,18 & 0,12 & 0,04 & 0,07 & 0,05 & - & 0,17 \\
\hline 82 & 0,44 & 0,44 & 0,4 & 0,31 & 0,09 & 0,19 & - & 0,42 \\
\hline
\end{tabular}

Na figura 62 os dados de nitrogênio amoniacal estão dispostos em função do tempo de operação do sistema. 


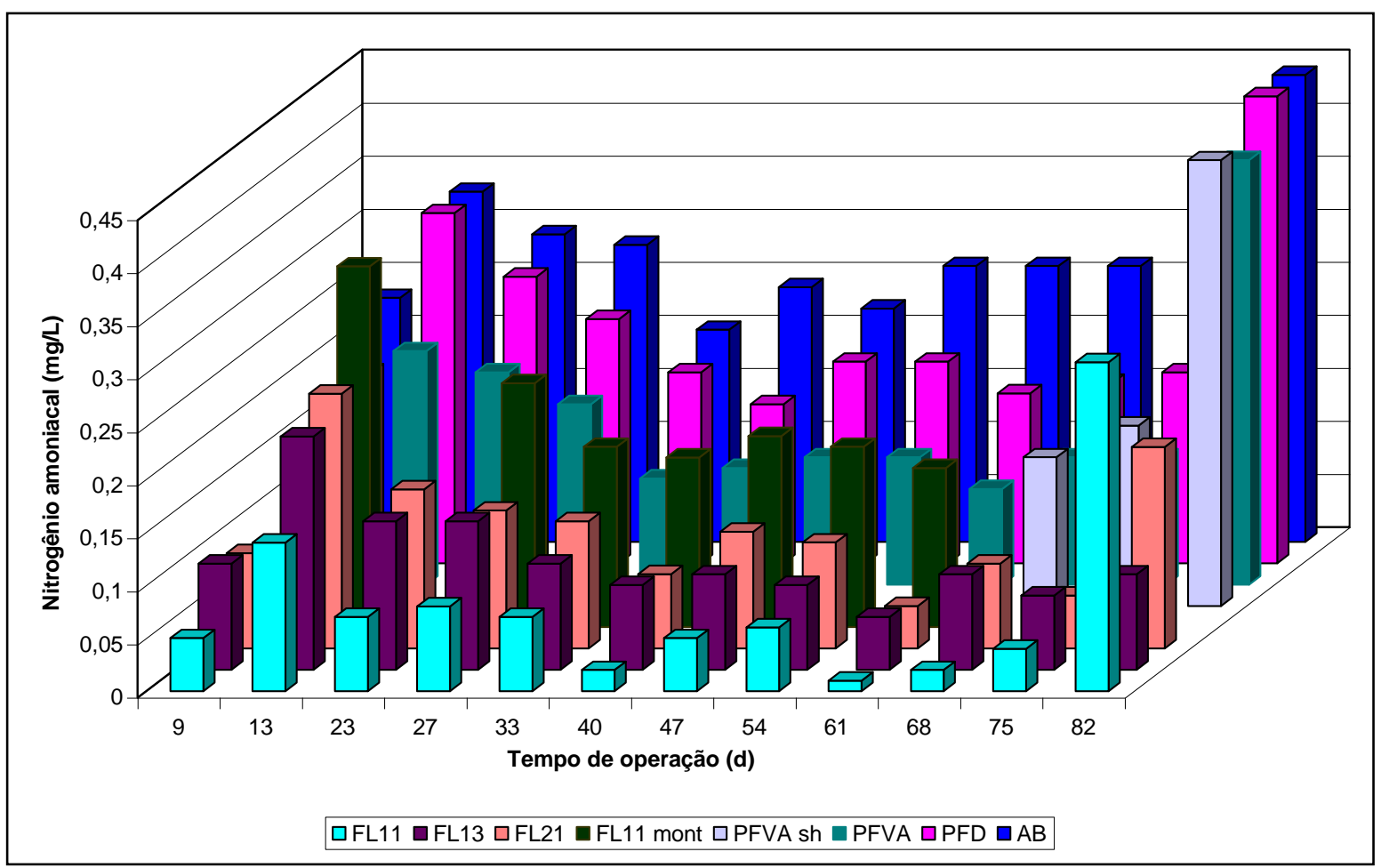

FIGURA 62 - Variações da concentração de nitrogênio amoniacal em função do tempo de operação para água bruta e unidades de filtração na carreira 3

\section{Fonte: TABELA 53}

Relativo a nitrito o PFD garantiu remoção média de 32,7 \% e o PFVA de 44,7 \%. Com base nos resultados estatísticos verificou-se que o filtro lento 2 foi significativamente melhor na remoção de nitrito que o filtro lento 1 , e que não houve diferenças entre FL13 e FL21 e FL11 e FL13 (tabela de C.62 a C.66). As remoções médias observadas no FL11, FL13 e FL21 foram de 43,45, 54,28 e 64,2 \%. A injeção da solução de substância causou um aumento médio de 40,49 \% na concentração de nitrito na água efluente do PFVA.

Pode observar os dados de nitrito na tabela 54 na figura 63. 
TABELA 54 - Resultados de nitrito em mg/l carreira 3

\begin{tabular}{ccccccccc}
\hline TO & AB & PFD & PFVA & FL11 & FL13 & FL21 & $\begin{array}{c}\text { FL1 } \\
\text { mont }\end{array}$ & $\begin{array}{c}\text { PFVA } \\
\text { sh }\end{array}$ \\
\hline 9 & - & - & 0,0052 & 0,0006 & 0,0016 & 0,0008 & - & - \\
\hline 13 & 0,0118 & 0,0082 & 0,0052 & 0,0022 & 0,0042 & 0,003 & 0,0073 & - \\
\hline 23 & 0,0109 & 0,0088 & 0,0052 & 0,0026 & 0,0034 & 0,02 & - & - \\
\hline 27 & 0,0086 & 0,0071 & 0,0037 & 0,024 & 0,0032 & 0,002 & 0,0056 & - \\
\hline 33 & 0,0077 & 0,0056 & 0,0029 & 0,002 & 0,0022 & 0,0016 & 0,0051 & - \\
\hline 40 & 0,077 & 0,0062 & 0,004 & 0,0018 & 0,022 & 0,018 & 0,0051 & - \\
\hline 47 & 0,072 & 0,059 & 0,026 & 0,022 & 0,022 & 0,026 & 0,045 & - \\
\hline 54 & 0,0101 & 0,0068 & 0,0032 & 0,0039 & 0,0021 & 0,0023 & 0,0057 & - \\
\hline 61 & 0,0102 & 0,0063 & 0,0026 & 0,003 & 0,0016 & 0,0012 & 0,004 & - \\
\hline 68 & 0,0133 & 0,0107 & 0,0048 & 0,0041 & 0,003 & 0,0016 & 0,0074 & - \\
\hline 75 & - & 0,0068 & 0,0038 & 0,006 & 0,0025 & 0,0017 & 0,006 & 0,0021 \\
\hline 82 & 0,0094 & 0,0112 & 0,0094 & 0,0018 & 0,0045 & 0,0039 & - & 0,049 \\
\hline
\end{tabular}

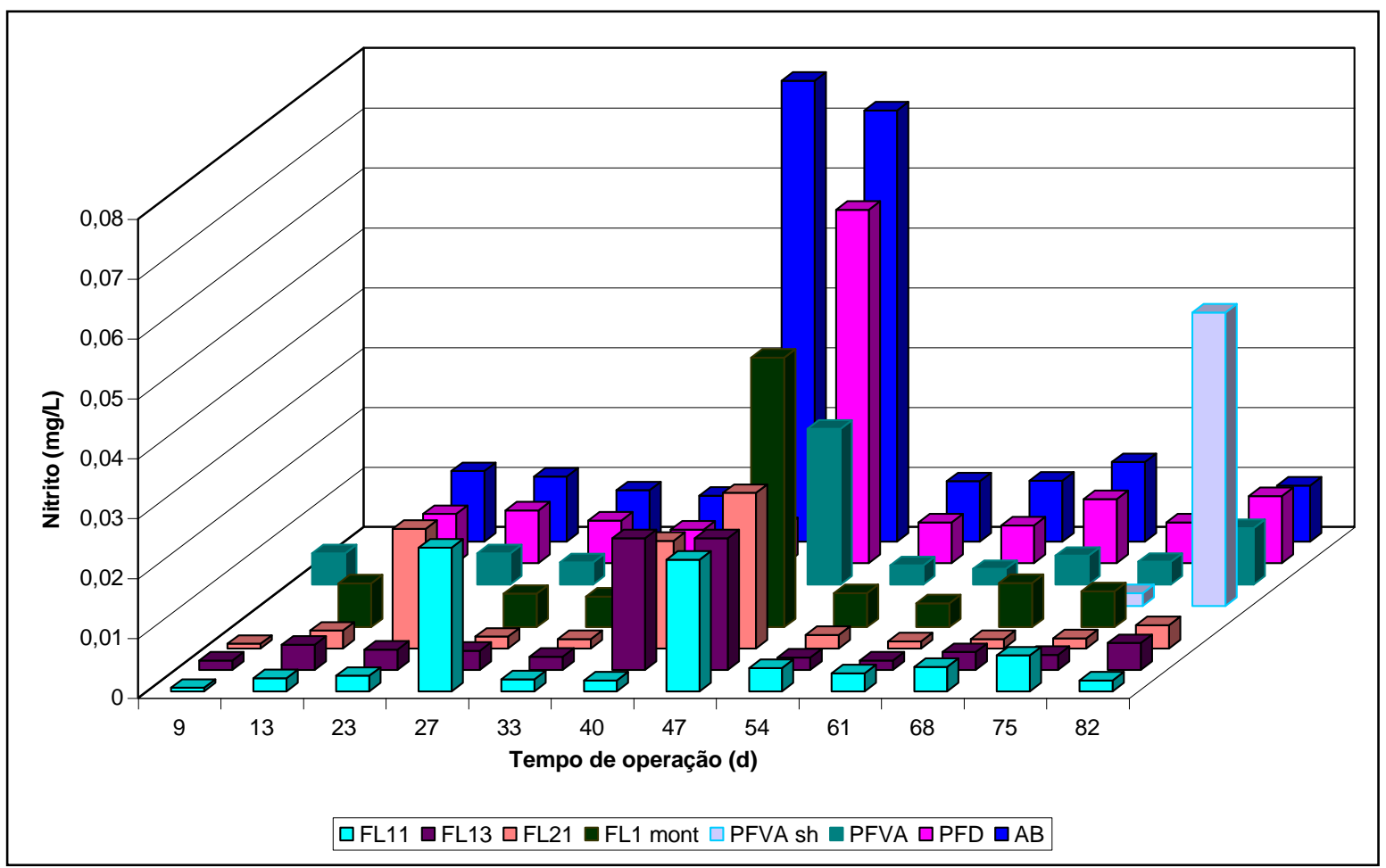

FIGURA 63 -Variações na concentração de nitrito para água bruta e unidades de filtração na carreira 3

Fonte: TABELA 54 
A respeito da remoção de nitrato, mas uma vez o filtro lento 1 foi estatisticamente melhor que o filtro lento 2 e o ponto FL 13, como pode-se apreciar nas tabelas de C.67 a C.72. Não foi encontrada diferença significativa de remoção entre FL13 e FL21. As remoções médias de nitrato encontradas para FL11, FL13 e FL21, foram de 42,45, 23,95 e 24,19\%. Para o PFD, os dados obtidos revelaram aumento da concentração de nitrato, entretanto tal fato deve ter ocorrido por erros experimentais. No PFVA verificou-se remoção média de $8,17 \%$

Os dados de nitrato resultantes da carreira 3, são mostrados na tabela 55. A dosagem da solução de substância húmica, resultou em um aumento médio de 17,66 \% na concentração de nitrato. Na figura 64 podem ser observados os dados de nitrato em função do tempo.

TABELA 55 - Resultados de nitrato em mg/L para água bruta e unidades da FiME na carreira 3

\begin{tabular}{ccccccccc}
\hline TO & AB & PFD & PFVA & FL11 & FL13 & FL21 & $\begin{array}{c}\text { FL11 } \\
\text { mont }\end{array}$ & $\begin{array}{c}\text { PFVA } \\
\text { sh }\end{array}$ \\
\hline 9 & 0,7307 & 0,7587 & 0,7026 & 0,5351 & 0,7302 & 0,6473 & & \\
\hline 13 & 1,1075 & 1,2202 & 1,2328 & 0,754 & 1,3232 & 1,3604 & 1,2392 & \\
\hline 23 & 0,8867 & 0,883 & 0,8774 & 0,4736 & 0,8532 & 0,808 & 1,0255 & \\
\hline 27 & 0,8076 & 0,8257 & 0,6441 & 0,8928 & 0,8066 & 1,0143 & & \\
\hline 33 & 0,733 & 0,7028 & 0,679 & 0,6362 & 0,7 & 0,6459 & 0,8653 & \\
\hline 40 & 0,6743 & 0,679 & 0,6422 & 0,4182 & 0,6035 & 0,577 & 0,7889 & \\
\hline 47 & 0,6827 & 0,679 & 0,6552 & 0,5733 & 0,6399 & 0,5961 & 0,8271 & \\
\hline 54 & 0,6082 & 0,6087 & 0,563 & 0,5816 & 0,6012 & 0,5565 & 0,1531 & \\
\hline 61 & 0,4764 & 0,5337 & 0,4424 & 0,4154 & 0,2822 & 0,3353 & 0,4699 & \\
\hline 68 & 0,5784 & 0,6292 & 0,5877 & 0,244 & 0,5779 & 0,7042 & 0,7922 & \\
\hline 75 & 0,495 & 0,5141 & 0,4564 & 0,373 & 0,5318 & 0,5095 & 0,6893 & 0,4582 \\
\hline 82 & 1,0479 & 1,0582 & 1,0037 & 0,4065 & 0,7815 & 0,7177 & 0,9743 & 1,217 \\
\hline
\end{tabular}




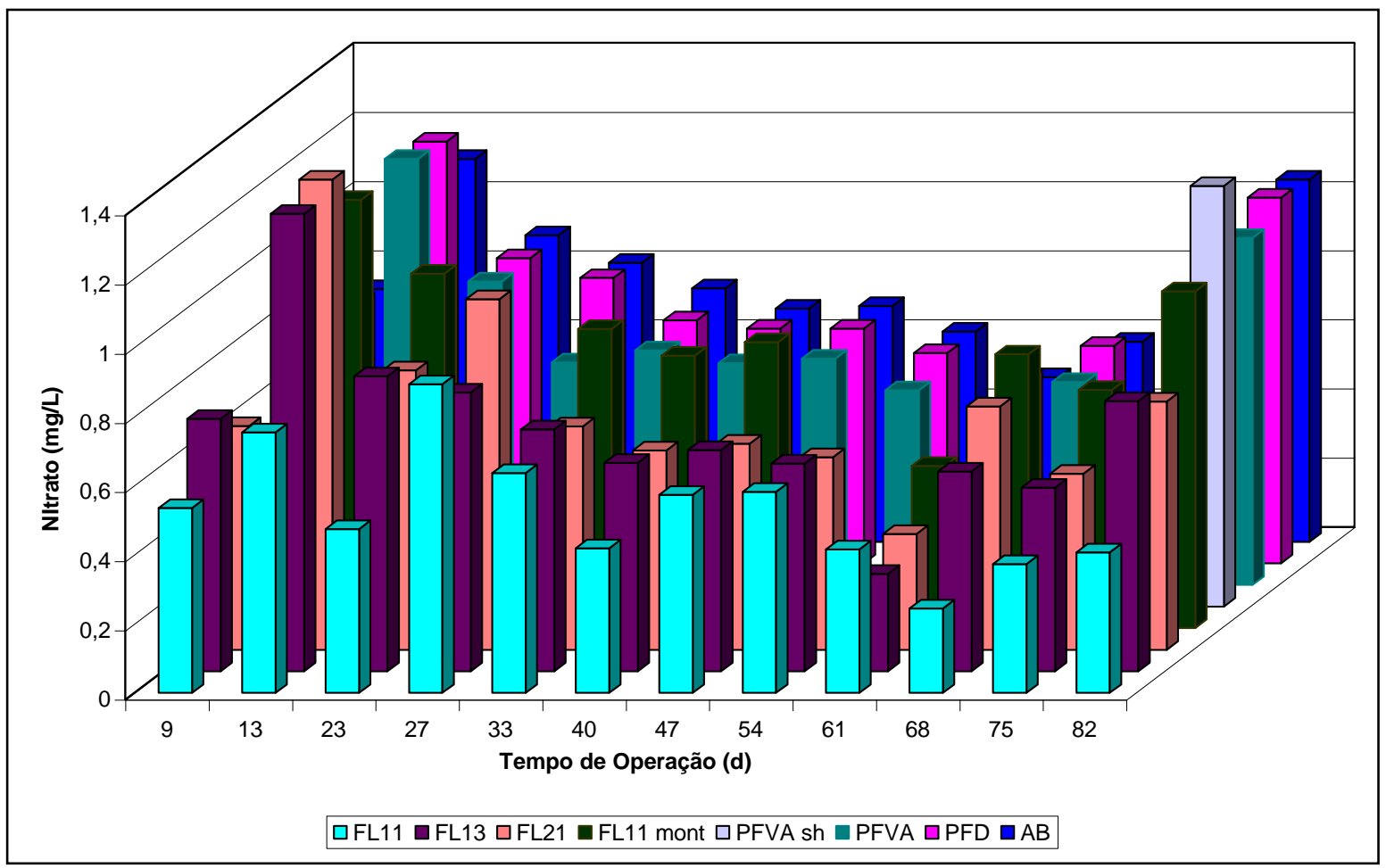

FIGURA 64 - Variações na concentração de nitrato para água bruta e unidades da FiME na carreira 3

\section{Fonte: TABELA 55}

\subsubsection{2 pH e acalinidade}

A adição da solução substâncias húmicas causou aumento do $\mathrm{pH}$ do efluente do PFVA, que variou na faixa de 0,14 a 8,9\% (média de 2,53 \%), o que foi atribuído ao uso de $\mathrm{NaOH}$ na preparação da referida solução, conforme citado anteriormente. (Materiais e métodos).

Quando se avalia separadamente os dias em que houve a introdução de ozônio, percebe-se que o mesmo causou diminuição do $\mathrm{pH}$, que variou entre 0,61 e 4,62 $\%$.(média de $2,58 \%$ ).

Como pode ser observado na tabela F.8, onde estão apresentados os resultados da carreira 3, o PFD e PFVA não causaram variações expressivas no $\mathrm{pH}$ da água bruta. Nota-se também que as unidades de filtração lenta promoveram decréscimos no potencial hidrogênionico, fato que foi observado por VERAS (1999) e que supostamente 
ocorreu pela respiração aeróbia de bactérias com conseqüente introdução de $\mathrm{CO}_{2}$ na massa líquida. Essa diminuição do pH (figura 65), ocasionado pela filtração lenta, foi mais acentuada no filtro lento 1, o que sugere maior atividade biológica no mesmo e talvez alguma reação química com carvão ativado.

A alcalinidade do efluente do PFVA sofreu um aumento médio de 13,21\% com a injeção da substância húmica. Pelos dados locados na tabela 56, pode notar que as unidades de pré-filtração e filtração lenta não causaram variação excessiva da alcalinidade.

TABELA 56 - Resultados de alcalinidade em $\mathrm{mg} / \mathrm{L}$ para água bruta e unidades de filtração na carreira 3

\begin{tabular}{cccccccc}
\hline TO & AB & PFD & PFVA & FL11 & FL13 & FL21 & FL1 mont \\
\hline 9 & 7,36 & 6,67 & 5,98 & 7,36 & 2,30 & 6,90 & 7,82 \\
\hline 13 & 5,98 & 5,98 & 5,98 & 8,28 & 8,28 & 7,36 & 7,82 \\
\hline 23 & 6,90 & 6,90 & 7,82 & 8,28 & 8,74 & 9,20 & 8,93 \\
\hline 27 & 7,36 & 6,90 & 7,36 & 8,28 & 5,52 & 8,74 & 6,90 \\
\hline 33 & 8,28 & 7,59 & 7,82 & 6,90 & 8,97 & 8,05 & 8,28 \\
\hline 40 & 6,90 & 6,90 & 6,90 & 7,36 & 8,05 & 8,28 & 7,36 \\
\hline 47 & 8,97 & 8,05 & 8,51 & 8,28 & 8,51 & 9,43 & 9,66 \\
\hline 54 & 6,67 & 6,67 & 7,82 & 6,44 & 8,97 & 8,74 & 8,28 \\
\hline 61 & 9,89 & 10,58 & 12,19 & 14,72 & 7,82 & 7,82 & 12,42 \\
\hline 68 & 7,13 & 6,90 & 7,13 & 6,79 & 7,71 & 6,90 & 7,71 \\
\hline 75 & 6,90 & 7,82 & 6,44 & 5,98 & 8,28 & 6,90 & 8,28 \\
\hline 82 & 4,14 & 3,22 & 4,14 & 9,66 & 6,90 & 6,90 & 5,52 \\
\hline
\end{tabular}




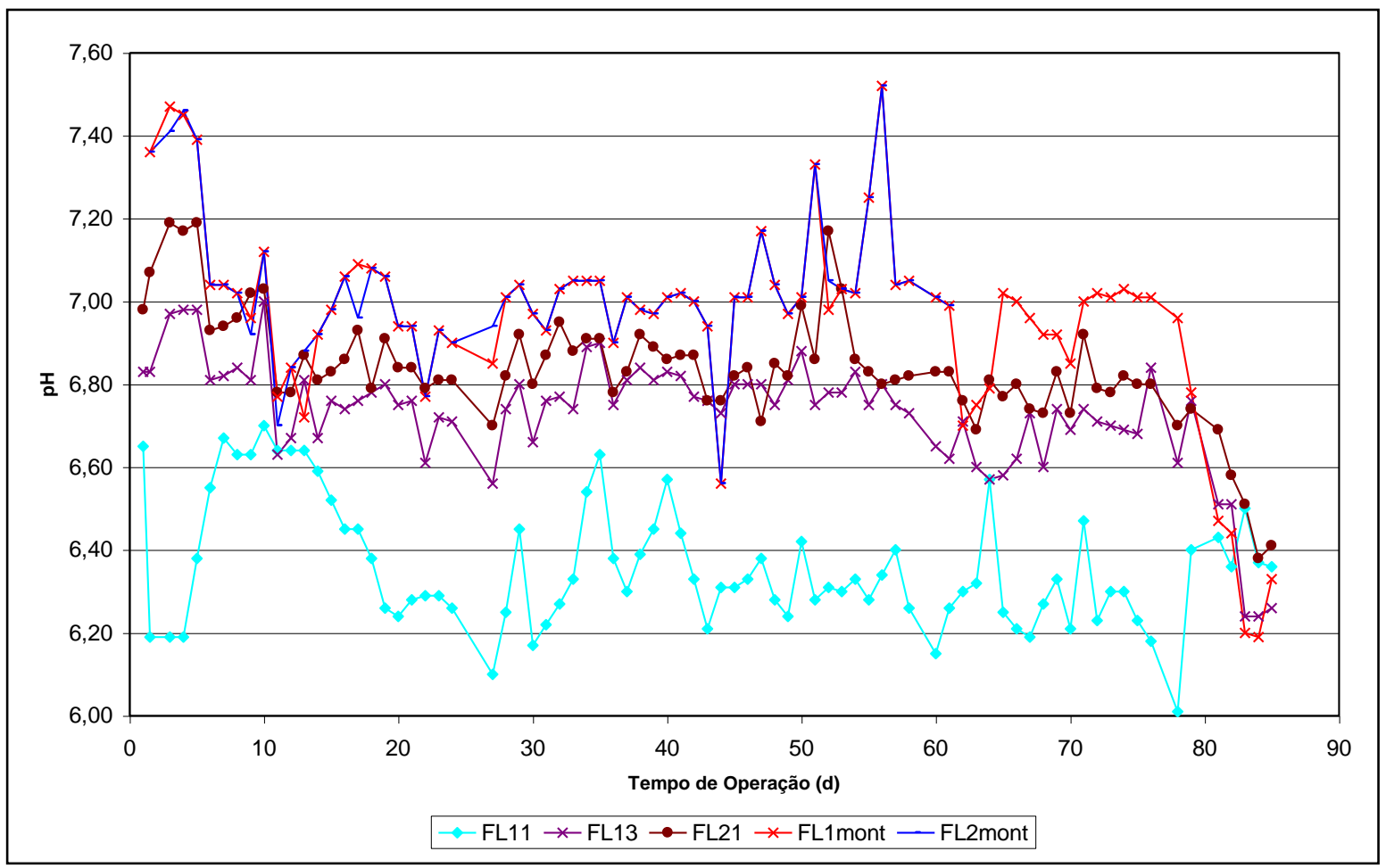

FIGURA 65 -Variações do valores de pH nos efluentes dos filtros lentos e seção

\section{FL13 na carreira 3}

\section{Fonte: TABELA F.8}

\subsubsection{Condutividade elétrica}

Os dados de condutividade oriundos da carreira 3, que podem ser vistos na tabela F.9, assemelham-se aos resultados da carreira 1. Também neste caso não se nota variações consideráveis do parâmetro citado, quando se compara os dados de água bruta e dos efluentes das unidades da FiME.

\subsubsection{Temperatura}

$\mathrm{Na}$ carreira 3 foram encontradas temperaturas mais baixas que na carreira 1 , como pode ser visto na tabela 68 , entretanto tal situação foi verificada apenas no $12^{\circ}$ dia de operação (tabela F.10) e não chegou a afetar a eficiência das unidades de filtração, como foi observado por MOLL et al. (1999), que estudaram filtros lentos em escala de 
bancada, operados em paralelo nas temperaturas de 5,20 e $35^{\circ} \mathrm{C}$, tratando água de fonte superficial. Os pesquisadores concluíram que a remoção de matéria orgânica foi significativamente menor no filtro operado a $5{ }^{\circ} \mathrm{C}$, em comparação com os filtros operados a 20 e $35^{\circ} \mathrm{C}$ que tiveram resultados similares. Na tabela 68 um resumo dos dados de temperatura da carreira 3 pode ser visualizado.

TABELA 57 - Resumo dos valores de temperatura em ${ }^{\circ} \mathrm{C}$ carreira 3

\begin{tabular}{lccccccccc}
\hline Valores & AB & PFD & PFVA & FL11 & FL13 & FL21 & $\begin{array}{c}\text { FL1 } \\
\text { mont }\end{array}$ & $\begin{array}{c}\text { FL2 } \\
\text { mont }\end{array}$ & $\begin{array}{c}\text { PFVA } \\
\text { sh }\end{array}$ \\
\hline Máximo & 30,0 & 29,0 & 32,0 & 32,0 & 32,0 & 33,0 & 32,0 & 32,0 & 30,0 \\
\hline Média & 23,0 & 23,6 & 24,5 & 24,3 & 24,5 & 24,3 & 24,8 & 24,3 & 25,5 \\
\hline Mínimo & 16,0 & 17,0 & 14,0 & 15,0 & 13,0 & 14,0 & 14,0 & 15,0 & 20,0 \\
\hline
\end{tabular}

\subsubsection{Perda de carga}

Não foi possível averiguar que interferência o ozônio poderia causar no desenvolvimento da perda de carga dos filtros lentos, haja vista que o mesmo começou a ser aplicado literalmente no final da carreira 3 e além disso o processo foi prejudicado por problemas técnicos no equipamento de ozonização.

Opostamente ao que ocorreu que na carreira 1, a carga hidráulica disponível para o filtro lento 2 acabou primeiro que a do filtro lento 1 e assim deu-se por encerrada a carreira para ambos os filtros. (ver figuras 66 e 67). 


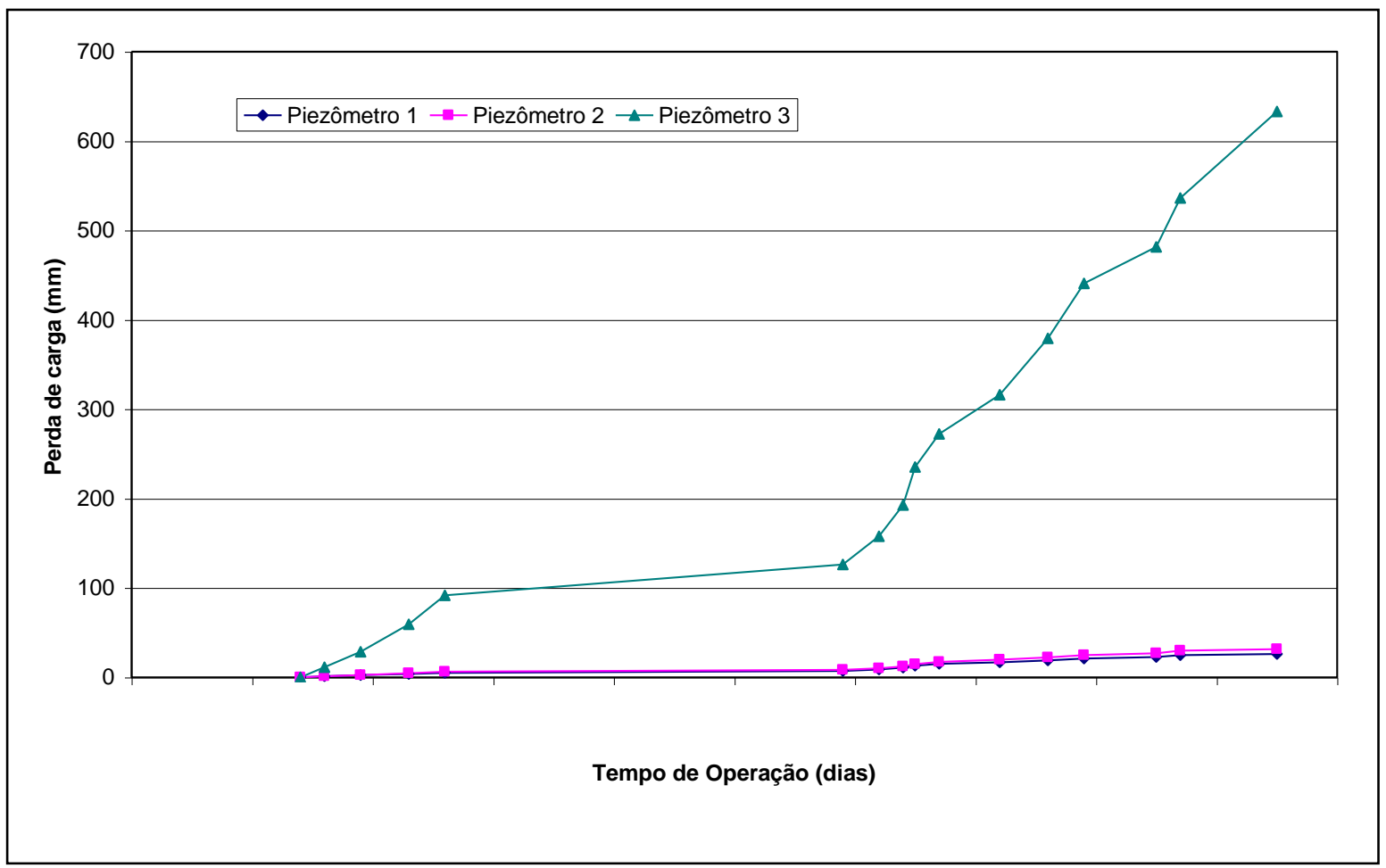

FIGURA 66 - Desenvolvimento da perda de carga do filtro lento 1 na carreira 3

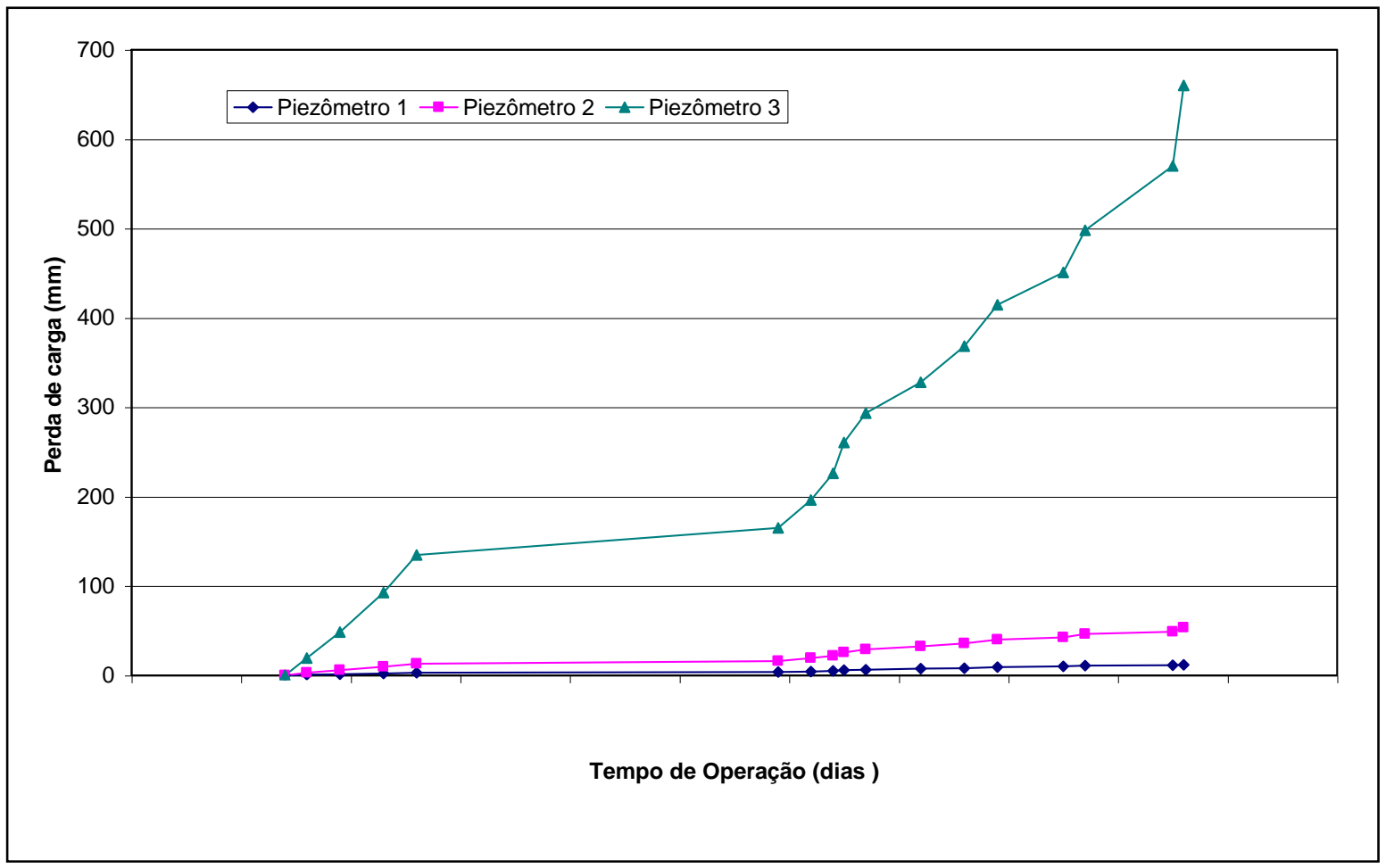

FIGURA 67 - Desenvolvimento da perda de carga no filtro lento 2 na carreira 3 


\section{CONCLUSÕES E RECOMENDAÇÕES}

Com base nos resultados obtidos, relativos à carreira 1, concluiu-se que:

a) Não houve diferenças significativas entre os filtros lentos com relação a remoção de turbidez, coliformes totais, Escherichia Coli, sólidos suspensos totais, cor aparente, carbono orgânico dissolvido, ferro total, nitrogênio amoniacal e nitrito;

b) $\mathrm{O}$ filtro lento 1 , dotado de meio filtrante composto de carvão ativado granular e areia, foi superior na remoção de cor verdadeira, absorvância, oxigênio consumido e nitrato em relação ao filtro lento 2, com meio filtrante de areia apenas;

c) Os dados amostrais do filtro lento 2 e da seção FL13, apresentaram correlações entre cor verdadeira e absorvância mais fortes que o filtro lento 1, apesar deste ter apresentado maior remoção dos referidos parâmetros;

d) A camada de carvão ativado no filtro lento 1 causou remoção média de 56\% na concentração de oxigênio dissolvido, o que sugere alguma reação química com o $\mathrm{CAG}$, haja visto que tal fato não foi verificado nas outras unidades do sistema;

e) A unidades da FiME não causaram variação expressiva de $\mathrm{pH}$, temperatura, alcalinidade e condutividade elétrica, em relação à água bruta. 
Com relação à carreira 3, concluiu-se que:

a) Não houve diferenças significativas entre os filtros lentos na remoção de Escherichia Coli, bactérias heterotróficas, sólidos suspensos totais, ferro total e absorvância;

b) $\mathrm{O}$ filtro lento 1 foi estatisticamente melhor na remoção de turbidez que o filtro lento 2 e o ponto FL13. Em 97,44 \% dos dias a turbidez do efluente do filtro lento 1 foi consistentemente menor que $5 \mathrm{uT}$, em 48,72\% menor que 2 uT e em $43,59 \%$ esteve compreendida entre 2 e 4 . Todavia no filtro lento $292,31 \%$ dos dados oriundos do efluente do mesmo estiveram abaixo de $5 \mathrm{uT}, 7,69 \%$ foram menores que 2 uT e 80,77\% ficaram na faixa de 2 a 4 uT;

c) Para coliformes totais, cor aparente, cor verdadeira, carbono orgânico dissolvido, oxigênio consumido, nitrogênio amoniacal e nitrato o filtro lento 1 também apresentou melhor desempenho que o filtro lento 2. A camada de carvão ativado granular presente no filtro lento 1 deve ter sido a causadora da eficiência superior do mesmo em relação ao filtro lento 2;

d) $\mathrm{O}$ fato dos filtros lentos não terem atendido o que preconiza a Portaria № 1469 de 29 de dezembro de 2000, do Ministério da Saúde, para o parâmetro turbidez, não significou depreciação da qualidade bacteriológica da água efluente;

e) Com exceção de FL11 e FL11 mont, os demais pontos apresentaram fortes correlações positivas entre COD e absorvância. Entre oxigênio consumido e COD também verificou-se fortes correlações, exceto para FL11;

f) O decréscimo significativo na concentração de oxigênio dissolvido ocorrido no filtro lento 1 indica que até o final da carreira não havia terminado a capacidade adsortiva do CAG; 
g) A introdução da solução de substância húmica no efluente do PFVA causou aumento médio de $29,7 \%$ na cor aparente, $44,53 \%$ na cor verdadeira e de 2,53 $\%$ no $\mathrm{pH}$

h) A unidades da FiME não causaram alterações significativas nos valores de alcalinidade, temperatura e condutividade elétrica.

i) A aplicação de ozônio causou remoção média de cor verdadeira de 43,09 \% e parece ter incrementado sensivelmente a remoção do referido parâmetro nos efluentes dos filtros lentos. O ozônio também promoveu redução de 27,2 \% na absorvância e quando combinado com a filtração lenta mostrou melhores resultados na remoção de COD.

Com base no trabalho realizado recomenda-se que:

a) No começo das pesquisas seja sempre realizada uma carreira de filtração sem adição de produtos químicos ou oxidantes, uma vez que a carreira 1 desenvolvida neste trabalho mostrou-se, de importância capital para as carreiras subseqüentes;

b) cuidado na manipulação das amostras nas unidades laboratoriais para evitar possível contaminação nas mesmas, principalmente no que se refere a determinação de ferro total, COD e fosfato

c) estudar o fenômeno da variação de fosfato nos efluentes dos filtros lentos

d) que o material húmico a ser utilizado seja preparado no mínimo com dois meses de antecedência ao início da parte experimental e que sejam 
caracterizadas as substâncias húmicas, diferenciando-se tamanho das moléculas e grupos funcionais;

e) sejam efetuadas carreiras inteiras de filtração lenta com aplicação de diferentes dosagens de ozônio, avaliando-se o desenvolvimento da perda de carga e a interferência da temperatura;

f) sejam estudadas as questões de adsorção no CAG utilizado, concomitantemente com o desenvolvimento do trabalho

g) que se pesquise a introdução de uma unidade de CAG posteriormente às unidades de filtração lenta

h) a Portaria № 1469 do Ministério da Sáude seja reformulada no que se refere ao parâmetro turbidez, para que o limite estabelecido para filtração lenta seja de 5 uT. 


\section{REFERÊNCIAS BIBLIOGRÁFICAS}

BAKER, M.N. (1948). The Quest for Pure Water. Journal AWWA, v.1

BAUER, M.J. et al. (1996). GAC Enhanced slow sand filtration (GAC Sandwich). In: ADVANCES IN SLOW SAND AND ALTERNATIVE BIOLOGICAL FILTRATION. John Wiley and Sons, England, april, 1996

BELLAMY, W.D.; HENDRICKS, D. W.; LOGSDON, G.S. (1985). Slow Sand Filtration: Influences of Some Selected Process Variables. Journal American Water Works Association, v.77,n.12, p. 62-66, december.

CAMEL, V.; BERMOND, A.(1998). The use of ozone and associated oxidation processes in drinking water treatment. Water Research, v.32, n.11, p.32083222.

CANEPA, L. (1982). Filtros de Arena en Acueductos Rurales. Informe Final. CEPIS/OMS/OPS. Lima, Peru.

CLESCERL, S. L et al. (1985). Standard Methods for the Examination of Water and Wastewater. 16 Th edition, APHA, AWWA and WEF, Whashington D.C.

COLLAZOS, A.E.A.P.(1990). Pré-filtração de pedregulho e areia grossa de fluxo descendente como pré-tratamento de filtro lento de areia. São Carlos. Dissertação (Mestrado)- Escola de Engenharia de São Carlos, Universidade de São Paulo. 
COLLINS, R.M. et al.(1992). Removing natural organic mattter by conventional slow sand filtration. Journal American Water Works Association. v.84, n.5, p.8090. May.

COLLINS, R.M. et al.(1996). Using granular media amendments to enhance NOM removal. Journal American Water Works Association. v.88, n.12, p. 48-61, december

DI BERNARDO, L. (1993). Métodos e técnicas de tratamento de água. Rio de Janeiro, ABES, v.2, p.281-401.

DI BERNARDO, L.; BRANDÃO, C.C.S.; HELLER, L. (1999). Tratamento de Águas de abastecimento por filtração em múltitplas etapas. Rio de Janeiro, ABES.

DI BERNARDO, L.; ROCHA, O. (1990). Remoção de algas em pré-filtro de fluxo ascendente com meio granular e pedregulho de areia grossa. In: IV SIMPÓSIO LUSO -BRASILEIRO DE ENGENHARIA SANITÁRIA E AMBIENTAL, Belo Horizonte, Brasil.

FOGEL, D. et al. (1993). Removing Giardia and Cryptosporidium by slow sand Filtration. Journal of Americam Water Works Association, v.85, n.11, p.77-85.

GALVIS, G.; FERNÁNDEZ, J.;VISSCHER, J.T.(1992). Comparative study of different pretreatment alternatives. In: ROUGHING FILTRATION IN WATER TREATMENT. June, Zurich, Switzerland.

GALVIS, G.;DI BERNARDO, L.; BRANDÃO, C.C.S.(1998). Filtração em múltiplas etapas no tratamento de águas de abastecimento. In: SIMPÓSIO LUSO -BRASILEIRO DE ENGENHARIA SANITÁRIA E AMBIENTAL, João Pessoa, Paraíba, Brasil. 
GALVIS, G.;LATORRE, J.; VISSCHER, J.T.(1999). Filtracíon en múltiples etapas: Tecnología innovativa para el tratamiento de agua. Santiago de Cali, Artes gráficas de Univalle.

GRAHAM, N.J.D.(1999). Removal of humic substances by oxidation/biofiltration processes - A review. Water Science \& Technology, v.40, n.9, p.141- 48.

HAARHOFF, J.; CLEASBY, J.L.(1991). Biological and physical mechanisms in slow sand filtration. In: LOGSDON, G.S.(ed.) SLOW SAND FILTRATION, ASCE, New York.

HAZEN, A. (1913). The Filtration of Water Public Supplies. 3.ed. New York, Jhon Wiley and Sons

HESPANHOL, I. (1969). Investigação sobre o comportamento e aplicabilidade de filtros lentos no Brasil. São Paulo, 163p. Tese (Doutorado) Faculdade de Higiene e Saúde Pública, Universidade de São Paulo.

HUISMAN,L.; WOOD, W.E.; (1974). Slow Sand Filtration. Geneva. World Health Organization.

LAPPONI, JUAN CARLOS (1997).Estatística usando Excel 5 e 7. São Paulo, Lapponi Treinamento e Editora.

LATORRE, J.;GALVIS. J.; VISSCHER, J.T. (1996). Performance evaluation of dynamic roughing filtration. In: ADVANCES IN SLOW SAND AND ALTERNATIVE BIOLOGICAL FILTRATION. John Wiley and Sons, England, april, 1996.

LLOYD, B. (1996). La vigilância y control de la calidad del agua: El desarollo de una herramienta de gestíon en el sector. In: CONFERENCIA 
INTERNACIONAL SOBRE MEJORAMIENTO DE LA CALIDAD DEL AGUA. Cali, de 30 de abril a 4 de maio, Colômbia.

MALLEY, J.P. et al.(1993). The performance and microbiology of ozone-enhanced biological filtration. Journal American Water Works Association. v.85, n.12,p. 47-57, december

MINISTÉRIO DA SAÚDE. Portaria № 1469 de 29 de dezembro de 2000.Diário Oficial $n^{0}$ 1, Brasília, 02/01/01.Seção 1, pág.19 e Diário Oficial $n^{\circ}$ 7, Brasília, 10/01/01.Seção 1, pág.26.

MOLL, D.M. (1999). Impact of temperature on drinking water biofilter performance and microbial community structure .Environmental Science \& Technology,v.33, n.14, p.2377-2382.

OWEN, D.M. et al.(1995). NOM characterization and treatability. Journal American Water Works Association. v.87, n.1, p. 46-63, january.

RICE, R.G. et al.(1981). Uses of ozone in drinking water treatment. Journal American Water Works Associaton. v.73, n.1, p.44-56.January.

SINGER, P.C.(1999). Humic substances as precursors for potentially harmful disinfection by-products. Water Science \& Technology, v.40, n.9, p.25-30.

TOLEDO, A. P. P. ( 1973). Contribuição ao estudo físico-químico de ácido húmico extraído de sedimento. São Paulo. 112p. Dissertação (Mestrado) - Instituto de Química da Universidade de São Paulo.

TOMINAGA, M.Y.; MIDIO, A .F. (1999). Exposição humana a trialometanos presentes em água tratada. Revista de Saúde Pública, v.33, n.4, p.413-21, agosto. 
VERAS, L.R.V.(1999). Tratamento de água superficial por meio de diferentes alternativas da tecnologia de filtração em múltiplas etapas. São Carlos. 246 p. Tese (Doutorado) - Escola de Engenharia de São Carlos, Universidade de São Paulo.

VISSCHER, J.T.; GALVIS, G.; LATORRE, J.(1996). Filtracíon en multiples etapas -FiME: bondades e limitaciones. In: CONFERENCIA INTERNACIONAL SOBRE MEJORAMIENTO DE LA CALIDAD DEL AGUA. Cali, de 30 de abril a 4 de maio, Colômbia.

WEBER, W.J.J.; JODELLAH, A.M.(1985). Removing humic substances by chemical treatment and adsorption. Journal American Water Works, v.77, n.4 p.132-37. April. 


\section{ANEXO A \\ Resultados Estatísticos \\ Carreira 1}


TABELA A.1 - Cálculos da médias de remoção de turbidez para FL11, FL13 e FL21 na carreira 1

\begin{tabular}{ccccc}
\hline Grupo & Contagem & Soma & Média & Variância \\
\hline R\%FL11 & 77 & 3195,8 & 41,503 & 521,37 \\
R\%FL13 & 77 & 2044,1 & 26,546 & 526,34 \\
R\%FL21 & 77 & 3033 & 39,389 & 432,83 \\
\hline
\end{tabular}

TABELA A.2 - Análise de variância para remoção de turbidez (FL11, FL13 e FL21) na carreira 1

\begin{tabular}{lcccccc}
\hline \multicolumn{7}{c}{ ANOVA: fator único } \\
\hline $\begin{array}{l}\text { Fonte da } \\
\text { variação }\end{array}$ & SQ & gl & MQ & F & Valor-P & F crítico \\
$\begin{array}{l}\text { Entre grupos } \\
\begin{array}{l}\text { Dentro dos } \\
\text { grupos }\end{array}\end{array}$ & 10090 & 2 & 5045,1 & 10,223 & $6 \mathrm{E}-05$ & 3,0354 \\
Total & 112522 & 228 & 493,52 & & & \\
\hline
\end{tabular}

TABELA A.3 - Teste z para turbidez

\begin{tabular}{lcc}
\hline & R\%FL11 & R\%FL21 \\
\hline Média & 41,503 & 39,389 \\
Variância conhecida & 521,37 & 432,83 \\
Observações & 77 & 77 \\
Hipótese & 0 & \\
$Z$ & 0,6006 & \\
P $(Z<=z)$ uni-caudal & 0,2741 & \\
z crítico uni-caudal & 1,6449 & \\
P $(Z<=z)$ bi-caudal & $\mathbf{0 , 5 4 8 1}$ & \\
z crítico bi-caudal & 1,96 & \\
\hline
\end{tabular}

TABELA A.4 - Teste $-\mathrm{z}$ para turbidez

\begin{tabular}{lcc}
\hline & R\%FL11 & R\%FL13 \\
\hline Média & 41,503 & 26,546 \\
Variância conhecida & 521,37 & 526,34 \\
Observações & 77 & 77 \\
Hipótese & 0 & \\
$Z$ & 4,0548 & \\
$P(Z<=z)$ uni- & $3 E-05$ & \\
z crítico uni- & 1,6449 & \\
$P(Z<=z)$ bi-caudal & $\mathbf{5 E - 0 5}$ & \\
z crítico bi-caudal & 1,96 & \\
\hline
\end{tabular}

TABELA A.5 - Teste - z para turbidez

\begin{tabular}{lcc}
\hline & R\%FL21 & R\%FL13 \\
\hline Média & 39,389 & 26,546 \\
Variância conhecida & 432,83 & 526,34 \\
Observações & 77 & 77 \\
Hipótese & 0 & \\
$Z$ & 3,6388 & \\
P $(Z<=z)$ uni-caudal & 0,0001 & \\
z crítico uni-caudal & 1,6449 & \\
P $(Z<=z)$ bi-caudal & $\mathbf{0 , 0 0 0 3}$ & \\
z crítico bi-caudal & 1,96 & \\
\hline
\end{tabular}


TABELA A.6 - Cálculos da médias de remoção de coliformes totais para FL11, FL13 e FL21 na carreira 1

\begin{tabular}{ccccc}
\hline Grupo & Contagem & Soma & Média & Variância \\
\hline R\%FL11 & 11 & 885,0733 & 80,46121 & 362,604 \\
R\%FL13 & 11 & 812,4837 & 73,86216 & 661,8072 \\
R\%FL21 & 11 & 910,1704 & 82,74276 & 293,9175 \\
\hline
\end{tabular}

TABELA A.7- Análise de variância para remoção de coliformes totais para FL11, FL13 e FL21 na carreira 1

\begin{tabular}{lcccccc}
\hline \multicolumn{7}{c}{ ANOVA:fator único } \\
\hline Fonte da variação & SQ & gl & MQ & F & Valor-P & F crítico \\
Entre grupos & 467,9329 & 2 & 233,9665 & 0,532416 & $\mathbf{0 , 5 9 2 6 3}$ & 3,315833 \\
Dentro dos grupos & 13183,29 & 30 & 439,4429 & & & \\
Total & 13651,22 & 32 & & & & \\
\hline
\end{tabular}

TABELA A.8 - Cálculos da médias de remoção de E.Coli para FL11, FL13 e FL21 na carreira 1

\begin{tabular}{ccccc}
\hline Grupo & Contagem & Soma & Média & Variância \\
\hline R\%FL11 & 11 & 937,4129 & 85,21935 & 138,421 \\
R\%FL13 & 11 & 740,3534 & 67,30485 & 713,3803 \\
R\%FL21 & 11 & 877,7869 & 79,79881 & 268,0694 \\
\hline
\end{tabular}

TABELA A.9 - Análise de variância para remoção de E.Coli para FL11, FL13 e FL21 na carreira 1

\begin{tabular}{lcccccc}
\hline \multicolumn{7}{c}{ ANOVA } \\
\hline Fonte da variação & SQ & gl & MQ & F & valor-P & F crítico \\
Entre grupos & 1856,838 & 2 & 928,419 & 2,487124 & $\mathbf{0 , 1 0 0 1 3 7}$ & 3,315833 \\
Dentro dos grupos & 11198,71 & 30 & 373,2902 & & & \\
Total & 13055,54 & 32 & & & & \\
\hline
\end{tabular}

TABELA A.10 - Cálculos da médias de remoção de SST para FL11, FL13 e FL21 na carreira 1

\begin{tabular}{ccccc}
\hline Grupo & Contagem & Soma & Média & Variância \\
\hline R\%FL11 & 16 & 858,1833 & 53,63646 & 2680,119 \\
R\%FL13 & 16 & 836,0578 & 52,25362 & 1983,756 \\
R\%FL21 & 16 & 1162,858 & 72,67864 & 659,0082 \\
\hline
\end{tabular}


TABELA A.11 - Análise de variância para remoção de SST para FL11, FL13 e FL21 na carreira 1

\begin{tabular}{lcccccc}
\hline \multicolumn{7}{c}{ ANOVA: fator único } \\
\hline Fonte da variação & SQ & Gl & MQ & F & Valor-P & F crítico \\
Entre grupos & 4169,058 & 2 & 2084,529 & 1,174849 & $\mathbf{0 , 3 1 8 1 5 9}$ & 3,20432 \\
Dentro dos grupos & 79843,26 & 45 & 1774,295 & & & \\
\hline
\end{tabular}

TABELA A.12 - Cálculos da médias de remoção de cor aparente para FL11, FL13 e FL21 na carreira 1

\begin{tabular}{ccccc}
\hline Grupo & Contagem & Soma & Média & Variância \\
\hline R\%FL11 & 37 & 1537,557 & 41,55559 & 424,9016 \\
R\%FL13 & 37 & 1017,1 & 27,48919 & 413,2286 \\
R\%FL21 & 37 & 1253,176 & 33,86961 & 450,0747 \\
\hline
\end{tabular}

TABELA A.13 - Análise de variância para remoção de cor aparente para FL11, FL13 e FL21 na carreira 1

\begin{tabular}{lcccccc}
\hline \multicolumn{7}{c}{ ANOVA: fator único } \\
\hline Fonte da variação & SQ & gl & MQ & F & valor-P & F crítico \\
Entre grupos & 3670,987 & 2 & 1835,494 & 4,274538 & $\mathbf{0 , 0 1 6 3 4 6}$ & 3,080388 \\
Dentro dos grupos & 46375,38 & 108 & 429,4016 & & & \\
Total & 50046,36 & 110 & & & & \\
\hline
\end{tabular}

TABELA A.14- Teste - z para cor aparente

\begin{tabular}{lcc}
\hline & R\%FL11 & R\%FL21 \\
\hline Média & 41,55559 & 33,86961 \\
Variância conhecida & 424,9016 & 450,0747 \\
& & \\
Observações & 37 & 37 \\
Hipótese da & 0 & \\
$Z$ & 1,580527 & \\
$\mathrm{P}(\mathrm{Z}<=\mathrm{z})$ uni-caudal & 0,056993 & \\
$\mathrm{Z}$ crítico uni-caudal & 1,644853 & \\
$\mathrm{P}(\mathrm{Z}<=\mathrm{z})$ bi-caudal & $\mathbf{0 , 1 1 3 9 8 6}$ & \\
& & \\
\hline
\end{tabular}

TABELA A.15 - Teste - z para cor aparente

\begin{tabular}{lcc}
\hline & R\%FL11 & R\%FL13 \\
\hline Média & 41,55559 & 27,48919 \\
Variância & 424,9016 & 413,2286 \\
conhecida & & \\
Observações & 37 & 37 \\
Hipótese & 0 & \\
$Z$ & 2,95548 & \\
$\mathrm{P}(\mathrm{Z}<=\mathrm{z})$ uni- & 0,001561 & \\
$\mathrm{z}$ crítico uni- & 1,644853 & \\
$\mathrm{P}(\mathrm{Z}<=\mathrm{z})$ bi-caudal & $\mathbf{0 , 0 0 3 1 2 2}$ & \\
$\mathrm{Z}$ crítico bi-caudal & 1,959961 & \\
\hline
\end{tabular}


TABELA A.16 - Teste -z para cor aparente

\begin{tabular}{lcc}
\hline & R\%FL13 & R\%FL21 \\
\hline Média & 27,48919 & 33,86961 \\
Variância conhecida & 413,2286 & 450,0747 \\
Observações & 37 & 37 \\
Hipótese da diferença de média & 0 & \\
$Z$ & $-1,3209$ & \\
$P(Z<=z)$ uni-caudal & 0,093268 & \\
z crítico uni-caudal & 1,644853 & \\
P $(Z<=z)$ bi-caudal & $\mathbf{0 , 1 8 6 5 3 6}$ & \\
z crítico bi-caudal & 1,959961 & \\
\hline
\end{tabular}

TABELA A.17 - Cálculos das médias de remoção de cor verdadeira para FL11, FL13 e FL21 na carreira 1

\begin{tabular}{rcccc}
\hline Grupo & Contagem & Soma & Média & Variância \\
\hline R\%FL11 & 14 & 826,6892 & 59,04923 & 238,9323 \\
R\%FL13 & 14 & 553,2587 & 39,51848 & 174,5861 \\
R\%FL21 & 14 & 564,2286 & 40,30204 & 191,1405 \\
\hline
\end{tabular}

TABELA A.18 - Análise de variância para remoção de cor verdadeira(FL11,FL13 e FL21) na carreira 1

\begin{tabular}{lcccccc}
\hline \multicolumn{7}{c}{ ANOVA: fator único } \\
\hline Fonte da variação & SQ & gl & MQ & F & valor-P & F crítico \\
Entre grupos & 3423,098 & 2 & 1711,549 & 8,491806 & $\mathbf{0 , 0 0 0 8 6 8}$ & 3,2381 \\
Dentro dos grupos & 7860,566 & 39 & 201,553 & & & \\
Total & 11283,66 & 41 & & & & \\
\hline
\end{tabular}

TABELA A.19 - Testes -F para cor verdadeira na carreira 1

\begin{tabular}{|c|c|c|c|c|c|c|}
\hline & R\%FL11 & R\%FL13 & R\%FL11 & R\%FL21 & R\%FL21 & R\%FL13 \\
\hline Média & 59,04923 & 39,51848 Média & 59,04923 & 40,30204 Média & 40,30204 & 39,51848 \\
\hline Variância & 238,9323 & 174,5861 Variância & 238,9323 & 191,1405 Variância & 191,1405 & 174,5861 \\
\hline $\begin{array}{l}\text { Observaç } \\
\text { ões }\end{array}$ & 14 & $\begin{array}{l}14 \text { Observaç } \\
\text { ões }\end{array}$ & 14 & $\begin{array}{l}14 \text { Observaç } \\
\text { ões }\end{array}$ & 14 & 14 \\
\hline $\mathrm{gl}$ & 13 & $13 \mathrm{Gl}$ & 13 & $13 \mathrm{Gl}$ & 13 & 13 \\
\hline $\mathrm{F}$ & 1,368564 & $\mathrm{~F}$ & 1,250035 & $\mathrm{~F}$ & 1,094821 & \\
\hline $\begin{array}{l}\mathrm{P}(\mathrm{F}<=\mathrm{f}) \\
\text { uni- } \\
\text { caudal }\end{array}$ & 0,289868 & $\begin{array}{l}\mathrm{P}(\mathrm{F}<=\mathrm{f}) \\
\text { uni- } \\
\text { caudal }\end{array}$ & 0,34669 & $\begin{array}{l}\mathrm{P}(\mathrm{F}<=\mathrm{f}) \\
\text { uni- } \\
\text { caudal }\end{array}$ & 0,43637 & 0 \\
\hline $\begin{array}{l}\text { F crítico } \\
\text { uni- } \\
\text { caudal }\end{array}$ & 2,576925 & $\begin{array}{l}\text { F crítico } \\
\text { uni- } \\
\text { caudal }\end{array}$ & 2,576925 & $\begin{array}{l}\text { F crítico } \\
\text { uni- } \\
\text { caudal }\end{array}$ & 2,576925 & \\
\hline
\end{tabular}


TABELA A.20 - Teste -T para cor verdadeira

Presumindo-se variâncias equivalentes

\begin{tabular}{lcc}
\hline & R\%FL11 & R\%FL21 \\
\hline Média & 59,04923 & 40,30204 \\
Variância & 238,9323 & 191,1405 \\
Observações & 14 & 14 \\
Variância agrupada & 215,0364 & \\
Hipótese & 0 & \\
Gl & 26 & \\
Stat t & 3,382432 & \\
P(T<=t) uni-caudal & 0,001142 & \\
t crítico uni-caudal & 1,705616 & \\
P(T<=t) bi-caudal & $\mathbf{0 , 0 0 2 2 8 4}$ & \\
\hline
\end{tabular}

TABELA A.21 - Teste -T para cor verdadeira Presumindo-se variâncias equivalentes

\begin{tabular}{lcc}
\hline & R\%FL11 & R\%FL13 \\
\hline Média & 59,04923 & 39,51848 \\
Variância & 238,9323 & 174,5861 \\
Observações & 14 & 14 \\
Variância agrupada & 206,7592 & \\
Hipótese & 0 & \\
Gl & 26 & \\
Stat t & 3,593647 \\
P(T<=t) uni- & 0,000668 \\
t crítico uni- & 1,705616 \\
$\mathrm{P}(\mathrm{T}<=\mathrm{t})$ bi-1 & $\mathbf{0 , 0 0 1 3 3 6}$ & \\
\hline
\end{tabular}

TABELA A.22 - Teste -T para cor verdadeira (FL13 e FL21)

Presumindo-se variâncias equivalentes

\begin{tabular}{lcc}
\hline & R\%FL13 & R\%FL21 \\
\hline Média & 39,51848 & 40,30204 \\
Variância & 174,5861 & 191,1405 \\
Observações & 14 & 14 \\
Variância agrupada & 182,8633 & \\
Hipótese da diferença de média & 0 & \\
Gl & 26 & \\
Stat t & $-0,15331$ & \\
P $(\mathrm{T}<=t)$ uni-caudal & 0,43967 & \\
t crítico uni-caudal & 1,705616 \\
$\mathrm{P}(\mathrm{T}<=\mathrm{t})$ bi-caudal & $\mathbf{0 , 8 7 9 3 4 1}$ & \\
t crítico bi-caudal & 2,055531 & \\
\hline
\end{tabular}

TABELA A.23 - Cálculos das médias de remoção de absorvância para FL11, FL13 e FL21 na carreira 1

\begin{tabular}{ccccc}
\hline Grupo & Contagem & Soma & Média & Variância \\
\hline R\%FL11 & 10 & 583,0634678 & 58,30635 & 264,4262 \\
R\%FL13 & 10 & 221,8679509 & 22,1868 & 140,1013 \\
R\%FL21 & 10 & 152,5690272 & 15,2569 & 376,8709 \\
\hline
\end{tabular}

TABELA A.24 - Análise de variância para remoção de absorvância (FL11, FL13 e FL21) na carreira 1

\begin{tabular}{lcccccc}
\hline \multicolumn{7}{c}{ ANOVA: fator único } \\
\hline Fonte da variação & $\mathrm{SQ}$ & $\mathrm{gl}$ & $\mathrm{MQ}$ & $\mathrm{F}$ & valor-P & F crítico \\
Entre grupos & 10686,33 & 2 & 5343,167 & 20,5138 & $\mathbf{3 , 8 2 E - 0 6}$ & 3,354131 \\
Dentro dos grupos & 7032,586 & 27 & 260,4661 & & & \\
\hline
\end{tabular}


TABELA A.25-Testes -F para absorvância

\begin{tabular}{|c|c|c|c|c|c|c|}
\hline & R\%FL21 & R\%FL11 & R\%FL21 & R\%FL13 & R\%FL11 & R\%FL13 \\
\hline Média & 17,475 & 59,884 Média & 17,47599 & 23,09217 Média & 59,8849 & 23,0921 \\
\hline Variância & 339,33 & $\begin{array}{c}\text { 230,165 Variânc } \\
\text { ia }\end{array}$ & 339,3318 & $\begin{array}{c}119,264 \text { Variânci } \\
\text { a }\end{array}$ & 230,165 & 119,264 \\
\hline $\begin{array}{l}\text { Observaçõ } \\
\text { es }\end{array}$ & 12 & $\begin{array}{l}12 \text { Observa } \\
\text { ções }\end{array}$ & 12 & $\begin{array}{l}12 \text { Observa } \\
\text { ções }\end{array}$ & 12 & 12 \\
\hline $\mathrm{gl}$ & 11 & $11 \mathrm{gl}$ & 11 & $11 \mathrm{gl}$ & 11 & 11 \\
\hline $\mathrm{F}$ & 1,4742 & $\mathrm{~F}$ & 2,845207 & $\mathrm{~F}$ & 1,92987 & \\
\hline $\begin{array}{l}\mathrm{P}(\mathrm{F}<=\mathrm{f}) \\
\text { uni-caudal }\end{array}$ & 0,2652 & $\begin{array}{l}\mathrm{P}(\mathrm{F}<=\mathrm{f}) \\
\text { uni- } \\
\text { caudal }\end{array}$ & 0,048504 & $\begin{array}{l}\mathrm{P}(\mathrm{F}<=\mathrm{f}) \\
\text { uni- } \\
\text { caudal }\end{array}$ & 0,14533 & \\
\hline F crítico & 2,81792 & $\begin{array}{l}\text { F crítico } \\
\text { caudal }\end{array}$ & 2,817927 & F crítico & 2,81792 & \\
\hline
\end{tabular}

TABELA A.26- Testes -T para absorvância

Presumindo-se variâncias equivalentes

\begin{tabular}{lcc}
\hline & R\%FL11 & \%RFL21 \\
\hline Média & 59,88491862 & 17,47599 \\
Variância & 230,1652779 & 339,3319 \\
Observações & 12 & 12 \\
Variância agrupada & 284,7485805 & \\
Hipótese & 0 & \\
Gl & 22 & \\
Stat t & 6,15605 \\
P(T<=t) uni-caudal & $1,69584 \mathrm{E}-06$ \\
t crítico uni-caudal & 1,717144187 \\
$\mathrm{P}(\mathrm{T}<=\mathrm{t})$ bi-caudal & $\mathbf{3 , 3 9 1 6 7 E - 0 6}$ \\
\hline
\end{tabular}

TABELA A.27- Testes -T para absorvância Presumindo-se variâncias equivalentes

\begin{tabular}{lcc}
\hline & $\mathrm{R} \% \mathrm{FL} 11$ & $\mathrm{R} \% \mathrm{FL} 13$ \\
\hline Média & 59,88491862 & 23,09217 \\
Variância & 230,1652779 & 119,2644 \\
Observações & 12 & 12 \\
Variância & 174,7148252 & \\
Hipótese & 0 & \\
Gl & 22 & \\
Stat t & 6,81825082 & \\
$\mathrm{P}(\mathrm{T}<=\mathrm{t})$ & $3,76309 \mathrm{E}-07$ & \\
t crítico uni- & 1,717144187 & \\
$\mathrm{P}(\mathrm{T}<=\mathrm{t})$ bi- & $\mathbf{7 , 5 2 6 1 8 E - 0 7}$ & \\
\hline
\end{tabular}

TABELA A.28- Testes -T para absorvância

Presumindo-se variâncias diferentes

\begin{tabular}{lcc}
\hline & R\%FL13 & R\%FL21 \\
\hline Média & 23,09217051 & 17,47599 \\
Variância & 119,2643724 & 339,3319 \\
Observações & 12 & 12 \\
Hipótese da diferença de média & 0 & \\
Gl & 18 & \\
Stat t & 0,908482155 & \\
$\mathrm{P}(\mathrm{T}<=\mathrm{t})$ uni-caudal & 0,187813562 & \\
$\mathrm{t}$ crítico uni-caudal & 1,734063062 & \\
$\mathrm{P}(\mathrm{T}<=\mathrm{t})$ bi-caudal & $\mathbf{0 , 3 7 5 6 2 7 1 2 5}$ & \\
\hline
\end{tabular}


TABELA A.29- Cálculo das médias de remoção de COD para FL11, FL13 e FL21 na carreira 1

\begin{tabular}{ccccc}
\hline Grupo & Contagem & Soma & Média & Variância \\
\hline R\%FL11 & 11 & 410,0203 & 37,27457 & 1091,60036 \\
R\%FL13 & 11 & 75,85781 & 6,896165 & 942,522824 \\
R\%FL21 & 11 & 214,0126 & 19,45569 & 1170,46133 \\
\hline
\end{tabular}

TABELA A.30- Análise de variância para remoção de COD (FL11, FL13 e FL21) na carreira 1

\begin{tabular}{lcccccc}
\hline \multicolumn{7}{c}{ ANOVA:fator único } \\
\hline Fonte da variação & SQ & gl & MQ & F & valor-P & F crítico \\
Entre grupos & 5126,373 & 2 & 2563,187 & 2,39954961 & $\mathbf{0 , 1 0 7 9 6 9}$ & 3,315833 \\
Dentro dos grupos & 32045,85 & 30 & 1068,195 & & & \\
Total & 37172,22 & 32 & & & & \\
\hline
\end{tabular}

TABELA A.31 - Teste - T para COD

Presumindo-se variâncias equivalentes

\begin{tabular}{lcc}
\hline & R\%FL11 & R\%FL21 \\
\hline Média & 37,27457 & 19,4556864 \\
Variância & 1091,6 & 1170,46133 \\
Observações & 11 & 11 \\
Variância agrupada & 1131,031 & \\
Hipótese & 0 & \\
Gl & 20 & \\
Stat t & 1,242581 & \\
P(T<=t) uni-caudal & 0,114197 & \\
t crítico uni-caudal & 1,724718 & \\
P(T<=t) bi-caudal & $\mathbf{0 , 2 2 8 3 9 5}$ & \\
t crítico bi-caudal & 2,085962 & \\
\hline
\end{tabular}

TABELA A.32 - Teste - T para COD

Presumindo-se variâncias equivalentes

\begin{tabular}{lcc}
\hline & R\%FL11 & R\%FL13 \\
\hline Média & 37,27457 & 6,896165 \\
Variância & 1091,6 & 942,5228 \\
Observações & 11 & 11 \\
Variância & 1017,062 & \\
Hipótese & 0 & \\
Gl & 20 & \\
Stat t & 2,233946 & \\
P(T<=t) uni- & 0,018533 & \\
t crítico uni- & 1,724718 & \\
P(T<=t) bi- & $\mathbf{0 , 0 3 7 0 6 6}$ & \\
t crítico bi- & 2,085962 \\
\hline
\end{tabular}

TABELA A.33 - Teste - T para remoção de COD

Presumindo-se variâncias equivalentes

\begin{tabular}{lcc}
\hline & R\%FL13 & R\%FL21 \\
\hline Média & 6,896165 & 19,45569 \\
Variância & 942,5228 & 1170,461 \\
Observações & 11 & 11 \\
Variância agrupada & 1056,492 & \\
Hipótese & 0 & \\
Gl & 20 & \\
Stat t & $-0,90619$ & \\
P $(T<=$ t) uni-caudal & 0,187811 & \\
t crítico uni-caudal & 1,724718 \\
P(T<=t) bi-caudal & $\mathbf{0 , 3 7 5 6 2 2}$ & \\
t crítico bi-caudal & 2,085962 & \\
\hline
\end{tabular}


TABELA A.34- Cálculo das médias de remoção de OC para FL11, FL13 e FL21 na carreira 1

\begin{tabular}{ccccc}
\hline Grupo & Contagem & Soma & Média & Variância \\
\hline R\%FL11 & 7 & 538,246 & 76,8923 & 419,0631 \\
R\%FL13 & 7 & 160,756 & 22,9651 & 825,9467 \\
R\%FL21 & 7 & 69,1498 & 9,87854 & 808,9247 \\
\hline
\end{tabular}

TABELA A.35- Análise de variância para remoção de OC (FL11,FL13 e FL21) na carreira 1

\begin{tabular}{lcccccc}
\hline \multicolumn{7}{c}{ ANOVA: fator único } \\
\hline Fonte da variação & $\mathrm{SQ}$ & $\mathrm{gl}$ & $\mathrm{MQ}$ & $\mathrm{F}$ & Valor-P & F crítico \\
Entre grupos & 17663,88 & 2 & 8831,94 & 12,90003 & $\mathbf{0 , 0 0 0 3 3 4}$ & 3,55456109 \\
Dentro dos grupos & 12323,61 & 18 & 684,645 & & & \\
\hline
\end{tabular}

TABELA A.36- Testes -F para remoção de OC na carreira 1

\begin{tabular}{lrrrrrr}
\hline & R\%FL13 \%RFL11 & R\%FL13 & R\%FL21 & R\%FL21 & \%RFL11 \\
\hline Média & 22,96514 & 76,89227 Média & 22,96514 & 9,878539 Média & 9,878539 & 76,89227 \\
Variânci & 825,9467 & 419,0631 Variânci & 825,9467 & 808,9247 Variânci & 808,9247 & 419,0631 \\
Observa & 7 & 7 Observa & 7 & 7 Observa & 7 & 7 \\
Gl & 6 & $6 \mathrm{gl}$ & 6 & $6 \mathrm{Gl}$ & 6 & 6 \\
$\mathrm{~F}$ & 1,970936 & $\mathrm{~F}$ & 1,021043 & $\mathrm{~F}$ & 1,930317 & \\
$\mathrm{P}(\mathrm{F}<=\mathrm{f})$ & 0,214731 & $\mathrm{P}(\mathrm{F}<=\mathrm{f})$ & 0,49024 & $\mathrm{P}(\mathrm{F}<=\mathrm{f})$ & $0,221758 \mathrm{~s}$ & \\
F crítico & 4,283862 & $\mathrm{~F}$ crítico & 4,283862 & $\mathrm{~F}$ crítico & 4,283862 & \\
\hline
\end{tabular}

TABELA A.37 - Teste - T para OC

Presumindo-se variâncias equivalentes

\begin{tabular}{lcc}
\hline & \%FL11 & R\%FL21 \\
\hline Média & 76,89227 & 9,878539 \\
Variância & 419,0631 & 808,9247 \\
Observações & 7 & 7 \\
Variância agrupada & 613,9939 & \\
Hipótese & 0 & \\
Gl & 12 & \\
Stat t & 5,059596 \\
P $(T<=t)$ uni-caudal & 0,00014 \\
t crítico uni-caudal & 1,782287 \\
P $(T<=t)$ bi-caudal & 0,00028 \\
t crítico bi-caudal & 2,178813 \\
\hline
\end{tabular}

TABELA A.38 - Teste - T para e OC

Presumindo-se variâncias equivalentes

\begin{tabular}{lcc}
\hline & \%RFL11 & R\%FL13 \\
\hline Média & 76,89227 & 22,9651447 \\
Variância & 419,0631 & 825,946680 \\
Observaçõe & 7 & 7 \\
Variância & 622,5049 & \\
Hipótese da & 0 & \\
Gl & 12 & \\
Stat t & 4,043616 \\
P $(T<=t)$ uni- & 0,000814 \\
t crítico & 1,782287 \\
P $($ < =t) bi- & 0,001629 & \\
t crítico bi- & 2,178813 & \\
\hline
\end{tabular}


TABELA A.39 - Teste - T para OC (FL13 e FL21)

Presumindo-se variâncias equivalentes

\begin{tabular}{lcc}
\hline & R\%FL13 & R\%FL21 \\
\hline Média & 22,9651 & 9,87854 \\
Variância & 825,947 & 808,925 \\
Observações & 7 & 7 \\
Variância agrupada & 817,436 & \\
Hipótese da diferença de média & 0 & \\
Gl & 12 & \\
Stat t & 0,85632 & \\
P(T<=t) uni-caudal & 0,2043 & \\
t crítico uni-caudal & 1,78229 \\
P $(T<=t)$ bi-caudal & $\mathbf{0 , 4 0 8 6}$ & \\
t crítico bi-caudal & 2,17881 & \\
\hline
\end{tabular}

TABELA A.40- Cálculo das médias de remoção de OD para FL11, FL13 e FL21 na carreira 1

\begin{tabular}{ccccc}
\hline Grupo & Contagem & Soma & Média & Variância \\
\hline rfl11\% & 7 & 377,6726 & 53,95323 & 156,5509737 \\
rfl13\% & 7 & 5,620858 & 0,80298 & 4,386070175 \\
rfl21\% & 7 & 13,84784 & 1,978263 & 7,507210537 \\
\hline
\end{tabular}

TABELA A.41- Cálculo das médias de remoção de ferro para FL11, FL13 e FL21 na carreira 1

\begin{tabular}{ccccc}
\hline Grupo & Contagem & Soma & Média & Variância \\
\hline R\%FL11 & 4 & 218,2366 & 54,55916 & 1023,212 \\
R\%FL13 & 4 & 296,1034 & 74,02585 & 259,0496 \\
R\%FL21 & 4 & 281,8164 & 70,45411 & 506,7442 \\
\hline
\end{tabular}

TABELA A.42- Análise de variância para remoção de ferro (FL11,FL13 e FL21) na carreira 1

\begin{tabular}{lcccccc}
\hline \multicolumn{7}{c}{ ANOVA } \\
\hline Fonte da variação & SQ & gl & MQ & F & valor-P & F crítico \\
Entre grupos & 859,1455 & 2 & 429,5727 & 0,720355 & $\mathbf{0 , 5 1 2 6 3 3}$ & 4,256492 \\
Dentro dos grupos & 5367,016 & 9 & 596,3351 & & & \\
Total & 6226,162 & 11 & & & & \\
\hline
\end{tabular}


TABELA A.43- Cálculo das médias de remoção de nitrogênio amoniacal para FL11, FL13 e FL21 na carreira 1

\begin{tabular}{ccccc}
\hline Grupo & Contagem & Soma & Média & Variância \\
\hline R\%FL11 & 5 & 257,0887 & 51,41775 & 1285,403 \\
R\%FL13 & 5 & 158,6471 & 31,72941 & 967,1411 \\
R\%FL21 & 5 & 177,7327 & 35,54654 & 1034,141 \\
\hline
\end{tabular}

TABELA A.44- Análise de variância para remoção de nitrogênio amoniacal (FL11,FL13 e FL21) na carreira 1

\begin{tabular}{lcccccc}
\hline \multicolumn{7}{c}{ ANOVA: fator único } \\
\hline Fonte da variação & SQ & Gl & MQ & F & valor-P & F crítico \\
Entre grupos & 1090,161 & 2 & 545,0803 & 0,497535 & $\mathbf{0 , 6 2 0 0 3 4}$ & 3,88529 \\
Dentro dos grupos & 13146,74 & 12 & 1095,562 & & & \\
Total & 14236,9 & 14 & & & & \\
\hline
\end{tabular}

TABELA A.45- Cálculo das médias de remoção de nitrito para FL11, FL13 e FL21 na carreira 1

\begin{tabular}{ccccc}
\hline Grupo & Contagem & Soma & Média & Variância \\
\hline R\%FL11 & 5 & 322,6455 & 64,5291 & 1042,218 \\
R\%FL13 & 5 & 119,8214 & 23,96427 & 2350,076 \\
R\%FL21 & 5 & 107,7768 & 21,55535 & 1038,214 \\
\hline
\end{tabular}

TABELA A.46- Análise de variância para remoção de nitrito (FL11,FL13 e FL21) na carreira 1

\begin{tabular}{lcccccc}
\hline \multicolumn{7}{c}{ ANOVA: fato único } \\
\hline Fonte da variação & SQ & gl & MQ & F & valor-P & F crítico \\
Entre grupos & 5830,086 & 2 & 2915,043 & 1,973843 & $\mathbf{0 , 1 8 1 5 1}$ & 3,88529 \\
Dentro dos grupos & 17722,03 & 12 & 1476,836 & & & \\
Total & 23552,12 & 14 & & & & \\
\hline
\end{tabular}

TABELA A.47- Cálculo das médias de remoção de nitrato para FL11, FL13 e FL21 na carreira 1

\begin{tabular}{ccccc}
\hline Grupo & Contagem & Soma & Média & Variância \\
\hline R\%FL11 & 5 & 399,6202011 & 79,92404 & 107,4291 \\
R\%FL13 & 5 & 66,25499464 & 13,251 & 72,14171 \\
R\%FL21 & 5 & $-5,906463162$ & $-1,18129$ & 455,7341 \\
\hline
\end{tabular}


TABELA A.48- Análise de variância para remoção de nitrato (FL11,FL13 e FL21) na carreira 1

\begin{tabular}{lcccccc}
\hline \multicolumn{7}{c}{ ANOVA } \\
\hline Fonte da variação & SQ & Gl & MQ & F & valor-P & F crítico \\
Entre grupos & 18719,43415 & 2 & 9359,717 & 44,1979 & $\mathbf{2 , 9 1 6 E - 0 6}$ & 3,88529 \\
Dentro dos grupos & 2541,219327 & 12 & 211,7683 & & & \\
Total & 21260,65348 & 14 & & & & \\
\hline
\end{tabular}

TABELA A.49- Testes -F para nitrato (FL11,FL13 e FL21) na carreira 1

\begin{tabular}{lrrrrrr}
\hline & R\%FL21 R\%FL11 & R\%FL21 & R\%FL13 & R\%FL11 & R\%FL13 \\
\hline Média & $-1,18129$ & 79,92404 Média & $-1,18129$ & 13,251 Média & 79,92404 & 13,251 \\
Variânci & 455,7341 & 107,4291 Variância & 455,7341 & 72,14171 Variância & 107,4291 & 72,14171 \\
Observa & 5 & 5 Observaç & 5 & 5 Observaç & 5 & 5 \\
Gl & 4 & 4 Gl & 4 & 4 gl & 4 & 4 \\
F & 4,242186 & $\mathrm{~F}$ & 6,317206 & $\mathrm{~F}$ & 1,489139 & \\
$\mathrm{P}(\mathrm{F}<=\mathrm{f})$ & 0,095285 & $\mathrm{P}(\mathrm{F}<=\mathrm{f})$ & 0,050926 & $\mathrm{P}(\mathrm{F}<=\mathrm{f})$ & 0,354515 \\
uni- & \multicolumn{7}{c}{ uni- } & caudal & uni- & \\
caudal & & F crítico & 6,388234 & caudal & \\
F crítico & 6,388234 & & F crítico & 6,388234 \\
\hline
\end{tabular}

TABELA A.50 - Teste - T para nitrato

Presumindo-se variâncias equivalentes

\begin{tabular}{lcc}
\hline & $\mathrm{R} \% \mathrm{FL} 11$ & $\mathrm{R} \% \mathrm{FL} 21$ \\
\hline Média & 79,924040 & $-1,1812926$ \\
Variância & 107,4290 & 455,7340 \\
Observações & 5 & 5 \\
Variância agrupada & 281,5815 & \\
Hipótese & 0 & \\
Gl & 8 & \\
Stat t & 7,6421808 & \\
$\mathrm{P}(\mathrm{T}<=\mathrm{t})$ uni-caudal & $3,030 \mathrm{E}-05$ & \\
$\mathrm{t}$ crítico uni-caudal & 1,85954 \\
$\mathrm{P}(\mathrm{T}<=\mathrm{t})$ bi-caudal & $\mathbf{6 , 0 6 1 E - 0 5}$ & \\
$\mathrm{t}$ crítico bi-caudal & 2,306005 & \\
\hline
\end{tabular}

TABELA A.51 - Teste - T para nitrato

Presumindo-se variâncias equivalentes

\begin{tabular}{lcc}
\hline & R\%FL11 & R\%FL13 \\
\hline Média & 79,92404022 & 13,251 \\
Variância & 107,4290547 & 72,14171 \\
Observações & 5 & 5 \\
Variância & 89,78538239 & \\
Hipótese & 0 \\
Gl & 8 \\
Stat t & 11,12544656 \\
P(T<=t) uni- & $1,90404 \mathrm{E}-06$ \\
t crítico uni- & 1,85954832 \\
P $(T<=t)$ bi- & $\mathbf{3 , 8 0 8 0 9 E - 0 6}$ \\
t crítico bi- & 2,306005626 \\
\hline
\end{tabular}


TABELA A.52 - Teste - T para nitrato

Presumindo-se variâncias equivalentes

\begin{tabular}{lcc}
\hline & R\%FL13 & R\%FL21 \\
\hline Média & 13,251 & $-1,181292632$ \\
Variância & 72,14171 & 455,734067 \\
Observações & 5 & 5 \\
Variância agrupada & 263,9379 & \\
Hipótese da diferença de média & 0 & \\
Gl & 8 & \\
Stat t & 1,404606 & \\
P(T<=t) uni-caudal & 0,098877 & \\
t crítico uni-caudal & 1,859548 & \\
P(T<=t) bi-caudal & $\mathbf{0 , 1 9 7 7 5 5}$ \\
\hline
\end{tabular}




\section{ANEXO B \\ Gráficos de correlação}

Carreira 1 


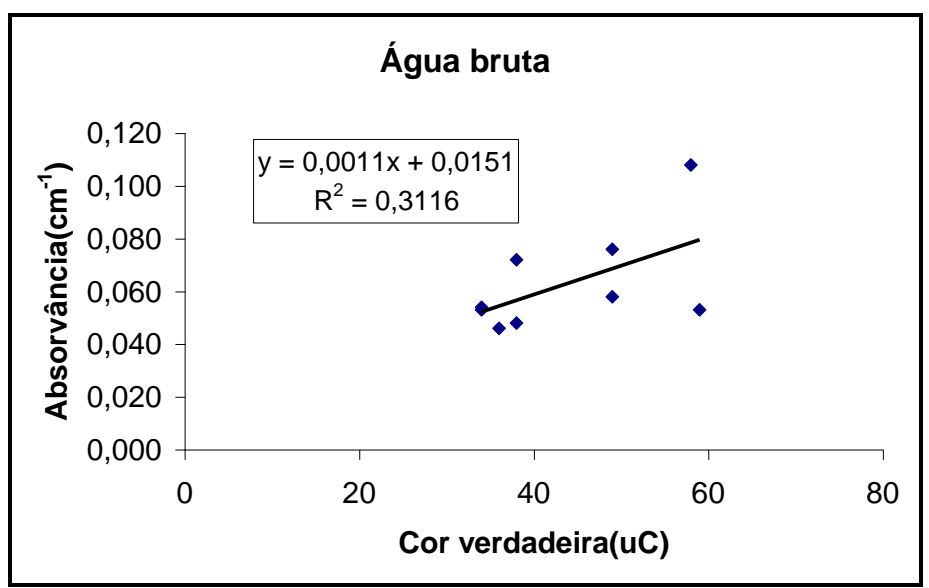

FIGURA B.1 - Correlação entre cor verdadeira e absorvância para água bruta na carreira 1

Fonte:Tabelas E.3 e E.4

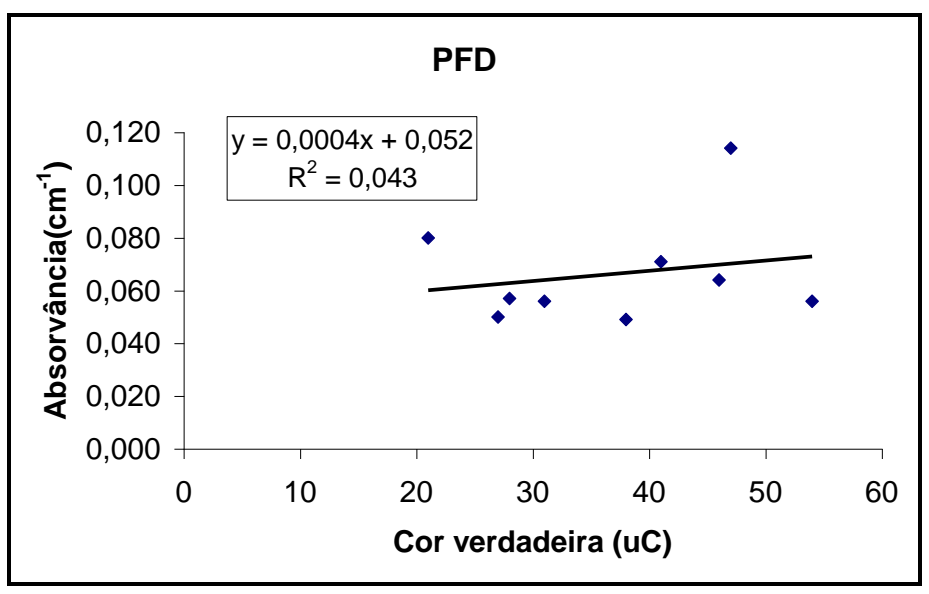

FIGURA B.2 - Correlação entre cor verdadeira e absorvância para o efluente do PFD na carreira 1

Fonte: Tabelas E.3 e E.4

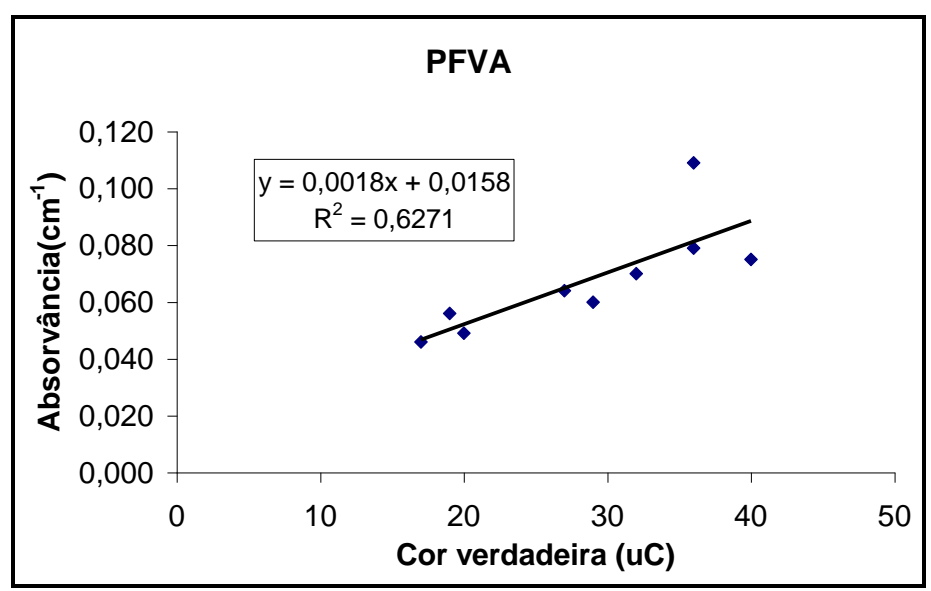

FIGURA B.3 - Correlação entre cor verdadeira e absorvância para o efluente do PFVA na carreira 1

Fonte: Tabelas E.3 e E.4 


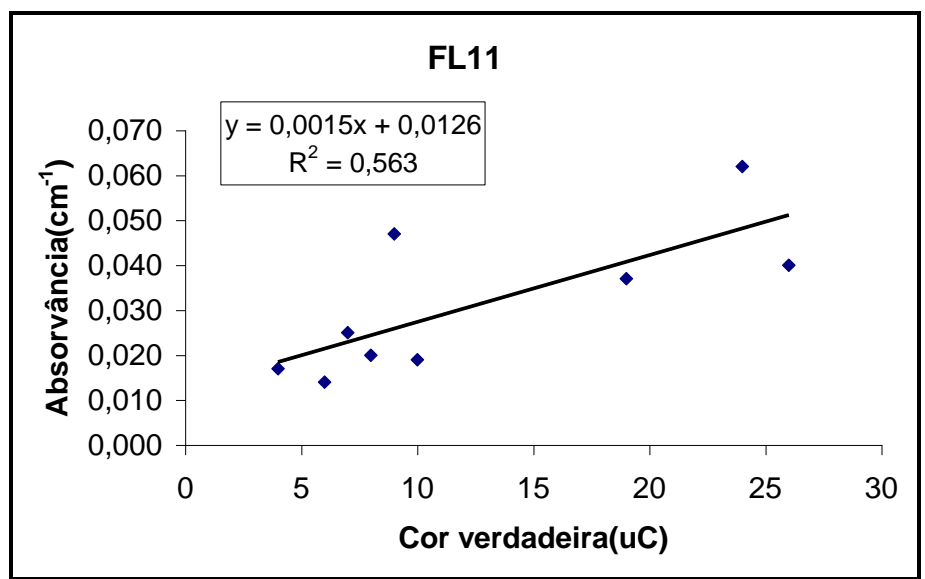

FIGURA B.4 - Correlação entre cor verdadeira e absorvância para o efluente do filtro lento 1 na carreira 1

Fonte : Tabelas E.3 e E.4

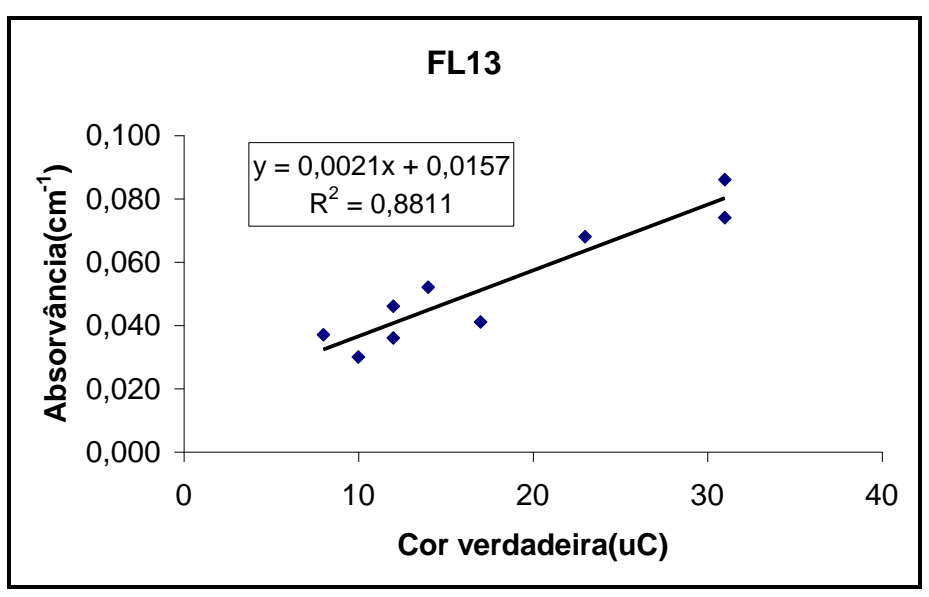

FIGURA B.5 - Correlação entre cor verdadeira e absorvância para o efluente da seção FL13 na carreira 1

Fonte: Tabelas E.3 e E.4

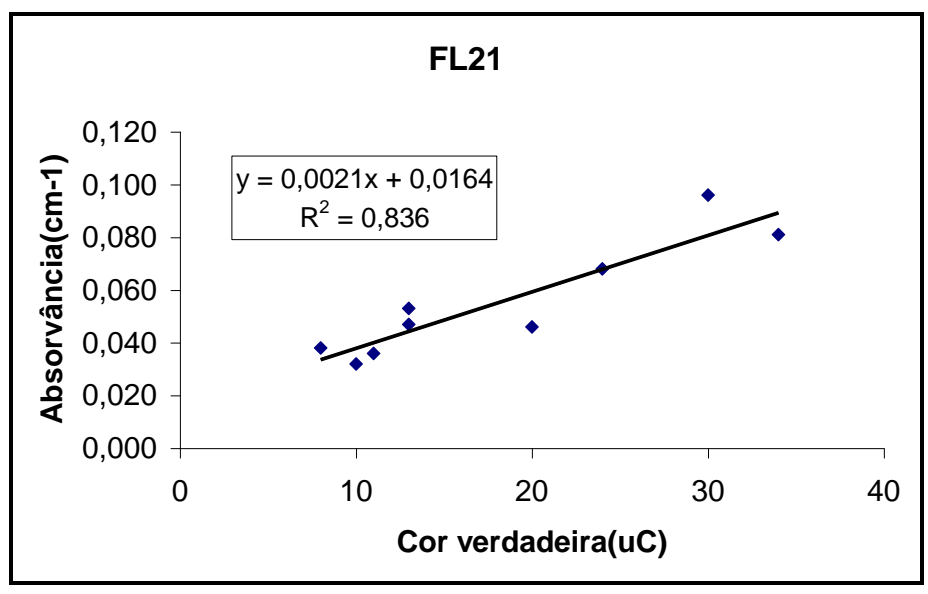

FIGURA B.6 - Correlação entre cor verdadeira e absorvância para o efluente do filtro lento 2 na carreira 1

Fonte: Tabelas E.3 e E.4 


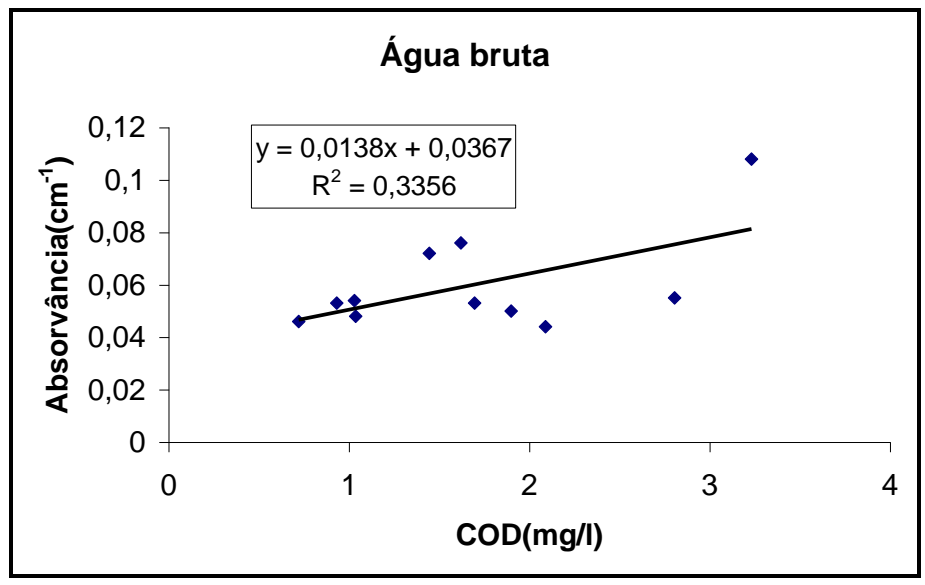

FIGURA B.7 - Correlação entre absorvância e carbono orgânico dissolvido para água bruta na carreira 1

Fonte: Tabelas E.4 e 20

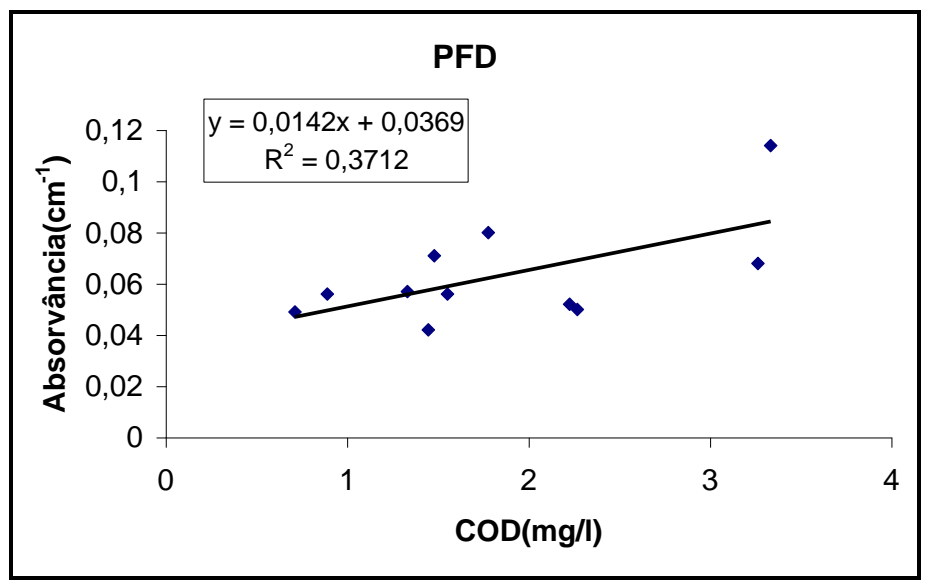

FIGURA B.8- Correlação entre absorvância e carbono orgânico dissolvido para o efluente do PFD na carreira 1

Fonte: Tabelas E.4 e 20

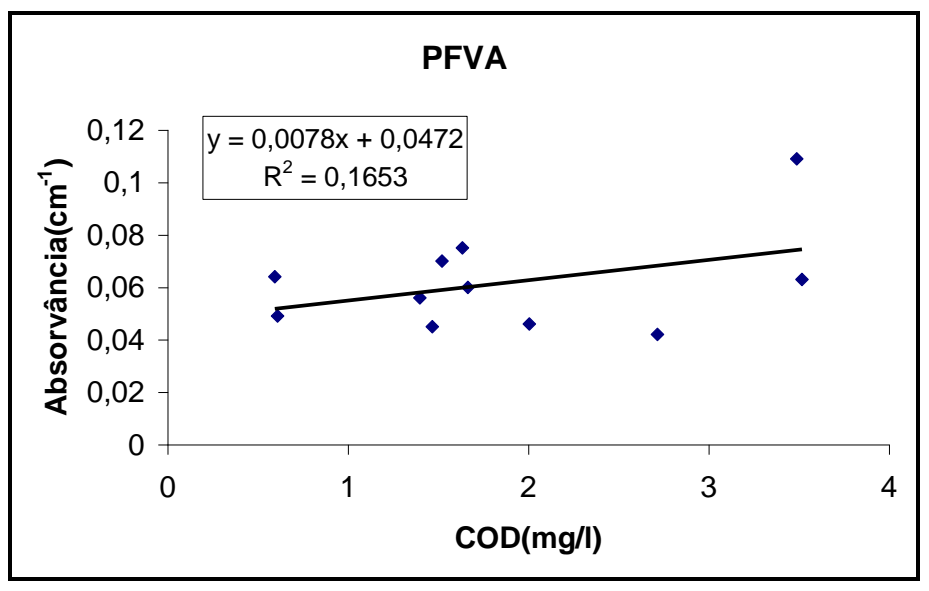

FIGURA B.9 - Correlação entre absorvância e carbono orgânico dissolvido para o efluente do PFVA na carreira 1

Fonte: Tabelas E.4 e 20 


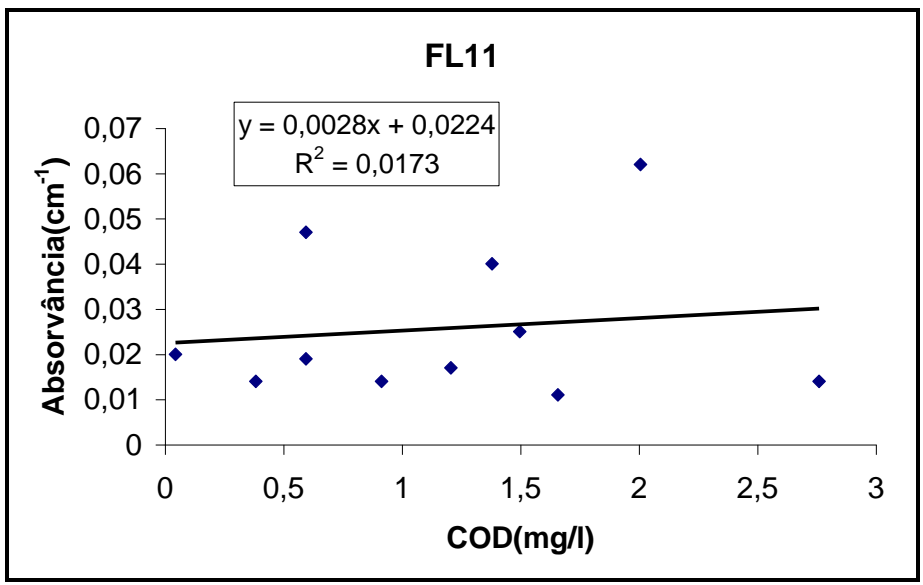

FIGURA B.10 - Correlação entre absorvância e carbono orgânico dissolvido para o efluente do filtro lento 1 na carreira 1 Fonte: Tabelas E.4 e 20

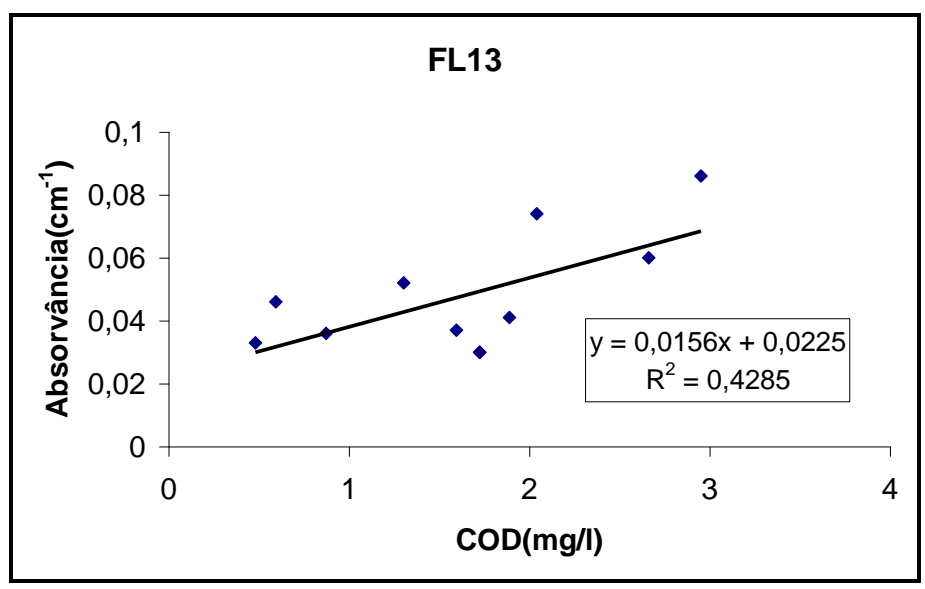

FIGURA B.11 - Correlação entre absorvância e carbono orgânico dissolvido para o efluente da seção FL13 na carreira 1 Fonte: Tabelas E.4 e 20

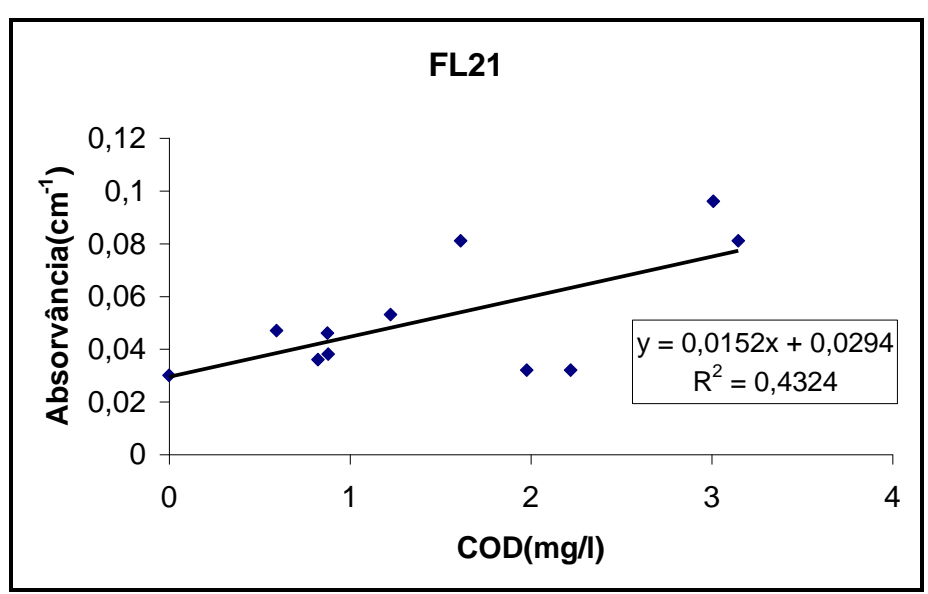

FIGURA B.12 - Correlação entre absorvância e carbono orgânico dissolvido para o efluente do filtro lento 2 na carreira 1 Fonte: Tabelas E.4 e 20 


\section{ANEXO C \\ Resultados Estatísticos}

Carreira 3 
TABELA C.1 - Cálculos da médias de remoção de turbidez para FL11, FL13 e FL21 na carreira 3

\begin{tabular}{ccccc}
\hline Grupo & Contagem & Soma & Média & Variância \\
\hline R\%FL11 & 78 & 5516,84 & 70,73 & 97,84 \\
R\%FL13 & 78 & 3918,88 & 50,24 & 187,45 \\
R\%FL21 & 78 & 4644,05 & 59,54 & 124,72 \\
\hline
\end{tabular}

TABELA C.2 - Análise de variância para remoção de turbidez (FL11, FL13 e FL21) na carreira 3

\begin{tabular}{lcccccc}
\hline \multicolumn{7}{c}{ ANOVA: fator único } \\
\hline Fonte da variação & SQ & gl & MQ & F & valor-P & F crítico \\
Entre grupos & 16414,9425 & 2 & 8207,47123 & 60,0539968 & $\mathbf{9 , 9 7 2 E - 2 2}$ & 3,0349198 \\
Dentro dos grupos & 31570,3526 & 231 & 136,668193 & & & \\
Total & 47985,2951 & 233 & & & & \\
\hline
\end{tabular}

TABELA C.3 - Teste z para turbidez

\begin{tabular}{lcc}
\hline & $\mathrm{R} \%$ FL11 & $\mathrm{R} \% \mathrm{FL} 21$ \\
\hline Média & 70,7286631 & 59,53908 \\
Variância conhecida & 97,8353536 & 124,7151 \\
& & 78 \\
Observações & 0 & 78 \\
$\begin{array}{l}\text { Hipótese da } \\
\text { diferença }\end{array}$ & 6,62440662 \\
$\mathrm{Z}$ & $1,7525 \mathrm{E}-11$ \\
$\mathrm{P}(\mathrm{Z}<=\mathrm{z})$ uni-caudal & \\
$\mathrm{z}$ crítico uni-caudal & 1,644853 \\
$\mathrm{P}(\mathrm{Z}<=\mathrm{z})$ bi-caudal & $\mathbf{3 , 5 0 4 9 E - 1 1}$ \\
$\mathrm{z}$ crítico bi-caudal & 1,95996108 \\
\hline
\end{tabular}

TABELA C. 4 - Teste z para turbidez

\begin{tabular}{lcc}
\hline & R\%FL11 & R\%FL13 \\
\hline Média & 70,72866307 & 50,24203 \\
Variância & 97,8353536 & 187,4541 \\
conhecida & & 78 \\
Observações & 78 & 78 \\
Hipótese da & 0 & \\
& \\
$\mathrm{z}$ & 10,71210913 \\
$\mathrm{P}(\mathrm{Z}<=\mathrm{z})$ uni- & 0 \\
caudal & \\
$\mathrm{z}$ crítico uni- & 1,644853 \\
caudal & \\
$\mathrm{P}(\mathrm{Z}<=\mathrm{z})$ bi-caudal & $\mathbf{0}$ \\
$\mathrm{z}$ crítico bi-caudal & 1,959961082 \\
\hline
\end{tabular}

TABELA C.5 - Teste z para turbidez

\begin{tabular}{lcc}
\hline & $\mathrm{R} \%$ FL13 & $\mathrm{R} \% \mathrm{FL} 21$ \\
\hline Média & 50,2420317 & 59,53908 \\
Variância conhecida & 187,454108 & 124,7151 \\
Observações & 78 & 78 \\
Hipótese & 0 & \\
$\mathrm{Z}$ & $-4,6472635$ & \\
$\mathrm{P}(\mathrm{Z}<=\mathrm{z})$ uni-caudal & $1,6836 \mathrm{E}-06$ & \\
$\mathrm{z}$ crítico uni-caudal & 1,644853 & \\
$\mathrm{P}(\mathrm{Z}<=\mathrm{z})$ bi-caudal & $\mathbf{3 , 3 6 7 4 E - 0 6}$ & \\
z crítico bi-caudal & 1,95996108 & \\
\hline
\end{tabular}


TABELA C.6 - Cálculos da médias de remoção de coliformes totais para FL11, FL13 e FL21 na carreira 3

\begin{tabular}{ccccc}
\hline Grupo & Contagem & Soma & Média & Variância \\
\hline R\%FL11 & 11 & 1085,7101 & 98,7009181 & 3,90384936 \\
R\%FL13 & 11 & 1064,49526 & 96,7722965 & 6,77239468 \\
R\%FL21 & 11 & 1022,82904 & 92,9844585 & 43,7185882 \\
\hline
\end{tabular}

TABELA C.7 - Análise de variância para remoção de coliformes totais(FL11, FL13 e FL21)

\begin{tabular}{lcccccc}
\hline \multicolumn{5}{c}{ ANOVA: fator único } \\
\hline Fonte da variação & SQ & gl & MQ & F & valor-P & F crítico \\
Entre grupos & 186,065765 & 2 & 93,0328824 & 5,13097726 & $\mathbf{0 , 0 1 2 1 1 7 0 3}$ & 3,31583294 \\
Dentro dos grupos & 543,948322 & 30 & 18,1316107 & & \\
Total & 730,014087 & 32 & & & \\
\hline
\end{tabular}

TABELA C. 8 - Testes -F para coliformes totais

\begin{tabular}{|c|c|c|c|c|c|c|}
\hline & R\%FL21 & R\%FL11 & R\%FL21 & R\%FL13 & R\%FL13 & $\mathrm{R} \% \mathrm{FL} 11$ \\
\hline Média & 92,98446 & 98,70092 Média & 92,98446 & 96,7723 Média & 96,7723 & 98,70092 \\
\hline Variância & 43,71859 & $\begin{array}{c}\text { 3,903849 Variânci } \\
\text { a }\end{array}$ & 43,71859 & $\begin{array}{c}\text { 6,772395 Variânci } \\
\text { a }\end{array}$ & 6,772395 & 3,903849 \\
\hline $\begin{array}{l}\text { Observaçõ } \\
\text { es }\end{array}$ & 11 & $\begin{array}{l}11 \text { Observaç } \\
\text { ões }\end{array}$ & 11 & $\begin{array}{l}11 \text { Observaç } \\
\text { ões }\end{array}$ & 11 & 11 \\
\hline gl & 10 & $10 \mathrm{gl}$ & 10 & $10 \mathrm{Gl}$ & 10 & 10 \\
\hline $\mathrm{F}$ & 11,19884 & $\mathrm{~F}$ & 6,455411 & $\mathrm{~F}$ & 1,734799 & \\
\hline $\mathrm{P}(\mathrm{F}<=\mathrm{f})$ & 0,000352 & $\mathrm{P}(\mathrm{F}<=\mathrm{f})$ & 0,003414 & $\mathrm{P}(\mathrm{F}<=\mathrm{f})$ & 0,199217 & \\
\hline F crítico & 2,97824 & F crítico & 2,97824 & F crítico & 2,97824 & \\
\hline
\end{tabular}

TABELA C.9 - Teste - $\mathrm{t}$ para coliformes totais

Presumindo-se variâncias diferentes

\begin{tabular}{lcc}
\hline & R\%FL11 & R\%FL21 \\
\hline Média & 98,70092 & 92,98446 \\
Variância & 3,903849 & 43,71859 \\
Observações & 11 & 11 \\
Hipótese da diferença de & 0 & \\
média & & \\
Gl & 12 & \\
Stat t & 2,747373 \\
P(T<=t) uni-caudal & 0,008844 \\
t crítico uni-caudal & 1,782287 \\
P(T<=t) bi-caudal & $\mathbf{0 , 0 1 7 6 8 8}$ \\
t crítico bi-caudal & 2,178813 \\
\hline
\end{tabular}

TABELA C.10 - Teste - t para CT

Presumindo-se variâncias diferentes

\begin{tabular}{lcc}
\hline & R\%FL21 & R\%FL13 \\
\hline Média & 92,98446 & 96,7723 \\
Variância & 43,71859 & 6,772395 \\
Observações & 11 & 11 \\
Hipótese da & 0 & \\
diferença de média & & \\
gl & 13 & \\
Stat t & $-1,76799$ \\
P(T<=t) uni-caudal & 0,050254 \\
t crítico uni-caudal & 1,770932 \\
P(T<=t) bi-caudal & $\mathbf{0 , 1 0 0 5 0 8}$ \\
t crítico bi-caudal & 2,160368 \\
\hline
\end{tabular}


TABELA C. 11 - Teste $-\mathrm{t}$ para coliformes

Presumindo-se variâncias equivalentes

\begin{tabular}{lcc}
\hline & R\%FL11 & R\%FL13 \\
\hline Média & 98,70092 & 96,7723 \\
Variância & 3,903849 & 6,772395 \\
Observações & 11 & 11 \\
Variância agrupada & 5,338122 & \\
Hipótese da & 0 & \\
Gl & 20 & \\
Stat t & 1,957646 & \\
P $(T<=t)$ uni-caudal & 0,032186 & \\
t crítico uni-caudal & 1,724718 & \\
$\mathrm{P}(\mathrm{T}<=t)$ bi-caudal & $\mathbf{0 , 0 6 4 3 7 2}$ & \\
$\mathrm{t}$ crítico bi-caudal & 2,085962 & \\
\hline
\end{tabular}

TABELA C.12 - Cálculos da médias de remoção de E.Coli para FL11, FL13 e FL21 na carreira 3

\begin{tabular}{ccccc}
\hline Grupo & Contagem & Soma & Média & Variância \\
\hline R\%FL11 & 11 & 1094,28571 & 99,4805195 & 2,96846011 \\
R\%FL13 & 11 & 1073,7147 & 97,6104273 & 12,3655461 \\
R\%FL21 & 11 & 1072,08707 & 97,4624613 & 40,2323976 \\
\hline
\end{tabular}

TABELA C.13 - Análise de variância para remoção de E.Coli (FL11, FL13 e FL21) na carreira 3

\begin{tabular}{lcccccc}
\hline \multicolumn{7}{c}{ ANOVA:fator único } \\
\hline Fonte da variação & SQ & gl & MQ & F & valor-P & F crítico \\
Entre grupos & 27,8362242 & 2 & 13,918112 & 0,75143132 & $\mathbf{0 , 4 8 0 3 6 1 8 7}$ & 3,31583294 \\
Dentro dos grupos & 555,664038 & 30 & 18,522134 & & & \\
Total & 583,500262 & 32 & & & & \\
\hline
\end{tabular}

TABELA C.14 - Cálculos da médias de remoção de bactérias heterotróficas para FL11, FL13 e FL21 na carreira 3

\begin{tabular}{ccccc}
\hline Grupo & Contagem & Soma & Média & Variância \\
\hline FL11 & 6 & 213,1813 & 35,53022 & 1147,343 \\
FL13 & 6 & 60,70247 & 10,11708 & 615,2628 \\
FL21 & 6 & 299,4045 & 49,90075 & 580,2214 \\
\hline
\end{tabular}


TABELA C.15 - Análise de variância para remoção de Bactérias heterotróficas(FL11, FL13 e FL21) na carreira 3

\begin{tabular}{lcccccc}
\hline \multicolumn{7}{c}{ ANOVA: fator único } \\
\hline Fonte da variação & $\mathrm{SQ}$ & $\mathrm{gl}$ & $\mathrm{MQ}$ & $\mathrm{F}$ & valor-P & F crítico \\
Entre grupos & 4870,162 & 2 & 2435,08 & 3,11813 & $\mathbf{0 , 0 7 3 7 2 2}$ & 3,682317 \\
Dentro dos grupos & 11714,13 & 15 & 780,942 & & & \\
Total & 16584,3 & 17 & & & & \\
\hline
\end{tabular}

TABELA C.16 - Cálculos da médias de remoção de SST para FL11, FL13 e FL21 na carreira 3

\begin{tabular}{ccccc}
\hline Grupo & Contagem & Soma & Média & Variância \\
\hline R\%FL11 & 21 & 1612,892 & 76,80436 & 123,0517 \\
R\%FL13 & 21 & 1500,387 & 71,44699 & 253,9269 \\
R\%FL21 & 21 & 1674,54 & 79,74002 & 436,7988 \\
\hline
\end{tabular}

TABELA C.17 - Análise de variância para remoção de SST(FL11, FL13 e FL21) na carreira 3

\begin{tabular}{lclcccc}
\hline \multicolumn{7}{c}{ ANOVA: fator único } \\
\hline Fonte da variação & SQ & gl & MQ & F & valor-P & F crítico \\
Entre grupos & 742,6582 & 2 & 371,3291 & 1,36890 & $\mathbf{0 , 2 6 2 2 1 4}$ & 3,150411 \\
Dentro dos grupos & 16275,55 & 60 & 271,2591 & & & \\
Total & 17018,21 & 62 & & & & \\
\hline
\end{tabular}

TABELA C.18 - Cálculos da médias de remoção de cor aparente para FL11, FL13 e FL21 na carreira 3

\begin{tabular}{ccccc}
\hline Grupo & Contagem & Soma & Média & Variância \\
\hline R\%FL11 & 77 & 5693,352 & 73,93964 & 50,70641 \\
R\%FL13 & 77 & 3821,592 & 49,63107 & 94,23339 \\
R\%FL21 & 77 & 4439,206 & 57,65203 & 73,35296 \\
\hline
\end{tabular}

TABELA C.19 - Análise de variância para remoção de cor aparente (FL11, FL13 e FL21) na carreira 3

\begin{tabular}{lcccccc}
\hline \multicolumn{7}{c}{ ANOVA: fator único } \\
\hline Fonte da variação & SQ & gl & MQ & F & valor-P & F crítico \\
Entre grupos & 23626,91 & 2 & 11813,46 & 162,3525 & $\mathbf{1 , 4 5 E}-44$ & 3,035438567 \\
Dentro dos grupos & 16590,25 & 228 & 72,76426 & & & \\
Total & 40217,16 & 230 & & & & \\
\hline
\end{tabular}


TABELA C.20 - Teste- z para cor aparente

\begin{tabular}{lcc}
\hline & R\%FL11 & R\%FL21 \\
\hline Média & 73,93964 & 57,65203 \\
Variância conhecida & 50,70641 & 73,35296 \\
Observações & 77 & 77 \\
Hipótese & 0 & \\
$Z$ & 12,83182 & \\
$P(Z<=z)$ uni-caudal & 0 & \\
z crítico uni-caudal & 1,644853 \\
P(Z<=z) bi-caudal & $\mathbf{0}$ & \\
z crítico bi-caudal & 1,959961 \\
\hline
\end{tabular}

TABELA C.21 - Teste- z para cor aparente

\begin{tabular}{lcc}
\hline & R\%FL11 & R\%FL13 \\
\hline Média & 73,93964 & 49,63107 \\
Variância & 50,70641 & 94,23339 \\
Observações & 77 & 77 \\
Hipótese & 0 & \\
z & 17,71785 \\
$\mathrm{P}(\mathrm{Z}<=\mathrm{z})$ uni-caudal & 0 \\
z crítico uni-caudal & 1,644853 \\
$\mathrm{P}(\mathrm{Z}<=\mathrm{z})$ bi-caudal & $\mathbf{0}$ & \\
z crítico bi-caudal & 1,959961 \\
\hline
\end{tabular}

TABELA C.22 - Teste- z para cor aparente

\begin{tabular}{lcc}
\hline & R\%FL13 & R\%FL21 \\
\hline Média & 49,63107 & 57,6520251 \\
Variância conhecida & 94,23339 & 73,35296 \\
Observações & 77 & 77 \\
Hipótese & 0 & \\
$Z$ & $-5,43691$ & \\
$\mathrm{P}(\mathrm{Z}<=\mathrm{z})$ uni-caudal & $2,72 \mathrm{E}-08$ & \\
$\mathrm{z}$ crítico uni-caudal & 1,644853 & \\
$\mathrm{P}(\mathrm{Z}<=\mathrm{z})$ bi-caudal & $\mathbf{5 , 4 3 E - 0 8}$ & \\
$\mathrm{z}$ crítico bi-caudal & $\mathbf{1 , 9 5 9 9 6 1}$ & \\
\hline
\end{tabular}

TABELA C.23 - Cálculos da médias de remoção de cor verdadeira para FL11, FL13 e FL21 na carreira 3

\begin{tabular}{ccccc}
\hline Grupo & Contagem & Soma & Média & Variância \\
\hline R\%FL11 & 66 & 4666,134 & 70,69899 & 61,54757 \\
R\%FL13 & 66 & 2840,965 & 43,04492 & 98,23029 \\
R\%FL21 & 66 & 3357,889 & 50,87711 & 101,4948 \\
\hline
\end{tabular}

TABELA C.24 - Análise de variância para remoção de cor verdadeira (FL11, FL13 e FL21) na carreira 3

\begin{tabular}{lcccccc}
\hline \multicolumn{7}{c}{ ANOVA: fator único } \\
\hline Fonte da variação & SQ & gl & MQ & F & Valor-P & F crítico \\
Entre grupos & 26817,96 & 2 & 13408,98 & 153,9653 & $\mathbf{7 , 6 0 9 1 2 E - 4 1}$ & 3,042231 \\
Dentro dos grupos & 16982,72 & 195 & 87,09089 & & & \\
Total & 43800,68 & 197 & & & & \\
\hline
\end{tabular}


TABELA C. 25 - Teste- $\mathrm{z}$ para cor verdadeira TABELA C. 26 - Teste- $\mathrm{z}$ para cor verdadeira

\begin{tabular}{lcc}
\hline & R\%FL11 & R\%FL21 \\
\hline Média & 70,69899 & 50,87711 \\
Variância conhecida & 61,54757 & 101,4948 \\
& & \\
Observações & 66 & 66 \\
Hipótese da & 0 & \\
z & 12,6115 \\
$\mathrm{P}(\mathrm{Z}<=\mathrm{z})$ uni-caudal & 0 \\
$\mathrm{z}$ crítico uni-caudal & 1,644853 \\
$\mathrm{P}(\mathrm{Z}<=\mathrm{z})$ bi-caudal & $\mathbf{0}$ \\
$\mathrm{z}$ crítico bi-caudal & 1,959961 \\
\hline
\end{tabular}

\begin{tabular}{lcc}
\hline & R\%FL11 & R\%FL13 \\
\hline Média & 70,69899 & 43,04492 \\
Variância & 61,54757 & 98,23029 \\
conhecida & & \\
Observações & 66 & 66 \\
Hipótese da & 0 & \\
$z$ & 17,77349 \\
$P(Z<=z)$ uni-caudal & 0 & \\
z crítico uni-caudal & 1,644853 \\
$P(Z<=z)$ bi-caudal & $\mathbf{0}$ & \\
z crítico bi-caudal & 1,959961 & \\
\hline
\end{tabular}

TABELA C. 27 - Teste- $z$ para cor verdadeira

\begin{tabular}{lcc}
\hline & R\%FL13 & R\%FL21 \\
\hline Média & 43,04492 & 50,87711 \\
Variância conhecida & 98,23029 & 101,4948 \\
Observações & 66 & 66 \\
Hipótese da & 0 & \\
Z & $-4,50234$ & \\
$\mathrm{P}(\mathrm{Z}<=\mathrm{z})$ uni-caudal & $3,363 \mathrm{E}-06$ \\
$\mathrm{z}$ crítico uni-caudal & 1,644853 \\
$\mathrm{P}(\mathrm{Z}<=\mathrm{z})$ bi-caudal & $\mathbf{6 , 7 2 7 E - 0 6}$ \\
$\mathrm{z}$ crítico bi-caudal & 1,959961 \\
\hline
\end{tabular}

TABELA C.28 - Cálculos da médias de remoção de absorvância para FL11, FL13 e FL21 na carreira 3

\begin{tabular}{ccccc}
\hline Grupo & Contagem & Soma & Média & Variância \\
\hline \% R FL11 & 18 & 1338,954 & 74,38633 & 48,59549 \\
\% R FL13 & 17 & 558,8759 & 32,87505 & 142,7242 \\
\% R FL21 & 18 & 1330,286 & 73,90475 & 1545,397 \\
\hline
\end{tabular}

TABELA C.29 - Análise de variância para remoção de absorvância (FL11, FL13 e FL21) na carreira 3

\begin{tabular}{lcccccc}
\hline \multicolumn{7}{c}{ ANOVA } \\
\hline Fonte da variação & SQ & gl & MQ & F & valor-P & F crítico \\
Entre grupos & 19669,84 & 2 & 9834,92 & 16,73661 & $\mathbf{2 , 7 3 E - 0 6}$ & 3,182606179 \\
Dentro dos grupos & 29381,45 & 50 & 587,629 & & & \\
Total & 49051,29 & 52 & & & & \\
\hline
\end{tabular}


TABELA C.30 - Testes-F para absorvância

\begin{tabular}{|c|c|c|c|c|c|c|}
\hline & \multicolumn{2}{|c|}{$\%$ RFL21 \%RFL13 } & \multicolumn{2}{|c|}{ \%RFL21 \%RFL11 } & \multicolumn{2}{|c|}{ \%RL13 \% R FL11 } \\
\hline Média & 73,90475 & 32,87505 Média & 73,90475 & 3632 Média & 32,87505 & 327 \\
\hline Variânci & 1545,397 & 142,7241 Variânci & 1545,397 & 549 Variânci & 142,7242 & 491 \\
\hline Observa & 18 & 17 Observaç & 18 & 18 Observaç & 17 & 18 \\
\hline $\mathrm{gl}$ & 17 & $16 \mathrm{gl}$ & 17 & $17 \mathrm{gl}$ & 16 & 17 \\
\hline $\mathrm{F}$ & 10,82785 & $\mathrm{~F}$ & 31,80123 & $\mathrm{~F}$ & 2,936984 & \\
\hline $\begin{array}{l}\mathrm{P}(\mathrm{F}<=\mathrm{f}) \\
\text { uni- } \\
\text { caudal }\end{array}$ & 8,84E-06 & $\begin{array}{l}\mathrm{P}(\mathrm{F}<=\mathrm{f}) \\
\text { uni- } \\
\text { caudal }\end{array}$ & 1,32E-09 & $\begin{array}{l}\mathrm{P}(\mathrm{F}<=\mathrm{f}) \\
\text { uni- } \\
\text { caudal }\end{array}$ & 0,016923 & \\
\hline F crítico & 2,316725 & F crítico & 2,271893 & F crítico & 2,2888 & \\
\hline
\end{tabular}

TABELA C.31 - Teste - t para absorvância

Presumindo-se variâncias diferentes

\begin{tabular}{lcc}
\hline & \% R FL11 & \% R FL21 \\
\hline Média & 74,38632781 & 73,90475 \\
Variância & 48,59549124 & 1545,397 \\
Observações & 18 & 18 \\
Hipótese da & 0 & \\
gl & 18 & \\
Stat t & 0,051175033 & \\
& $\mathrm{P}(\mathrm{T}<=\mathrm{t})$ uni- & 0,479875 \\
& $\begin{array}{c}\text { caudal } \\
\text { t crítico uni- }\end{array}$ & 1,734063 \\
& caudal & \\
& $\mathrm{P}(\mathrm{T}<=\mathrm{t})$ bi-caudal & $\mathbf{0 , 9 5 9 7 5}$ \\
& $\mathrm{t}$ crítico bi-caudal & 2,100924 \\
\hline
\end{tabular}

TABELA C.32 - Teste - t para absorvância Presumindo-se variâncias diferentes

\begin{tabular}{lcc}
\hline & \% R FL11 & \% R FL13 \\
\hline Média & 74,3863278 & 32,87505 \\
Variância & 48,5954912 & 142,7242 \\
Observações & 18 & 17 \\
Hipótese da & 0 & \\
gl & 25 & \\
Stat t & 12,4622589 & \\
& $\mathrm{P}(\mathrm{T}<=\mathrm{t})$ uni- & $1,59 \mathrm{E}-12$ \\
& caudal & \\
& $\mathrm{t}$ crítico uni- & 1,70814 \\
& caudal & \\
& $\mathrm{P}(\mathrm{T}<=\mathrm{t})$ bi-caudal & $\mathbf{3 , 1 8 E}-12$ \\
& $\mathrm{t}$ crítico bi-caudal & 2,059537 \\
\hline
\end{tabular}

TABELA C.33 - Teste $-\mathrm{t}$ para absorvância

Presumindo-se variâncias diferentes

\begin{tabular}{lcc}
\hline & \% R FL13 & \% R FL21 \\
\hline Média & 32,87505 & 73,9047516 \\
Variância & 142,7242 & 1545,39653 \\
Observações & 17 & 18 \\
Hipótese da & 0 & \\
gl & 20 & \\
Stat t & $-4,22625$ & \\
& $\mathrm{P}(\mathrm{T}<=\mathrm{t})$ uni-caudal & 0,000207 \\
& $\mathrm{t}$ crítico uni-caudal & 1,724718 \\
& $\mathrm{P}(\mathrm{T}<=\mathrm{t})$ bi-caudal & $\mathbf{0 , 0 0 0 4 1}$ \\
& $\mathrm{t}$ crítico bi-caudal & 2,085962 \\
\hline
\end{tabular}


TABELA C.34 - Cálculos da médias de remoção de COD para FL11, FL13 e FL21 na carreira 3

\begin{tabular}{ccccc}
\hline Grupo & Contagem & Soma & Média & Variância \\
\hline \%R FL11 & 16 & 994,3285 & 62,14553 & 297,2153 \\
\%R FL13 & 13 & 299,9974 & 23,07672 & 175,9071 \\
\%R FL21 & 10 & 250,7245 & 25,07245 & 210,9959 \\
\hline
\end{tabular}

TABELA C.35 - Análise de variância para remoção de COD (FL11, FL13 e FL21)

\begin{tabular}{lcccccc}
\hline \multicolumn{7}{c}{ ANOVA: fator único } \\
\hline Fonte da variação & SQ & gl & MQ & F & valor-P & F crítico \\
Entre grupos & 13792,55 & 2 & 6896,274 & 29,31785 & $\mathbf{2 , 7 8 2 6 3 E - 0 8}$ & 3,259444 \\
Dentro dos grupos & 8468,078 & 36 & 235,2244 & & & \\
Total & 22260,63 & 38 & & & & \\
\hline
\end{tabular}

TABELA C.36 - Testes- F para COD na carreira 3

\begin{tabular}{|c|c|c|c|c|c|c|}
\hline & \multicolumn{2}{|c|}{ \%R FL11 \%R FL13 } & \multicolumn{2}{|c|}{ \%R FL11 \%R FL21 } & \multicolumn{2}{|c|}{ \%R FL21 \%R FL13 } \\
\hline Média & 62,14553 & 23,07672 Média & 62,145532 & 25,07245 Média & 25,07245 & 23,07672 \\
\hline Variânc & 297,2153 & 175,9071 Variânc & $\begin{array}{r}297,21533 \\
4\end{array}$ & $210,9959 \mathrm{Va}$ & 210,9959 & 175,9070 \\
\hline Observ & 16 & $13 \mathrm{Ob}$ & 16 & $10 \mathrm{Ot}$ & 10 & 13 \\
\hline $\mathrm{gl}$ & 15 & $12 \mathrm{Gl}$ & 15 & $9 \mathrm{gl}$ & 9 & 12 \\
\hline $\mathrm{F}$ & 1,689615 & $\mathrm{~F}$ & 1,4086311 & $\mathrm{~F}$ & 1,199473 & \\
\hline $\mathrm{P}(\mathrm{F}<=\mathrm{f})$ & $\mathbf{0 , 1 8 2 5 8 8}$ & $P(F<=f)$ & 0,3074312 & $P(F<=f)$ & 0,376056 & \\
\hline $\begin{array}{l}\text { F crítico } \\
\text { uni- }\end{array}$ & 2,616851 & $\begin{array}{l}\text { F } \\
\text { crítico } \\
\text { uni- }\end{array}$ & 3,0061073 & $\begin{array}{l}\text { F crítico } \\
\text { uni- } \\
\text { caudal }\end{array}$ & 2,796376 & \\
\hline
\end{tabular}

TABELA C.37 - Teste - t para COD

Presumindo-se variâncias equivalentes

\begin{tabular}{lcc}
\hline & \%R FL11 & \%R FL21 \\
\hline Média & 62,14553235 & 25,07245 \\
Variância & 297,2153342 & 210,9959 \\
Observações & 16 & 10 \\
Variância agrupada & 264,8830296 & \\
Hipótese da & 0 & \\
diferença de média & & \\
gl & 24 \\
Stat t & 5,650735786 \\
$\mathrm{P}(\mathrm{T}<=\mathrm{t})$ uni-caudal & $4,04493 \mathrm{E}-06$ \\
$\mathrm{t}$ crítico uni-caudal & 1,710882316 \\
$\mathrm{P}(\mathrm{T}<=\mathrm{t})$ bi-caudal & $\mathbf{8 , 0 8 9 8 7 E - 0 6}$ \\
$\mathrm{t}$ crítico bi-caudal & 2,063898137 \\
\hline
\end{tabular}

TABELA C. 38 - Teste $-\mathrm{t}$ para COD

Presumindo-se variâncias equivalentes

\begin{tabular}{lcc}
\hline & \%R FL11 & \%R FL13 \\
\hline Média & 62,14553 & 23,07672 \\
Variância & 297,2153 & 175,9071 \\
Observações & 16 & 13 \\
Variância agrupada & 243,3006 & \\
Hipótese & 0 \\
& \\
gl & 27 \\
Stat t & 6,707973 \\
$\mathrm{P}(\mathrm{T}<=\mathrm{t})$ uni-caudal & $1,68 \mathrm{E}-07$ \\
$\mathrm{t}$ crítico uni-caudal & 1,703288 \\
$\mathrm{P}(\mathrm{T}<=\mathrm{t})$ bi-caudal & $\mathbf{3 , 3 5 E - 0 7}$ \\
$\mathrm{t}$ crítico bi-caudal & 2,051829 & \\
\hline
\end{tabular}


TABELA C.39- Teste-t para COD

Presumindo-se variâncias equivalentes

\begin{tabular}{lcc}
\hline & \%R FL13 & \%R FL21 \\
\hline Média & 23,07672 & 25,07245 \\
Variância & 175,9071 & 210,9959 \\
Observações & 13 & 10 \\
Variância agrupada & 190,9451 & \\
Hipótese & 0 & \\
gl & 21 \\
Stat t & $-0,34336$ \\
P(T<=t) uni-caudal & 0,367369 \\
t crítico uni-caudal & 1,720744 \\
P(T<=t) bi-caudal & $\mathbf{0 , 7 3 4 7 3 9}$ \\
t crítico bi-caudal & 2,079614 \\
\hline
\end{tabular}

TABELA C.40 - Cálculos da médias de remoção de OC para FL11, FL13 e FL21 na carreira 3

\begin{tabular}{ccccc}
\hline Grupo & Contagem & Soma & Média & Variância \\
\hline R\%FL11 & 19 & 1525,176 & 80,27244 & 211,3026 \\
R\%FL13 & 19 & 779,9265 & 41,04876 & 613,0205 \\
R\%FL21 & 17 & 763,7625 & 44,9272 & 536,7304 \\
\hline
\end{tabular}

TABELA C.41 - Análise de variância para remoção de OC (FL11, FL13 e FL21) na carreira 3

\begin{tabular}{lcccccc}
\hline \multicolumn{6}{c}{ ANOVA: fator único } \\
\hline Fonte da variação & SQ & gl & MQ & F & valor-P & F crítico \\
Entre grupos & 17523,1832 & 2 & 8761,59 & 19,44901 & $\mathbf{4 , 9 3 9 4 E - 0 7}$ & 3,175145 \\
Dentro dos grupos & 23425,5009 & 52 & 450,490 & & & \\
Total & 40948,6841 & 54 & & & & \\
\hline
\end{tabular}

TABELA C.42 - Testes -F para oxigênio consumido na carreira 3

\begin{tabular}{|c|c|c|c|c|c|c|}
\hline & $\%$ FL13 & $\%$ FL11 & $\%$ FL13 & $\%$ FL21 & $\%$ FL21 & $\%$ FL11 \\
\hline Média & 41,04876 & 80,27244 Média & 41,04876 & 44,92720 Média & 44,9272 & 80,27243 \\
\hline Variânci & $\begin{array}{r}613,0204 \\
6\end{array}$ & 211,3026 Variânci & 613,0205 & $\begin{array}{c}536,7303 \text { Variânci } \\
6\end{array}$ & 536,7304 & $\begin{array}{r}211,3025 \\
8\end{array}$ \\
\hline Observa & 19 & 19 Observaç & 19 & 17 Observaç & 17 & 19 \\
\hline $\mathrm{gl}$ & 18 & $18 \mathrm{Gl}$ & 18 & $16 \mathrm{Gl}$ & 16 & 18 \\
\hline $\mathrm{F}$ & $\begin{array}{r}2,901149 \\
7\end{array}$ & $\mathrm{~F}$ & 1,142139 & $\mathrm{~F}$ & 2,540103 & \\
\hline $\begin{array}{l}\mathrm{P}(\mathrm{F}<=\mathrm{f}) \\
\text { uni- }\end{array}$ & 0,014649 & $\begin{array}{l}\mathrm{P}(\mathrm{F}<=\mathrm{f}) \\
\text { uni- }\end{array}$ & 0,397639 & $\begin{array}{l}\mathrm{P}(\mathrm{F}<=\mathrm{f}) \\
\text { uni-c }\end{array}$ & $\mathbf{0 , 0 2 9 7 6 9}$ & \\
\hline $\begin{array}{l}\text { F crítico } \\
\text { uni- } \\
\text { caudal }\end{array}$ & $\begin{array}{r}2,217198 \\
7\end{array}$ & $\begin{array}{l}\text { F crítico } \\
\text { uni- } \\
\text { caudal }\end{array}$ & 2,30164 & $\begin{array}{l}\text { F crítico } \\
\text { uni- } \\
\text { caudal }\end{array}$ & 2,249585 & \\
\hline
\end{tabular}


TABELA C.43- Teste $-\mathrm{t}$ para OD

Presumindo-se variâncias equivalentes equivalentes

\begin{tabular}{lcc}
\hline & $\mathrm{R} \%$ FL11 & $\mathrm{R} \% \mathrm{FL} 21$ \\
\hline Média & 80,2724361 & 44,9272 \\
Variância & 211,302586 & 536,7304 \\
Observações & 19 & 17 \\
Hipótese da diferença & 0 & \\
de média & & \\
gl & 26 & \\
Stat t & 5,40940681 & \\
$\mathrm{P}(\mathrm{T}<=\mathrm{t})$ uni-caudal & $5,7222 \mathrm{E}-06$ \\
$\mathrm{t}$ crítico uni-caudal & 1,70561634 \\
$\mathrm{P}(\mathrm{T}<=\mathrm{t})$ bi-caudal & $\mathbf{1 , 1 4 4 4 E - 0 5}$ \\
$\mathrm{t}$ crítico bi-caudal & 2,05553079 \\
\hline
\end{tabular}

TABELA C. 44 - Teste $-\mathrm{t}$ para OD

Presumindo-se variâncias

\begin{tabular}{lcc}
\hline & R\%FL13 & R\%FL11 \\
\hline Média & 41,04876 & 80,27244 \\
Variância & 613,0205 & 211,3026 \\
Observações & 19 & 19 \\
Hipótese da diferença & 0 & \\
de média & & \\
gl & 29 & \\
Stat t & $-5,95493$ \\
P(T<=t) uni-caudal & $9,01 \mathrm{E}-07$ \\
t crítico uni-caudal & 1,699127 \\
P(T<=t) bi-caudal & $\mathbf{1 , 8 E - 0 6}$ \\
t crítico bi-caudal & 2,045231 \\
\hline
\end{tabular}

TABELA C.45 - Teste-t para OD

Presumindo-se variâncias diferentes

\begin{tabular}{lcc}
\hline & R\%FL13 & R\%FL21 \\
\hline Média & 41,04876 & 44,92720 \\
Variância & 613,0205 & 536,7303 \\
Observações & 19 & 17 \\
Variância agrupada & 577,1192 & \\
Hipótese da diferença & 0 & \\
gl & 34 & \\
Stat t & $-0,48359$ & \\
P $(\mathrm{T}<=t)$ uni-caudal & 0,31589 & \\
t crítico uni-caudal & 1,690923 \\
P $(T<=t)$ bi-caudal & $\mathbf{0 , 6 3 1 7 7 9}$ & \\
t crítico bi-caudal & 2,032243 & \\
\hline
\end{tabular}

TABELA C.46 - Cálculos da médias de remoção de OD para FL11, FL13 e FL21 na carreira 3

\begin{tabular}{ccccc}
\hline Grupo & Contagem & Soma & Média & Variância \\
\hline \% R FL11 & 11 & 706,434 & 64,22128 & 633,1539 \\
\%R FL13 & 9 & 106,9795 & 11,88661 & 36,4014 \\
\%R FL21 & 9 & 56,54265 & 6,282516 & 14,26427 \\
\hline
\end{tabular}

TABELA C.47 - Cálculos da médias de remoção de ferro para FL11, FL13 e FL21 na carreira 3

\begin{tabular}{ccccc}
\hline Grupo & Contagem & Soma & Média & Variância \\
\hline R\%FL11 & 6 & 447,0521 & 74,50869 & 261,36 \\
R\%FL13 & 7 & 398,8219 & 56,97456 & 1127,321 \\
R\%FL21 & 5 & 314,4624 & 62,89249 & 747,871 \\
\hline
\end{tabular}


TABELA C.48 - Análise de variância para remoção de ferro (FL11, FL13 e FL21) na carreira 3

\begin{tabular}{lcccccc}
\hline \multicolumn{7}{c}{ ANOVA } \\
\hline Fonte da variação & $\mathrm{SQ}$ & $\mathrm{gl}$ & $\mathrm{MQ}$ & $\mathrm{F}$ & valor-P & F crítico \\
Entre grupos & 1010,365 & 2 & 505,1824 & 0,685011 & $\mathbf{0 , 5 1 9 1 7 6}$ & 3,682317 \\
Dentro dos grupos & 11062,21 & 15 & 737,4808 & & & \\
Total & 12072,58 & 17 & & & & \\
\hline
\end{tabular}

TABELA C.49 - Cálculos da médias de remoção de fosfato para FL11, FL13 e FL21 na carreira 3

\begin{tabular}{ccccc}
\hline Grupo & Contagem & Soma & Média & Variância \\
\hline \%R FL11 & 9 & 285,3094 & 31,70105 & 991,4404 \\
\%R FL13 & 8 & 537,7705 & 67,22132 & 644,2366 \\
\% R FL21 & 7 & 413,8771 & 59,1253 & 389,1269 \\
\hline
\end{tabular}

TABELA C.50 - Análise de variância para remoção de fosfato (FL11, FL13 e FL21) na carreira 3

\begin{tabular}{lcccccc}
\hline \multicolumn{7}{c}{ ANOVA: fato único } \\
\hline Fonte da variação & SQ & gl & MQ & F & valor-P & F crítico \\
Entre grupos & 5912,244 & 2 & 2956,122 & 4,201327 & $\mathbf{0 , 0 2 9 1 9 1}$ & 3,466795 \\
Dentro dos grupos & 14775,94 & 21 & 703,6162 & & & \\
Total & 20688,18 & 23 & & & & \\
\hline
\end{tabular}

TABELA C.51 - Testes F para fosfato na carreira 3

\begin{tabular}{|c|c|c|c|c|c|c|}
\hline & $\%$ RFL11 & \%RFL13 & \%RFL11 & \%RFL21 & \%RFL13 & \%RFL21 \\
\hline Média & 31,70105 & 67,22132 Média & 31,70105 & 59,1253 Média & 67,22132 & 59,1253 \\
\hline Variância & 991,4404 & 644,2366 Variância & 991,4404 & 389,1269 Variância & 644,2366 & 389,1269 \\
\hline Observaç & 9 & 8 Observaç & 9 & 7 Observaç & 8 & 7 \\
\hline $\mathrm{gl}$ & 8 & $7 \mathrm{Gl}$ & 8 & $6 \mathrm{gl}$ & 7 & 6 \\
\hline $\mathrm{F}$ & 1,538938 & $\mathrm{~F}$ & 2,547859 & $\mathrm{~F}$ & 1,655595 & \\
\hline $\begin{array}{l}\mathrm{P}(\mathrm{F}<=\mathrm{f}) \\
\text { uni- } \\
\text { caudal }\end{array}$ & 0,291697 & $\begin{array}{l}\mathrm{P}(\mathrm{F}<=\mathrm{f}) \\
\text { uni- } \\
\text { caudal }\end{array}$ & $\mathbf{0 , 1 3 5 3 8 7}$ & $\begin{array}{l}\mathrm{P}(\mathrm{F}<=\mathrm{f}) \\
\text { uni- } \\
\text { caudal }\end{array}$ & 0,277859 & \\
\hline $\begin{array}{l}\text { F crítico } \\
\text { uni- } \\
\text { caudal }\end{array}$ & 3,725717 & $\begin{array}{l}\text { F crítico } \\
\text { uni- } \\
\text { caudal }\end{array}$ & 4,146813 & $\begin{array}{l}\text { F crítico } \\
\text { uni- } \\
\text { caudal }\end{array}$ & 4,206669 & \\
\hline
\end{tabular}


TABELA C.52- Teste $-\mathrm{t}$ para fosfato

Presumindo-se variâncias equivalentes

\begin{tabular}{lcc}
\hline & \%R FL11 & \% R FL21 \\
\hline Média & 31,70105 & 59,1253 \\
Variância & 991,4404 & 389,1269 \\
Observações & 9 & 7 \\
Variância agrupada & 733,306 & \\
Hipótese da diferença & 0 \\
de média & \\
gl & 14 \\
Stat t & $-2,00957$ \\
$\mathrm{P}(\mathrm{T}<=\mathrm{t})$ uni-caudal & 0,032079 \\
$\mathrm{t}$ crítico uni-caudal & 1,761309 \\
$\mathrm{P}(\mathrm{T}<=\mathrm{t})$ bi-caudal & $\mathbf{0 , 0 6 4 1 5 8}$ \\
$\mathrm{t}$ crítico bi-caudal & 2,144789 \\
\hline
\end{tabular}

TABELA C.53- Teste $-\mathrm{t}$ para fosfato

Presumindo-se variâncias equivalentes

\begin{tabular}{lcc}
\hline & \%R FL11 & \%R FL13 \\
\hline Média & 31,70105 & 67,22132 \\
Variância & 991,4404 & 644,2366 \\
Observações & 9 & 8 \\
Variância agrupada & 829,4119 & \\
Hipótese & 0 \\
gl & 15 \\
Stat t & $-2,53824$ \\
$\mathrm{P}(\mathrm{T}<=\mathrm{t})$ uni-caudal & 0,011361 \\
$\mathrm{t}$ crítico uni-caudal & 1,753051 \\
$\mathrm{P}(\mathrm{T}<=\mathrm{t})$ bi-caudal & $\mathbf{0 , 0 2 2 7 2 1}$ \\
$\mathrm{t}$ crítico bi-caudal & 2,131451 \\
\hline
\end{tabular}

TABELA C.54- Teste - $\mathrm{t}$ para fosfato

Presumindo-se variâncias equivalentes

\begin{tabular}{lrr}
\hline & \%R FL13 & \% R FL21 \\
\hline Média & 67,22132 & 59,1253 \\
Variância & 644,2366 & 389,1269 \\
Observações & 8 & 7 \\
Variância agrupada & 526,4936 & \\
Hipótese da diferença de média & 0 & \\
gl & 13 & \\
Stat t & 0,681747 & \\
P(T<=t) uni-caudal & 0,253682 & \\
t crítico uni-caudal & 1,770932 & \\
P(T<=t) bi-caudal & $\mathbf{0 , 5 0 7 3 6 3}$ \\
t crítico bi-caudal & 2,160368 \\
\hline
\end{tabular}

TABELA C.55 - Cálculos da médias de remoção de nitrogênio amoniacal para FL11, FL13 e FL21

\begin{tabular}{ccccc}
\hline Grupo & Contagem & Soma & Média & Variância \\
\hline \%R FL11 & 9 & 382,0861 & 42,45401 & 310,4952 \\
\%R FL13 & 8 & 191,6729 & 23,95911 & 51,50037 \\
\% R FL21 & 8 & 193,5276 & 24,19095 & 32,93185 \\
\hline
\end{tabular}

TABELA C.56 - Análise de variância para remoção de nitrogênio amoniacal (FL11, FL13 e FL21) na carreira 3

\begin{tabular}{lcccccc}
\hline \multicolumn{7}{c}{ ANOVA: fator único } \\
\hline Fonte da variação & SQ & gl & MQ & F & valor-P & F crítico \\
Entre grupos & 1945,867 & 2 & 972,9337 & 6,960855 & $\mathbf{0 , 0 0 4 5 4 7}$ & 3,443361 \\
Dentro dos grupos & 3074,987 & 22 & 139,7722 & & & \\
Total & 5020,855 & 24 & & & & \\
\hline
\end{tabular}


TABELA C.57 - Testes -F para nitrogênio amoniacal na carreira 3

\begin{tabular}{|c|c|c|c|c|c|c|}
\hline & $\%$ RFL11 & $\%$ RFL13 & $\%$ RFL11 & $\%$ RFL21 & $\%$ RFL13 & $\%$ RFL21 \\
\hline Média & 42,45401 & 23,95911 Média & 42,45401 & 24,19095 Média & 23,95911 & 24,19095 \\
\hline $\begin{array}{l}\text { Variânci } \\
\text { a }\end{array}$ & 310,4952 & 51,50037 Variância & 310,4952 & 32,93185 Variância & 51,50037 & 32,93185 \\
\hline $\begin{array}{l}\text { Observa } \\
\text { cõ }\end{array}$ & 9 & $\begin{array}{l}8 \text { Observaç } \\
\tilde{\text { o }}\end{array}$ & 9 & $\begin{array}{l}8 \text { Observaç } \\
\tilde{\text { o }}\end{array}$ & 8 & \\
\hline gl & 8 & $7 \mathrm{gl}$ & 8 & $7 \mathrm{gl}$ & 7 & \\
\hline $\mathbf{F}$ & 6,028991 & $\mathrm{~F}$ & 9,428417 & $\mathrm{~F}$ & 1,563847 & \\
\hline $\begin{array}{l}\mathbf{P}(\mathbf{F}<=\mathbf{f}) \\
\text { uni- } \\
\text { caudal }\end{array}$ & 0,01426 & $\begin{array}{l}\mathrm{P}(\mathrm{F}<=\mathrm{f}) \\
\text { uni- } \\
\text { caudal }\end{array}$ & 0,003902 & $\begin{array}{l}\mathrm{P}(\mathrm{F}<=\mathrm{f}) \\
\text { uni- } \\
\text { caudal }\end{array}$ & 0,284823 & \\
\hline $\begin{array}{l}\text { F crítico } \\
\text { uni- } \\
\text { caudal }\end{array}$ & 3,725717 & $\begin{array}{l}\text { F crítico } \\
\text { uni- } \\
\text { caudal }\end{array}$ & 3,725717 & $\begin{array}{l}\text { F crítico } \\
\text { uni- } \\
\text { caudal }\end{array}$ & 3,787051 & \\
\hline
\end{tabular}

TABELA C.58- Teste - $\mathrm{t}$ para N.amoniacal

Presumindo-se variâncias diferentes

\begin{tabular}{lcc}
\hline & \%R FL11 \%R FL13 \\
\hline Média & 42,45401 & 23,95911 \\
Variância & 310,4952 & 51,50037 \\
Observações & 9 & 8 \\
Hipótese da diferença & 0 & \\
de média & & \\
gl & 11 \\
Stat t & 2,890639 \\
P(T<=t) uni-caudal & 0,007345 \\
t crítico uni-caudal & 1,795884 \\
P(T<=t) bi-caudal & $\mathbf{0 , 0 1 4 6 8 9}$ \\
t crítico bi-caudal & 2,200986 \\
\hline
\end{tabular}

TABELA C.59- Teste - $\mathrm{t}$ para N.amoniacal

Presumindo-se variâncias diferentes

\begin{tabular}{lcc}
\hline & \%R FL11 \% R FL21 \\
\hline Média & 42,45401 & 24,19095 \\
Variância & 310,4952 & 32,93185 \\
Observações & 9 & 8 \\
Hipótese da diferença & 0 & \\
de média & & \\
Gl & 10 \\
Stat t & 2,938936 \\
$\mathrm{P}(\mathrm{T}<=\mathrm{t})$ uni-caudal & 0,007406 \\
$\mathrm{t}$ crítico uni-caudal & 1,812462 \\
$\mathrm{P}(\mathrm{T}<=\mathrm{t})$ bi-caudal & $\mathbf{0 , 0 1 4 8 1 2}$ \\
$\mathrm{t}$ crítico bi-caudal & 2,228139 \\
\hline
\end{tabular}

TABELA C.60- Teste $-\mathrm{t}$ para N.amoniacal

Presumindo-se variâncias equivalentes

\begin{tabular}{lcc}
\hline & \%R FL13 & \% R FL21 \\
\hline Média & 23,95911 & 24,19095 \\
Variância & 51,50037 & 32,93185 \\
Observações & 8 & 8 \\
Variância agrupada & 42,21611 & \\
Hipótese da diferença de média & 0 & \\
gl & 14 \\
Stat t & $-0,07136$ \\
P(T<=t) uni-caudal & 0,472059 \\
t crítico uni-caudal & 1,761309 \\
P(T<=t) bi-caudal & $\mathbf{0 , 9 4 4 1 1 7}$ \\
t crítico bi-caudal & 2,144789 & \\
\hline
\end{tabular}


TABELA C.61 - Cálculos da médias de remoção de nitrito para FL11, FL13 e FL21 na carreira 3

\begin{tabular}{ccccc}
\hline Grupo & Contagem & Soma & Média & Variância \\
\hline \%R FL11 & 8 & 347,6379 & 43,45473 & 554,1668 \\
\%R FL13 & 8 & 434,2474 & 54,28093 & 63,08032 \\
\% R FL21 & 8 & 513,7337 & 64,21671 & 120,2578 \\
\hline
\end{tabular}

TABELA C.62 - Análise de variância para remoção de nitrito (FL11,FL13 e FL21) na carreira 3

\begin{tabular}{lcccccc}
\hline \multicolumn{7}{c}{ ANOVA: fator único } \\
\hline Fonte da variação & $\mathrm{SQ}$ & $\mathrm{gl}$ & $\mathrm{MQ}$ & $\mathrm{F}$ & valor-P & F crítico \\
Entre grupos & 1725,296 & 2 & 862,6478 & 3,509052 & $\mathbf{0 , 0 4 8 4 3 9}$ & 3,466795 \\
Dentro dos grupos & 5162,535 & 21 & 245,835 & & & \\
Total & 6887,83 & 23 & & & & \\
\hline
\end{tabular}

TABELA C.63 - Testes-F para nitrito

\begin{tabular}{|c|c|c|c|c|c|c|}
\hline & $\%$ RFL11 & $\%$ RFL13 & \%RFL11 & \%RFL21 & \%RFL21 & \%RFL13 \\
\hline Média & 43,45473 & 54,28093 Média & 43,45473 & 64,21671 Média & 64,21671 & 54,28093 \\
\hline Variância & 554,1668 & 63,08032 Variância & 554,1668 & 120,2578 Variância & 120,2578 & 63,08032 \\
\hline Observaç & 8 & 8 Observaç & 8 & 8 Observaç & 8 & 8 \\
\hline$\tilde{\mathrm{o}}$ & & $\tilde{o}$ & & $\tilde{o}$ & & \\
\hline $\mathrm{gl}$ & 7 & $7 \mathrm{gl}$ & 7 & $7 \mathrm{gl}$ & 7 & 7 \\
\hline $\mathrm{F}$ & 8,785098 & $\mathrm{~F}$ & 4,608157 & $\mathrm{~F}$ & 1,906423 & \\
\hline $\begin{array}{l}\mathrm{P}(\mathrm{F}<=\mathrm{f}) \\
\text { uni- } \\
\text { caudal }\end{array}$ & $\mathbf{0 , 0 0 5 1 7}$ & $\begin{array}{l}\mathrm{P}(\mathrm{F}<=\mathrm{f}) \\
\text { uni- } \\
\text { caudal }\end{array}$ & $\mathbf{0 , 0 3 0 7 7 8}$ & $\begin{array}{l}\mathrm{P}(\mathrm{F}<=\mathrm{f}) \\
\text { uni- } \\
\text { caudal }\end{array}$ & 0,206967 & \\
\hline $\begin{array}{l}\text { F crítico } \\
\text { uni- } \\
\text { caudal }\end{array}$ & 3,787051 & $\begin{array}{l}\text { F crítico } \\
\text { uni- } \\
\text { caudal }\end{array}$ & 3,787051 & $\begin{array}{l}\text { F crítico } \\
\text { uni- } \\
\text { caudal }\end{array}$ & 3,787051 & \\
\hline
\end{tabular}

TABELA C.64- Teste - t para nitrito

Presumindo-se variâncias diferentes

\begin{tabular}{lcc}
\hline & \%R FL11 \%R FL13 \\
\hline Média & 43,45473 & 54,28093 \\
Variância & 554,1668 & 63,08032 \\
Observações & 8 & 8 \\
Hipótese da diferença & 0 & \\
de média & & \\
gl & 9 \\
Stat t & $-1,23251$ \\
P(T<=t) uni-caudal & 0,124491 \\
t crítico uni-caudal & 1,833114 \\
$\mathrm{P}(\mathrm{T}<=\mathrm{t})$ bi-caudal & $\mathbf{0 , 2 4 8 9 8 3}$ \\
$\mathrm{t}$ crítico bi-caudal & 2,262159 \\
\hline
\end{tabular}

TABELA C.65- Teste - $\mathrm{t}$ para nitrito

Presumindo-se variâncias diferentes

\begin{tabular}{lcc}
\hline & \%R FL11 \% R FL21 \\
\hline Média & 43,45473 & 64,21671 \\
Variância & 554,1668 & 120,2578 \\
Observações & 8 & 8 \\
Hipótese da diferença & 0 & \\
de média & & \\
gl & 10 \\
Stat t & $-2,26124$ \\
$\mathrm{P}(\mathrm{T}<=\mathrm{t})$ uni-caudal & 0,023634 \\
$\mathrm{t}$ crítico uni-caudal & 1,812462 \\
$\mathrm{P}(\mathrm{T}<=\mathrm{t})$ bi-caudal & $\mathbf{0 , 0 4 7 2 6 9}$ \\
$\mathrm{t}$ crítico bi-caudal & 2,228139 \\
\hline
\end{tabular}


TABELA C.66- Teste - t para nitrito

Presumindo-se variâncias equivalentes

\begin{tabular}{lcc}
\hline & \%R FL13 & \% R FL21 \\
\hline Média & 54,28093 & 64,21671 \\
Variância & 63,08032 & 120,2578 \\
Observações & 8 & 8 \\
Variância agrupada & 91,66906 & \\
Hipótese da diferença de média & 0 & \\
gl & 14 & \\
Stat t & $-2,07549$ & \\
P(T<=t) uni-caudal & 0,028425 & \\
t crítico uni-caudal & 1,761309 & \\
P(T<=t) bi-caudal & $\mathbf{0 , 0 5 6 8 4 9}$ & \\
t crítico bi-caudal & 2,144789 & \\
\hline
\end{tabular}

TABELA C.67 - Cálculos da médias de remoção de nitrato para FL11, FL13 e FL21 na carreira 3

\begin{tabular}{ccccc}
\hline Grupo & Contagem & Soma & Média & Variância \\
\hline \%R FL11 & 9 & 382,0861 & 42,45401 & 310,4952 \\
\%R FL13 & 8 & 191,6729 & 23,95911 & 51,50037 \\
\% R FL21 & 8 & 193,5276 & 24,19095 & 32,93185 \\
\hline
\end{tabular}

TABELA C.68 - Análise de variância para remoção de nitrato (FL11,FL13 e FL21)

\begin{tabular}{lcccccc}
\hline \multicolumn{7}{c}{ ANOVA } \\
\hline Fonte da variação & $\mathrm{SQ}$ & $\mathrm{gl}$ & $\mathrm{MQ}$ & $\mathrm{F}$ & valor-P & F crítico \\
Entre grupos & 1945,867 & 2 & 972,9337 & 6,960855 & $\mathbf{0 , 0 0 4 5 4 7}$ & 3,443361 \\
Dentro dos grupos & 3074,987 & 22 & 139,7722 & & & \\
\hline
\end{tabular}

TABELA C.69 - Testes-F para nitrato na carreira 3

\begin{tabular}{|c|c|c|c|c|c|c|}
\hline & $\%$ RFL11 & $\%$ RFL13 & $\%$ RFL11 & $\%$ RFL21 & $\%$ RFL13 & $\%$ RFL21 \\
\hline Média & 42,45401 & 23,95911 Média & 42,45401 & 24,19095 Média & 23,95911 & 24,19095 \\
\hline Variância & 310,4952 & 51,50037 Variância & 310,4952 & 32,93185 Variância & 51,50037 & 32,93185 \\
\hline Observaç & 9 & 8 Observaç & 9 & 8 Observaç & 8 & 8 \\
\hline$\tilde{\mathrm{o}}$ & & $\tilde{\mathrm{o}}$ & & $\tilde{o}$ & & \\
\hline $\mathrm{gl}$ & 8 & $7 \mathrm{gl}$ & 8 & $7 \mathrm{gl}$ & 7 & 7 \\
\hline $\mathrm{F}$ & 6,028991 & $\mathrm{~F}$ & 9,428417 & $\mathrm{~F}$ & 1,563847 & \\
\hline $\begin{array}{l}\mathrm{P}(\mathrm{F}<=\mathrm{f}) \\
\text { uni- } \\
\text { caudal }\end{array}$ & 0,01426 & $\begin{array}{l}\mathrm{P}(\mathrm{F}<=\mathrm{f}) \\
\text { uni- } \\
\text { caudal }\end{array}$ & 0,003902 & $\begin{array}{l}\mathrm{P}(\mathrm{F}<=\mathrm{f}) \\
\text { uni- } \\
\text { caudal }\end{array}$ & $\mathbf{0 , 2 8 4 8 2 3}$ & \\
\hline $\begin{array}{l}\text { F crítico } \\
\text { uni- } \\
\text { caudal }\end{array}$ & 3,725717 & $\begin{array}{l}\text { F crítico } \\
\text { uni- } \\
\text { caudal }\end{array}$ & 3,725717 & $\begin{array}{l}\text { F crítico } \\
\text { uni- } \\
\text { caudal }\end{array}$ & 3,787051 & \\
\hline
\end{tabular}


TABELA C.70- Teste $-\mathrm{t}$ para nitrato

Presumindo-se variâncias diferentes

\begin{tabular}{lcc}
\hline & \%R FL11 \% R FL21 \\
\hline Média & 42,45401 & 24,19095 \\
Variância & 310,4952 & 32,93185 \\
Observações & 9 & 8 \\
Hipótese da diferença & 0 & \\
de média & \\
gl & 10 \\
Stat t & 2,938936 \\
P(T<=t) uni-caudal & 0,007406 \\
t crítico uni-caudal & 1,812462 \\
P(T<=t) bi-caudal & $\mathbf{0 , 0 1 4 8 1 2}$ \\
t crítico bi-caudal & 2,228139 \\
\hline
\end{tabular}

TABELA C.71- Teste - $\mathrm{t}$ para nitrato

Presumindo-se variâncias diferentes

\begin{tabular}{lcc}
\hline & \%R FL11 & \% R FL13 \\
\hline Média & 42,45401 & 23,95911 \\
Variância & 310,4952 & 51,50037 \\
Observações & 9 & 8 \\
Hipótese da diferença & 0 & \\
de média & & \\
gl & 11 \\
Stat t & 2,890639 \\
P(T<=t) uni-caudal & 0,007345 \\
t crítico uni-caudal & 1,795884 \\
P(T<=t) bi-caudal & $\mathbf{0 , 0 1 4 6 8 9}$ \\
t crítico bi-caudal & 2,200986 \\
\hline
\end{tabular}

TABELA C.72- Teste $-\mathrm{t}$ para nitrato

Presumindo-se variâncias equivalentes

\begin{tabular}{lcc}
\hline & \%R FL13 & \% R FL21 \\
\hline Média & 23,95911 & 24,19095 \\
Variância & 51,50037 & 32,93185 \\
Observações & 8 & 8 \\
Variância agrupada & 42,21611 & \\
Hipótese da diferença de média & 0 & \\
gl & 14 & \\
Stat t & $-0,07136$ & \\
$\mathrm{P}(\mathrm{T}<=\mathrm{t})$ uni-caudal & 0,472059 & \\
$\mathrm{t}$ crítico uni-caudal & 1,761309 & \\
$\mathrm{P}(\mathrm{T}<=\mathrm{t})$ bi-caudal & $\mathbf{0 , 9 4 4 1 1 7}$ & \\
$\mathrm{t}$ crítico bi-caudal & 2,144789 \\
\hline
\end{tabular}




\section{ANEXO D \\ Gráficos de correlação}

Carreira 3 


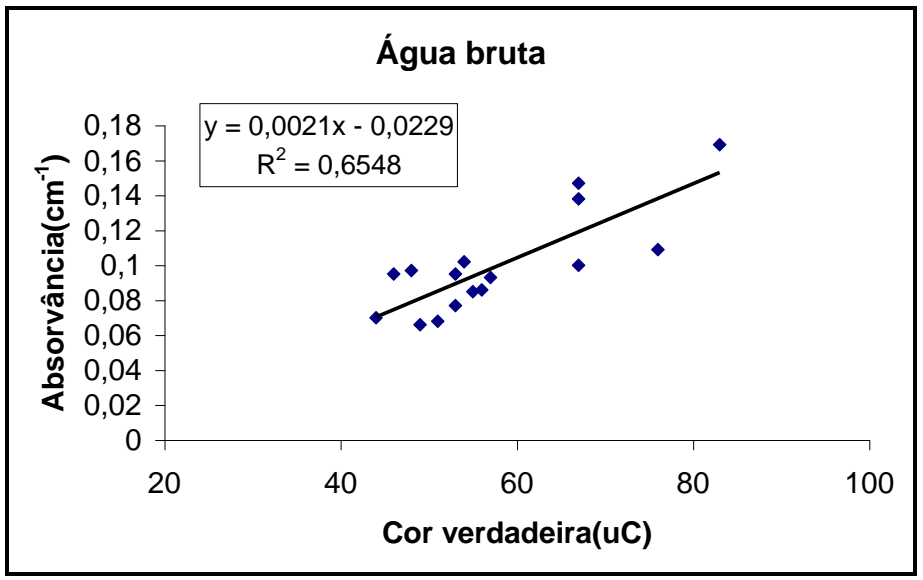

FIGURA D.1- Correlação entre cor verdadeira e absorvância para água bruta na carreira 3

Fonte:Tabelas F.4 e F.5

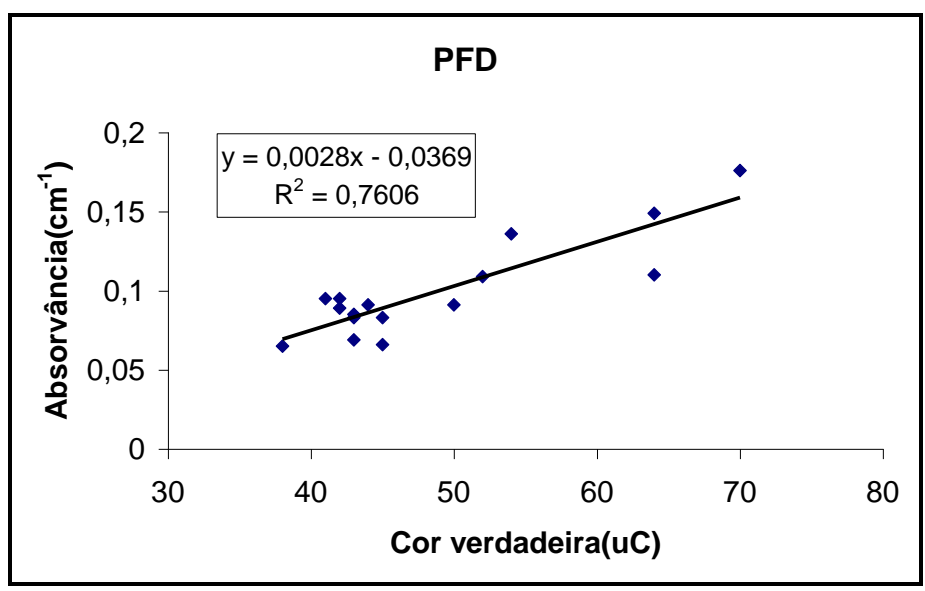

FIGURA D.2- Correlação entre cor verdadeira e absorvância para o efluente do PFD na carreira 3

Fonte: Tabelas F.4 e F.5

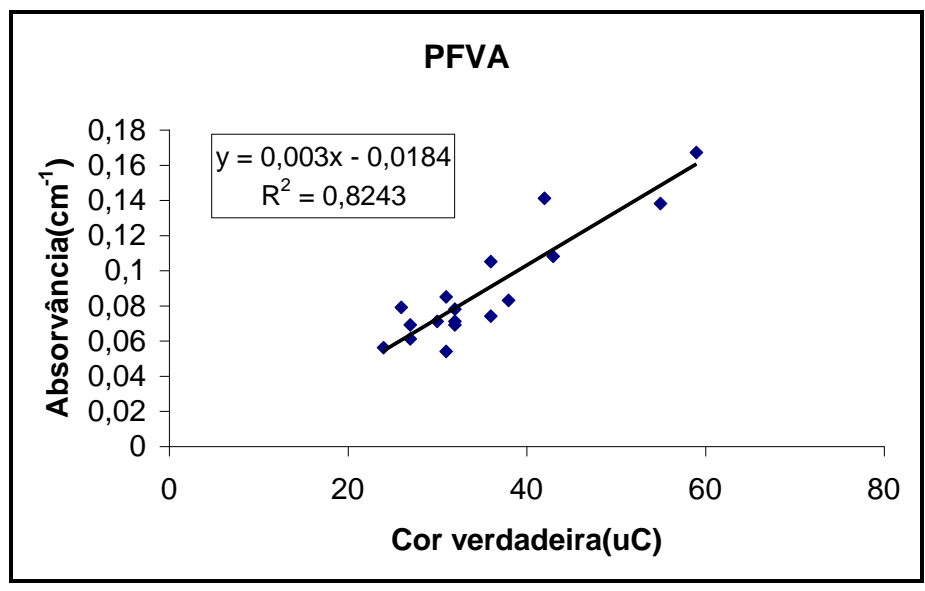

FIGURA D.3- Correlação entre cor verdadeira e absorvância para o efluente do PFVA na carreira 3

Fonte: Tabelas F.4 e F.5 


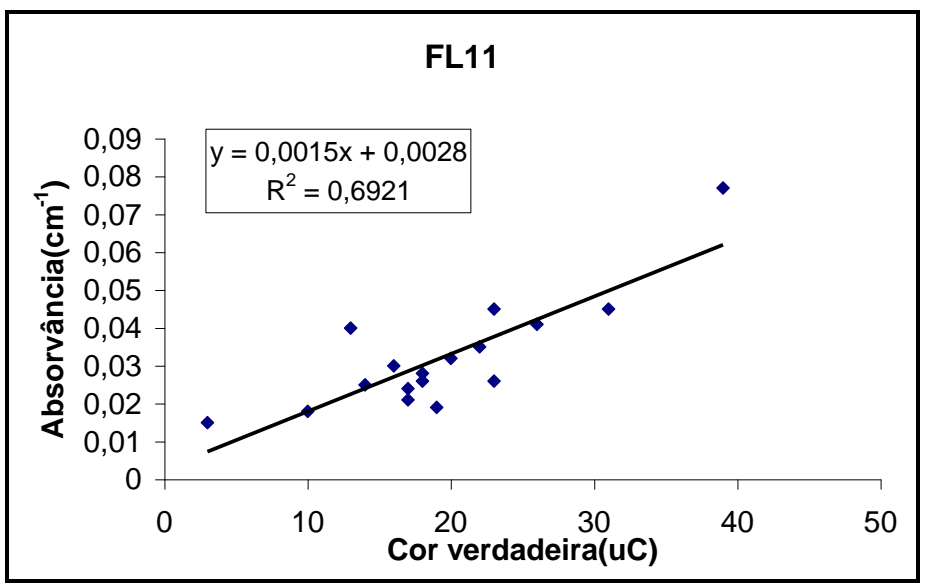

FIGURA D.4- Correlação entre cor verdadeira e absorvância para o efluente do filtro lento 1 na carreira 3

Fonte: Tabelas F.4 e F.5

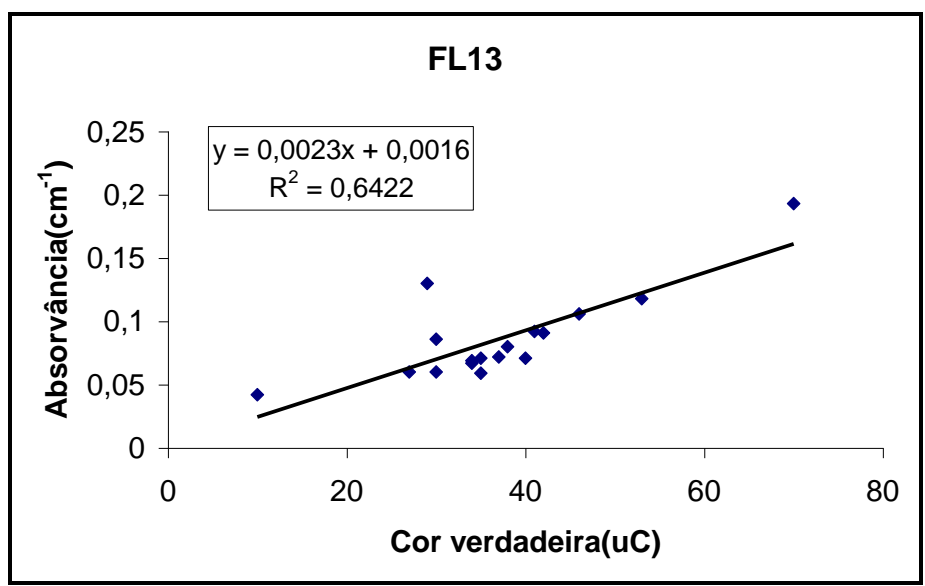

FIGURA D.5- Correlação entre cor verdadeira e absorvância para o efluente da seção FL13 na carreira 3

Fonte: Tabelas F.4 e F.5

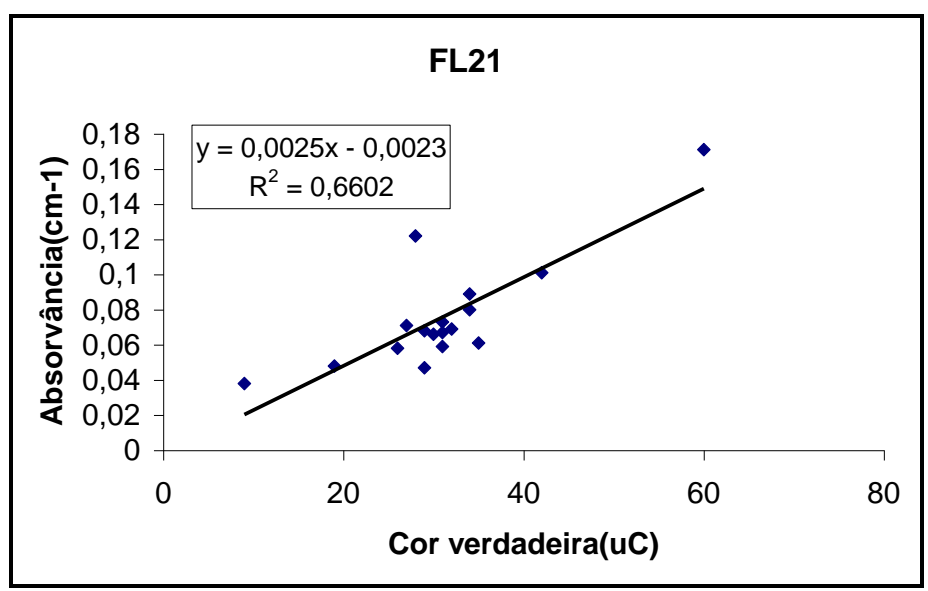

FIGURA D.6- Correlação entre cor verdadeira e absorvância para o efluente do filtro lento 2 carreira 3

Fonte: Tabelas F.4 e F.5 


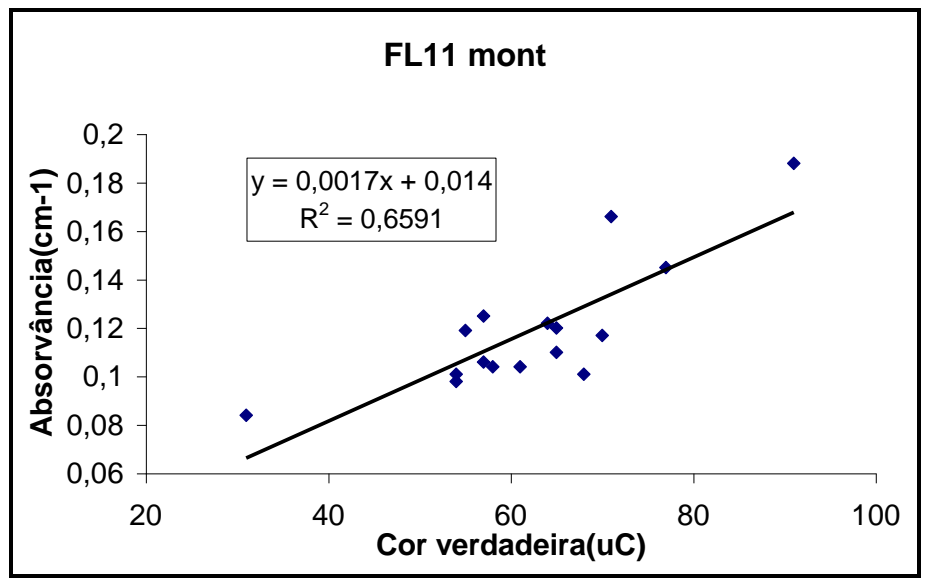

FIGURA D.7- Correlação entre cor verdadeira e absorvância para o efluente da seção FL11mont na carreira 3

Fonte: Tabelas F.4 e F.5

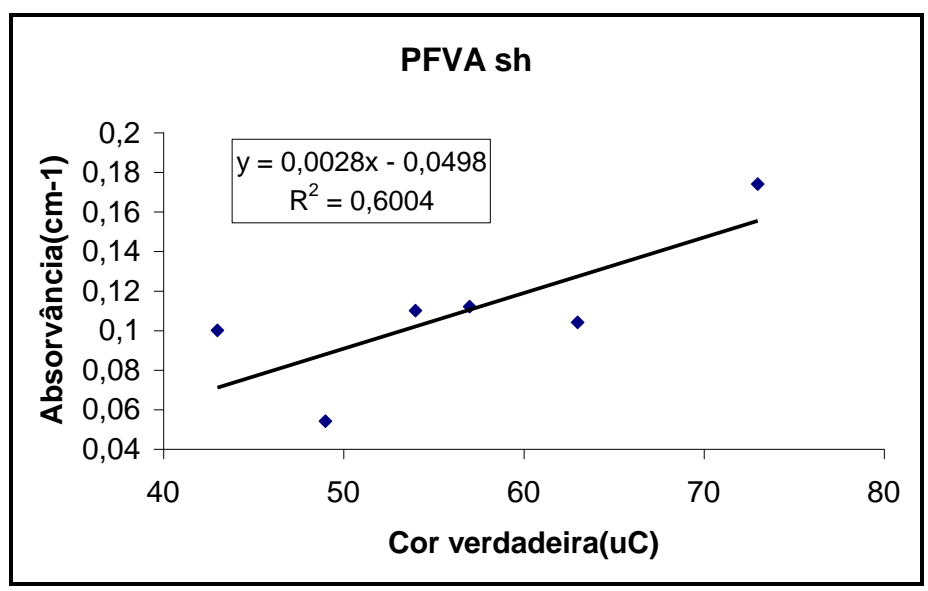

FIGURA D.8- Correlação entre cor verdadeira e absorvância para o efluente da seção PFVÂsh na carreira 3

Fonte: Tabelas F.4 e F.5

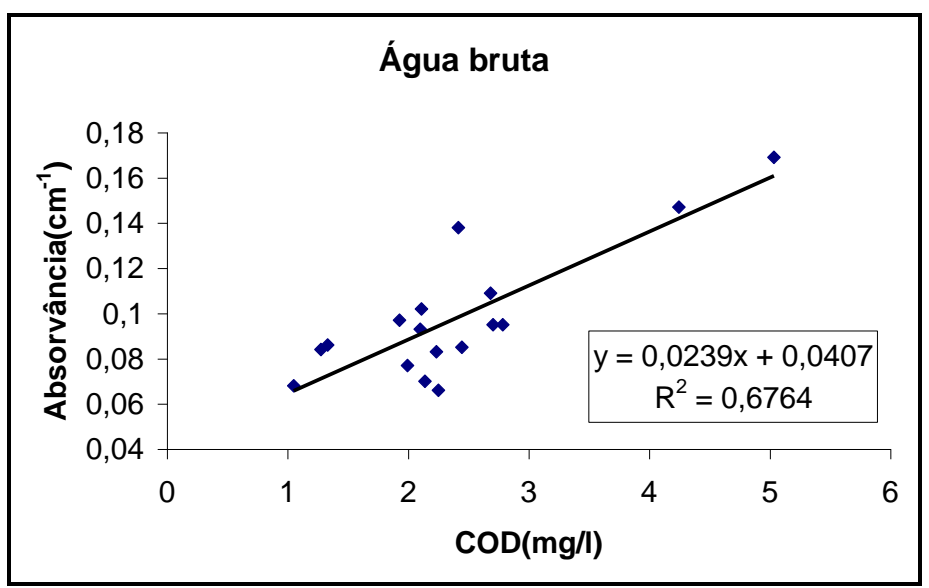

FIGURA D.9 - Correlação entre absorvância e carbono orgânico dissolvido para água bruta na carreira 3

Fonte: Tabelas F.5 e F.6 


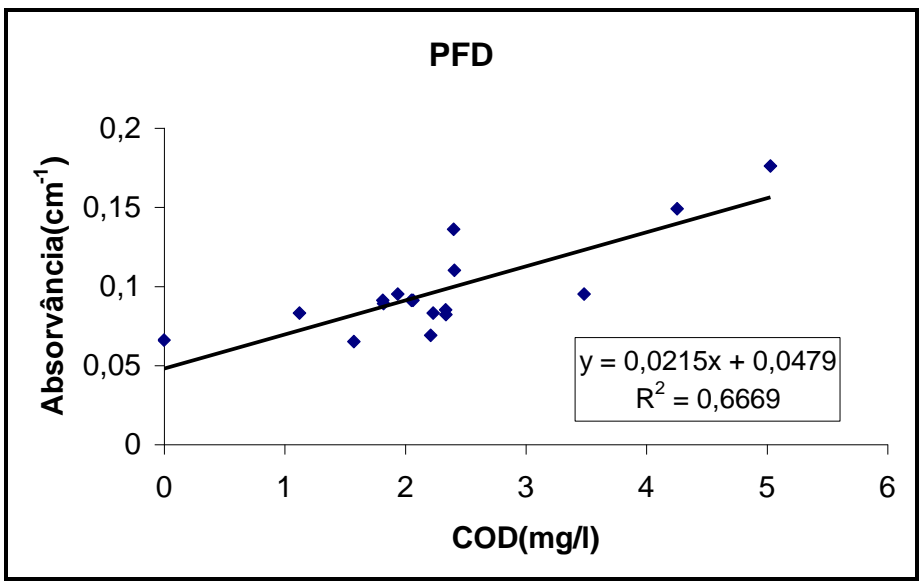

FIGURA D.10 - Correlação entre absorvância e carbono orgânico dissolvido para o efluente do PFD na carreira 3

Fonte: Tabelas F.5 e F.6

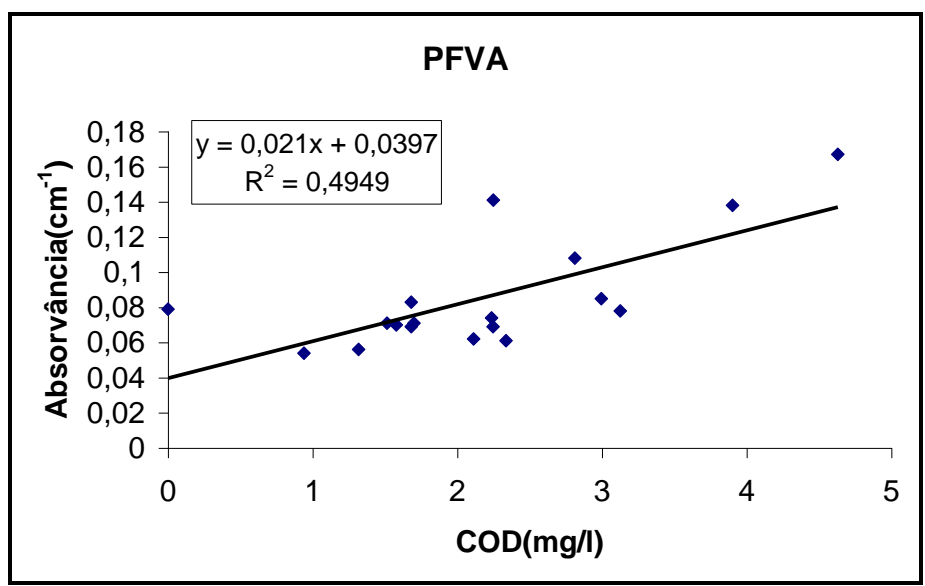

FIGURA D.11 - Correlação entre absorvância e carbono orgânico dissolvido para o efluente do PFVA na carreira 3

Fonte: Tabelas F.5 e F.6

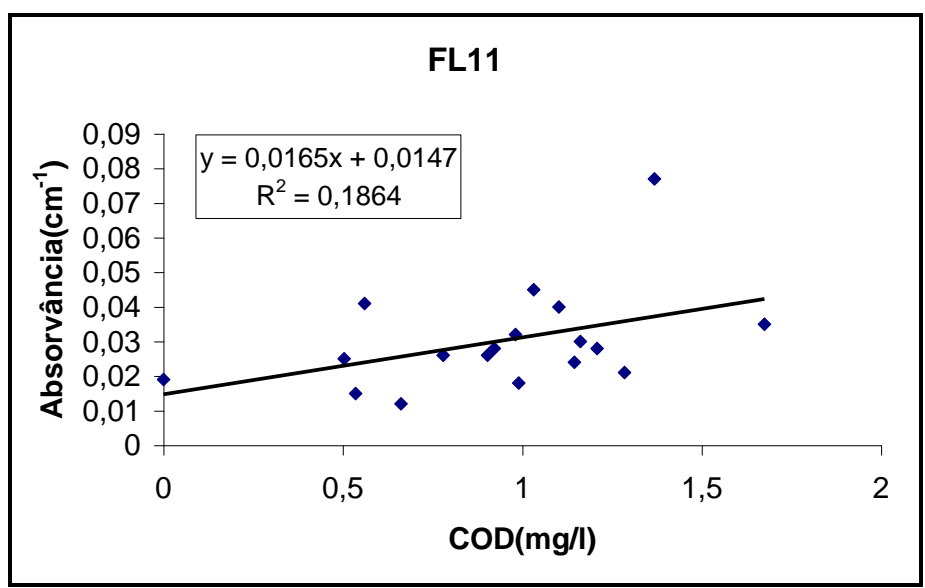

FIGURA D.12 - Correlação entre absorvância e carbono orgânico dissolvido para efluente do filtro lento 1 na carreira 3

Fonte: Tabelas F.5 e F.6 


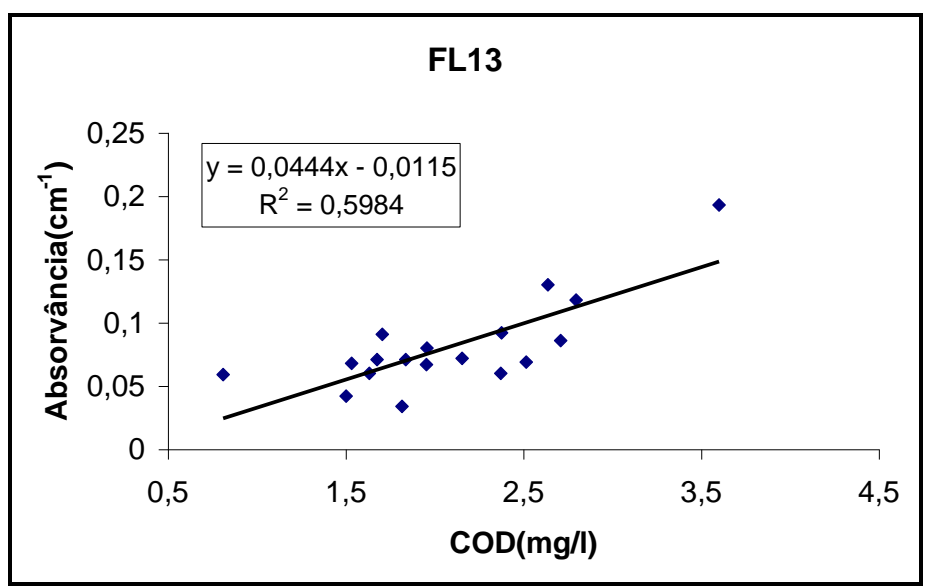

FIGURA D.13 - Correlação entre absorvância e carbono orgânico dissolvido para o efluente da seção FL13 na carreira Fonte: Tabelas F.5 e F.6

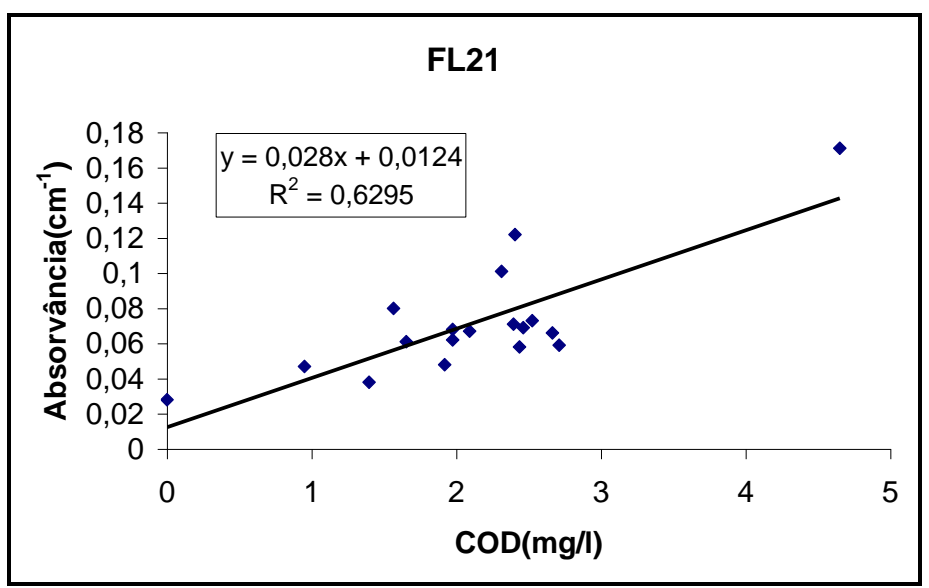

FIGURA D.14 - Correlação entre absorvância e carbono orgânico dissolvido para o efluente do filtro lento 2 carreira 3

Fonte: Tabelas F.5 e F.6

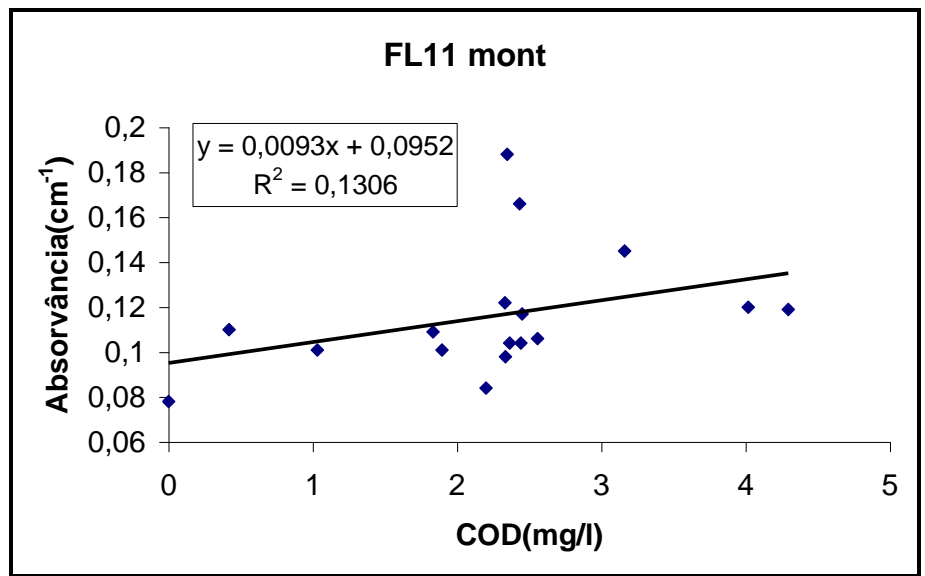

FIGURA D.15 - Correlação entre absorvância e carbono orgânico dissolvido para o efluente da seção FL11mont na carreira 3 Fonte: Tabelas F.5 e F.6 


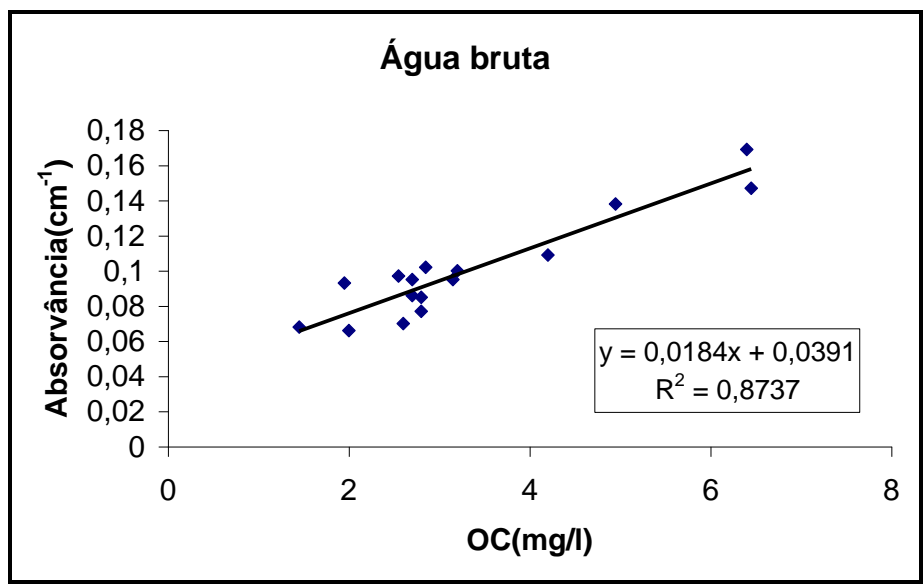

FIGURA D.16 - Correlação entre absorvância e OC para água bruta na carreira 3

Fonte: Tabelas F.5 e F.7

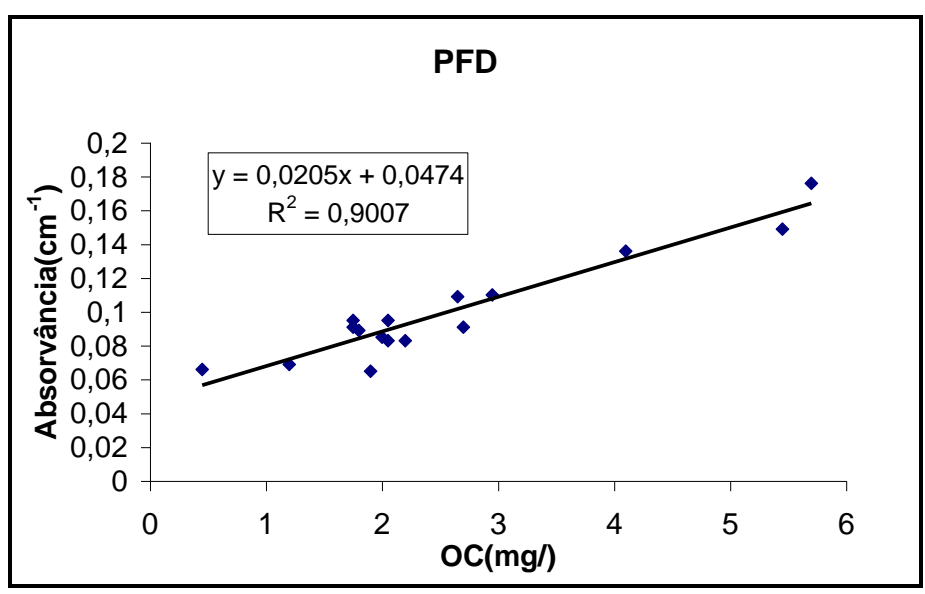

FIGURA D.17 - Correlação entre absorvância e OC para o efluente do PFD na carreira 3

Fonte: Tabelas F.5 e F.7

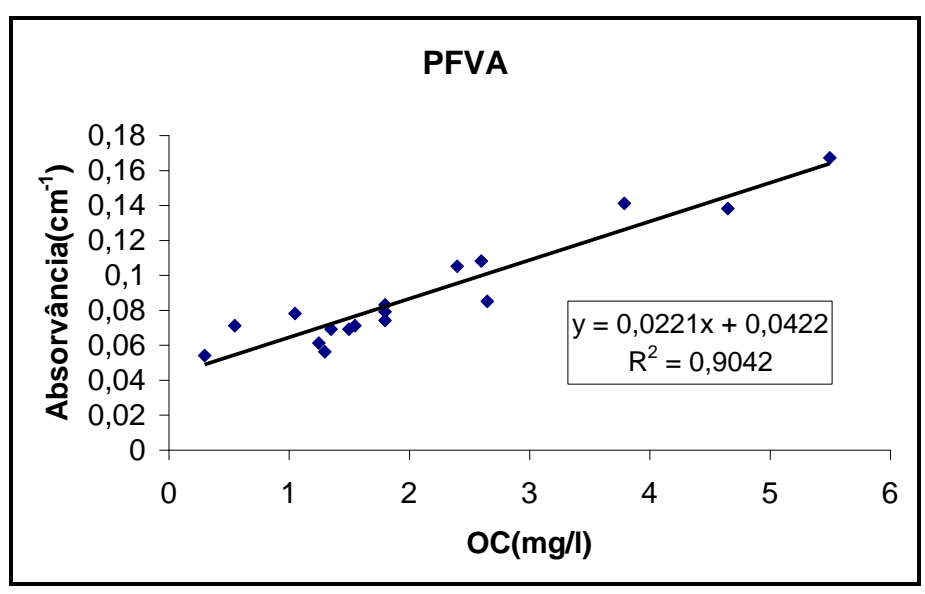

FIGURA D.18 - Correlação entre absorvância e OC para o efluente do PFVA na carreira 3

Fonte: Tabelas F.5 e F.7 


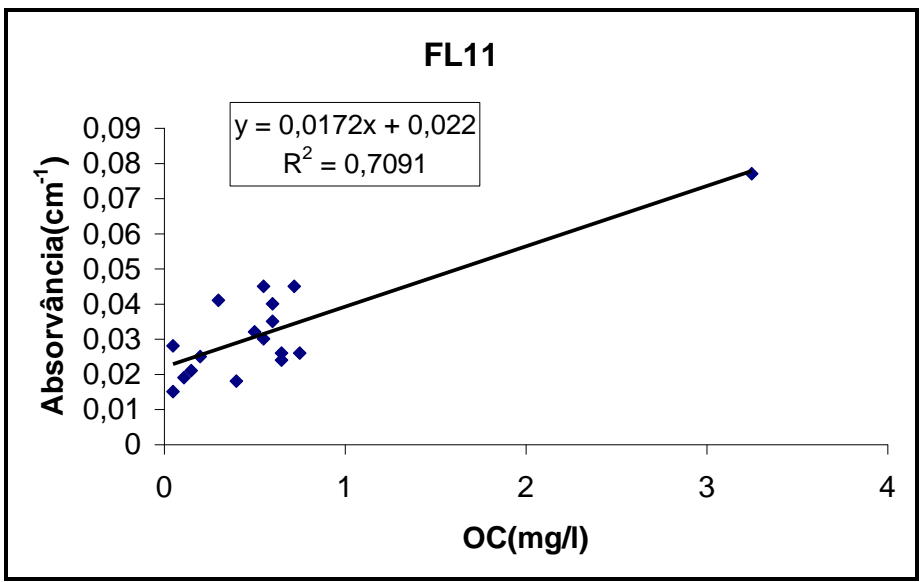

FIGURA D.19 - Correlação entre absorvância e OC para o efluente do filtro lento 1 na carreira 3

Fonte: Tabelas F.5 e F.7

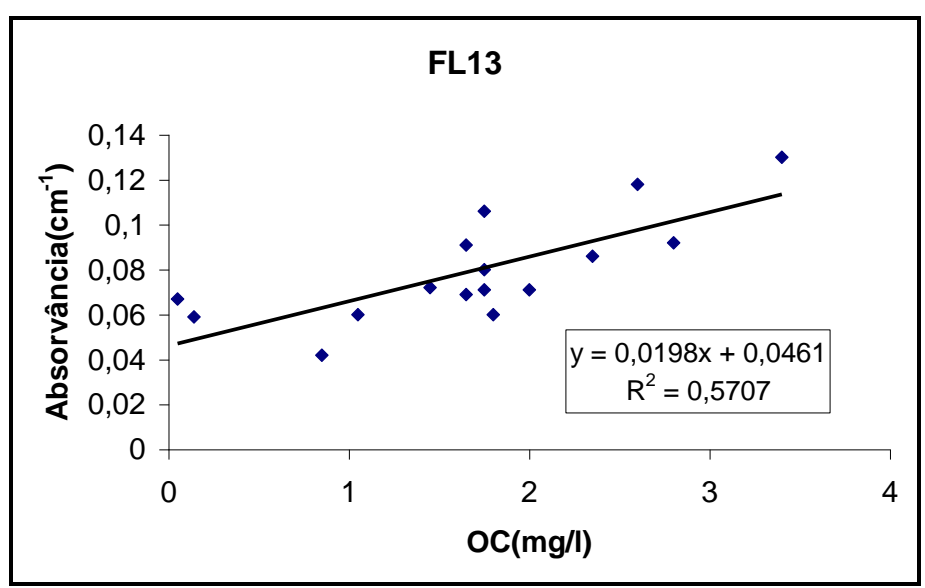

FIGURA D.20 - Correlação entre absorvância e OC para o efluente da seção FL13 na carreira 3

Fonte: Tabelas F.5 e F.7

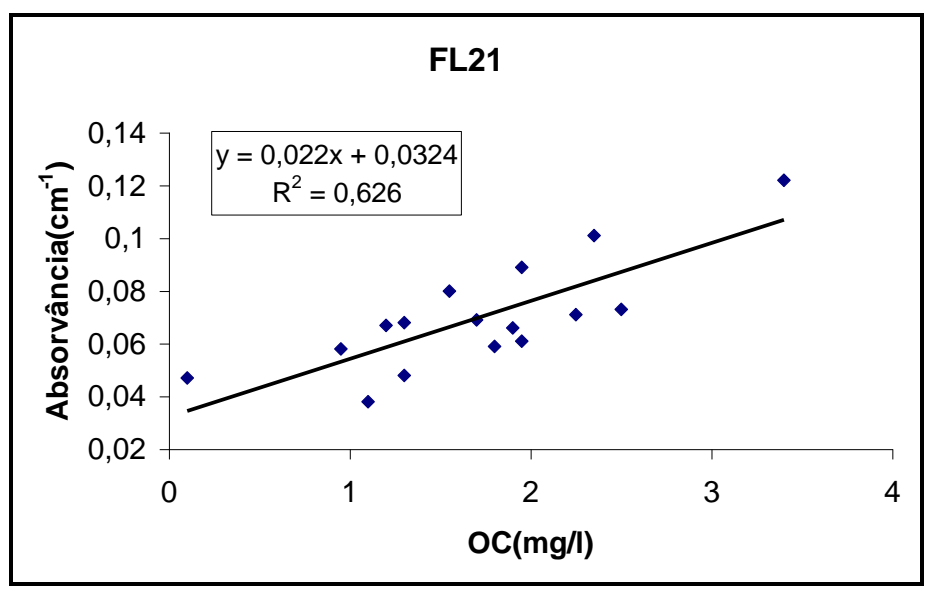

FIGURA D.21 - Correlação entre absorvância e OC para o efluente do filtro lento 2 na carreira 3

Fonte: Tabelas F.5 e F.7 


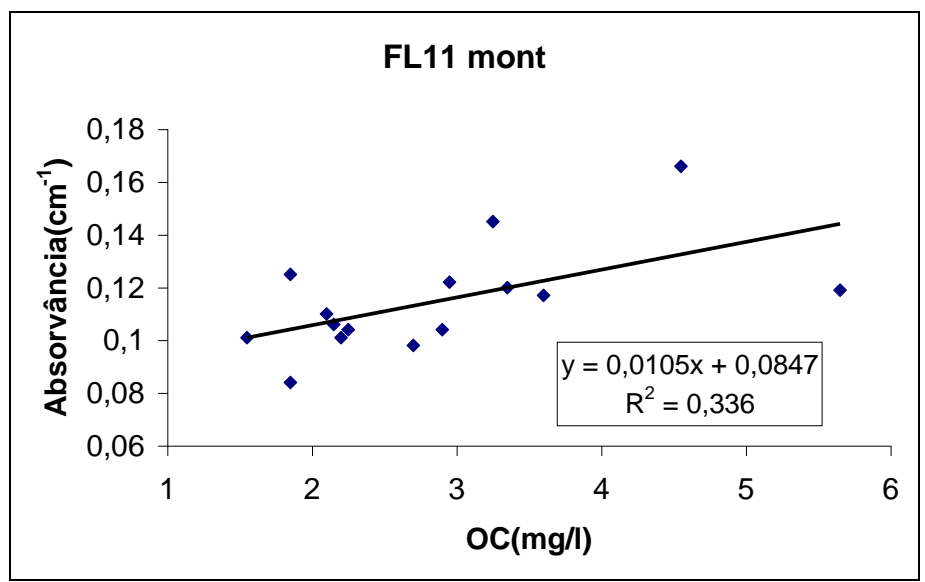

FIGURA D.22 - Correlação entre absorvância e OC para o efluente da seção FL11mont na carreira 3

Fonte: Tabelas F.5 e F.7

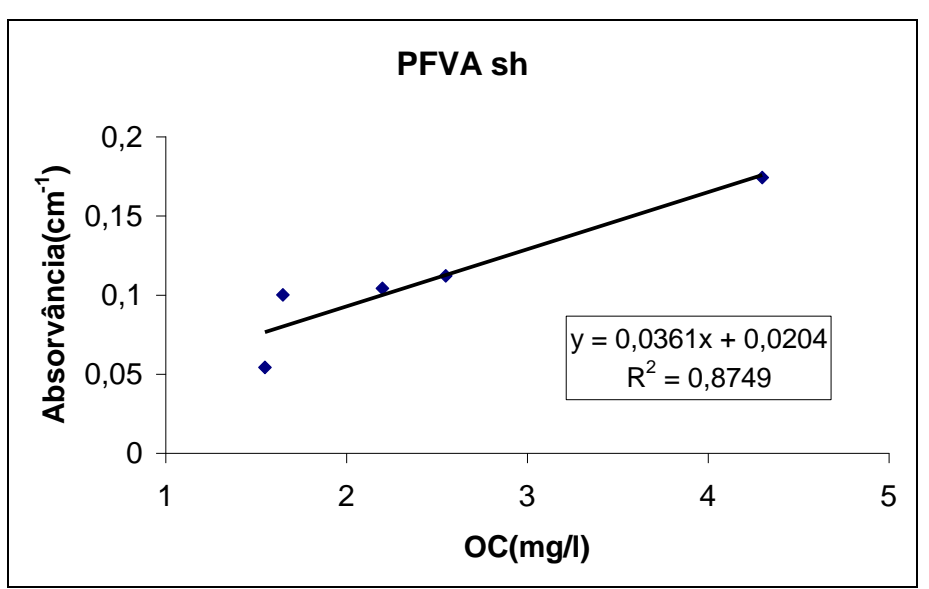

FIGURA D.23 - Correlação entre absorvância e OC para o efluente da seção PFVAsh na carreira 3

Fonte: Tabelas F.5 e F.7

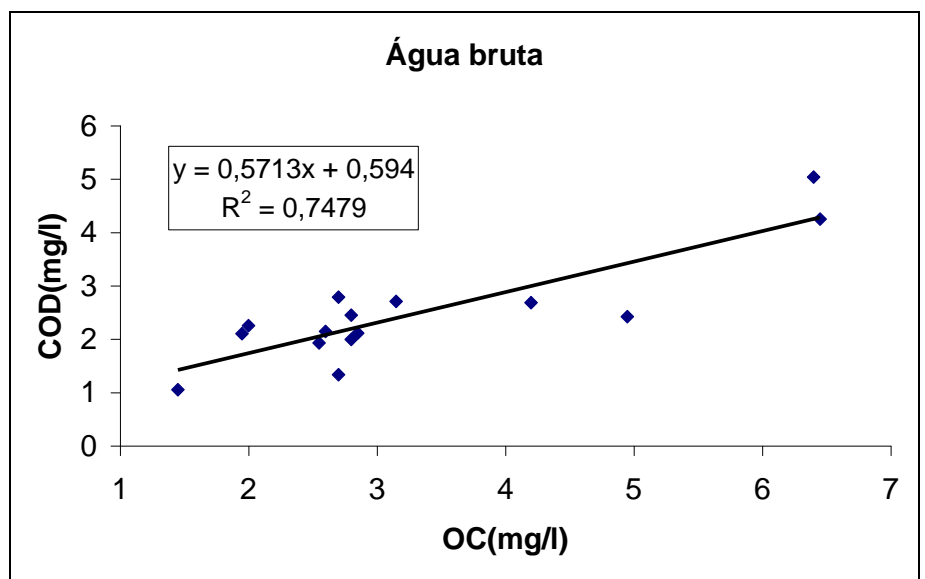

FIGURA D.24 - Correlação entre COD e OC para água bruta na carreira 3

Fonte: Tabelas F.6 e F.7 


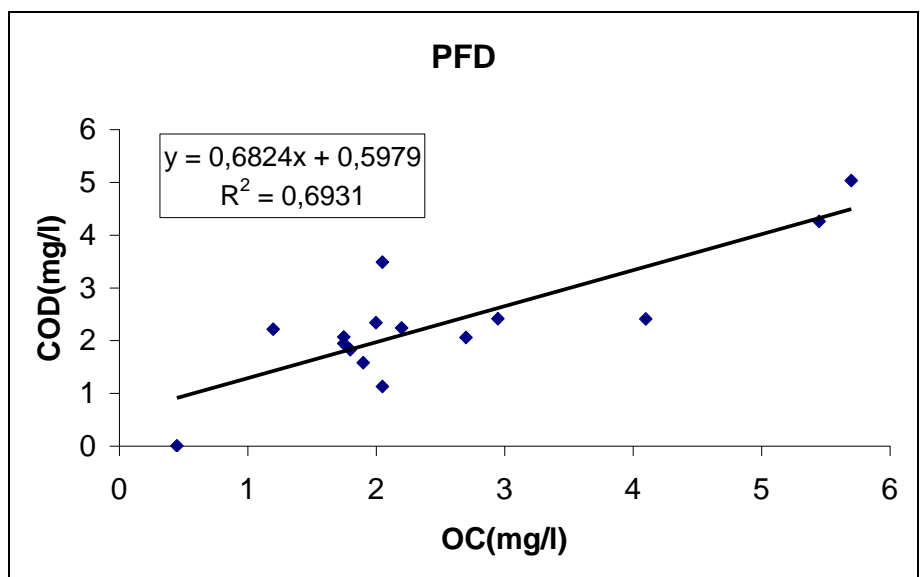

FIGURA D.25 - Correlação entre COD e OC para o efluente do PFD na carreira 3

Fonte: Tabelas F.6 e F.7

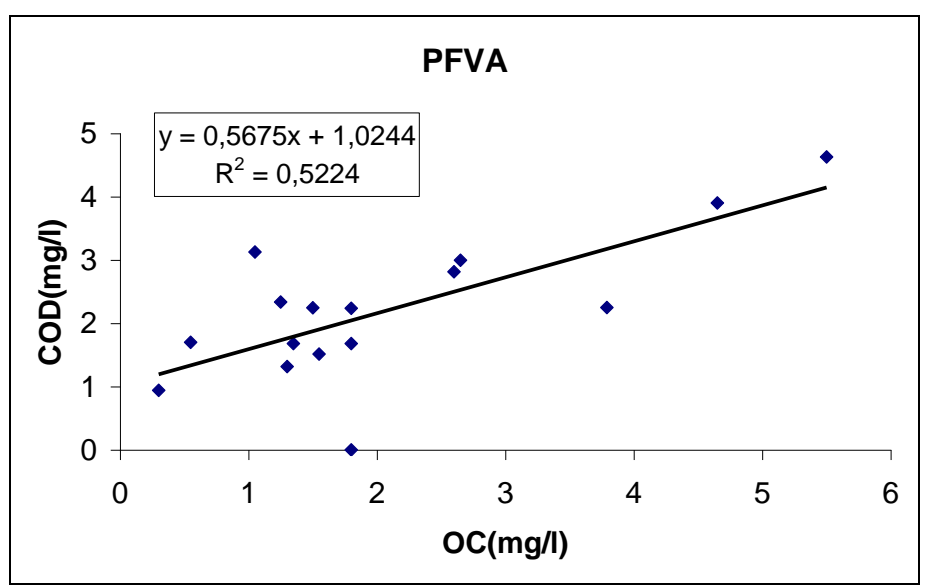

FIGURA D.26 - Correlação entre COD e OC para o efluente do PFVA na carreira 3

Fonte: Tabelas F.6 e F.7

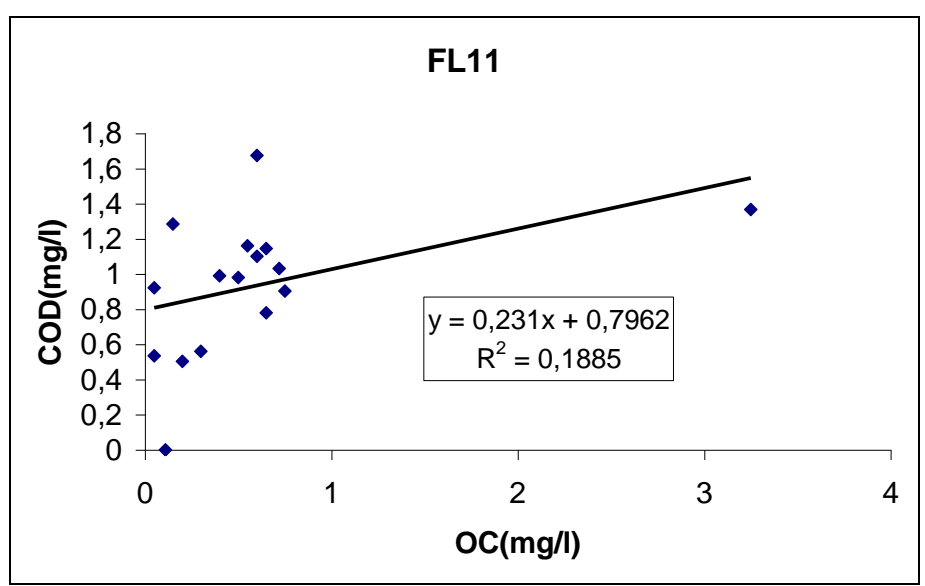

FIGURA D.27 - Correlação entre COD e OC para o efluente do filtro lento 1 na carreira 3

Fonte: Tabelas F.6 e F.7 


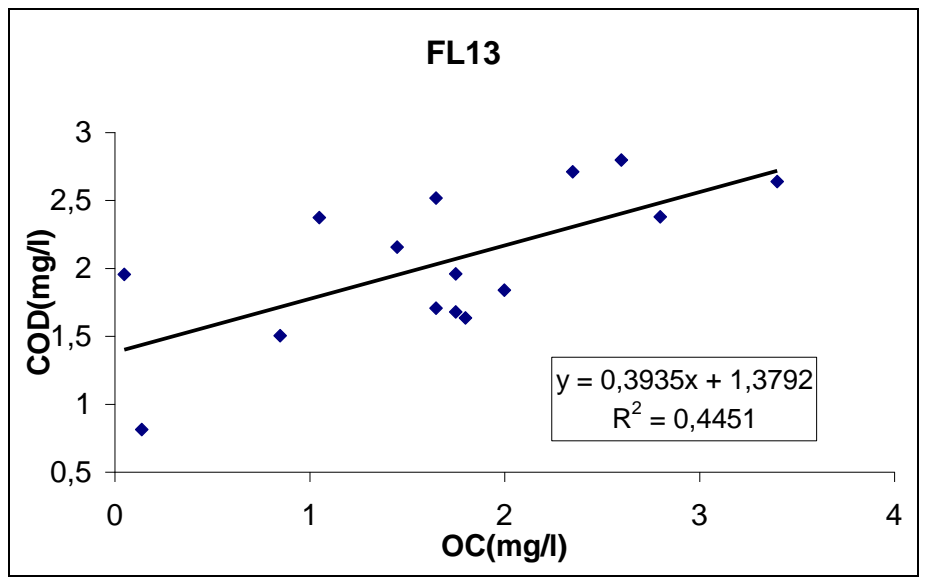

FIGURA D.28 - Correlação entre COD e OC para o efluente da seção FL13 na carreira 3

Fonte: Tabelas F.6 e F.7

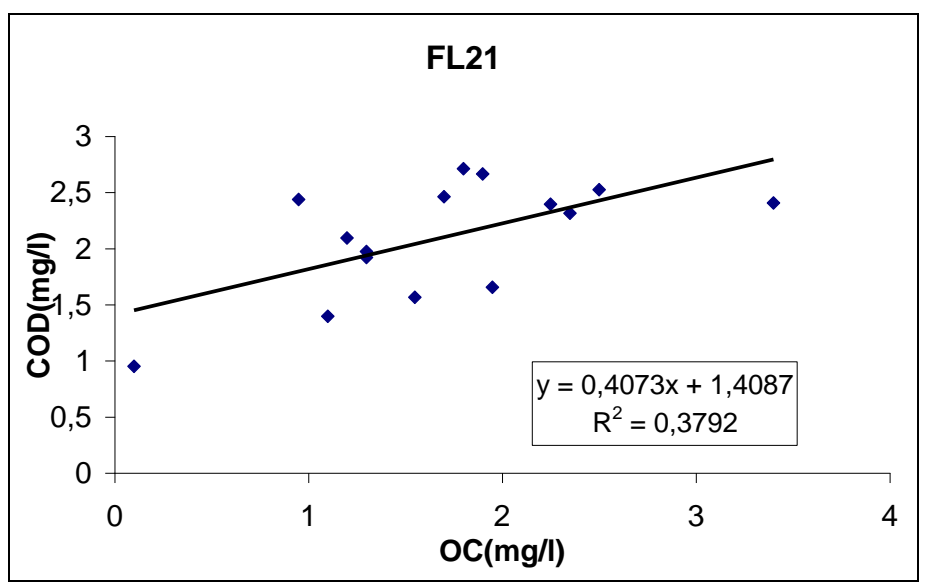

FIGURA D.29 - Correlação entre COD e OC para o efluente do filtro lento 2 na carreira 3

Fonte: Tabelas F.6 e F.7

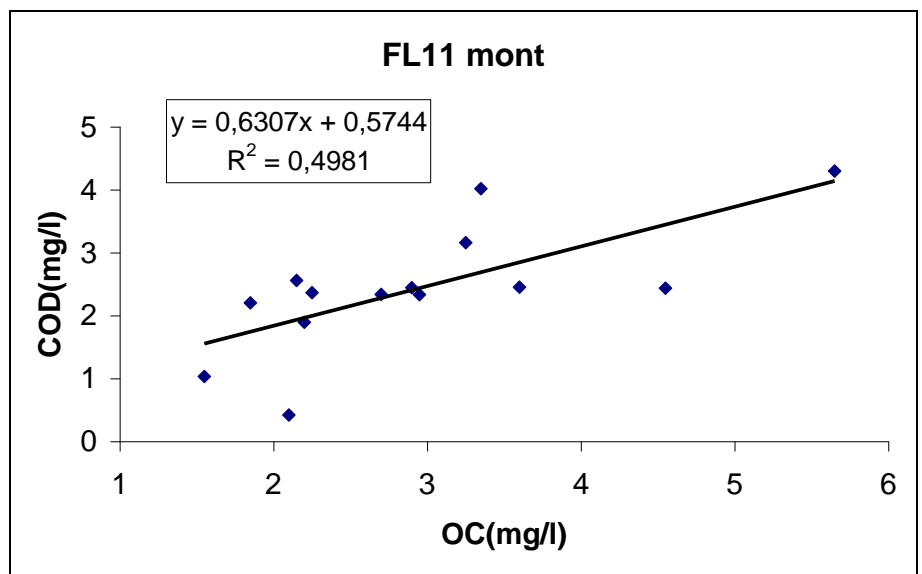

FIGURA D.30 - Correlação entre COD e OC para o efluente da seção FL11mont na carreira 3

Fonte: Tabelas F.6 e F.7 


\begin{abstract}
ANEXO E
Tabelas com resultados de turbidez, sólidos suspensos totais, cor aparente, cor verdadeira, absorvância, e temperatura da carreira 1.
\end{abstract}


TABELA E.1 - Resultados de turbidez em uT e \% de remoções nos pré-filtros e filtros lentos na carreira 1

\begin{tabular}{|c|c|c|c|c|c|c|c|c|c|c|c|c|}
\hline Data & TO & $\mathbf{A B}$ & PFD & PFVA & FL11 & FL13 & FL21 & r\%PFD & \%PFVA & r\%FL11 & r\%FL13 & r\%FL21 \\
\hline 20.02 & 6 & 28,4 & 23,5 & 16,9 & 15,6 & 16,1 & 16,7 & 17,25 & 28,09 & 7,69 & 4,73 & 1,18 \\
\hline 21.02 & 7 & 22,20 & 18,70 & 14,70 & 8,67 & 14,60 & 13,80 & 15,77 & 21,39 & 41,02 & 0,68 & 6,12 \\
\hline 22.02 & 8 & 27,80 & 18,10 & 13,90 & 11,20 & 12,00 & 14,40 & 34,89 & 23,20 & 19,42 & 13,67 & $-3,60$ \\
\hline 23.02 & 9 & 24,90 & 16,70 & 12,50 & 9,97 & 10,80 & 12,20 & 32,93 & 25,15 & 20,24 & 13,60 & 2,40 \\
\hline 24.02 & 10 & 24,90 & 16,30 & 11,80 & 9,64 & 10,80 & 10,10 & 34,54 & 27,61 & 18,31 & 8,47 & 14,41 \\
\hline 26.02 & 12 & 55,90 & 42,60 & 22,20 & 3,14 & 23,10 & 4,45 & 23,79 & 47,89 & 85,86 & $-4,05$ & 79,95 \\
\hline 27.02 & 13 & 39,20 & 31,80 & 19,90 & 14,80 & 18,00 & 14,20 & 18,88 & 37,42 & 25,63 & 9,55 & 28,64 \\
\hline 28.02 & 14 & 37,20 & 26,60 & 16,60 & 12,20 & 15,40 & 11,70 & 28,49 & 37,59 & 26,51 & 7,23 & 29,52 \\
\hline 29.02 & 15 & 98,90 & 77,30 & 23,90 & 14,80 & 20,60 & 15,30 & 21,84 & 69,08 & 38,08 & 13,81 & 35,98 \\
\hline 01.03 & 16 & 56,30 & 45,10 & 40,40 & 46,50 & 52,50 & 44,70 & 19,89 & 10,42 & $-15,10$ & $-29,95$ & $-10,64$ \\
\hline 02.03 & 17 & 42,80 & 32,20 & 26,40 & 28,40 & 30,90 & 26,20 & 24,77 & 18,01 & $-7,58$ & $-17,05$ & 0,76 \\
\hline 03.03 & 18 & 32,60 & 22,60 & 19,60 & 20,30 & 22,90 & 18,80 & 30,67 & 13,27 & $-3,57$ & $-16,84$ & 4,08 \\
\hline 04.03 & 19 & 30,90 & 18,20 & 15,00 & 14,10 & 16,60 & 12,60 & 41,10 & 17,58 & 6,00 & $-10,67$ & 16,00 \\
\hline 05.03 & 20 & 25,50 & 17,00 & 14,40 & 11,70 & 14,50 & 10,30 & 33,33 & 15,29 & 18,75 & $-0,69$ & 28,47 \\
\hline 06.03 & 21 & 26,20 & 16,30 & 12,70 & 9,51 & 10,70 & 8,16 & 37,79 & 22,09 & 25,12 & 15,75 & 35,75 \\
\hline 07.03 & 22 & 29,70 & 17,10 & 13,20 & 8,54 & 10,20 & 6,94 & 42,42 & 22,81 & 35,30 & 22,73 & 47,42 \\
\hline 08.03 & 23 & 50,10 & 27,00 & 14,70 & 9,81 & 10,60 & 8,63 & 46,11 & 45,56 & 33,27 & 27,89 & 41,29 \\
\hline 09.03 & 24 & 43,60 & 30,10 & 20,40 & 20,50 & 19,20 & 19,40 & 30,96 & 32,23 & $-0,49$ & 5,88 & 4,90 \\
\hline 10.03 & 25 & 34,50 & 20,60 & 16,00 & 15,80 & 16,80 & 14,90 & 40,29 & 22,33 & 1,25 & $-5,00$ & 6,88 \\
\hline 11.03 & 26 & 44,20 & 28,70 & 12,20 & 10,40 & 12,30 & 9,76 & 35,07 & 57,49 & 14,75 & $-0,82$ & 20,00 \\
\hline 12.03 & 27 & 27,90 & 20,00 & 14,40 & 10,80 & 12,50 & 10,30 & 28,32 & 28,00 & 25,00 & 13,19 & 28,47 \\
\hline 13.03 & 28 & 24,50 & 15,50 & 12,60 & 10,80 & 11,70 & 10,10 & 36,73 & 18,71 & 14,29 & 7,14 & 19,84 \\
\hline 14.03 & 29 & 21,90 & 14,70 & 12,10 & 9,75 & 11,00 & 9,25 & 32,88 & 17,69 & 19,42 & 9,09 & 23,55 \\
\hline 15.03 & 30 & 21,50 & 14,10 & 11,40 & 6,83 & 2,31 & 6,00 & 34,42 & 19,15 & 40,09 & 79,74 & 47,37 \\
\hline 16.03 & 31 & 14,16 & 13,99 & 10,76 & 9,46 & 11,50 & 8,81 & 1,20 & 23,09 & 12,08 & $-6,88$ & 18,10 \\
\hline 17.03 & 32 & 21,00 & 17,58 & 13,91 & 9,18 & 11,80 & 9,10 & 16,29 & 20,88 & 33,98 & 15,17 & 34,57 \\
\hline 18.03 & 33 & 20,98 & 17,14 & 12,91 & 8,45 & 8,78 & 7,50 & 18,30 & 24,68 & 34,55 & 31,99 & 41,91 \\
\hline 19.03 & 34 & 22,70 & 17,70 & 13,10 & 8,44 & 11,00 & 7,74 & 22,03 & 25,99 & 35,57 & 16,03 & 40,92 \\
\hline
\end{tabular}


Continuação da TABELA E.1 - Resultados de turbidez em uT e \% de remoções nos pré-filtros e filtros lentos na carreira 1

\begin{tabular}{|c|c|c|c|c|c|c|c|c|c|c|c|c|}
\hline Data & TO & $\mathbf{A B}$ & PFD & PFVA & FL11 & FL13 & FL21 & r\%PFD & \%PFVA & r\%FL11 & r\%FL13 & r\%FL21 \\
\hline 21.03 & 36 & 25,79 & 21,71 & 18,55 & 20,95 & 19,40 & 20,23 & 15,82 & 14,56 & $-12,94$ & $-4,58$ & $-9,06$ \\
\hline 22.03 & 37 & 21,46 & 15,76 & 10,75 & 7,55 & 8,21 & 8,41 & 26,56 & 31,79 & 29,77 & 23,63 & 21,77 \\
\hline 23.03 & 38 & 21,40 & 16,37 & 10,34 & 6,69 & 7,53 & 7,33 & 23,50 & 36,84 & 35,30 & 27,18 & 29,11 \\
\hline 24.03 & 39 & 20,72 & 15,34 & 10,08 & 6,27 & 8,47 & 7,62 & 25,97 & 34,29 & 37,80 & 15,97 & 24,40 \\
\hline 25.03 & 40 & 21,55 & 14,90 & 9,28 & 6,49 & 7,42 & 6,69 & 30,86 & 37,72 & 30,06 & 20,04 & 27,91 \\
\hline 26.03 & 41 & 20,11 & 14,84 & 9,71 & 6,42 & 7,88 & 6,33 & 26,21 & 34,57 & 33,84 & 18,85 & 34,85 \\
\hline 27.03 & 42 & 27,73 & 19,35 & 17,01 & 7,81 & 10,80 & 7,41 & 30,22 & 12,09 & 54,07 & 36,51 & 56,44 \\
\hline 28.03 & 43 & 19,10 & 13,27 & 8,78 & 6,85 & 7,59 & 6,95 & 30,52 & 33,84 & 21,98 & 13,55 & 20,84 \\
\hline 29.03 & 44 & 21,99 & 12,75 & 8,03 & 5,25 & 9,64 & 5,39 & 42,02 & 37,02 & 34,62 & $-20,05$ & 32,88 \\
\hline 30.03 & 45 & 18,02 & 14,51 & 8,90 & 6,28 & 7,15 & 6,23 & 19,48 & 38,66 & 29,44 & 19,66 & 30,00 \\
\hline 31.03 & 46 & 32,46 & 27,82 & 12,72 & 6,51 & 11,10 & 6,60 & 14,29 & 54,28 & 48,81 & 12,74 & 48,15 \\
\hline 01.04 & 47 & 24,30 & 17,10 & 9,72 & 5,82 & 9,16 & 5,95 & 29,63 & 43,16 & 40,12 & 5,76 & 38,79 \\
\hline 02.04 & 48 & 19,20 & 15,60 & 9,04 & 4,27 & 6,04 & 4,82 & 18,75 & 42,05 & 52,77 & 33,19 & 46,68 \\
\hline 03.04 & 49 & 19,98 & 13,84 & 7,33 & 3,48 & 3,99 & 4,16 & 30,73 & 47,02 & 52,54 & 45,58 & 43,26 \\
\hline 04.04 & 50 & 19,80 & 15,30 & 7,97 & 4,49 & 5,27 & 4,63 & 22,73 & 47,91 & 43,66 & 33,88 & 41,91 \\
\hline 05.04 & 51 & 18,60 & 13,50 & 7,25 & 3,18 & 4,05 & 3,74 & 27,42 & 46,30 & 56,14 & 44,14 & 48,41 \\
\hline 06.04 & 52 & 17,60 & 13,60 & 7,15 & 2,81 & 3,71 & 3,35 & 22,73 & 47,43 & 60,70 & 48,11 & 53,15 \\
\hline 07.04 & 53 & 17,10 & 13,40 & 7,48 & 2,42 & 3,93 & 3,30 & 21,64 & 44,18 & 67,65 & 47,46 & 55,88 \\
\hline 08.04 & 54 & 18,40 & 14,40 & 8,00 & 2,50 & 4,20 & 3,33 & 21,74 & 44,44 & 68,75 & 47,50 & 58,38 \\
\hline 09.04 & 55 & 19,00 & 13,80 & 7,79 & 2,73 & 3,42 & 3,12 & 27,37 & 43,55 & 64,96 & 56,10 & 59,95 \\
\hline 10.04 & 56 & 22,10 & 14,00 & 7,54 & 2,49 & 3,37 & 2,95 & 36,65 & 46,14 & 66,98 & 55,31 & 60,88 \\
\hline 11.04 & 57 & 21,80 & 14,70 & 7,46 & 2,61 & 3,22 & 3,13 & 32,57 & 49,25 & 65,01 & 56,84 & 58,04 \\
\hline 12.04 & 58 & 19,50 & 14,90 & 8,28 & 2,63 & 4,18 & 3,04 & 23,59 & 44,43 & 68,24 & 49,52 & 63,29 \\
\hline 13.04 & 59 & 20,80 & 15,80 & 8,05 & 2,87 & 3,51 & 3,08 & 24,04 & 49,05 & 64,35 & 56,40 & 61,74 \\
\hline 14.04 & 60 & 19,40 & 13,50 & 6,73 & 1,74 & 3,53 & 2,71 & 30,41 & 50,15 & 74,15 & 47,55 & 59,73 \\
\hline 15.04 & 61 & 17,90 & 13,80 & 6,98 & 2,24 & 2,97 & 2,53 & 22,91 & 49,42 & 67,91 & 57,45 & 63,75 \\
\hline 16.04 & 62 & 18,00 & 12,90 & 6,62 & 2,49 & 3,25 & 2,67 & 28,33 & 48,68 & 62,39 & 50,91 & 59,67 \\
\hline
\end{tabular}


Continuação da TABELA E.1 - Resultados de turbidez em uT e \% deremoções nos pré-filtros e filtros lentos na carreira 1

\begin{tabular}{|c|c|c|c|c|c|c|c|c|c|c|c|c|}
\hline Data & TO & $\overline{\mathrm{AB}}$ & PFD & PFVA & FL11 & FL13 & FL21 & r\%PFD & $\%$ PFVA & r\%FL11 & r\%FL13 & r\%FL21 \\
\hline 17.04 & 63 & 16,70 & 12,30 & 6,38 & 2,17 & 2,98 & 2,46 & 26,35 & 48,13 & 65,99 & 53,29 & 61,44 \\
\hline 18.04 & 64 & 19,30 & 14,60 & 6,58 & 2,04 & 3,05 & 2,50 & 24,35 & 54,93 & 69,00 & 53,65 & 62,01 \\
\hline 19.04 & 65 & 19,80 & 13,70 & 7,95 & 2,59 & 3,81 & 2,70 & 30,81 & 41,97 & 67,42 & 52,08 & 66,04 \\
\hline 20.04 & 66 & 19,70 & 13,70 & 6,82 & 2,90 & 3,97 & 2,69 & 30,46 & 50,22 & 57,48 & 41,79 & 60,56 \\
\hline 21.04 & 67 & 18,00 & 12,20 & 6,44 & 2,63 & 3,78 & 2,73 & 32,22 & 47,21 & 59,16 & 41,30 & 57,61 \\
\hline 22.04 & 68 & 17,50 & 11,50 & 6,09 & 2,57 & 3,90 & 2,65 & 34,29 & 47,04 & 57,80 & 35,96 & 56,49 \\
\hline 23.04 & 69 & 15,80 & 10,70 & 6,05 & 2,84 & 3,83 & 2,69 & 32,28 & 43,46 & 53,06 & 36,69 & 55,54 \\
\hline 24.04 & 70 & 16,8 & 11,6 & 5,57 & 2,46 & 3,13 & 2,56 & 30,95 & 51,98 & 55,83 & 43,81 & 54,04 \\
\hline 25.04 & 71 & 17,5 & 11,8 & 5,51 & 2,42 & 3,11 & 2,63 & 32,57 & 53,31 & 56,08 & 43,56 & 52,27 \\
\hline 26.04 & 72 & 17 & 11,2 & 5,6 & 2,46 & 3,32 & 2,49 & 34,12 & 50,00 & 56,07 & 40,71 & 55,54 \\
\hline 27.04 & 74 & 16,9 & 11,1 & 5,33 & 2,45 & 3,33 & 2,67 & 34,32 & 51,98 & 54,03 & 37,52 & 49,91 \\
\hline 29.04 & 75 & 17,9 & 11,4 & 5,52 & 2,74 & 3,87 & 2,73 & 36,31 & 51,58 & 50,36 & 29,89 & 50,54 \\
\hline 30.04 & 76 & 14,5 & 11 & 5,61 & 2,37 & 3,3 & 2,42 & 24,14 & 49,00 & 57,75 & 41,18 & 56,86 \\
\hline 01.05 & 77 & 17,4 & 11,1 & 5,52 & 2,49 & 3,51 & 2,52 & 36,21 & 50,27 & 54,89 & 36,41 & 54,35 \\
\hline 02.05 & 78 & 16,9 & 11,2 & 5,43 & 2,49 & 3,12 & 2,23 & 33,73 & 51,52 & 54,14 & 42,54 & 58,93 \\
\hline 03.05 & 79 & 18,4 & 11,9 & 5,23 & 2,45 & 2,95 & 2,2 & 35,33 & 56,05 & 53,15 & 43,59 & 57,93 \\
\hline 04.05 & 80 & 16,4 & 10,6 & 5,33 & 2,14 & 3,08 & 3,41 & 35,37 & 49,72 & 59,85 & 42,21 & 36,02 \\
\hline 05.05 & 81 & 16,7 & 11 & 4,89 & 1,87 & 3,32 & 2,78 & 34,13 & 55,55 & 61,76 & 32,11 & 43,15 \\
\hline 06.05 & 82 & 16,9 & 10,7 & 4,87 & 1,97 & 3,32 & 2,78 & 36,69 & 54,49 & 59,55 & 31,83 & 42,92 \\
\hline 07.05 & 83 & 14,4 & 10,5 & 4,95 & 2,13 & 3,34 & 2,28 & 27,08 & 52,86 & 56,97 & 32,53 & 53,94 \\
\hline 09.05 & 85 & 15,5 & 10,2 & 4,69 & 1,55 & 3,29 & 1,82 & 34,19 & 54,02 & 66,95 & 29,85 & 61,19 \\
\hline
\end{tabular}


TABELA E.2 - Resultados de cor aparente em uH e \% de remoções nos pré-filtros e filtros lentos na carreira 1

\begin{tabular}{|c|c|c|c|c|c|c|c|c|c|c|c|c|}
\hline Data & TO & AB & PFD & PFVA & FL11 & FL13 & FL21 & $\%$ rPFD & \%rPFVa & \%rFL11 & \%rFL13 & \%rFL21 \\
\hline & 0 & 280 & 199 & 224 & 153 & 190 & 196 & 28,93 & $-12,56$ & 31,70 & 15,18 & 12,50 \\
\hline & 1 & 260 & 231 & 202 & 160 & 192 & 199 & 11,15 & 12,55 & 20,79 & 4,95 & 1,49 \\
\hline & 4 & 275 & 234 & 184 & 129 & 157 & 155 & 14,91 & 21,37 & 29,89 & 14,67 & 15,76 \\
\hline & 5 & 216 & 191 & 149 & 122 & 133 & 141 & 11,57 & 21,99 & 18,12 & 10,74 & 5,37 \\
\hline 21.02 & 7 & 215 & 177 & 139 & 104 & 121 & 122 & 17,67 & 21,47 & 25,18 & 12,95 & 12,23 \\
\hline 22.02 & 8 & 206 & 160 & 117 & 84 & 103 & 111 & 22,33 & 26,88 & 28,21 & 11,97 & 5,13 \\
\hline 25.02 & 11 & 428 & 344 & 174 & 39 & 168 & 24 & 19,63 & 49,42 & 77,59 & 3,45 & 86,21 \\
\hline 26.02 & 12 & 335 & 281 & 169 & 111 & 142 & 115 & 16,12 & 39,86 & 34,32 & 15,98 & 31,95 \\
\hline 29.03 & 15 & 446 & 313 & 253 & 220 & 259 & 229 & 29,82 & 19,17 & 13,04 & $-2,37$ & 9,49 \\
\hline 08.03 & 23 & 328 & 237 & 170 & 126 & 155 & 140 & 27,74 & 28,27 & 25,88 & 8,82 & 17,65 \\
\hline 09.03 & 24 & 266 & 173 & 130 & 111 & 134 & 115 & 34,96 & 24,86 & 14,62 & $-3,08$ & 11,54 \\
\hline 12.03 & 27 & 198 & 138 & 112 & 83 & 107 & 86 & 30,30 & 18,84 & 25,89 & 4,46 & 23,21 \\
\hline 13.03 & 28 & 211 & 140 & 109 & 90 & 117 & 95 & 33,65 & 22,14 & 17,43 & $-7,34$ & 12,84 \\
\hline 14.03 & 29 & 184 & 130 & 102 & 54 & 49 & 54 & 29,35 & 21,54 & 47,06 & 51,96 & 47,06 \\
\hline 15.03 & 30 & 183 & 143 & 99 & 98 & 80 & 75 & 21,86 & 30,77 & 1,01 & 19,19 & 24,24 \\
\hline 19.03 & 34 & 380 & 320 & 234 & 89 & 112 & 86 & 15,79 & 26,88 & 61,97 & 52,14 & 63,25 \\
\hline 20.03 & 35 & 220 & 185 & 151 & 139 & 148 & 154 & 15,91 & 18,38 & 7,95 & 1,99 & $-1,99$ \\
\hline 22.03 & 37 & 184 & 140 & 92 & 56 & 65 & 61 & 23,91 & 34,29 & 39,13 & 29,35 & 33,70 \\
\hline 24.03 & 39 & 177 & 130 & 79 & 45 & 58 & 56 & 26,55 & 39,23 & 43,04 & 26,58 & 29,11 \\
\hline 25.03 & 40 & 193 & 138 & 88 & 53 & 64 & 55 & 28,50 & 36,23 & 39,77 & 27,27 & 37,50 \\
\hline 26.03 & 41 & 222 & 170 & 95 & 68 & 71 & 81 & 23,42 & 44,12 & 28,42 & 25,26 & 14,74 \\
\hline 27.04 & 42 & 185 & 134 & 79 & 54 & 60 & 57 & 27,57 & 41,04 & 31,65 & 24,05 & 27,85 \\
\hline 28.03 & 43 & 178 & 125 & 77 & 46 & 54 & 52 & 29,78 & 38,40 & 40,26 & 29,87 & 32,47 \\
\hline 29.03 & 44 & 174 & 142 & 82 & 47 & 51 & 50 & 18,39 & 42,25 & 42,68 & 37,80 & 39,02 \\
\hline 31.03 & 46 & 196 & 156 & 86 & 44 & 59 & 52 & 20,41 & 44,87 & 48,84 & 31,40 & 39,53 \\
\hline 02.04 & 48 & 161 & 124 & 72 & 36 & 43 & 39 & 22,98 & 41,94 & 50,00 & 40,28 & 45,83 \\
\hline 03.04 & 49 & 177 & 132 & 69 & 36 & 44 & 42 & 25,42 & 47,73 & 47,83 & 36,23 & 39,13 \\
\hline
\end{tabular}


Continuação da TABELA E.2 - Resultados de cor aparente em uH e \% de remoções nos pré-filtros e filtros lentos na carreira 1

\begin{tabular}{|c|c|c|c|c|c|c|c|c|c|c|c|c|}
\hline Data & TO & AB & PFD & PFVA & FL11 & FL13 & FL21 & \%rPFD & \%rPFVa & \%rFL11 & \%rFL13 & \%rFL21 \\
\hline 08.04 & 54 & 169 & 132 & 78 & 31 & 40 & 42 & 21,89 & 40,91 & 60,26 & 48,72 & 46,15 \\
\hline 09.04 & 55 & 196 & 156 & 86 & 44 & 59 & 52 & 20,41 & 44,87 & 48,84 & 31,40 & 39,53 \\
\hline 10.04 & 56 & 180 & 127 & 62 & 17 & 27 & 22 & 29,44 & 51,18 & 72,58 & 56,45 & 64,52 \\
\hline 12.04 & 58 & 163 & 128 & 62 & 16 & 23 & 23 & 21,47 & 51,56 & 74,19 & 62,90 & 62,90 \\
\hline 16.04 & 62 & 132 & 103 & 49 & 11 & 11 & 21 & 21,97 & 52,43 & 77,55 & 77,55 & 57,14 \\
\hline 18.04 & 64 & 147 & 123 & 57 & 18 & 31 & 26 & 16,33 & 53,66 & 68,42 & 45,61 & 54,39 \\
\hline 23.04 & 69 & 137 & 95 & 47 & 18 & 27 & 22 & 30,66 & 50,53 & 61,70 & 42,55 & 53,19 \\
\hline 26.04 & 72 & 133 & 91 & 44 & 17 & 24 & 19 & 31,58 & 51,65 & 61,36 & 45,45 & 56,82 \\
\hline 02.05 & 78 & 129 & 94 & 41 & 14 & 22 & 17 & 27,13 & 56,38 & 65,85 & 46,34 & 58,54 \\
\hline 03.05 & 79 & 132 & 96 & 44 & 20 & 28 & 25 & 27,27 & 54,17 & 54,55 & 36,36 & 43,18 \\
\hline
\end{tabular}

TABELA E.3 - Resultados de cor verdadeira em uH e \% de remoções nos pré-filtros e filtros lentos na carreira 1

\begin{tabular}{|c|c|c|c|c|c|c|c|c|c|c|c|c|}
\hline Data & TO & $\overline{A B}$ & PFD & PFVA & FL11 & FL13 & FL21 & \%rPFD & \%rPFVA & \%rFL11 & \%rFL13 & \%rFL21 \\
\hline 23.03 & 38 & 58 & 47 & 36 & 24 & 31 & 30 & 18,97 & 23,40 & 33,33 & 13,89 & 16,67 \\
\hline 28.03 & 43 & 59 & 54 & 40 & 26 & 31 & 34 & 8,47 & 25,93 & 35,00 & 22,50 & 15,00 \\
\hline 30.03 & 45 & 65 & 47 & 38 & 23 & 29 & 27 & 27,69 & 19,15 & 39,47 & 23,68 & 28,95 \\
\hline 03.04 & 49 & 49 & 46 & 36 & 19 & 23 & 24 & 6,12 & 21,74 & 47,22 & 36,11 & 33,33 \\
\hline 06.04 & 52 & 38 & 21 & 32 & 7 & 14 & 13 & 44,74 & $-52,38$ & 78,13 & 56,25 & 59,38 \\
\hline 10.04 & 56 & 49 & 41 & 29 & 10 & 17 & 20 & 16,33 & 29,27 & 65,52 & 41,38 & 31,03 \\
\hline 11.04 & 57 & 48 & 36 & 26 & 9 & 16 & 14 & 25,00 & 27,78 & 65,38 & 38,46 & 46,15 \\
\hline 13.04 & 59 & 38 & 38 & 27 & 9 & 12 & 13 & 0,00 & 28,95 & 66,67 & 55,56 & 51,85 \\
\hline 17.04 & 63 & 34 & 28 & 19 & 4 & 8 & 8 & 17,65 & 32,14 & 78,95 & 57,89 & 57,89 \\
\hline 18.04 & 64 & 42 & 34 & 23 & 5 & 11 & 11 & 19,05 & 32,35 & 78,26 & 52,17 & 52,17 \\
\hline 24.04 & 70 & 36 & 31 & 20 & 8 & 12 & 11 & 13,89 & 35,48 & 60,00 & 40,00 & 45,00 \\
\hline 27.04 & 74 & 34 & 27 & 17 & 6 & 10 & 10 & 20,59 & 37,04 & 64,71 & 41,18 & 41,18 \\
\hline 03.05 & 79 & 37 & 35 & 18 & 7 & 11 & 10 & 5,41 & 48,57 & 61,11 & 38,89 & 44,44 \\
\hline 04.05 & 80 & 40 & 32 & 17 & 8 & 11 & 10 & 20,00 & 46,88 & 52,94 & 35,29 & 41,18 \\
\hline
\end{tabular}


TABELA E.4 - Resultados de absorvância - $254 \mathrm{~nm}\left(\mathrm{~cm}^{-1}\right)$ e \% de remoções nos pré-filtros e filtros lentos na carreira 1

\begin{tabular}{|c|c|c|c|c|c|c|c|c|c|c|c|c|}
\hline Data & TO & AB & PFD & PFVA & FL11 & FL13 & FL21 & r\%PFD & r\%PFVA & r\%FL11 & \%rFL13 & \%rFL21 \\
\hline 14.03 & 29 & 0,055 & 0,068 & 0,063 & 0,011 & 0,060 & 0,081 & $-23,64$ & 7,35 & 82,54 & 4,76 & $-28,57$ \\
\hline 23.03 & 38 & 0,108 & 0,114 & 0,109 & 0,062 & 0,086 & 0,096 & $-5,56$ & 4,39 & 43,12 & 21,10 & 11,93 \\
\hline 28.03 & 43 & 0,053 & 0,056 & 0,075 & 0,040 & 0,074 & 0,081 & $-5,66$ & $-33,93$ & 46,67 & 1,33 & $-8,00$ \\
\hline 03.04 & 49 & 0,058 & 0,064 & 0,079 & 0,037 & 0,068 & 0,068 & $-10,34$ & $-23,44$ & 53,16 & 13,92 & 13,92 \\
\hline 06.04 & 52 & 0,072 & 0,080 & 0,070 & 0,025 & 0,052 & 0,053 & $-11,11$ & 12,50 & 64,29 & 25,71 & 24,29 \\
\hline 10.04 & 56 & 0,076 & 0,071 & 0,060 & 0,019 & 0,041 & 0,046 & 6,58 & 15,49 & 68,33 & 31,67 & 23,33 \\
\hline 13.04 & 59 & 0,048 & 0,049 & 0,064 & 0,047 & 0,046 & 0,047 & $-2,08$ & $-30,61$ & 26,56 & 28,13 & 26,56 \\
\hline 17.04 & 63 & 0,054 & 0,057 & 0,056 & 0,017 & 0,037 & 0,038 & $-5,56$ & 1,75 & 69,64 & 33,93 & 32,14 \\
\hline 24.04 & 70 & 0,046 & 0,056 & 0,049 & 0,020 & 0,036 & 0,036 & $-21,74$ & 12,50 & 59,18 & 26,53 & 26,53 \\
\hline 27.04 & 74 & 0,053 & 0,05 & 0,046 & 0,014 & 0,03 & 0,032 & 5,66 & 8,00 & 69,57 & 34,78 & 30,43 \\
\hline 03.05 & 79 & 0,044 & 0,052 & 0,042 & 0,014 & 0,03 & 0,032 & $-18,18$ & 19,23 & 66,67 & 28,57 & 23,81 \\
\hline 08.05 & 84 & 0,05 & 0,042 & 0,045 & 0,014 & 0,033 & 0,03 & 16,00 & $-7,14$ & 68,89 & 26,67 & 33,33 \\
\hline
\end{tabular}

TABELA E.5 - Medidas de temperatura em ${ }^{\circ} \mathrm{C}$ na carreira 1

\begin{tabular}{|c|c|c|c|c|c|c|c|}
\hline Data & TO & AB & PFD & PFVA & F11 & F13 & F21 \\
\hline $17 / 02 / 00$ & 3 & 22,5 & 21,5 & 22,0 & 21,0 & 19,0 & 21,0 \\
\hline $19 / 02 / 00$ & 5 & 23,0 & 23,0 & 22,0 & 20,0 & 20,0 & 20,0 \\
\hline $25 / 03 / 00$ & 40 & 25,5 & 28,0 & 28,0 & 25,0 & 26,0 & 26,0 \\
\hline $01 / 04 / 00$ & 47 & 26,0 & 26,0 & 25,0 & 25,0 & 24,0 & 24,0 \\
\hline $03 / 04 / 00$ & 49 & 23,0 & 20,0 & 21,0 & 20,5 & 20,0 & 19,0 \\
\hline $04 / 04 / 00$ & 50 & 22,0 & 23,0 & 22,5 & 21,0 & 20,0 & 20,0 \\
\hline $05 / 04 / 00$ & 51 & 23,5 & 22,0 & 23,0 & 21,5 & 23,0 & 22,0 \\
\hline $06 / 04 / 00$ & 52 & & 24,0 & 22,5 & 21,0 & 20,0 & 20,5 \\
\hline $08 / 04 / 00$ & 54 & 24,0 & 25,5 & 24,0 & 26,0 & 25,0 & 24,0 \\
\hline $09 / 04 / 00$ & 55 & 24,0 & 22,5 & 23,5 & 22,0 & 21,5 & 24,0 \\
\hline $10 / 04 / 00$ & 56 & 23,0 & 23,0 & 22,5 & 22,5 & 23,0 & 23,0 \\
\hline $11 / 04 / 00$ & 57 & 24,0 & 24,0 & 23,0 & 24,0 & 24,5 & 23,5 \\
\hline
\end{tabular}


Continuação da TABELA E.5 - Medidas de temperatura em ${ }^{\circ} \mathrm{C}$ na carreira 1

\begin{tabular}{|l|l|l|l|l|l|l|l|}
\hline $12 / 04 / 00$ & 58 & 24,5 & 23,5 & 23,0 & 23,0 & 22,5 & 24,0 \\
\hline $13 / 04 / 00$ & 59 & 24,0 & 22,5 & 22,5 & 23,0 & 23,0 & 22,0 \\
\hline $15 / 04 / 00$ & 61 & 25,0 & 27,0 & 25,0 & 27,0 & 27,0 & 27,0 \\
\hline $16 / 04 / 00$ & 62 & 22,0 & 23,0 & 21,0 & 22,5 & 21,5 & 22,5 \\
\hline $17 / 04 / 00$ & 63 & 22,0 & 22,0 & 21,0 & 21,0 & 21,0 & 21,0 \\
\hline $18 / 04 / 00$ & 64 & 24,0 & 23,0 & 24,5 & 23,0 & 23,0 & 24,5 \\
\hline $19 / 04 / 00$ & 65 & 22,5 & 24,0 & 22,0 & 24,0 & 23,5 & 22,0 \\
\hline $20 / 04 / 00$ & 66 & 22,5 & 20,5 & 22,0 & 20,0 & & \\
\hline $21 / 04 / 00$ & 67 & 21,0 & 22,0 & 19,5 & 18,5 & 19,0 & 19,0 \\
\hline $22 / 04 / 00$ & 68 & 22,0 & 21,0 & 21,5 & 19,5 & 20,0 & 19,0 \\
\hline $23 / 04 / 00$ & 69 & 21,0 & 21,5 & 20,0 & 18,0 & 17,5 & 18,0 \\
\hline $24 / 04 / 00$ & 70 & 20,0 & 22,0 & 20,0 & 21,0 & 19,0 & 21,0 \\
\hline $25 / 04 / 00$ & 71 & 19,5 & 20,0 & 21,0 & 19,0 & 19,0 & 21,0 \\
\hline $26 / 04 / 00$ & 72 & 21,5 & 20,5 & 21,0 & 21,5 & 19,5 & 20,0 \\
\hline $27 / 04 / 00$ & 73 & 20,5 & 22,0 & 20,0 & 21,5 & 19,0 & 21,0 \\
\hline $28 / 04 / 00$ & 74 & 20,0 & 20,5 & 21,5 & 20,5 & 21,0 & 21,5 \\
\hline $30 / 04 / 00$ & 76 & 22,5 & 21,5 & 21,0 & 22,5 & 22,0 & 21,0 \\
\hline $01 / 05 / 00$ & 77 & 22,0 & 24,0 & 22,5 & 24,0 & 24,0 & 23,0 \\
\hline $02 / 05 / 00$ & 78 & 22,0 & 23,5 & 21,5 & 22,0 & 22,5 & 23,5 \\
\hline $03 / 05 / 00$ & 79 & 23,5 & 22,5 & 22,5 & 22,0 & 23,0 & 24,0 \\
\hline $04 / 05 / 00$ & 80 & 22,0 & 22,0 & 23,5 & 24,0 & 22,0 & 24,0 \\
\hline $05 / 05 / 00$ & 81 & 25,0 & 27,0 & 27,0 & 28,5 & 30,0 & 27,0 \\
\hline $06 / 05 / 00$ & 82 & 24,5 & 24,0 & 24,5 & 25,0 & 23,0 & 21,5 \\
\hline $07 / 05 / 00$ & 83 & 22,0 & 20,0 & 19,0 & 20,0 & 20,0 & 19,0 \\
\hline $08 / 05 / 00$ & 84 & 22,0 & 20,5 & 19,5 & 19,5 & 20,0 & 21,0 \\
\hline
\end{tabular}




\begin{abstract}
ANEXO F
Tabelas com resultados de turbidez, sólidos suspensos totais, cor aparente, cor verdadeira, absorvância, $\mathrm{COD}, \mathrm{OC}, \mathbf{p H}$, condutividade elétrica e temperatura da carreira 3.
\end{abstract}


TABELA F.1- Resultados de turbidez em uT e \% de remoções nos pré-filtros e filtros lentos

\begin{tabular}{|c|c|c|c|c|c|c|c|c|c|c|c|c|c|c|c|}
\hline \begin{tabular}{|l|l|} 
Data \\
\end{tabular} & TO & $\mathbf{A B}$ & PFD & PFVA & FL11 & FL13 & FL21 & FL1mont & FL2mont & PFVAsh & R\%PFD & R\%PFVa & R\%FL11 & R\%FL13 & R\%FL21 \\
\hline 23.08 & $\overline{1}$ & 13,70 & 10,00 & 6,24 & 0,37 & 2,84 & 1,11 & 7,08 & 6,68 & & & & & & \\
\hline 23.04 & 1,5 & 13,00 & 10,30 & 6,03 & 1,21 & 2,85 & 1,97 & 5,99 & 6,32 & & & & & & \\
\hline 25.08 & 3 & 15,60 & 9,84 & 6,17 & 1,31 & 3,22 & 1,81 & 6,61 & 6,55 & & & & & & \\
\hline 26.08 & 4 & 15,3 & 11,2 & 6,32 & 2,67 & 3,92 & 2,57 & 6,71 & 6,47 & & 26,80 & 43,57 & 57,75 & 37,97 & 59,34 \\
\hline 27.08 & 5 & 11,5 & 9,41 & 6,31 & 2,41 & 3,52 & 2,55 & 6,37 & 6,49 & & 18,17 & 32,94 & 61,81 & 44,22 & 59,59 \\
\hline 28.08 & 6 & 11,3 & 9,52 & 6,33 & 2,38 & 3,53 & 2,56 & 6,38 & 6,51 & & 15,75 & 33,51 & 62,40 & 44,23 & 59,56 \\
\hline 29.08 & 7 & 31,9 & 22,2 & 12 & 3,45 & 5,05 & 3,11 & 12,3 & 13,1 & & 30,41 & 45,95 & 71,25 & 57,92 & 74,08 \\
\hline 30.08 & 8 & 17,6 & 13,2 & 9,06 & 3,69 & 5,68 & 3,77 & 9,18 & 8,92 & & 25,00 & 31,36 & 59,27 & 37,31 & 58,39 \\
\hline 31.08 & 9 & 16,9 & 11,4 & 7,17 & 2,07 & 3,83 & 2,2 & 6,95 & 6,97 & & 32,54 & 37,11 & 71,13 & 46,58 & 69,32 \\
\hline \begin{tabular}{|l|}
01.09 \\
\end{tabular} & 10 & 14,4 & 10,8 & 6,33 & 1,7 & 3,17 & 2,15 & 6,39 & 6,48 & & 25,00 & 41,39 & 73,14 & 49,92 & 66,03 \\
\hline \begin{tabular}{|l|}
02.09 \\
\end{tabular} & 11 & 32,6 & 15,2 & 7,97 & 1,8 & 2,96 & 1,95 & 8,28 & 8,05 & & 53,37 & 47,57 & 77,42 & 62,86 & 75,53 \\
\hline \begin{tabular}{|l|l|}
03.09 \\
\end{tabular} & 12 & 30 & 21,1 & 16,7 & 6,57 & 9,86 & 6,29 & 17 & 17,5 & & 29,67 & 20,85 & 60,66 & 40,96 & 62,34 \\
\hline \begin{tabular}{|l|l|}
04.09 \\
\end{tabular} & 13 & 24,8 & 18,2 & 13,7 & 6,66 & 8,54 & 6,61 & 13,6 & 13,8 & & 26,61 & 24,73 & 51,39 & 37,66 & 51,75 \\
\hline 05.09 & 14 & 19,8 & 14,4 & 10 & 4,6 & 6,81 & 4,65 & 10,2 & 10,2 & & 27,27 & 30,56 & 54,00 & 31,90 & 53,50 \\
\hline 06.09 & 15 & 22,5 & 14,6 & 10,5 & 2,18 & 3,86 & 2,9 & 10,9 & 9,85 & & 35,11 & 28,08 & 79,24 & 63,24 & 72,38 \\
\hline 07.09 & 16 & 20,6 & 17,1 & 9,39 & 2,57 & 4,27 & 3,06 & 9,48 & 9,61 & & 16,99 & 45,09 & 72,63 & 54,53 & 67,41 \\
\hline \begin{tabular}{|c|}
08.09 \\
\end{tabular} & 17 & 17,9 & 12,1 & 9,05 & 2,3 & 4,12 & 2,74 & 9,04 & 9,17 & & 32,40 & 25,21 & 74,59 & 54,48 & 69,72 \\
\hline \begin{tabular}{|c|}
09.09 \\
\end{tabular} & 18 & 18,5 & 13,8 & 8,7 & 2,41 & 3,91 & 2,75 & 8,72 & 8,79 & & 25,41 & 36,96 & 72,30 & 55,06 & 68,39 \\
\hline 11.09 & 20 & 16,6 & 15,6 & 8,44 & 1,9 & 7,75 & 2,1 & 8,86 & 8,65 & & 6,02 & 45,90 & 77,49 & 8,18 & 75,12 \\
\hline 12.09 & 21 & 18,5 & 13,2 & 8,23 & 2,03 & 4,53 & 2,59 & 8,3 & 8,75 & & 28,65 & 37,65 & 75,33 & 44,96 & 68,53 \\
\hline \begin{tabular}{|c|}
13.09 \\
\end{tabular} & 22 & 50,4 & 43,7 & 11,8 & 2,24 & 3,96 & 2,51 & 11,9 & 12,8 & & 13,29 & 73,00 & 81,02 & 66,44 & 78,73 \\
\hline \begin{tabular}{|l|}
14.09 \\
\end{tabular} & 23 & 21,3 & 16,8 & 11,9 & 3,78 & 6,36 & \begin{tabular}{|l|}
4,47 \\
\end{tabular} & 11,7 & 11,7 & & 21,13 & 29,17 & 68,24 & 46,55 & 62,44 \\
\hline \begin{tabular}{|l|}
15.09 \\
\end{tabular} & 24 & 17,6 & 12,9 & 8,32 & 1,9 & 4,42 & 2,91 & 8,15 & 8,03 & & 26,70 & 35,50 & 77,16 & 46,88 & 65,02 \\
\hline 16.09 & 25 & 16,6 & 11,9 & 7,19 & 2,08 & 4,05 & 2,57 & 7,31 & 7,39 & & 28,31 & 39,58 & 71,07 & 43,67 & 64,26 \\
\hline 18.09 & 26 & 34,1 & 23,8 & 12,6 & 3,29 & 6,05 & 3,27 & 13,6 & 12,9 & & 30,21 & 47,06 & 73,89 & 51,98 & 74,05 \\
\hline \begin{tabular}{|l|}
19.09 \\
\end{tabular} & 27 & 21,2 & 14,7 & 9,02 & 4,78 & 6,77 & 4,54 & 11,3 & 9,18 & & 30,66 & 38,64 & 47,01 & 24,94 & 49,67 \\
\hline \begin{tabular}{|l|}
20.09 \\
\end{tabular} & 28 & 20,2 & 14,5 & 7,16 & 3,62 & 5,19 & 3,68 & 7,28 & 7,19 & & 28,22 & 50,62 & 49,44 & 27,51 & 48,60 \\
\hline
\end{tabular}


Continuação da TABELA F.1- Resultados de turbidez em uT e \% de remoções nos pré-filtros e filtros lentos

\begin{tabular}{|c|c|c|c|c|c|c|c|c|c|c|c|c|c|c|c|}
\hline Data & TO & $\mathbf{A B}$ & PFD & PFVA & FL11 & FL13 & FL21 & FL1mont & FL2mont & PFVAsh & R\%PFD & R\%PFVa & R\%FL11 & R\%FL13 & R\%FL21 \\
\hline 21.09 & 29 & 18 & 14,4 & 6,9 & 3,28 & \begin{tabular}{|l|}
4,51 \\
\end{tabular} & 3,3 & 7,2 & 7,31 & & 20,00 & 52,08 & 52,46 & 34,64 & 52,17 \\
\hline 22.09 & 30 & 18,9 & 12,7 & 6,33 & 2,73 & \begin{tabular}{|l|l|}
4,38 \\
\end{tabular} & 3,7 & 6,27 & 6,32 & & 32,80 & 50,16 & $\begin{array}{l}56,87 \\
\end{array}$ & 30,81 & 41,55 \\
\hline 23.09 & 31 & 13,9 & 12,9 & 6,29 & 2,08 & \begin{tabular}{|l|}
4,35 \\
\end{tabular} & 3,11 & 7,04 & 6,2 & & 7,19 & 51,24 & 66,93 & 30,84 & 50,56 \\
\hline 24.09 & 32 & 28,8 & 17,1 & 7,22 & 2,86 & 4,68 & 3,46 & 7,4 & 7,2 & & 40,63 & 57,78 & 60,39 & 35,18 & 52,08 \\
\hline 25.09 & 33 & 17,1 & 11,8 & 6,86 & 3,32 & 4,42 & 3,83 & 7,06 & 6,99 & & 30,99 & 41,86 & 51,60 & 35,57 & 44,17 \\
\hline 26.09 & 34 & 17 & 12,6 & 6,64 & 3,42 & \begin{tabular}{|l|}
4,56 \\
\end{tabular} & 3,82 & 6,7 & 6,67 & & 25,88 & 47,30 & 48,49 & 31,33 & 42,47 \\
\hline 27.09 & 35 & 16,6 & 11,3 & 5,95 & 2,76 & \begin{tabular}{|l|}
4,12 \\
\end{tabular} & 3,2 & 6,1 & 6,18 & & 31,93 & 47,35 & 53,61 & 30,76 & 46,22 \\
\hline 28.09 & 36 & 15,6 & 10,3 & 5,77 & 2,48 & 3,24 & 2,81 & 5,99 & 5,97 & & 33,97 & 43,98 & 57,02 & 43,85 & 51,30 \\
\hline \begin{tabular}{|l|}
29.09 \\
\end{tabular} & 37 & 14,8 & 10,5 & 5,66 & 1,73 & 3,15 & 2,93 & 5,56 & 5,53 & & 29,05 & 46,10 & 69,43 & 44,35 & 48,23 \\
\hline 30.09 & 38 & 15,2 & 10,4 & 5,66 & 1,8 & 3,04 & 2,8 & 5,9 & 6,13 & & 31,58 & 45,58 & 68,20 & 46,29 & 50,53 \\
\hline 01.09 & 39 & 16 & 13,1 & 7,23 & 1,8 & 3,33 & 2,93 & 7,34 & 7,4 & & 18,13 & 44,81 & 75,10 & 53,94 & 59,47 \\
\hline 02.10 & 40 & 17,7 & 12 & 6,41 & 2,18 & 3,19 & 2,83 & 6,8 & 7,34 & & 32,20 & 46,58 & 65,99 & 50,23 & 55,85 \\
\hline 03.10 & 41 & 17,6 & 10,8 & 5,68 & 1,78 & 3,09 & 2,85 & 6,01 & 5,89 & & 38,64 & 47,41 & 68,66 & 45,60 & 49,82 \\
\hline 04.10 & 42 & 20,6 & 13 & 5,99 & 2,39 & 2,99 & 3 & 5,93 & 6,07 & & 36,89 & 53,92 & 60,10 & 50,08 & 49,92 \\
\hline \begin{tabular}{|l|}
05.10 \\
\end{tabular} & 43 & 20,8 & 13,4 & 8,71 & 2,36 & 3,37 & 2,85 & 9,18 & 8,88 & & 35,58 & 35,00 & 72,90 & 61,31 & 67,28 \\
\hline 06.10 & 44 & 17 & 14,2 & 5,34 & 1,52 & 3,09 & 2,77 & 5,43 & 5,63 & & 16,47 & 62,39 & 71,54 & 42,13 & 48,13 \\
\hline 07.10 & 45 & 16,1 & 12,3 & 7,06 & 1,83 & 3,51 & 3,26 & 7,47 & 7,34 & & 23,60 & 42,60 & 74,08 & 50,28 & 53,82 \\
\hline 08.10 & 46 & 14 & 10,2 & 6,22 & 2,22 & 3,42 & 3,52 & 6,84 & 6,33 & & 27,14 & 39,02 & 64,31 & 45,02 & 43,41 \\
\hline \begin{tabular}{|l|}
09.10 \\
\end{tabular} & 47 & 16,6 & 12,1 & 6,4 & 1,99 & 2,93 & 2,86 & 6,8 & 6,87 & & 27,11 & 47,11 & \begin{tabular}{|c|}
68,91 \\
\end{tabular} & 54,22 & 55,31 \\
\hline 10.10 & 48 & 18,4 & 12,03 & 6,65 & 2,26 & 2,71 & 2,91 & 7,79 & 6,73 & & 34,62 & 44,72 & 66,02 & 59,25 & 56,24 \\
\hline 11.10 & 49 & 17 & 12,8 & 6,96 & 1,93 & 2,81 & 2,93 & 7,29 & 6,93 & & 24,71 & 45,63 & 72,27 & $\begin{array}{l}59,63 \\
\end{array}$ & 57,90 \\
\hline 12.10 & 50 & 16,4 & 11,4 & 6,03 & 1,86 & 2,4 & 2,59 & 5,98 & 5,99 & & 30,49 & 47,11 & 69,15 & 60,20 & 57,05 \\
\hline 13.10 & 51 & 17,5 & 11,1 & 5,78 & 1,54 & 2,73 & 3,07 & 5,85 & 6,01 & & 36,57 & 47,93 & 73,36 & 52,77 & 46,89 \\
\hline \begin{tabular}{|l|}
14.10 \\
\end{tabular} & 52 & 18,5 & 12,6 & 6 & 1,7 & 2,37 & 2,61 & 6,21 & 6,21 & & 31,89 & 52,38 & 71,67 & 60,50 & 56,50 \\
\hline \begin{tabular}{|l|}
15.10 \\
\end{tabular} & 53 & 18,7 & 13 & 5,53 & 1,62 & 2,47 & 2,6 & 5,81 & 5,8 & & 30,48 & 57,46 & 70,71 & 55,33 & 52,98 \\
\hline 16.10 & 54 & 18 & 11,6 & 6,05 & 1,66 & 2,35 & 2,45 & 5,94 & 5,95 & & 35,56 & 47,84 & 72,56 & 61,16 & 59,50 \\
\hline 17.10 & 55 & 21,5 & 12,3 & 6,12 & 1,61 & 2,42 & 2,39 & 5,85 & 5,96 & & 42,79 & 50,24 & 73,69 & 60,46 & 60,95 \\
\hline 18.10 & 56 & 19,9 & 10,7 & 6,32 & 1,37 & 4,04 & 2,43 & 6,03 & 5,64 & & 46,23 & 40,93 & 78,32 & 36,08 & 61,55 \\
\hline
\end{tabular}


Continuação da TABELA F.1- Resultados de turbidez em uT e \% de remoções nos pré-filtros e filtros lentos

\begin{tabular}{|c|c|c|c|c|c|c|c|c|c|c|c|c|c|c|c|}
\hline Data & TO & $\mathbf{A B}$ & PFD & PFVA & FL11 & FL13 & FL21 & FL1mont & FL2mont & \begin{tabular}{|l} 
PFVAsh \\
\end{tabular} & R\%PFD & R\%PFVa & \begin{tabular}{|l|} 
R\%FL11 \\
\end{tabular} & R\%FL13 & \begin{tabular}{|l|} 
R\%FL21 \\
\end{tabular} \\
\hline 19.10 & 57 & 18,5 & 10,8 & 5,97 & 1,24 & 2,14 & 2,7 & 5,79 & 5,66 & & 41,62 & 44,72 & 79,23 & 64,15 & 54,77 \\
\hline 20.10 & 58 & 19,5 & 11,3 & 5,15 & 1,21 & 1,83 & 1,95 & 5,65 & 5,29 & & 42,05 & 54,42 & 76,50 & 64,47 & 62,14 \\
\hline 22.10 & 60 & 18,6 & 11 & 5,04 & 1,34 & 1,97 & 2,01 & 4,91 & 4,78 & 5,04 & 40,86 & 54,18 & 73,41 & 60,91 & 60,12 \\
\hline 23.10 & 61 & 19,9 & 10,9 & 4,9 & 1 & 1,66 & 1,65 & 5,19 & & 4,74 & 45,23 & 55,05 & 79,59 & 66,12 & 66,33 \\
\hline 24.10 & 62 & 19,1 & 11,1 & 5,13 & 1,06 & 1,5 & 1,34 & 4,57 & & 4,97 & 41,88 & 53,78 & 79,34 & 70,76 & 73,88 \\
\hline 25.10 & 63 & 19,5 & 11,3 & 6,41 & 1,08 & 1,84 & 1,8 & 6,17 & & 6 & 42,05 & 43,27 & 83,15 & 71,29 & 71,92 \\
\hline 26.10 & 64 & 20 & 12,7 & 6,46 & 0,99 & 1,98 & 1,91 & 6,91 & & 7,01 & 36,50 & 49,13 & 84,67 & 69,35 & 70,43 \\
\hline 27.10 & 65 & 61,2 & 49,8 & 12 & 2,66 & 2,99 & 3,07 & 12 & & 12,4 & 18,63 & 75,90 & 77,83 & 75,08 & 74,42 \\
\hline 28.10 & 66 & 21,1 & 11,6 & 6,67 & 1,88 & 3,49 & 3,76 & 6,28 & & 5,94 & 45,02 & 42,50 & 71,81 & 47,68 & 43,63 \\
\hline 29.10 & 67 & 15,8 & 12,2 & 5,94 & 1,69 & 3,05 & 3,14 & 6,36 & & 6,56 & 22,78 & 51,31 & 71,55 & 48,65 & 47,14 \\
\hline 30.10 & 68 & 18,6 & 12,4 & 6,7 & 1,56 & 2,64 & 2,68 & 6,41 & & 6,52 & 33,33 & 45,97 & 76,72 & 60,60 & 60,00 \\
\hline 31.10 & 69 & 17,9 & 11 & 5,92 & 1,53 & 2,82 & 2,48 & 6,21 & & 5,92 & 38,55 & 46,18 & 74,16 & 52,36 & 58,11 \\
\hline 01.11 & 70 & 17,5 & 10,8 & $\begin{array}{l}5,99 \\
\end{array}$ & 1,54 & 2,49 & 2,3 & 5,84 & & 5,77 & 38,29 & 44,54 & 74,29 & 58,43 & 61,60 \\
\hline 02.11 & 71 & 15,6 & 10,6 & 5,9 & 1,05 & 2,28 & 2,55 & 5,51 & & 4,96 & 32,05 & 44,34 & 82,20 & 61,36 & 56,78 \\
\hline 03.11 & 72 & 18,3 & 12,3 & 5,84 & 0,96 & 3,24 & 1,89 & 5,75 & & 5,75 & 32,79 & 52,52 & 83,56 & 44,52 & 67,64 \\
\hline 04.11 & 73 & 15,8 & 10,7 & 5,24 & 1,29 & 3,43 & 2,29 & 5,61 & & 5,03 & 32,28 & 51,03 & 75,38 & 34,54 & 56,30 \\
\hline 05.11 & 74 & 14,8 & 10,6 & 5,76 & 1,29 & 2,92 & 2,17 & 5,82 & & 5,22 & 28,38 & 45,66 & 77,60 & 49,31 & 62,33 \\
\hline 06.11 & 75 & 19,3 & 18,1 & 11,8 & 1,58 & 2,37 & 1,97 & 6,29 & & 6,29 & 6,22 & 34,81 & 86,61 & 79,92 & 83,31 \\
\hline 07.11 & 76 & 18,5 & 11,8 & 6,39 & 1,77 & 3,58 & 2,41 & 6,19 & & 6,21 & 36,22 & 45,85 & 72,30 & 43,97 & 62,28 \\
\hline 09.11 & 78 & 19,2 & 12,8 & 6,59 & 1,13 & 2,23 & 1,78 & 6,35 & & 6,04 & 33,33 & 48,52 & 82,85 & 66,16 & $\begin{array}{l}72,99 \\
\end{array}$ \\
\hline 10.11 & 79 & 18,1 & 13,5 & 5,93 & 1,81 & 2,53 & 1,66 & 6,8 & & 6,71 & 25,41 & 56,07 & 69,48 & 57,34 & 72,01 \\
\hline 12.11 & 81 & 56,1 & 47,3 & 38,6 & 1,38 & 7,72 & 3,88 & 53 & & 38,2 & 15,69 & 18,39 & 96,42 & 80,00 & 89,95 \\
\hline 13.11 & 82 & 37,4 & 30,5 & 21,4 & 4,81 & 10,2 & 10,5 & 24,9 & & 21,4 & 18,45 & 29,84 & 77,52 & 52,34 & 50,93 \\
\hline \begin{tabular}{|l|l}
14.11 \\
\end{tabular} & 83 & 82,9 & 81 & 28,3 & 2,64 & 8,19 & 7,67 & 17,5 & & 25,8 & 2,29 & 65,06 & 90,67 & 71,06 & 72,90 \\
\hline 15.11 & 84 & 28,7 & 21,3 & 16,1 & 4,67 & 11,4 & 12 & 23,5 & & 14,3 & 25,78 & 24,41 & 70,99 & 29,19 & 25,47 \\
\hline 16.11 & 85 & 25,5 & 20,7 & 12,8 & 3,2 & \begin{tabular}{|l|l}
7,99 \\
\end{tabular} & 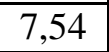 & 11,8 & & 12,8 & 18,82 & 38,16 & 75,00 & 37,58 & 41,09 \\
\hline
\end{tabular}


TABELA F.2 - Resultados de sólidos suspensos totais (mg/L) e \% de remoções nos pré-filtros e filtros lentos

\begin{tabular}{|c|c|c|c|c|c|c|c|c|c|c|c|c|}
\hline Data & TO & AB & PFD & PFVA & FL11 & FL13 & FL21 & R\%PFD & R\%PFV & R\%FL11 & R\%FL13 & R\%FL21 \\
\hline 31.08 & 9 & 9,54 & 3,20 & 1,12 & 0,46 & 0,48 & 0,03 & 66,45 & 65,00 & 58,93 & 57,14 & 96,89 \\
\hline 04.09 & 12 & 11,00 & 5,33 & 4,40 & 0,72 & 1,77 & 1,48 & 51,52 & 17,50 & 83,64 & 59,74 & 66,36 \\
\hline 11.09 & 19 & 7,20 & 4,21 & 2,32 & 0,22 & 0,54 & 0,07 & 41,52 & 44,90 & 90,52 & 76,67 & 96,92 \\
\hline 14.09 & 23 & 10,40 & 5,69 & 3,52 & 0,54 & 0,74 & 0,24 & 45,27 & 38,16 & 84,55 & 78,90 & 93,18 \\
\hline 19.09 & 27 & 12,60 & 4,53 & 2,07 & 0,74 & 0,91 & 0,65 & 64,02 & 54,41 & 64,19 & 56,13 & 68,67 \\
\hline 21.09 & 29 & 13,17 & 8,27 & 2,17 & 0,29 & 0,71 & 0,31 & 37,22 & 73,73 & 86,84 & 67,49 & 85,77 \\
\hline 25.09 & 33 & 9,82 & 0,72 & 1,93 & 0,55 & 0,85 & 0,37 & 92,67 & $-168,23$ & 71,40 & 55,93 & 80,67 \\
\hline 28.09 & 36 & 7,72 & 3,16 & 1,28 & 0,21 & 0,57 & 0,21 & 59,05 & 59,49 & 83,77 & 55,33 & 83,25 \\
\hline 02.10 & 40 & 9,84 & 4,11 & 2,18 & 0,51 & 0,35 & 0,24 & 58,27 & 46,85 & 76,53 & 84,15 & 89,01 \\
\hline 05.10 & 43 & 11,76 & 4,76 & 2,08 & 0,40 & 0,48 & 0,27 & 59,52 & 56,30 & 80,92 & 77,12 & 86,95 \\
\hline 09.10 & 47 & 4,00 & 4,84 & 1,31 & 0,31 & 0,52 & 0,85 & $-21,00$ & 72,85 & 76,35 & 60,46 & 35,69 \\
\hline 11.10 & 49 & 10,70 & 5,87 & 2,90 & 0,57 & 0,71 & 0,67 & 45,17 & 50,64 & 80,40 & 75,55 & 76,85 \\
\hline 16.10 & 54 & 7,80 & 2,53 & 0,29 & 0,03 & 0,02 & 0,06 & 67,52 & 88,72 & 88,80 & 93,33 & 80,00 \\
\hline 19.10 & 57 & 9,40 & 2,93 & 1,37 & 0,27 & 0,38 & 0,27 & 68,79 & 53,25 & 80,56 & 72,22 & 80,56 \\
\hline 23.10 & 61 & 10,80 & 2,59 & 0,47 & 0,10 & 0,00 & 0,00 & 75,99 & 82,00 & 78,57 & 100,00 & 100,00 \\
\hline 26.10 & 64 & 11,00 & 4,00 & 1,66 & 0,33 & 0,35 & 0,12 & 63,64 & 58,57 & 79,89 & 78,76 & 92,85 \\
\hline 30.10 & 68 & 10,60 & 4,40 & 1,09 & 0,54 & 0,09 & 0,15 & 58,49 & 75,32 & 50,15 & 92,11 & 86,35 \\
\hline 01.11 & 70 & 10,20 & 2,67 & 0,69 & 0,25 & 0,44 & 0,60 & 73,86 & 74,29 & 63,89 & 36,11 & 12,50 \\
\hline 06.11 & 75 & 11,40 & 4,53 & 1,89 & 0,61 & 0,38 & 0,03 & 60,23 & 58,40 & 67,68 & 79,80 & 98,23 \\
\hline 09.11 & 78 & 10,75 & 4,27 & 0,91 & 0,27 & 0,40 & 0,20 & 60,31 & 78,57 & 70,83 & 56,25 & 78,12 \\
\hline 13.11 & 82 & 16,40 & 8,67 & 5,80 & 0,32 & 0,74 & 0,83 & 47,15 & 33,08 & 94,48 & 87,19 & 85,71 \\
\hline
\end{tabular}


TABELA F.3 - Resultados de cor aparente em uH e \% de remoções nos pré-filtros e filtros lentos

\begin{tabular}{|c|c|c|c|c|c|c|c|c|c|c|c|c|c|c|c|}
\hline Data & TO & $\mathbf{A B}$ & PFD & PFVA & FL11 & FL13 & FL21 & FL1mont & FL2mont & PFVAsh & R\%PFD & R\%PFV & R\%FL11 & R\%FL13 & R\%FL21 \\
\hline 23.08 & 1 & 148 & 101 & 63 & 9 & 33 & 12 & 78 & 73 & & & & & & \\
\hline 23.08 & 1,50 & 110 & 94 & 54 & 9 & 28 & 16 & 76 & 77 & & & & & & \\
\hline 24.08 & 2 & 129 & 93 & 59 & 11 & 34 & 17 & 79 & 81 & & & & & & \\
\hline 27.08 & 5 & 142 & 101 & 58 & 29 & 49 & 36 & 88 & 88 & & 28,87 & 42,57 & 67,05 & 44,32 & 59,09 \\
\hline 28.08 & 6 & 100 & 89 & 59 & 27 & 45 & 31 & 81 & 89 & & 11,00 & 33,71 & 66,67 & 44,44 & 61,73 \\
\hline 29.08 & 7 & 275 & 217 & 115 & 38 & 70 & 48 & 142 & 137 & & 21,09 & 47,00 & 73,24 & 50,70 & 66,20 \\
\hline 30.08 & 8 & 153 & 126 & 86 & 42 & 77 & 57 & 112 & 114 & & 17,65 & 31,75 & 62,50 & 31,25 & 49,11 \\
\hline 31.08 & 9 & 146 & 116 & 74 & 34 & 62 & 43 & 97 & 101 & & 20,55 & 36,21 & 64,95 & 36,08 & 55,67 \\
\hline 01.09 & 10 & 123 & 100 & 63 & 18 & 51 & 34 & 91 & 92 & & 18,70 & 37,00 & 80,22 & 43,96 & 62,64 \\
\hline 02.09 & 11 & 234 & 140 & 71 & 22 & 45 & 32 & 97 & 96 & & 40,17 & 49,29 & 77,32 & 53,61 & 67,01 \\
\hline 03.09 & 12 & 250 & 204 & 162 & 64 & 114 & 79 & 180 & 189 & & 18,40 & 20,59 & 64,44 & 36,67 & 56,11 \\
\hline 04.09 & 13 & 205 & 169 & 136 & 72 & 113 & 89 & 165 & 167 & & 17,56 & 19,53 & 56,36 & 31,52 & 46,06 \\
\hline 05.09 & 14 & 165 & 136 & 97 & 49 & 85 & 67 & 124 & 126 & & 17,58 & 28,68 & 60,48 & 31,45 & 45,97 \\
\hline 06.09 & 15 & 165 & 127 & 87 & 23 & 55 & 40 & 116 & 116 & & 23,03 & 31,50 & 80,17 & 52,59 & 65,52 \\
\hline 07.09 & 16 & 184 & 158 & 91 & 25 & 63 & 49 & 120 & 121 & & 14,13 & 42,41 & 79,17 & 47,50 & 59,17 \\
\hline 08.09 & 17 & 150 & 116 & 89 & 30 & 67 & 50 & 121 & 121 & & 22,67 & 23,28 & 75,21 & 44,63 & 58,68 \\
\hline 09.09 & 18 & 147 & 126 & 86 & 29 & 63 & 40 & 113 & 112 & & 14,29 & 31,75 & 74,34 & 44,25 & 64,60 \\
\hline 11.09 & 19 & 145 & 145 & 88 & 27 & 78 & 39 & 116 & 111 & & 0,00 & 39,31 & 76,72 & 32,76 & 66,38 \\
\hline 12.09 & 20 & 155 & 123 & 83 & 26 & 58 & 36 & 111 & 115 & & 20,65 & 32,52 & 76,58 & 47,75 & 67,57 \\
\hline 13.09 & 21 & 372 & 336 & 106 & 28 & 61 & 42 & 143 & 141 & & 9,68 & 68,45 & 80,42 & 57,34 & 70,63 \\
\hline 14.09 & 22 & 181 & 155 & 116 & 41 & 77 & 63 & 142 & 144 & & 14,36 & 25,16 & 71,13 & 45,77 & 55,63 \\
\hline 15.09 & 23 & 162 & 130 & 79 & 19 & 49 & 39 & 108 & 107 & & 19,75 & 39,23 & 82,41 & 54,63 & 63,89 \\
\hline 16.09 & 24 & 146 & 122 & 81 & 32 & 64 & 48 & 110 & 114 & & 16,44 & 33,61 & 70,91 & 41,82 & 56,36 \\
\hline 18.09 & 25 & 242 & 192 & 107 & 30 & 73 & 47 & 139 & 141 & & 20,66 & 44,27 & 78,42 & 47,48 & 66,19 \\
\hline 19.09 & 27 & 178 & 142 & 88 & 45 & 76 & 54 & 121 & 121 & & 20,22 & 38,03 & 62,81 & 37,19 & 55,37 \\
\hline 20.09 & 28 & 175 & 136 & 71 & 34 & 39 & 51 & 105 & 103 & & 22,29 & 47,79 & 67,62 & 62,86 & 51,43 \\
\hline 21.09 & 29 & 162 & 126 & 72 & 32 & 62 & 43 & 91 & 91 & & 22,22 & 42,86 & 64,84 & 31,87 & 52,75 \\
\hline 22.09 & 30 & 166 & 126 & 65 & 38 & 61 & 50 & 94 & 94 & & 24,10 & 48,41 & 59,57 & 35,11 & 46,81 \\
\hline
\end{tabular}


Continuação da TABELA F.3 - Resultados de cor aparente em uH e \% de remoções nos pré-filtros e filtros lentos

\begin{tabular}{|c|c|c|c|c|c|c|c|c|c|c|c|c|c|c|c|}
\hline Data & TO & $\overline{A B}$ & PFD & PFVA & FL11 & FL13 & FL21 & FL1mont & FL2mont & PFVAsh & R\%PFD & R\%PFV & R\%FL11 & R\%FL13 & R\%FL21 \\
\hline 23.09 & 31 & 133 & 123 & 60 & 24 & 56 & 41 & 96 & 94 & & 7,52 & 51,22 & 75,00 & 41,67 & 57,29 \\
\hline 24.09 & 32 & 214 & 156 & 70 & 32 & 63 & 49 & 100 & 100 & & 27,10 & 55,13 & 68,00 & 37,00 & 51,00 \\
\hline 25.09 & 33 & 142 & 115 & 71 & 39 & 62 & 49 & 100 & 99 & & 19,01 & 38,26 & 61,00 & 38,00 & 51,00 \\
\hline 26.09 & 34 & 145 & 115 & 69 & 43 & 63 & 58 & 98 & 98 & & 20,69 & 40,00 & 56,12 & 35,71 & 40,82 \\
\hline 27.09 & 35 & 134 & 102 & 60 & 35 & 55 & 48 & 94 & 89 & & 23,88 & 41,18 & 62,77 & 41,49 & 48,94 \\
\hline 28.09 & 36 & 133 & 95 & 57 & 28 & 50 & 41 & 87 & 87 & & 28,57 & 40,00 & 67,82 & 42,53 & 52,87 \\
\hline 29.09 & 37 & 123 & 96 & 53 & 19 & 41 & 36 & 84 & 85 & & 21,95 & 44,79 & 77,38 & 51,19 & 57,14 \\
\hline 30.09 & 38 & 129 & 96 & 56 & 23 & 42 & 38 & 85 & 86 & & 25,58 & 41,67 & 72,94 & 50,59 & 55,29 \\
\hline 01.10 & 39 & 140 & 117 & 68 & 20 & 47 & 42 & 101 & 103 & & 16,43 & 41,88 & 80,20 & 53,47 & 58,42 \\
\hline 02.10 & 40 & 146 & 110 & 65 & 26 & 46 & 43 & 92 & 91 & & 24,66 & 40,91 & 71,74 & 50,00 & 53,26 \\
\hline 03.10 & 41 & 149 & 103 & 56 & 22 & 44 & 42 & 87 & 87 & & 30,87 & 45,63 & 74,71 & 49,43 & 51,72 \\
\hline 04.10 & 42 & 168 & 121 & 57 & 26 & 46 & 42 & 93 & 93 & & 27,98 & 52,89 & 72,04 & 50,54 & 54,84 \\
\hline 05.10 & 43 & 167 & 120 & 84 & 30 & 49 & 46 & 116 & 117 & & 28,14 & 30,00 & 74,14 & 57,76 & 60,34 \\
\hline 06.10 & 44 & 141 & 112 & 56 & 22 & 45 & 44 & 84 & 89 & & 20,57 & 50,00 & 73,81 & 46,43 & 47,62 \\
\hline 07.10 & 45 & 139 & 121 & 72 & 20 & 46 & 42 & 109 & 106 & & 12,95 & 40,50 & 81,65 & 57,80 & 61,47 \\
\hline 08.10 & 46 & 123 & 100 & 63 & 32 & 51 & 52 & 98 & 97 & & 18,70 & 37,00 & 67,35 & 47,96 & 46,94 \\
\hline 09.10 & 47 & 149 & 119 & 69 & 29 & 50 & 45 & 97 & 96 & & 20,13 & 42,02 & 70,10 & 48,45 & 53,61 \\
\hline 10.10 & 48 & 153 & 126 & 69 & 24 & 51 & 44 & 112 & 100 & & 17,65 & 45,24 & 78,57 & 54,46 & 60,71 \\
\hline 11.10 & 49 & 143 & 116 & 64 & 25 & 43 & 39 & 96 & 99 & & 18,88 & 44,83 & 73,96 & 55,21 & 59,38 \\
\hline 12.10 & 50 & 142 & 114 & 65 & 23 & 35 & 38 & 82 & 86 & & 19,72 & 42,98 & 71,95 & 57,32 & 53,66 \\
\hline 13.10 & 51 & 149 & 113 & 60 & 19 & 37 & 38 & 90 & 88 & & 24,16 & 46,90 & 78,89 & 58,89 & 57,78 \\
\hline 14.10 & 52 & 163 & 111 & 56 & 17 & 33 & 32 & 82 & 82 & & 31,90 & 49,55 & 79,27 & 59,76 & 60,98 \\
\hline 15.10 & 53 & 155 & 121 & 54 & 22 & 39 & 39 & 86 & 88 & & 21,94 & $\begin{array}{l}55,37 \\
\end{array}$ & 74,42 & 54,65 & 54,65 \\
\hline 16.10 & 54 & 153 & 108 & 58 & 24 & 42 & 38 & 90 & 93 & & 29,41 & 46,30 & 73,33 & 53,33 & $\begin{array}{l}57,78 \\
\end{array}$ \\
\hline 17.10 & 55 & 163 & 118 & 53 & 19 & 38 & 36 & 83 & 83 & & 27,61 & 55,08 & 77,11 & 54,22 & 56,63 \\
\hline 18.10 & 56 & 162 & 110 & 51 & 23 & 35 & 36 & 80 & 81 & & 32,10 & 53,64 & 71,25 & 56,25 & 55,00 \\
\hline 19.10 & 57 & 147 & 98 & 50 & 17 & 36 & 34 & 84 & 84 & & 33,33 & 48,98 & 79,76 & 57,14 & 59,52 \\
\hline 20.10 & 58 & 164 & 106 & 52 & 15 & 34 & 28 & 64 & 64 & & 35,37 & 50,94 & 76,56 & 46,88 & 56,25 \\
\hline
\end{tabular}


Continuação da TABELA F.3 - Resultados de cor aparente em uH e \% de remoções nos pré-filtros e filtros lentos

\begin{tabular}{|c|c|c|c|c|c|c|c|c|c|c|c|c|c|c|c|}
\hline Data & TO & $\mathbf{A B}$ & PFD & PFVA & FL11 & $\overline{\text { FL13 }}$ & FL21 & FL1mont & FL2mont & PFVAsh & R\%PFD & R\%PFV & R\%FL11 & R\%FL13 & R\%FL21 \\
\hline 22.10 & 60 & 144 & 101 & 48 & 13 & 22 & 18 & 54 & 54 & 67 & 29,86 & 52,48 & 75,93 & 59,26 & 66,67 \\
\hline 23.10 & 61 & 145 & 105 & 46 & 11 & 19 & 18 & 59 & & 74 & 27,59 & 56,19 & 81,36 & 67,80 & 69,49 \\
\hline 24.10 & 62 & 150 & 104 & 49 & 11 & 15 & 14 & 42 & & 74 & 30,67 & 52,88 & 73,81 & 64,29 & 66,67 \\
\hline 25.10 & \begin{tabular}{|l|}
63 \\
\end{tabular} & \begin{tabular}{|l}
159 \\
\end{tabular} & 103 & 51 & 15 & 20 & 19 & 50 & & 83 & 35,22 & 50,49 & 70,00 & 60,00 & 62,00 \\
\hline 26.10 & \begin{tabular}{|l|}
64 \\
\end{tabular} & \begin{tabular}{|l|l}
176 \\
\end{tabular} & 119 & 62 & 18 & 27 & 22 & 69 & & 92 & 32,39 & 47,90 & 73,91 & 60,87 & 68,12 \\
\hline 27.10 & \begin{tabular}{|l|}
65 \\
\end{tabular} & 426 & 338 & 95 & 19 & 44 & 39 & 128 & & 125 & 20,66 & 71,89 & 85,16 & 65,63 & 69,53 \\
\hline 28.10 & \begin{tabular}{|l|}
66 \\
\end{tabular} & \begin{tabular}{|l}
166 \\
\end{tabular} & 105 & 54 & 18 & 39 & 45 & 83 & & 79 & 36,75 & 48,57 & 78,31 & 53,01 & 45,78 \\
\hline 29.10 & 67 & 142 & 114 & 56 & 17 & 40 & 35 & 81 & & 84 & 19,72 & 50,88 & 79,01 & 50,62 & 56,79 \\
\hline 30.10 & 68 & 153 & 109 & 62 & 25 & 41 & 40 & 89 & & 73 & 28,76 & 43,12 & 71,91 & 93 & 55,06 \\
\hline 31.10 & 69 & 154 & 108 & 59 & 21 & 42 & 37 & 85 & & 85 & 29,87 & 45,37 & 75,29 & 50,59 & 56,47 \\
\hline 01.11 & 70 & 139 & 96 & 56 & 24 & 43 & 42 & 84 & & 82 & 30,94 & 41,67 & 71,43 & 48,81 & 50,00 \\
\hline 02.11 & 71 & 120 & 87 & 44 & 16 & 35 & 39 & 72 & & 75 & 27,50 & 49,43 & 77,78 & 51,39 & 45,83 \\
\hline 03.11 & 72 & 146 & 104 & 59 & 21 & 46 & 35 & 90 & & 85 & 28,77 & 43,27 & 76,67 & 48,89 & 61,11 \\
\hline 04.11 & 73 & 134 & 97 & 48 & 21 & 46 & 33 & 90 & & 90 & 27,61 & 50,52 & 76,67 & 48,89 & 63,33 \\
\hline 05.11 & 74 & 129 & 96 & 50 & 23 & 46 & 35 & 93 & & 83 & 25,58 & 47,92 & 75,27 & 50,54 & 62,37 \\
\hline 06.11 & 75 & 162 & 138 & 58 & 25 & 43 & 37 & 94 & & 118 & 14,81 & 57,97 & 73,40 & 54,26 & 60,64 \\
\hline 07.11 & \begin{tabular}{|l|}
76 \\
\end{tabular} & 155 & 101 & 52 & 25 & 53 & 36 & 92 & & 89 & 34,84 & 48,51 & 72,83 & 42,39 & 60,87 \\
\hline 09.11 & 78 & 141 & 107 & 49 & 14 & 33 & 23 & 79 & & 86 & 24,11 & 54,21 & 82,28 & 58,23 & 70,89 \\
\hline 10.11 & \begin{tabular}{|l|}
79 \\
\end{tabular} & 144 & 113 & 53 & 7 & 23 & 15 & 52 & & 82 & 21,53 & 53,10 & 86,54 & 55,77 & 71,15 \\
\hline 12.11 & 81 & 475 & 358 & 314 & 23 & 53 & 40 & 415 & & 342 & 24,63 & 12,29 & 94,46 & 87,23 & 90,36 \\
\hline 13.11 & 82 & 251 & 219 & 166 & 26 & 79 & 73 & 184 & & 188 & 12,75 & 24,20 & 85,87 & 57,07 & 60,33 \\
\hline 14.11 & 83 & 521 & 521 & 201 & 19 & 61 & 75 & 123 & & 223 & 0,00 & 61,42 & 84,55 & 50,41 & 39,02 \\
\hline 15.11 & 84 & 218 & 196 & 119 & 39 & 85 & 95 & 173 & & 155 & 10,09 & 39,29 & 77,46 & 50,87 & 45,09 \\
\hline 16.11 & 85 & 199 & 164 & 111 & 23 & 68 & 67 & 105 & & 148 & 17,59 & 32,32 & 78,10 & 35,24 & 36,19 \\
\hline
\end{tabular}


TABELA F.4 - Resultados de cor verdadeira em uH e \% de remocões nos pré-filtros e filtros lentos

\begin{tabular}{|c|c|c|c|c|c|c|c|c|c|c|c|c|c|c|c|}
\hline \begin{tabular}{|l|} 
Data \\
\end{tabular} & TO & $\mathbf{A B}$ & PFD & PFVA & FL11 & FL13 & FL21 & FL1mont & FL2mont & PFVAsh & R\%PFD & R\%PFVa & R\%FL11 & R\%FL13 & \begin{tabular}{|l|} 
R\%FL21 \\
\end{tabular} \\
\hline 23.08 & 1 & 40 & 34 & 28 & 2 & 15 & 6 & 41 & 42 & & & & & & \\
\hline 23.08 & 1,50 & 38 & 36 & 27 & 6 & 15 & 9 & 44 & 46 & & & & & & \\
\hline 25.08 & 2 & 45 & 36 & 28 & 7 & 20 & 11 & 48 & 49 & & & & R\%FL11 & R\%FL13 & R\%FL21 \\
\hline 26.08 & 4 & 40 & 39 & 27 & 19 & 30 & 24 & 55 & 57 & & 2,50 & 30,77 & 65,45 & 45,45 & 56,36 \\
\hline 28.08 & 5 & 34 & 32 & 27 & 14 & 28 & 19 & 48 & 49 & & 5,88 & 15,63 & 70,83 & 41,67 & 60,42 \\
\hline \begin{tabular}{|l|}
29.08 \\
\end{tabular} & 6 & 92 & 64 & 48 & 21 & 40 & 28 & 70 & 71 & & 30,43 & 25,00 & 70,00 & 42,86 & 60,00 \\
\hline 30.08 & 7 & 59 & 53 & 40 & 25 & 47 & 38 & 65 & 68 & & 10,17 & 24,53 & 61,54 & 27,69 & 41,54 \\
\hline 31.08 & 8 & 46 & 41 & 31 & 16 & 41 & 31 & 61 & 61 & & 10,87 & 24,39 & 73,77 & 32,79 & 49,18 \\
\hline 01.09 & 9 & 46 & 40 & 28 & 10 & 32 & 23 & 58 & 59 & & 13,04 & 30,00 & 82,76 & 44,83 & 60,34 \\
\hline 02.09 & 10 & 79 & 50 & 30 & 13 & 32 & 23 & 55 & 57 & & 36,71 & 40,00 & 76,36 & 41,82 & 58,18 \\
\hline 03.09 & 11 & 94 & 89 & 75 & 35 & 67 & 54 & 96 & 97 & & 5,32 & 15,73 & 63,54 & 30,21 & 43,75 \\
\hline \begin{tabular}{|l|}
04.09 \\
\end{tabular} & 12 & 83 & 70 & 59 & 39 & 70 & 60 & 91 & 94 & & 15,66 & 15,71 & 57,14 & 23,08 & 34,07 \\
\hline \begin{tabular}{|l|}
05.09 \\
\end{tabular} & 13 & 56 & 54 & 44 & 29 & 57 & 49 & 71 & 73 & & 3,57 & 18,52 & 59,15 & 19,72 & 30,99 \\
\hline \begin{tabular}{|l|}
06.09 \\
\end{tabular} & 14 & 64 & 54 & 39 & 16 & 38 & 31 & 69 & 69 & & 15,63 & 27,78 & 76,81 & 44,93 & 55,07 \\
\hline \begin{tabular}{|l|}
07.09 \\
\end{tabular} & 15 & 51 & 46 & 33 & 10 & 34 & 29 & 61 & 63 & & 9,80 & 28,26 & 83,61 & 44,26 & 52,46 \\
\hline \begin{tabular}{|l|}
08.09 \\
\end{tabular} & 16 & 59 & 51 & 39 & 18 & 40 & 35 & 73 & 73 & & 13,56 & 23,53 & 75,34 & 45,21 & 52,05 \\
\hline \begin{tabular}{|l|}
09.09 \\
\end{tabular} & 17 & 63 & 44 & 35 & 18 & 38 & 28 & 62 & 64 & & 30,16 & 20,45 & 70,97 & 38,71 & 54,84 \\
\hline \begin{tabular}{|l|}
11.09 \\
\end{tabular} & 19 & 52 & 49 & 38 & 18 & 41 & 29 & 67 & 65 & & 5,77 & 22,45 & 73,13 & 38,81 & 56,72 \\
\hline \begin{tabular}{|l|}
12.09 \\
\end{tabular} & 20 & 59 & 53 & 37 & 15 & 36 & 27 & 66 & 68 & & 10,17 & 30,19 & 77,27 & 45,45 & 59,09 \\
\hline \begin{tabular}{|l|}
13.09 \\
\end{tabular} & 21 & 118 & 94 & 45 & 19 & 35 & 29 & 70 & 71 & & 20,34 & 52,13 & 72,86 & 50,00 & 58,57 \\
\hline \begin{tabular}{|l}
14.09 \\
\end{tabular} & 22 & 70 & 63 & 50 & 25 & 49 & 43 & 77 & 81 & & 10,00 & 20,63 & 67,53 & 36,36 & 44,16 \\
\hline \begin{tabular}{|l|}
15.09 \\
\end{tabular} & 23 & 67 & 54 & 42 & 13 & 29 & 28 & 71 & 69 & & 19,40 & 22,22 & 81,69 & 59,15 & 60,56 \\
\hline \begin{tabular}{|l}
16.09 \\
\end{tabular} & 24 & 62 & 52 & 38 & 15 & 40 & 33 & 69 & 71 & & 16,13 & 26,92 & 78,26 & 42,03 & 52,17 \\
\hline \begin{tabular}{|l}
18.09 \\
\end{tabular} & 25 & 70 & 68 & 20 & 35 & 43 & 27 & 73 & 78 & & 2,86 & 70,59 & 52,05 & 41,10 & 63,01 \\
\hline \begin{tabular}{|l|}
19.09 \\
\end{tabular} & 27 & 76 & 64 & 43 & 31 & 53 & 42 & 77 & 77 & & 15,79 & 32,81 & 59,74 & 31,17 & 45,45 \\
\hline \begin{tabular}{|l|}
20.09 \\
\end{tabular} & 28 & 72 & 52 & 38 & 22 & 43 & 38 & 69 & 70 & & 27,78 & 26,92 & 68,12 & 37,68 & 44,93 \\
\hline 21.09 & 29 & 67 & 52 & 36 & 23 & 46 & 34 & 57 & 59 & & 22,39 & 30,77 & 59,65 & 19,30 & 40,35 \\
\hline 22.09 & 30 & 54 & 49 & 34 & 20 & 38 & 32 & 63 & 65 & & 9,26 & 30,61 & 68,25 & 39,68 & 49,21 \\
\hline
\end{tabular}


Continuação da TABELA F.4 - Resultados de cor verdadeira em uH e \% de remoções nos pré-filtros de filtros lentos

\begin{tabular}{|c|c|c|c|c|c|c|c|c|c|c|c|c|c|c|c|}
\hline \begin{tabular}{|l|} 
Data \\
\end{tabular} & TO & $\mathbf{A B}$ & PFD & PFVA & FL11 & FL13 & FL21 & FL1mont & FL2mont & \begin{tabular}{|l} 
PFVAsh \\
\end{tabular} & R\%PFD & R\%PFVa & R\%FL11 & \begin{tabular}{|l} 
R\%FL13 \\
\end{tabular} & \begin{tabular}{|l|} 
R\%FL21 \\
\end{tabular} \\
\hline 23.09 & 31 & 51 & 46 & 34 & 18 & 34 & 32 & 63 & 66 & & 9,80 & 26,09 & 71,43 & 46,03 & 49,21 \\
\hline \begin{tabular}{|l|}
24.09 \\
\end{tabular} & 32 & 64 & 55 & 37 & 26 & 44 & 37 & 70 & 70 & & 14,06 & 32,73 & 62,86 & 37,14 & 47,14 \\
\hline 25.09 & 33 & 48 & 42 & 38 & 26 & 42 & 34 & 64 & 64 & & 12,50 & 9,52 & 59,38 & 34,38 & 46,88 \\
\hline 26.09 & 34 & 50 & 44 & 36 & 28 & 42 & 40 & 64 & 64 & & 12,00 & 18,18 & 56,25 & 34,38 & 37,50 \\
\hline 27.09 & 35 & 66 & 45 & 33 & 26 & 39 & 36 & 61 & 62 & & 31,82 & 26,67 & 57,38 & 36,07 & 40,98 \\
\hline 28.09 & 36 & 42 & 36 & 27 & 20 & 37 & 31 & 58 & 60 & & 14,29 & 25,00 & 65,52 & 36,21 & 46,55 \\
\hline 29.09 & 37 & 43 & 37 & 26 & 14 & 30 & 27 & 58 & 60 & & 13,95 & 29,73 & 75,86 & 48,28 & 53,45 \\
\hline 30.09 & 38 & 42 & 36 & 26 & 15 & 31 & 29 & 56 & 57 & & 14,29 & 27,78 & 73,21 & 44,64 & 48,21 \\
\hline 01.10 & 39 & 55 & 44 & 31 & 15 & 29 & 32 & 63 & 63 & & 20,00 & 29,55 & 76,19 & 53,97 & 49,21 \\
\hline 02.10 & 40 & 56 & 43 & 30 & 18 & 35 & 30 & 57 & 59 & & 23,21 & 30,23 & 68,42 & 38,60 & 47,37 \\
\hline 03.10 & 41 & 55 & 41 & 32 & 17 & 31 & 29 & 58 & 59 & & 25,45 & 21,95 & 70,69 & 46,55 & 50,00 \\
\hline 04.10 & 42 & 58 & 43 & 29 & 17 & 32 & 30 & 60 & 60 & & 25,86 & 32,56 & 71,67 & 46,67 & 50,00 \\
\hline 05.10 & 43 & 53 & 44 & 36 & 23 & 40 & 35 & 70 & 68 & & 16,98 & 18,18 & 67,14 & 42,86 & 50,00 \\
\hline 06.10 & 44 & 58 & 44 & 27 & 17 & 35 & 29 & 62 & 64 & & 24,14 & 38,64 & 72,58 & 43,55 & 53,23 \\
\hline 07.10 & 45 & 52 & 47 & 35 & 14 & 34 & 28 & 71 & 72 & & 9,62 & 25,53 & 80,28 & 52,11 & 60,56 \\
\hline 08.10 & 46 & 52 & 45 & 35 & 22 & 38 & 36 & 70 & 69 & & 13,46 & 22,22 & 68,57 & 45,71 & 48,57 \\
\hline 09.10 & 47 & 57 & 50 & 32 & 22 & 38 & 32 & 65 & 66 & & 12,28 & 36,00 & 66,15 & 41,54 & 50,77 \\
\hline \begin{tabular}{|l|}
10.10 \\
\end{tabular} & 48 & 55 & 48 & 33 & 18 & 36 & 33 & 69 & 67 & & 12,73 & 31,25 & 73,91 & 47,83 & 52,17 \\
\hline 11.10 & 49 & 55 & 43 & 32 & 17 & 34 & 31 & 65 & 65 & & 21,82 & 25,58 & 73,85 & 47,69 & 52,31 \\
\hline 12.10 & 50 & 52 & 44 & 34 & 18 & 25 & 28 & 39 & 39 & & 15,38 & 22,73 & 53,85 & 35,90 & 28,21 \\
\hline 13.10 & 51 & 54 & 43 & 32 & 15 & 30 & 29 & 62 & 60 & & 20,37 & 25,58 & 75,81 & 51,61 & 53,23 \\
\hline 14.10 & 52 & & & & & & & & & & & & & & \\
\hline \begin{tabular}{|l|}
15.10 \\
\end{tabular} & 53 & & & & & & & & & & & & & & \\
\hline \begin{tabular}{|l|}
16.10 \\
\end{tabular} & 54 & & & & & & & & & & & & & & \\
\hline \begin{tabular}{|l}
17.10 \\
\end{tabular} & 55 & & & & & & & & & & & & & & \\
\hline 18.10 & 56 & & & & & & & & & & & & & & \\
\hline 20.10 & 57 & & & & & & & & & & & & & & \\
\hline 21.10 & 58 & & & & & & & & & & & & & & \\
\hline
\end{tabular}


Continuação da TABELA F.4 - Resultados de cor verdadeira em uH e \% de remoções nos pré-filtros de filtros lentos

\begin{tabular}{|l|c|c|c|c|c|c|c|c|c|c|c|c|c|c|c|}
\hline Data & TO & AB & PFD & PFVA & FL11 & FL13 & FL21 & FL1mont & FL2mont & PFVAsh & R\%PFD & R\% PFVa & R\%FL11 & R\%FL13 & R\%FL21 \\
\hline 23.10 & 60 & & & & & & & & & & & & & & \\
\hline 24.10 & 61 & & & & & & & & & & & & & & \\
\hline 25.10 & 62 & & & & & & & & & & & & & & \\
\hline 26.10 & 64 & 54 & 42 & 26 & 3 & 10 & 9 & 31 & & 57 & 22,22 & 38,10 & 90,32 & 67,74 & 70,97 \\
\hline 27.10 & 65 & 79 & 81 & 54 & 14 & 30 & 30 & 70 & & 68 & $(2,53)$ & 33,33 & 80,00 & 57,14 & 57,14 \\
\hline 28.10 & 66 & 68 & 59 & 31 & 16 & 24 & 33 & 59 & & 59 & 13,24 & 47,46 & 72,88 & 59,32 & 44,07 \\
\hline 29.10 & 67 & 54 & 47 & 29 & 12 & 26 & 25 & 57 & & 58 & 12,96 & 38,30 & 78,95 & 54,39 & 56,14 \\
\hline 30.10 & 68 & 53 & 45 & 32 & 18 & 34 & 29 & 55 & & 43 & 15,09 & 28,89 & 67,27 & 38,18 & 47,27 \\
\hline 31.10 & 69 & 48 & 42 & 32 & 15 & 30 & 27 & 57 & & 54 & 12,50 & 23,81 & 73,68 & 47,37 & 52,63 \\
\hline 01.11 & 70 & 49 & 43 & 27 & 17 & 30 & 26 & 54 & & 54 & 12,24 & 37,21 & 68,52 & 44,44 & 51,85 \\
\hline 02.11 & 71 & 44 & 38 & 27 & 14 & 25 & 26 & 52 & & 51 & 13,64 & 28,95 & 73,08 & 51,92 & 50,00 \\
\hline 03.11 & 72 & 47 & 39 & 28 & 14 & 28 & 26 & 59 & & 60 & 17,02 & 28,21 & 76,27 & 52,54 & 55,93 \\
\hline 04.11 & 73 & 48 & 40 & 28 & 18 & 32 & 28 & 67 & & 67 & 16,67 & 30,00 & 73,13 & 52,24 & 58,21 \\
\hline 05.11 & 74 & 46 & 39 & 27 & 17 & 33 & 22 & 67 & & 57 & 15,22 & 30,77 & 74,63 & 50,75 & 67,16 \\
\hline 06.11 & 75 & 51 & 45 & 31 & 19 & 35 & 29 & 68 & & 49 & 11,76 & 31,11 & 72,06 & 48,53 & 57,35 \\
\hline 07.11 & 76 & 48 & 40 & 26 & 23 & 37 & 30 & 64 & & 64 & 16,67 & 35,00 & 64,06 & 42,19 & 53,13 \\
\hline 09.11 & 78 & 44 & 38 & 24 & 10 & 27 & 19 & 54 & & 63 & 13,64 & 36,84 & 81,48 & 50,00 & 64,81 \\
\hline 10.11 & 79 & 48 & 43 & 24 & 7 & 15 & 11 & 27 & & 61 & 10,42 & 44,19 & 74,07 & 44,44 & 59,26 \\
\hline 12.11 & 81 & 83 & 83 & 83 & 13 & 24 & 18 & 83 & & 112 & - & - & 84,34 & 71,08 & 78,31 \\
\hline 13.11 & 82 & 67 & 64 & 55 & 14 & 30 & 27 & 55 & & 73 & 4,48 & 14,06 & 74,55 & 45,45 & 50,91 \\
\hline 14.11 & 83 & 92 & 96 & 69 & 11 & 28 & 26 & 41 & & 98 & $(4,35)$ & 28,13 & 73,17 & 31,71 & 36,59 \\
\hline 15.11 & 84 & 81 & 77 & 59 & 18 & 34 & 39 & 46 & & 81 & 4,94 & 23,38 & 60,87 & 26,09 & 15,22 \\
\hline 16.11 & 85 & 71 & 71 & 56 & 16 & 33 & 32 & 47 & & 91 & - & 21,13 & 65,96 & 29,79 & 31,91 \\
\hline
\end{tabular}


TABELA F.5 - Resultados de absorvância $\mathrm{em} \mathrm{cm}^{-1} \mathrm{e} \%$ de reduções nos pré-filtros e filtros lentos

\begin{tabular}{|c|c|c|c|c|c|c|c|c|c|c|c|c|c|c|}
\hline Data & TO & AB & PFD & PFVA & FL11 & FL13 & FL21 & FL11 mont & PFVA sh & \%R PFD & \%RPFVA & \% R FL11 & \% R FL13 & \% R FL21 \\
\hline 31.08 & 9 & 0,095 & 0,095 & 0,085 & 0,03 & 0,092 & 0,073 & 0,104 & & 0,00 & 10,53 & 71,15 & 11,54 & 42,47 \\
\hline 04.09 & 13 & 0,169 & 0,176 & 0,167 & 0,077 & 0,193 & 0,171 & 0,188 & & $-4,14$ & 5,11 & 59,04 & $-2,66$ & 9,94 \\
\hline 14.09 & 23 & 0,138 & 0,136 & 0,141 & 0,04 & 0,13 & 0,122 & 0,166 & & 1,45 & $-3,68$ & 75,90 & 21,69 & 36,07 \\
\hline 19.09 & 27 & 0,109 & 0,11 & 0,108 & 0,045 & 0,118 & 0,101 & 0,145 & & $-0,92$ & 1,82 & 68,97 & 18,62 & 43,56 \\
\hline 21.09 & 29 & 0,1 & 0,109 & 0,105 & 0,045 & 0,106 & 0,089 & 0,125 & & $-9,00$ & 3,67 & 64,00 & 15,20 & 40,45 \\
\hline 25.09 & 33 & 0,097 & 0,089 & 0,083 & 0,041 & 0,091 & 0,08 & 0,122 & & 8,25 & 6,74 & 66,39 & 25,41 & 52,50 \\
\hline 28.09 & 36 & & & 0,069 & 0,032 & 0,072 & 0,067 & 0,104 & & & & 69,23 & 30,77 & 55,22 \\
\hline 02.10 & 40 & 0,086 & 0,083 & 0,071 & 0,026 & 0,071 & 0,066 & 0,106 & & 3,49 & 14,46 & 75,47 & 33,02 & 60,61 \\
\hline 05.10 & 43 & 0,095 & 0,091 & 0,074 & 0,026 & 0,071 & 0,061 & 0,117 & & 4,21 & 18,68 & 77,78 & 39,32 & 91,80 \\
\hline 09.10 & 47 & 0,093 & 0,091 & 0,078 & 0,035 & 0,08 & 0,069 & 0,12 & & 2,15 & 14,29 & 70,83 & 33,33 & 73,91 \\
\hline 11.10 & 49 & 0,085 & 0,085 & 0,069 & 0,024 & 0,069 & 0,059 & 0,11 & & 0,00 & 18,82 & 78,18 & 37,27 & 86,44 \\
\hline 16.10 & 54 & 0,084 & 0,082 & 0,07 & 0,028 & 0,068 & 0,062 & 0,109 & & 2,38 & 14,63 & 74,31 & 37,61 & 75,81 \\
\hline 23.10 & 61 & 0,083 & 0,091 & 0,062 & 0,012 & 0,034 & 0,028 & 0,078 & 0,104 & $-9,64$ & 31,87 & 84,62 & 56,41 & 178,57 \\
\hline 26.10 & 64 & 0,102 & 0,095 & 0,079 & 0,015 & 0,042 & 0,038 & 0,084 & 0,112 & 6,86 & 16,84 & 82,14 & 50,00 & 121,05 \\
\hline 30.10 & 68 & 0,077 & 0,083 & 0,071 & 0,028 & 0,067 & 0,068 & & 0,1 & $-7,79$ & 14,46 & & & \\
\hline 01.11 & 70 & 0,066 & 0,069 & 0,061 & 0,021 & 0,06 & 0,058 & 0,098 & 0,11 & $-4,55$ & 11,59 & 78,57 & 38,78 & 68,97 \\
\hline 06.11 & 75 & 0,068 & 0,066 & 0,054 & 0,019 & 0,059 & 0,047 & 0,101 & 0,054 & 2,94 & 18,18 & 81,19 & 41,58 & 114,89 \\
\hline 09.11 & 78 & 0,07 & 0,065 & 0,056 & 0,018 & 0,06 & 0,048 & 0,101 & 0,104 & 7,14 & 13,85 & 82,18 & 40,59 & 110,42 \\
\hline 13.11 & 82 & 0,147 & 0,149 & 0,138 & 0,025 & 0,086 & 0,071 & 0,119 & 0,174 & $-1,36$ & 7,38 & 78,99 & 27,73 & 67,61 \\
\hline
\end{tabular}


TABELA F.6 - Resultados de carbono carbono orgânico dissolvido em mg/l e \% de remoções nos pré-filtros e filtros lentos

\begin{tabular}{|c|c|c|c|c|c|c|c|c|c|c|c|c|c|c|c|}
\hline Data & TO & AB & PFD & PFVA & FL11 & FL13 & FL21 & FL1 mont & PFVA sh & \%R PFD & \%RPFVA & \%R FL11 & \%R FL13 & \%R FL21 \\
\hline 31.08 & 9 & 2,70 & 3,48 & 3,00 & 1,16 & 2,38 & 2,52 & 2,44 & & $-28,80$ & $-16,29$ & 52,43 & 2,66 & $-3,36$ \\
\hline 04.09 & 13 & 5,03 & 5,03 & 4,63 & 1,37 & 3,60 & 4,65 & 2,35 & & 0,06 & $-8,66$ & 41,71 & $-53,39$ & $-98,13$ \\
\hline 14.09 & 22 & 2,42 & 2,40 & 2,25 & 1,10 & 2,64 & 2,41 & 2,43 & & 0,62 & $-6,85$ & 54,74 & $-8,38$ & 1,17 \\
\hline 19.09 & 27 & 2,68 & 2,41 & 2,81 & 1,03 & 2,80 & 2,31 & 3,16 & & 10,25 & 14,40 & 67,35 & 11,52 & 26,81 \\
\hline 21.09 & 29 & & & & & & & & & & & & & \\
\hline 25.09 & 33 & 1,93 & 1,82 & 1,68 & 0,56 & 1,71 & 1,57 & 2,33 & & 5,55 & $-8,33$ & 75,98 & 26,86 & 32,86 \\
\hline 28.09 & 36 & 1,98 & 1,94 & 1,68 & 0,98 & 2,16 & 2,09 & 2,36 & & 2,12 & $-15,29$ & 58,50 & 8,84 & 11,51 \\
\hline 02.10 & 40 & 1,33 & 1,12 & 1,51 & 0,78 & 1,68 & 2,66 & 2,56 & & 15,62 & 25,77 & 69,52 & 34,45 & $-4,14$ \\
\hline 05.10 & 43 & 2,79 & 2,05 & 2,24 & 0,90 & 1,84 & 1,65 & 2,45 & & 26,32 & 8,23 & 63,14 & 24,98 & 32,53 \\
\hline 09.10 & 47 & 2,10 & 2,07 & 3,13 & 1,67 & 1,96 & 2,46 & 4,02 & & 1,62 & 33,94 & 58,32 & 51,28 & 38,73 \\
\hline 11.10 & 49 & 2,45 & 2,34 & 2,25 & 1,15 & 2,52 & 2,71 & 0,42 & & 4,50 & $-3,92$ & $-173,27$ & $-500,48$ & $-547,02$ \\
\hline 16.10 & 54 & 1,28 & 2,34 & 1,58 & 1,21 & 1,53 & 1,97 & 1,83 & & $-83,23$ & $-48,16$ & 34,06 & 16,32 & $-7,75$ \\
\hline 23.10 & 61 & 2,23 & 1,82 & 2,11 & 0,66 & 1,82 & 0,00 & 0,00 & 2,08 & 18,76 & 14,06 & & & \\
\hline 26.10 & 64 & 2,11 & 1,94 & 0,00 & 0,54 & 1,50 & 1,40 & 2,20 & & 8,20 & & 75,68 & 31,73 & 36,55 \\
\hline 30.10 & 68 & 1,99 & 2,23 & 1,70 & 0,92 & 1,95 & 1,97 & 2,42 & & $-11,99$ & $-31,36$ & 61,88 & 19,19 & 18,37 \\
\hline 01.11 & 70 & 2,25 & 2,21 & 2,34 & 1,28 & 2,37 & 2,44 & 2,33 & & 1,73 & 5,35 & 44,98 & $-1,63$ & $-4,33$ \\
\hline 06.11 & 75 & 1,05 & 0,00 & 0,94 & 0,00 & 0,81 & 0,95 & 1,03 & & 100,00 & 100,00 & 100,00 & 21,43 & 7,95 \\
\hline 09.11 & 78 & 2,14 & 1,58 & 1,32 & 0,99 & 1,63 & 1,92 & 1,90 & & 26,40 & $-19,50$ & 47,76 & 13,83 & $-1,27$ \\
\hline 13.11 & 82 & 4,25 & 4,26 & 3,90 & 0,50 & 2,71 & 2,39 & 4,30 & 4,44 & & $-9,07$ & 88,28 & 36,92 & 44,26 \\
\hline
\end{tabular}


TABELA F.7 - Resultados de oxigênio consumido em mg/L e \% de remoções nos pré-filtros e filtros lentos

\begin{tabular}{|r|c|c|c|c|c|c|c|c|r|r|r|r|r|r|}
\hline Data & TO & AB & PFD & PFVA & FL11 & FL13 & FL21 & FL11 mont & PFVA sh & \% R PFD & \% RPFVA & \%FL11 & \%FL13 & \%FL21 \\
\hline $31 / 08$ & 9 & 3,15 & 2,05 & 2,65 & 0,55 & 2,8 & 2,5 & 2,9 & & 34,92 & & 81,03 & 3,45 & 13,79 \\
\hline 04.09 & 13 & 6,4 & 5,7 & 5,5 & 3,25 & & & & & 10,94 & 3,51 & & & \\
\hline 14.09 & 23 & 4,95 & 4,1 & 3,79 & 0,6 & 3,4 & 3,4 & 4,55 & & 17,17 & 7,56 & 86,81 & 25,27 & 25,27 \\
\hline 19.09 & 27 & 4,2 & 2,95 & 2,6 & 0,72 & 2,6 & 2,35 & 3,25 & & 29,76 & 11,86 & 77,85 & 20,00 & 27,69 \\
\hline 21.09 & 29 & 3,2 & 2,65 & 2,4 & 0,55 & 1,75 & 1,95 & 1,85 & & 17,19 & 9,43 & 70,27 & 5,41 & \\
\hline 25.09 & 33 & 2,55 & 1,8 & 1,8 & 0,3 & 1,65 & 1,55 & 2,95 & & 29,41 & 0,00 & 89,83 & 44,07 & 47,46 \\
\hline 28.09 & 36 & 2 & 1,7 & 1,35 & 0,5 & 1,45 & 1,2 & 2,25 & & 15,00 & 20,59 & 77,78 & 35,56 & 46,67 \\
\hline 02.10 & 40 & 2,7 & 2,05 & 1,55 & 0,65 & 1,75 & 1,9 & 2,15 & & 24,07 & 24,39 & 69,77 & 18,60 & 11,63 \\
\hline 05.10 & 43 & 2,7 & 2,7 & 1,8 & 0,75 & 2 & 1,95 & 3,6 & & 0,00 & 33,33 & 79,17 & 44,44 & 45,83 \\
\hline 09.10 & 47 & 1,95 & 1,75 & 1,05 & 0,6 & 1,75 & 1,7 & 3,35 & & 10,26 & 40,00 & 82,09 & 47,76 & 49,25 \\
\hline 11.10 & 49 & 2,8 & 2 & 1,5 & 0,65 & 1,65 & 1,8 & 2,1 & & 28,57 & 25,00 & 69,05 & 21,43 & 14,29 \\
\hline 16.10 & 54 & 2,55 & 1,85 & 1,3 & 1,3 & 1,6 & 1,5 & 2,4 & & 27,45 & 29,73 & 45,83 & 33,33 & 37,50 \\
\hline 23.10 & 61 & 2,6 & 1,6 & 1,2 & 0,65 & 0,5 & 0,75 & 4,75 & & 38,46 & 25,00 & 86,32 & 89,47 & 84,21 \\
\hline 26.10 & 64 & 2,85 & 1,75 & 1,8 & 0,05 & 0,85 & 1,1 & 1,85 & 2,55 & 38,60 & & 97,30 & 54,05 & 40,54 \\
\hline 30.10 & 68 & 2,8 & 2,2 & 0,55 & 0,05 & 0,05 & 1,3 & 0,1 & 1,65 & 21,43 & 75,00 & 50,00 & 50,00 & \\
\hline 01.11 & 70 & 2 & 1,2 & 1,25 & 0,15 & 1,05 & 0,95 & 2,7 & & 40,00 & & 94,44 & 61,11 & 64,81 \\
\hline 06.11 & 75 & 1,45 & 0,45 & 0,3 & 0,11 & 0,14 & 0,1 & 1,55 & 1,55 & 68,97 & 33,33 & 92,90 & 90,97 & 93,55 \\
\hline 09.11 & 78 & 2,6 & 1,9 & 1,3 & 0,4 & 1,8 & 1,3 & 2,2 & 2,2 & 26,92 & 31,58 & 81,82 & 18,18 & 40,91 \\
\hline 13.11 & 82 & 6,45 & 5,45 & 4,65 & 0,2 & 2,35 & 2,25 & 5,65 & 4,3 & 15,50 & 14,68 & 96,46 & 58,41 & 60,18 \\
\hline
\end{tabular}


TABELA F.8 - Resultados de pH

\begin{tabular}{|l|c|c|c|c|c|c|c|c|c|c|}
\hline Data & TO & AB & PFD & PFVA & FL11 & FL13 & FL21 & FL1mont & FL2mont & PFVAssh \\
\hline 24.08 & 1 & 7,22 & 7,39 & 7,35 & 6,65 & 6,83 & 6,98 & & & \\
\hline 25.08 & 2 & 7,22 & 7,24 & 7,2 & 6,19 & 6,83 & 7,07 & 7,36 & 7,36 & \\
\hline 26.08 & 3 & 7,06 & 7,27 & 7,21 & 6,19 & 6,97 & 7,19 & 7,47 & 7,41 & \\
\hline 27.08 & 4 & 7,01 & 7,29 & 7,22 & 6,19 & 6,98 & 7,17 & 7,45 & 7,46 & \\
\hline 28.08 & 5 & 7 & 7,24 & 7,11 & 6,38 & 6,98 & 7,19 & 7,39 & 7,39 & \\
\hline 29.08 & 6 & 6,59 & 6,85 & 6,97 & 6,55 & 6,81 & 6,93 & 7,04 & 7,04 & \\
\hline 30.08 & 7 & 6,6 & 6,79 & 6,66 & 6,67 & 6,82 & 6,94 & 7,04 & 7,04 & \\
\hline 31.08 & 8 & 6,76 & 6,85 & 6,86 & 6,63 & 6,84 & 6,96 & 7,02 & 7,02 & \\
\hline 01.09 & 9 & 6,8 & 6,91 & 6,91 & 6,63 & 6,81 & 7,02 & 6,96 & 6,92 & \\
\hline 02.09 & 10 & 6,89 & 6,91 & 6,95 & 6,7 & 7 & 7,03 & 7,12 & 7,12 & \\
\hline 03.09 & 11 & 6,6 & 6,67 & 6,63 & 6,64 & 6,63 & 6,78 & 6,77 & 6,7 & \\
\hline 04.09 & 12 & 6,6 & 6,69 & 6,71 & 6,64 & 6,67 & 6,78 & 6,84 & 6,84 & \\
\hline 05.09 & 13 & 6,65 & 6,84 & 6,71 & 6,64 & 6,81 & 6,87 & 6,72 & 6,88 & \\
\hline 06.09 & 14 & 6,73 & 6,85 & 6,75 & 6,59 & 6,67 & 6,81 & 6,92 & 6,92 & \\
\hline 07.09 & 15 & 6,6 & 6,85 & 6,78 & 6,52 & 6,76 & 6,83 & 6,98 & 6,98 & \\
\hline 08.09 & 16 & 6,77 & 6,88 & 6,85 & 6,45 & 6,74 & 6,86 & 7,06 & 7,06 & \\
\hline 09.09 & 17 & 6,78 & 7 & 6,85 & 6,45 & 6,76 & 6,93 & 7,09 & 6,96 & \\
\hline 11.09 & 18 & 6,81 & 6,79 & 6,9 & 6,38 & 6,78 & 6,79 & 7,08 & 7,08 & \\
\hline 12.09 & 19 & 6,73 & 6,85 & 6,89 & 6,26 & 6,8 & 6,91 & 7,06 & 7,06 & \\
\hline 13.09 & 20 & 6,57 & 6,67 & 6,79 & 6,24 & 6,75 & 6,84 & 6,94 & 6,94 & \\
\hline 14.09 & 21 & 6,62 & 6,69 & 6,6 & 6,28 & 6,76 & 6,84 & 6,94 & 6,94 & \\
\hline 15.09 & 22 & 6,67 & 6,82 & 6,69 & 6,29 & 6,61 & 6,79 & 6,77 & 6,77 & \\
\hline 16.09 & 23 & 6,72 & 6,83 & 6,77 & 6,29 & 6,72 & 6,81 & 6,93 & 6,93 & \\
\hline 18.09 & 24 & 6,65 & 6,83 & 6,76 & 6,26 & 6,71 & 6,81 & 6,9 & 6,9 & \\
\hline 19.09 & 27 & 6,7 & 6,74 & 6,52 & 6,1 & 6,56 & 6,7 & 6,85 & 6,94 & \\
\hline 20.09 & 28 & 6,81 & 6,93 & 6,84 & 6,25 & 6,74 & 6,82 & 7,01 & 7,01 & \\
\hline 21.09 & 29 & 6,84 & 6,98 & 6,92 & 6,45 & 6,8 & 6,92 & 7,04 & 7,04 & \\
\hline 22.09 & 30 & 6,73 & 6,78 & 6,79 & 6,17 & 6,66 & 6,8 & 6,97 & 6,97 & \\
\hline & & & & & & & & & & \\
\hline
\end{tabular}


Continuação da TABELA F.8 - Resultados de pH

\begin{tabular}{|l|c|c|c|c|c|c|c|c|c|c|}
\hline Data & TO & AB & PFD & PFVA & FL11 & FL13 & FL21 & FL1mont & FL2mont & PFVAssh \\
\hline 22.09 & 31 & 6,81 & 6,88 & 6,85 & 6,22 & 6,76 & 6,87 & 6,93 & 6,93 & \\
\hline 23.09 & 32 & 6,77 & 6,94 & 6,78 & 6,27 & 6,77 & 6,95 & 7,03 & 7,03 & \\
\hline 24.09 & 33 & 6,77 & 6,81 & 6,9 & 6,33 & 6,74 & 6,88 & 7,05 & 7,05 & \\
\hline 25.09 & 34 & 6,78 & 6,91 & 6,85 & 6,54 & 6,89 & 6,91 & 7,05 & 7,05 & \\
\hline 26.09 & 35 & 6,78 & 6,85 & 6,9 & 6,63 & 6,9 & 6,91 & 7,05 & 7,05 & \\
\hline 27.09 & 36 & 6,77 & 6,85 & 6,76 & 6,38 & 6,75 & 6,78 & 6,9 & 6,9 & \\
\hline 28.09 & 37 & 6,77 & 6,85 & 6,87 & 6,3 & 6,81 & 6,83 & 7,01 & 7,01 & \\
\hline 29.09 & 38 & 6,82 & 6,86 & 6,77 & 6,39 & 6,84 & 6,92 & 6,98 & 6,98 & \\
\hline 30.09 & 39 & 6,81 & 6,86 & 6,84 & 6,45 & 6,81 & 6,89 & 6,97 & 6,97 & \\
\hline 01.10 & 40 & 6,81 & 6,83 & 6,81 & 6,57 & 6,83 & 6,86 & 7,01 & 7,01 & \\
\hline 02.10 & 41 & 6,79 & 6,83 & 6,83 & 6,44 & 6,82 & 6,87 & 7,02 & 7,02 & \\
\hline 03.10 & 42 & 6,74 & 6,76 & 6,81 & 6,33 & 6,77 & 6,87 & 7 & 7 & \\
\hline 04.10 & 43 & 6,74 & 6,77 & 6,68 & 6,21 & 6,76 & 6,76 & 6,94 & 6,94 & \\
\hline 05.10 & 44 & 6,64 & 6,77 & 6,67 & 6,31 & 6,73 & 6,76 & 6,56 & 6,56 & \\
\hline 06.10 & 45 & 6,83 & 6,9 & 6,88 & 6,31 & 6,8 & 6,82 & 7,01 & 7,01 & \\
\hline 07.10 & 46 & 6,72 & 6,93 & 6,88 & 6,33 & 6,8 & 6,84 & 7,01 & 7,01 & \\
\hline 08.10 & 47 & 6,87 & 6,87 & 6,84 & 6,38 & 6,8 & 6,71 & 7,17 & 7,17 & \\
\hline 09.10 & 48 & 6,79 & 6,87 & 6,81 & 6,28 & 6,75 & 6,85 & 7,04 & 7,04 & \\
\hline 10.10 & 49 & 6,78 & 6,87 & 6,83 & 6,24 & 6,81 & 6,82 & 6,97 & 6,97 & \\
\hline 11.10 & 50 & 6,86 & 6,98 & 6,99 & 6,42 & 6,88 & 6,99 & 7,01 & 7,01 & \\
\hline 12.10 & 51 & 6,78 & 6,92 & 6,89 & 6,28 & 6,75 & 6,86 & 7,33 & 7,33 & \\
\hline 13.10 & 52 & 6,85 & 6,84 & 6,85 & 6,31 & 6,78 & 7,17 & 6,98 & 7,05 & \\
\hline 14.10 & 53 & 6,98 & 6,86 & 6,83 & 6,3 & 6,78 & 7,03 & 7,03 & 7,03 & \\
\hline 15.10 & 54 & 6,96 & 6,92 & 6,88 & 6,33 & 6,83 & 6,86 & 7,02 & 7,02 & \\
\hline 16.10 & 55 & 6,73 & 6,83 & 6,96 & 6,28 & 6,75 & 6,83 & 7,25 & 7,25 & \\
\hline 17.10 & 56 & 6,73 & 6,86 & 6,85 & 6,34 & 6,8 & 6,8 & 7,52 & 7,52 & \\
\hline 18.10 & 57 & 6,99 & 6,89 & 6,85 & 6,4 & 6,75 & 6,81 & 7,04 & 7,04 & \\
\hline 19.10 & 58 & 6,72 & 6,85 & 6,8 & 6,26 & 6,73 & 6,82 & 7,05 & 7,05 & \\
\hline & & & & & & & & & & \\
\hline
\end{tabular}


Continuação da TABELA F.8 - Resultados de pH

\begin{tabular}{|c|c|c|c|c|c|c|c|c|c|c|}
\hline Data & TO & AB & PFD & PFVA & FL11 & FL13 & FL21 & FL1mont & FL2mont & PFVAssh \\
\hline 22.10 & 60 & 6,69 & 6,85 & 6,82 & \begin{tabular}{|l|}
6,15 \\
\end{tabular} & 6,65 & 6,83 & 7,01 & 7,01 & 6,9 \\
\hline 23.10 & 61 & 6,61 & 6,87 & 6,83 & 6,26 & 6,62 & 6,83 & 6,99 & 6,99 & \\
\hline 24.10 & 62 & 6,63 & 6,81 & 6,86 & 6,3 & 6,71 & 6,76 & 6,7 & & 6,83 \\
\hline 25.10 & \begin{tabular}{|l|}
63 \\
\end{tabular} & 6,59 & 6,71 & 6,92 & 6,32 & 6,6 & 6,69 & 6,75 & & 6,74 \\
\hline \begin{tabular}{|l|}
26.10 \\
\end{tabular} & \begin{tabular}{|l|}
64 \\
\end{tabular} & 6,66 & 6,71 & 6,99 & \begin{tabular}{|l|}
6,57 \\
\end{tabular} & 6,57 & 6,81 & 6,79 & & 6,68 \\
\hline \begin{tabular}{|l|}
27.10 \\
\end{tabular} & 65 & 6,69 & 6,75 & 6,85 & 6,25 & 6,58 & 6,77 & 7,02 & & 6,7 \\
\hline \begin{tabular}{|l|}
28.10 \\
\end{tabular} & 66 & 6,73 & 6,78 & 6,85 & \begin{tabular}{|l|}
6,21 \\
\end{tabular} & 6,62 & 6,8 & 7 & & 6,81 \\
\hline \begin{tabular}{|l|}
29.10 \\
\end{tabular} & 67 & 6,72 & 6,78 & 6,84 & 6,19 & 6,73 & 6,74 & 6,96 & & 6,81 \\
\hline \begin{tabular}{|l|}
30.10 \\
\end{tabular} & \begin{tabular}{|l|}
68 \\
\end{tabular} & 6,72 & 6,7 & 6,9 & \begin{tabular}{|l|}
6,27 \\
\end{tabular} & 6,6 & 6,73 & 6,92 & & 6,74 \\
\hline 31.10 & \begin{tabular}{|l|}
69 \\
\end{tabular} & 6,71 & 6,8 & 6,91 & 6,33 & 6,74 & 6,83 & 6,92 & & 6,81 \\
\hline |01.11 & \begin{tabular}{|l|}
70 \\
\end{tabular} & 6,63 & 6,74 & 6,85 & \begin{tabular}{|l|}
6,21 \\
\end{tabular} & 6,69 & 6,73 & 6,85 & & 6,7 \\
\hline \begin{tabular}{|l|}
02.11 \\
\end{tabular} & 71 & 6,75 & 6,85 & 6,99 & 6,47 & 6,74 & 6,92 & 7 & & 6,92 \\
\hline \begin{tabular}{|l|}
03.11 \\
\end{tabular} & 72 & 6,7 & 6,83 & 6,91 & 6,23 & 6,71 & \begin{tabular}{|l}
6,79 \\
\end{tabular} & 7,02 & & 6,89 \\
\hline \begin{tabular}{|l|}
04.11 \\
\end{tabular} & \begin{tabular}{|l|}
73 \\
\end{tabular} & 6,72 & 6,82 & 6,94 & 6,3 & 6,7 & 6,78 & 7,01 & & 6,81 \\
\hline 05.11 & \begin{tabular}{|l|}
74 \\
\end{tabular} & 6,83 & 6,75 & 6,94 & 6,3 & \begin{tabular}{|l|}
6,69 \\
\end{tabular} & 6,82 & 7,03 & & 6,82 \\
\hline |06.11 & 75 & 6,84 & 6,76 & 6,92 & 6,23 & 6,68 & 6,8 & 7,01 & & 6,79 \\
\hline |07.11 & 76 & 6,73 & 6,8 & 7 & \begin{tabular}{|l|}
6,18 \\
\end{tabular} & 6,84 & 6,8 & 7,01 & & 6,77 \\
\hline |09.11 & 78 & 6,66 & 6,74 & 6,94 & \begin{tabular}{|l|}
6,01 \\
\end{tabular} & 6,61 & 6,7 & 6,96 & & 6,66 \\
\hline |10.11 & 79 & 6,7 & 6,82 & 7,02 & 6,4 & 6,76 & 6,74 & 6,78 & & 6,89 \\
\hline |12.11 & 81 & 6,25 & 6,52 & 6,74 & \begin{tabular}{|l|}
6,43 \\
\end{tabular} & 6,51 & 6,69 & 6,47 & & 6,62 \\
\hline $\mid 13.11$ & 82 & 6,42 & 6,47 & 6,61 & \begin{tabular}{|l|}
6,36 \\
\end{tabular} & 6,51 & 6,58 & 6,44 & & 6,48 \\
\hline |14.11 & 83 & 6,38 & 6,49 & 6,62 & 6,5 & 6,24 & 6,51 & 6,2 & & 6,48 \\
\hline \begin{tabular}{|l|}
15.11 \\
\end{tabular} & 84 & 6,31 & 6,56 & 6,6 & \begin{tabular}{|l|}
6,37 \\
\end{tabular} & 6,24 & 6,38 & 6,19 & & 6,49 \\
\hline \begin{tabular}{|l|}
16.11 \\
\end{tabular} & 85 & 6,46 & 6,57 & 6,8 & \begin{tabular}{|l}
6,36 \\
\end{tabular} & 6,26 & 6,41 & 6,33 & & 6,51 \\
\hline
\end{tabular}


TABELA F.9 - Resultados de condutividade elétrica $(\mu \mathrm{s} / \mathrm{cm})$

\begin{tabular}{|c|c|c|c|c|c|c|c|c|c|}
\hline Data & TO & AB & PFD & PFVA & FL11 & FL13 & FL21 & FL1mont & PFVAssh \\
\hline 31.08 & 9 & 20,40 & 20,50 & 20,60 & 23,40 & 24,20 & 24,40 & 22,7 & \\
\hline 04.09 & 13 & 22,00 & 22,20 & 22,30 & 22,50 & 26,20 & 26,30 & 26 & \\
\hline 11.09 & 19 & 19,78 & 19,85 & 19,56 & 22,90 & 22,20 & 21,90 & 21,7 & \\
\hline 14.09 & 23 & 18,88 & 18,98 & 19,37 & 20,80 & 23,30 & 22,60 & 21,7 & \\
\hline 19.09 & 27 & 19,29 & 18,74 & 18,93 & 19,30 & 20,80 & 20,50 & 21 & \\
\hline 21.09 & 29 & 18,20 & 18,54 & 18,65 & 20,20 & 20,90 & 20,70 & 18,4 & \\
\hline 25.09 & 33 & 17,86 & 17,89 & 18,09 & 18,67 & 20,10 & 19,80 & 20,6 & \\
\hline 28.09 & 36 & 22,40 & 16,97 & 17,36 & 18,67 & 19,33 & 19,51 & 19,16 & \\
\hline 02.10 & 40 & 20,20 & 17,06 & 17,17 & 20,00 & 20,00 & 20,00 & 19,61 & \\
\hline 05.10 & 43 & 18,18 & 17,65 & 18,67 & 19,14 & 20,50 & 19,90 & 20,8 & \\
\hline 09.10 & 47 & 16,81 & 17,14 & 17,20 & 19,67 & 19,45 & 19,23 & 19,78 & \\
\hline 11.10 & 49 & 17,65 & 17,21 & 17,64 & 20,50 & 21,30 & 20,60 & 20,5 & \\
\hline 16.10 & 54 & 16,89 & 16,92 & 16,77 & 16,73 & 18,26 & 18,73 & 18,9 & \\
\hline 19.10 & 57 & 18,14 & 18,27 & 17,80 & 20,00 & 54,30 & 21,60 & 20,6 & \\
\hline 23.10 & 61 & 18,10 & 17,08 & 19,44 & 20,10 & 19,80 & 19,60 & 19,69 & 17,19 \\
\hline 26.10 & 64 & 16,63 & 16,63 & 17,44 & 19,97 & 21,00 & 20,10 & 19,7 & 19,44 \\
\hline 30.10 & 68 & 16,85 & 16,60 & 18,76 & 16,67 & 23,50 & 18,20 & 18,94 & 17,4 \\
\hline 01.11 & 70 & 17,33 & 16,93 & 18,57 & 17,38 & 18,95 & 18,45 & 18,91 & 17,16 \\
\hline 06.11 & 75 & 16,78 & 16,77 & 19,51 & 18,65 & 20,80 & 20,10 & 19,2 & 17,38 \\
\hline 09.11 & 78 & 15,94 & 16,19 & 19,23 & 19,73 & 19,32 & 18,97 & 18,98 & 16,62 \\
\hline 13.11 & 82 & 16,21 & 16,34 & 18,53 & 24,00 & 24,30 & 23,30 & 19,6 & 17,08 \\
\hline & & & & & & & & & \\
\hline
\end{tabular}


TABELA F.10- Medidas de temperatura em ${ }^{\circ} \mathrm{C}$

\begin{tabular}{|l|c|c|c|c|c|c|c|c|c|}
\hline Data & TO & AB & PFD & PFVA & FL11 & FL13 & FL21 & FL1mont & PFVAssh \\
\hline 24.08 & 1 & 20 & 22 & 20 & 22,5 & 21 & 23,5 & & \\
\hline 25.08 & 2 & 20 & 22 & 22 & 23,5 & 23 & 23 & 22 & \\
\hline 26.08 & 3 & 22 & 24 & 25 & 25 & 28 & 25 & 27 & \\
\hline 27.08 & 4 & 21 & 25 & 25 & 25,0 & 27 & 25 & 27 & \\
\hline 28.08 & 5 & 20 & 20,5 & 19 & 18,5 & 19 & 19,5 & 20 & \\
\hline 29.08 & 6 & 18,5 & 18,0 & 19,5 & 16 & 17 & 16 & 18 & \\
\hline 30.08 & 7 & 19 & 18 & 17,5 & 17 & 16,5 & 18 & 17 & \\
\hline 31.08 & 8 & 19 & 20 & 20 & 18,5 & 19,0 & 18,5 & 19,5 & \\
\hline 01.09 & 9 & 22 & 21,5 & 25 & 25,0 & 24,5 & 23,5 & 24 & \\
\hline 02.09 & 10 & 20 & 20 & 18 & 18 & 18 & 17 & 18 & \\
\hline 03.09 & 11 & 18 & 17 & 18 & 17,5 & 17,5 & 16 & 17 & \\
\hline 04.09 & 12 & 16 & 17 & 14 & 15 & 13 & 14 & 14 & \\
\hline 05.09 & 13 & 18 & 19,5 & 19 & 16,5 & 16,5 & 17,5 & 19,0 & \\
\hline 06.09 & 14 & 20 & 20,0 & 21,0 & 20,5 & 21,0 & 19,0 & 22,5 & \\
\hline 07.09 & 15 & 21 & 21 & 25 & 25 & 25 & 23 & 24 & \\
\hline 08.09 & 16 & 20,5 & 20,5 & 24 & 22 & 22,5 & 22 & 24 & \\
\hline 09.09 & 17 & 21,5 & 22,5 & 21 & 20,5 & 20 & 19,5 & 21 & \\
\hline 11.09 & 18 & 21 & 22 & 22 & 22 & 21,5 & 21 & 23 & \\
\hline 12.09 & 19 & 22 & 23,5 & 23 & 22,5 & 22 & 22,5 & 24 & \\
\hline 13.09 & 20 & 22 & 22 & 22,5 & 20,5 & 22 & 20 & 21,5 & \\
\hline 14.09 & 21 & 21,5 & 21,5 & 22 & 21 & 21 & 21 & 20,5 & \\
\hline 15.09 & 22 & 23 & 24,5 & 28 & 26 & 28 & 25,5 & 27,5 & \\
\hline 16.09 & 23 & 23,5 & 22 & 23 & 25,5 & 24,5 & 24 & 22,5 & \\
\hline 18.09 & 24 & 22,5 & 24 & 24,5 & 25,5 & 25 & 26 & 24 & \\
\hline 19.09 & 27 & 22,5 & 24 & 22,5 & 22 & 22,5 & 22 & 24 & \\
\hline 20.09 & 28 & 24 & 25 & 28,5 & 26,5 & 29 & 28 & 29 & \\
\hline 21.09 & 29 & 23,5 & 23 & 24 & 22 & 22 & 23 & 22 & \\
\hline 22.09 & 30 & 24 & 25 & 29 & 28 & 31 & 29 & 29 & \\
\hline
\end{tabular}


Continuação da TABELA F.10- Medidas de temperatura em ${ }^{\circ} \mathrm{C}$

\begin{tabular}{|c|c|c|c|c|c|c|c|c|c|}
\hline Data & TO & AB & PFD & PFVA & FL11 & FL13 & FL21 & FL1mont & PFVAssh \\
\hline 23.09 & 31 & 25 & 24 & 27 & 29 & 27 & 28 & 26,5 & \\
\hline 24.09 & 32 & 24 & 25 & 29 & 29 & 31 & 28 & 29,5 & \\
\hline 25.09 & 33 & 22,5 & 22 & 21,5 & 20 & 20 & 20 & 21 & \\
\hline 26.09 & 34 & 20 & 21,5 & 22,5 & 20 & 22 & 20 & 21 & \\
\hline 27.09 & 35 & 20 & 22,5 & 23 & 21,5 & 22,5 & 22 & 24 & \\
\hline 28.09 & 36 & 19 & 19 & 18,5 & 18 & 19 & 18 & 20 & \\
\hline 29.09 & 37 & 22 & 24 & 27 & 24 & 27 & 27 & 28 & \\
\hline 30.09 & 38 & 21,5 & 22,5 & 22,5 & 24,5 & 23 & 24 & 22 & \\
\hline 01.10 & 39 & 22 & 23 & 25 & 26 & 26,5 & 26 & 25 & \\
\hline 02.10 & 40 & 21,5 & 22,5 & 20,5 & 22 & 20 & 22 & 22 & \\
\hline 03.10 & 41 & 25 & 28 & 27 & 30 & 30 & 29 & 30 & \\
\hline 04.10 & 42 & 25 & 27 & 29,5 & 28 & 29 & 28 & 30 & \\
\hline 05.10 & 43 & 24 & 23 & 22,5 & 23 & 22 & 22 & 23,5 & \\
\hline 06.10 & 44 & 24 & 23 & 25 & 25 & 24 & 26 & 25 & \\
\hline 07.10 & 45 & 24 & 24 & 26 & 27 & 26 & 27 & 27,5 & \\
\hline 08.10 & 46 & 23 & 24,5 & 26,5 & 26,5 & 28 & 28 & 27 & \\
\hline 09.10 & 47 & 22,5 & 22,5 & 21,5 & 22 & 22 & 23 & 22,5 & \\
\hline 10.10 & 48 & 24 & 25 & 30 & 29 & 29 & 29 & 30 & \\
\hline 11.10 & 49 & 24 & 25 & 24 & 23 & 23 & 24 & 23 & \\
\hline 12.10 & 50 & 25 & 25 & 24 & 24 & 24 & 24 & 24 & \\
\hline 13.10 & 51 & 26 & 29 & 32 & 32 & 31 & 31 & 32 & \\
\hline 14.10 & 52 & 26 & 26 & 30 & 29 & 30 & 30 & 30 & \\
\hline 15.10 & 53 & 26 & 28 & 31 & 30,5 & 30 & 30 & 31 & \\
\hline 16.10 & 54 & 22 & 23 & 22 & 21 & 22 & 23 & 22 & \\
\hline 17.10 & 55 & 26 & 27 & 30 & 30 & 32 & 29 & 30 & \\
\hline 18.10 & 56 & 26 & 27 & 28 & 27 & 28,5 & 28 & 30 & \\
\hline 19.10 & 57 & 24 & 25 & 24 & 25 & 25 & 26 & 25 & \\
\hline 20.10 & 58 & 26 & 27 & 31 & 29 & 30 & 30,5 & 31 & \\
\hline & & & & & & & & \\
\hline
\end{tabular}


Continuação da TABELA F.10- Medidas de temperatura em ${ }^{\circ} \mathrm{C}$

\begin{tabular}{|c|c|c|c|c|c|c|c|c|c|}
\hline Data & TO & AB & PFD & PFVA & FL11 & FL13 & FL21 & FL1mont & PFVAssh \\
\hline 22.10 & 60 & 26 & 28 & 32 & 32 & 32 & 33 & 32 & \\
\hline 23.10 & 61 & 25 & 26 & 25 & 27 & 26 & 27 & 26 & \\
\hline 24.10 & 62 & 25 & 26 & 25 & 25 & 25 & 25 & 25 & \\
\hline 25.10 & 63 & 25 & 23 & 24 & 24 & 22 & 23 & 22 & \\
\hline 26.10 & 64 & 24 & 24 & 24 & 24 & 24 & 23 & 25 & 25 \\
\hline 27.10 & 65 & 26 & 25 & 27 & 28 & 26 & 26 & 26 & 27 \\
\hline 28.10 & 66 & 24 & 26 & 26 & 28 & 28 & 28 & 27 & 27 \\
\hline 29.10 & 67 & 22 & 22 & 24,5 & 25 & 24 & 25 & 24 & 23 \\
\hline 30.10 & 68 & 22 & 23 & 22 & 20 & 20,5 & 21 & 21 & 20 \\
\hline 31.10 & 69 & 24 & 23 & 23 & 23 & 22,5 & 24 & 24 & 23 \\
\hline 01.11 & 70 & 22,5 & 24 & 22 & 24 & 23 & 22,5 & 24 & 22 \\
\hline 02.11 & 71 & 26 & 25,5 & 28 & 30 & 31 & 29 & 30 & 29 \\
\hline 03.11 & 72 & 26 & 26 & 29 & 29 & 29 & 29 & 31 & 30 \\
\hline 04.11 & 73 & 26 & 26 & 28,5 & 29,5 & 29 & 29 & 30 & 27 \\
\hline 05.11 & 74 & 30 & 26,5 & 26 & 29 & 26 & 30 & 30,5 & 29 \\
\hline 06.11 & 75 & 24 & 24 & 24 & 24 & 23 & 25 & 24 & 24 \\
\hline 07.11 & 76 & 25 & 26 & 26 & 25 & 26,5 & 27 & 27 & 27 \\
\hline 09.11 & 78 & 24 & 23 & 23,5 & 24 & 22 & 23 & 24 & 23 \\
\hline 10.11 & 79 & 25 & 26 & 31 & 29 & 31 & 30 & 30 & 28 \\
\hline 12.11 & 81 & 24 & 27 & 28 & 26 & 29 & 27,5 & 30 & 29 \\
\hline 13.11 & 82 & 24 & 23 & 22 & 24 & 23 & 22 & 24 & 22 \\
\hline 14.11 & 83 & 24,5 & 24 & 24 & 24 & 23,5 & 23 & 23,5 & 23 \\
\hline 15.11 & 84 & 23 & 23 & 27 & 24 & 27 & 26 & 24 & 28 \\
\hline 16.11 & 85 & 24 & 25 & 24 & 24 & 24 & 24 & 24 & 23 \\
\hline
\end{tabular}

